\title{
Reservoir Characteristics and Lateral Variability of the Marcellus Formation at the Allegheny Mountain Front
}

\author{
Bruno J. Abersold \\ brunoabersold@gmail.com
}

Follow this and additional works at: https://researchrepository.wvu.edu/etd

Part of the Geology Commons

\section{Recommended Citation}

Abersold, Bruno J., "Reservoir Characteristics and Lateral Variability of the Marcellus Formation at the Allegheny Mountain Front" (2021). Graduate Theses, Dissertations, and Problem Reports. 10188. https://researchrepository.wvu.edu/etd/10188

This Thesis is protected by copyright and/or related rights. It has been brought to you by the The Research Repository @ WVU with permission from the rights-holder(s). You are free to use this Thesis in any way that is permitted by the copyright and related rights legislation that applies to your use. For other uses you must obtain permission from the rights-holder(s) directly, unless additional rights are indicated by a Creative Commons license in the record and/ or on the work itself. This Thesis has been accepted for inclusion in WVU Graduate Theses, Dissertations, and Problem Reports collection by an authorized administrator of The Research Repository @ WVU. For more information, please contact researchrepository@mail.wvu.edu. 


\title{
Reservoir Characteristics and Lateral Variability of the Marcellus Formation at the Allegheny Mountain Front
}

\author{
Bruno Abersold \\ Thesis submitted \\ To the Eberly College of Arts and Sciences \\ At West Virginia University \\ In partial fulfillment of the requirements for the degree of \\ Master of Science in \\ Geology
}

Timothy Carr, PhD., Committee Chair

Dengliang Gao, PhD.

Mr. Ian Costello

Department of Geology and Geography

Morgantown, West Virginia

2021

Keywords: Marcellus Formation, Natural Gas, Allegheny Mountain Front, Well Log Analysis, Core Analysis

Copyright 2021 Bruno Abersold 


\begin{abstract}
Reservoir Characteristic and Lateral Variability of the Marcellus Formation at the Allegheny Mountain Front

Bruno Abersold
\end{abstract}

The Marcellus Formation, a large shale gas reservoir located within in the Appalachian basin, produces the energy that fuels the economy across the United States. Well data and rock core for the Coastal $1 \mathrm{H}$ well, found in Fayette County, Pennsylvania, provides the basis to understand reservoir characteristics and depositional processes of the Marcellus Formation across the basin. The well is located near along the eastern edge of the productive fairway and adjacent to the Allegheny mountain front. We used characteristics, such as total organic carbon (TOC), geomechanical properties, and lithology, to integrate with ten other available wells across the basin. Specifically, MIP3H is the nearest well and used in conjunction with the Coastal $1 \mathrm{H}$. The wells fall into 3 groups which are near, far, and outliers. The near group is comprised of the Coastal 1H, MIP3H, Boggess 17H, and the Poseidon 8M. The far group of wells encompasses the Dunham 4H, Armstrong 1, and Goff 5. Lastly, the outlier group utilizes the Tippens 6HS, St. Whipkey, and Coldstream 1MH.

The Marcellus Formation was divided into five informal units - three shale layers (upper, middle, and lower), separated by two limestone beds. Ternary diagrams visualize the mineralogical composition of the Marcellus Formation. Consistently they indicate that carbonate and silica content increase with depth and clay decreases. These minerals can indicate the quantity of organic content present. Total organic carbon, however, increases with depth in only certain wells. Geomechanical properties vary the most when looking at the individual units of a well and brittleness decrease upwards with increased clay content. Overall, the Marcellus Formation is weak, and brittle compared to adjacent units. The Coastal $1 \mathrm{H}$ shares similar lithological properties with the nearby wells, however, it is less organic rich and less brittle in comparison to the other study wells. In general, it seems that the lower Marcellus is the optimal unit for hydraulic fracturing, as it is the most brittle and organic rich. 


\section{ACKNOWLEDGEMENTS}

While I knew completing a master's thesis would be difficult, I really had no idea. Without the support of the Department of Geology and Geography, this would not be possible. Before moving to Morgantown, I had heard rumors of how tight knit the mountaineer community was. When I arrived, those rumors became true. The faculty and staff of our department and across West Virginia University were very supportive. Moving to a new place and dealing with isolation is stress inducing. Without all the friends I have made here, I may have never gotten this far.

I would like to specifically thank my thesis committee. Dr. Carr, my research advisor, has been fantastic in these strange times, migrating to a mostly online world was difficult. Adjusting to remote work would not have been possible without his help. Dr. Gao is a great professor and very patient. Learning the complexities of geophysics and 3D interpretation helped guide my thesis work. Without Ian Costello and Infinity Natural Resources, none of this work would be possible. They graciously donated a monumental amount of data to West Virginia University.

A big part of a successful thesis comes down to the courses you take while performing research. Through our department, I was able to learn programming languages, thin section analysis, stratigraphic interpretation, basin analysis, and data interpretation. My abilities in science and my understanding of geology have both grown exponentially. I would like to thank Dr. Andrews for allowing me to perform thin section analysis with his microscope and Dr. Bennison for teaching me sedimentary petrology. Natalie Odegaarden was exceptionally helpful throughout these last two years as a mentor and a friend.

Lastly, I'd like to thank my parents, my mother for encouraging me to believe in myself and pursue science, my father for passing on his work ethic and never allowing me to quit. Finally, I'm grateful for Dr. Raymond Beiersdorfer and the geology professors at Youngstown State University for mentoring me during my undergraduate education. 


\section{Table of Contents}

Title Page

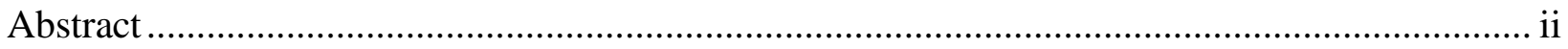

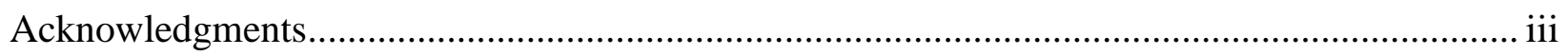

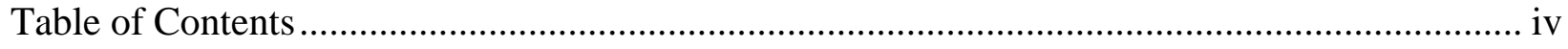

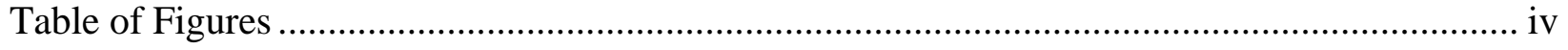

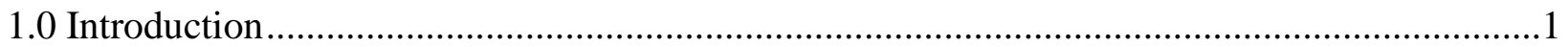

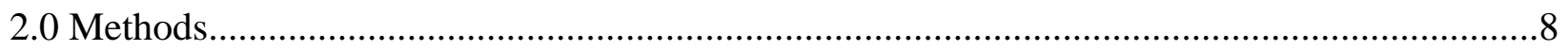

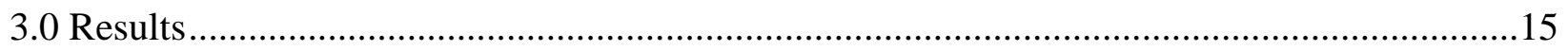

Coastal 1H Lithological Data Analysis.......................................................................18

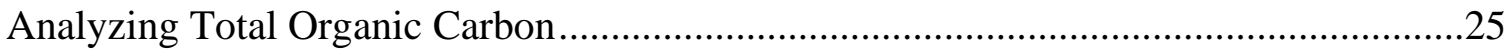

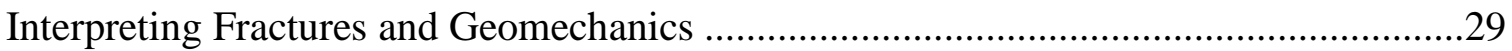

Marcellus-Onondaga Transition ……………………….............................................

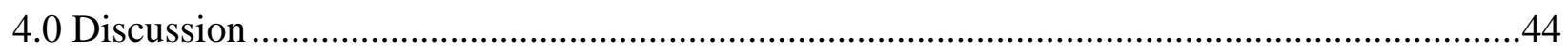

Marcellus Formation Differences in Lithological Data ...................................................4

Interpreting Total Organic Carbon of the Marcellus Formation..........................................45

Variation in Brittleness of the Marcellus Formation ..........................................................48

Defining the Marcellus Onondaga Contact...................................................................50

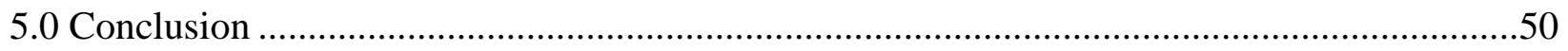

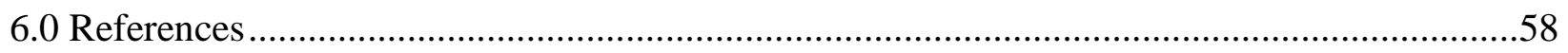

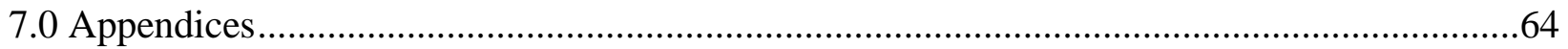

Appendix 1: Regional Correlation .............................................................................64

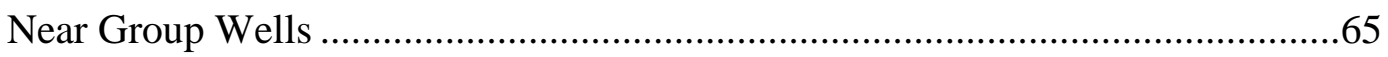

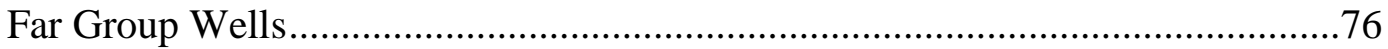

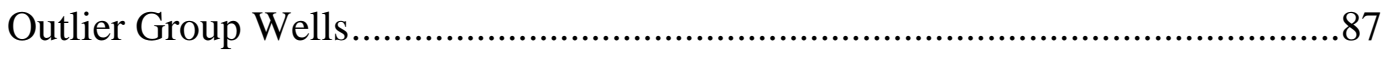

Appendix 2: Shale Lithofacies Classification..............................................................92

Appendix 3: Core and Thin Section Observations ......................................................97 


\section{Table of Figures}

Figure 1, Data from the EIA .........................................................................................

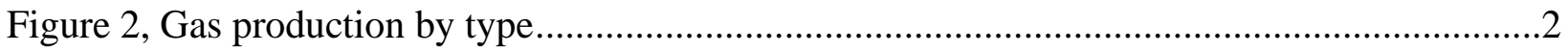

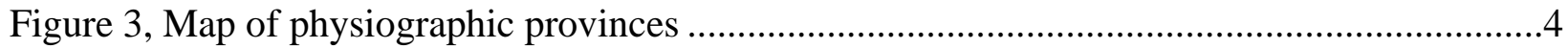

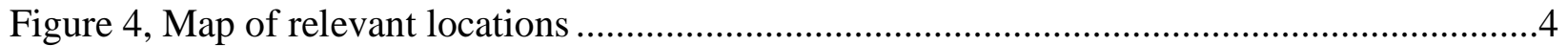

Figure 5, Geologic history map ...................................................................................

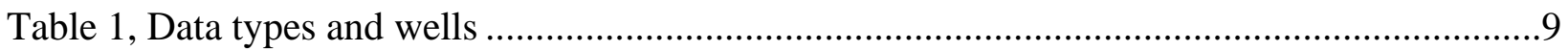

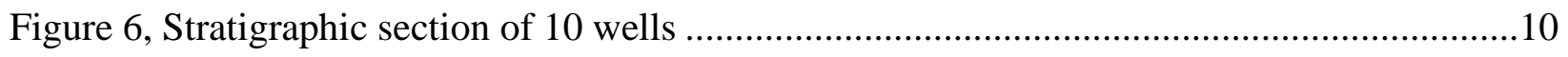

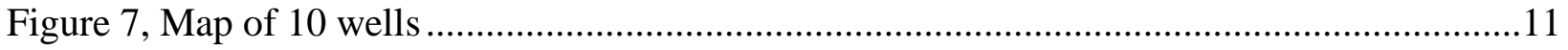

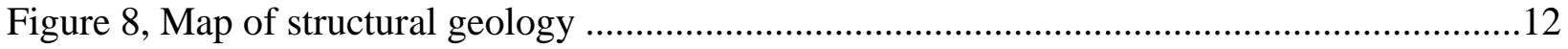

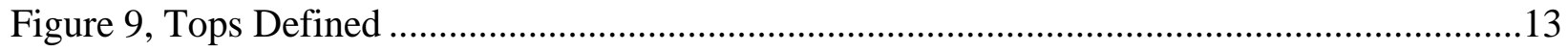

Figure 10, Nomenclature guidelines for sedimentary rocks ..............................................15

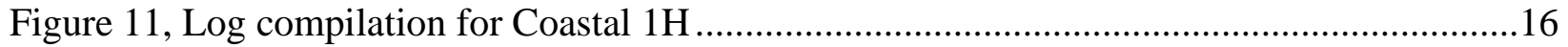

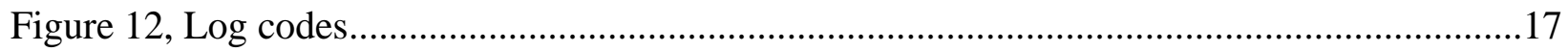

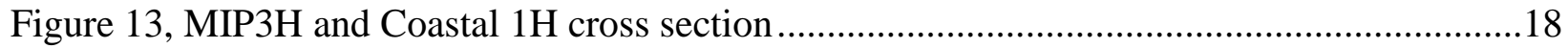

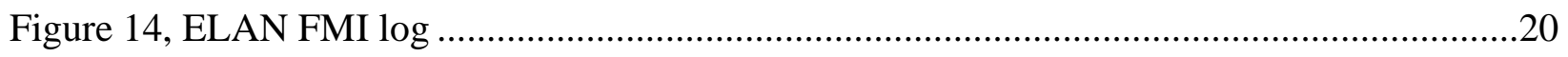

Figure 15, Coastal 1H ELAN ternary ….............................................................................21

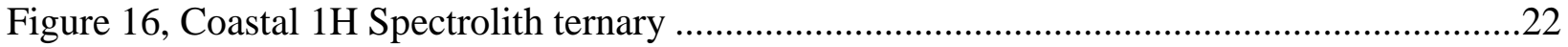

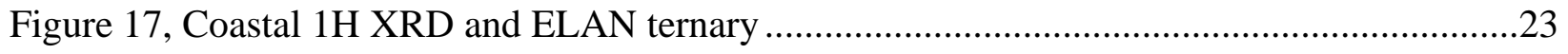

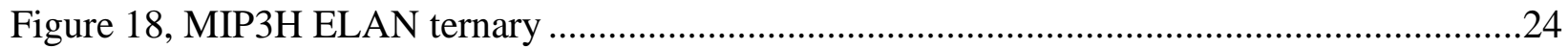

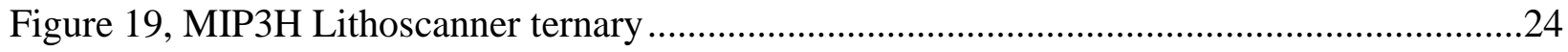

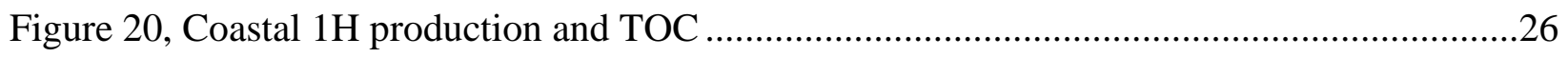

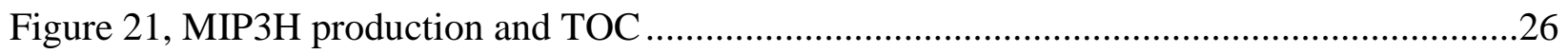

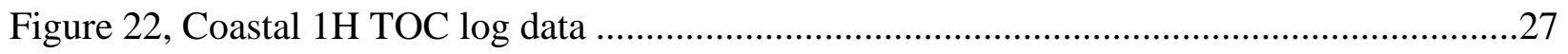

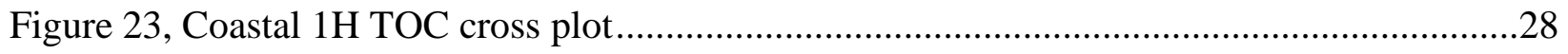

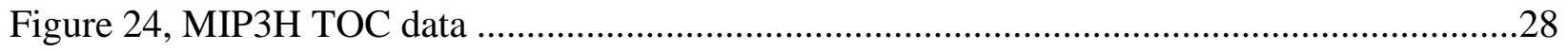

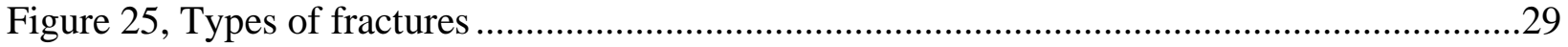

Figure 26, Rosette diagrams of resistive and open fractures .................................................30

Figure 27, Rosette diagrams of drilling fractures and borehole breakouts ...............................31

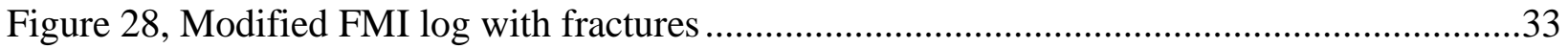


Figure 29, Symbols, description, and equations for geomechanical properties.....

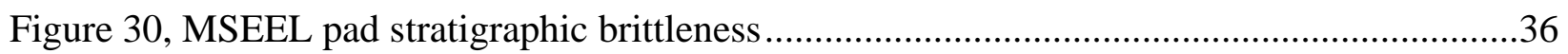

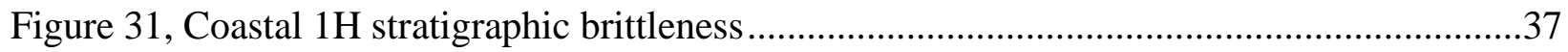

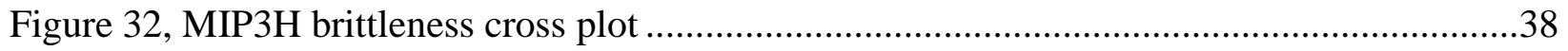

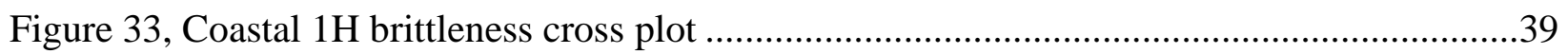

Figure 34, Chemical composition of ash bed minerals .........................................................41

Figure 35, Coldstream 1MH core description section .....................................................42

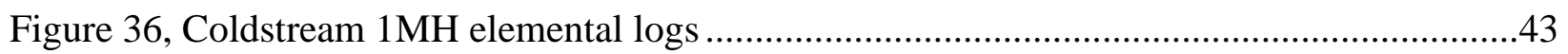

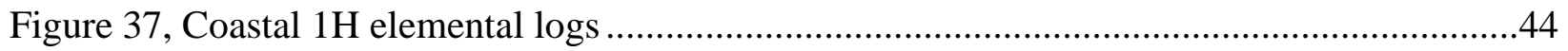

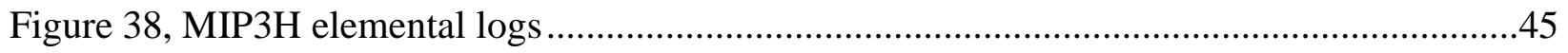

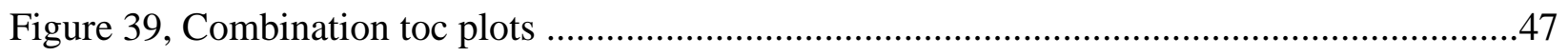

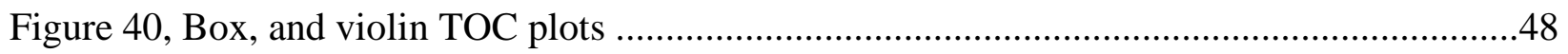

Figure 41, Combination brittleness plots ........................................................................49

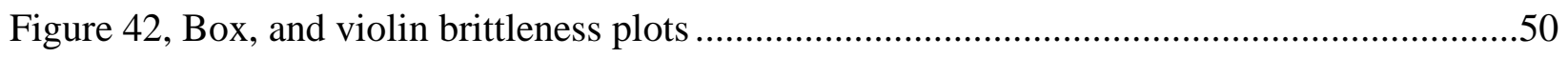

Figure 43, Coastal 1H TOC and brittleness cross plot........................................................52

Figure 44, MIP3H TOC and brittleness cross plot ...........................................................53

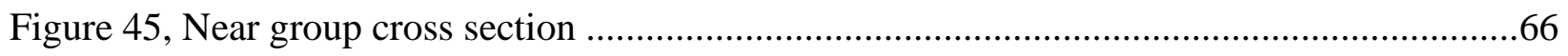

Figure 46, Boggess 17H ELAN ternary …....................................................................67

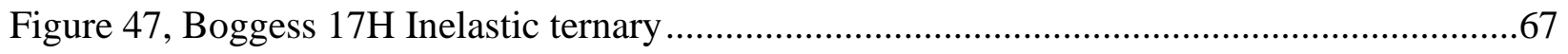

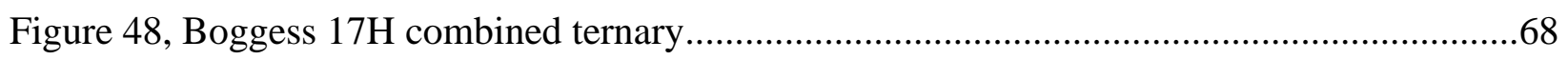

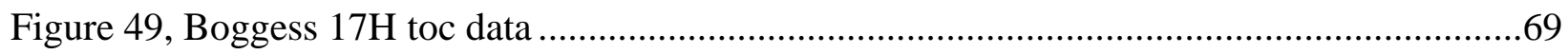

Figure 50, Boggess $17 \mathrm{H}$ brittleness cross plot ................................................................ 70

Figure 51, Boggess 17H elemental logs .................................................................... 71

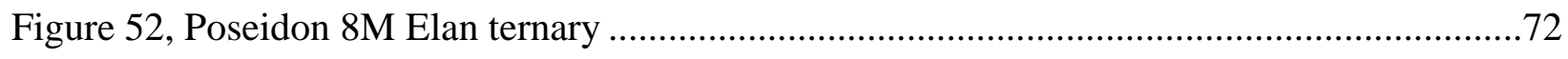

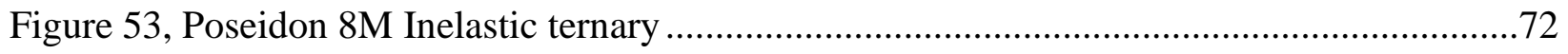

Figure 54, Poseidon 8M combined ternary ….................................................................. 73

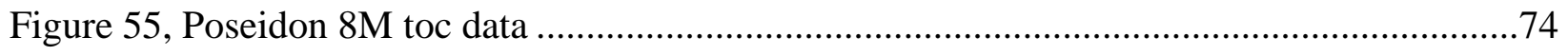

Figure 56, Poseidon 8M brittleness cross plot ................................................................75 
Figure 57, Far group cross section ........................................................................................

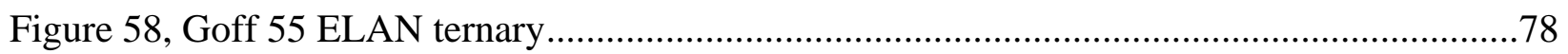

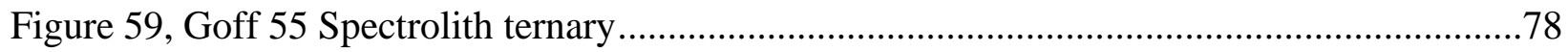

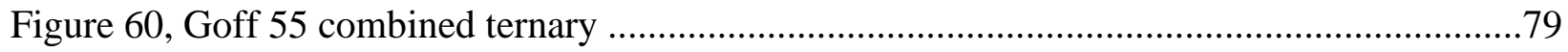

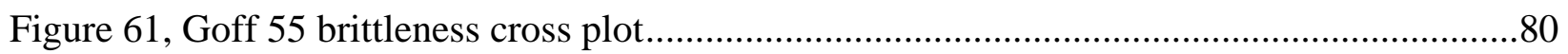

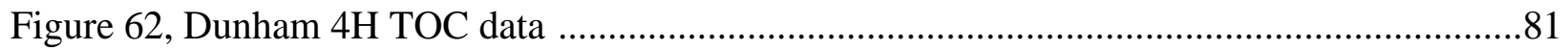

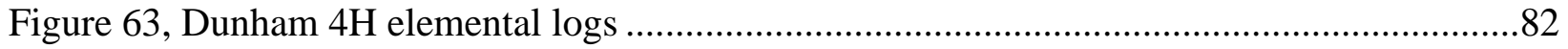

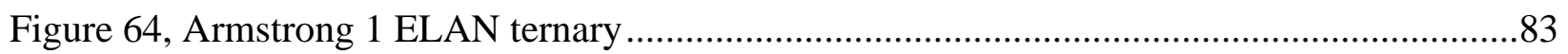

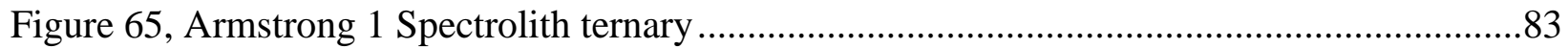

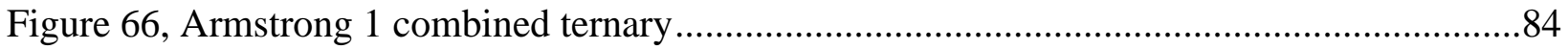

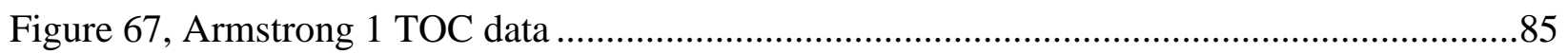

Figure 68, Armstrong 1 geomechanical cross plot …………………….....................................

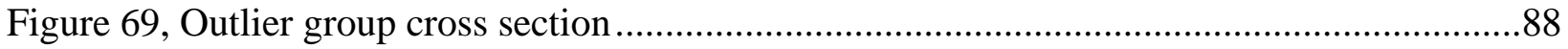

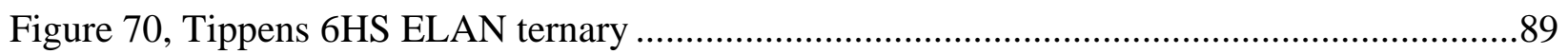

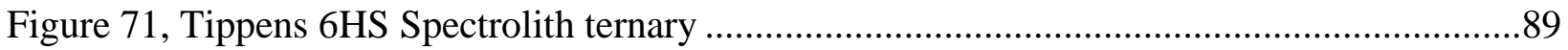

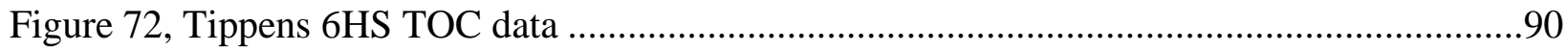

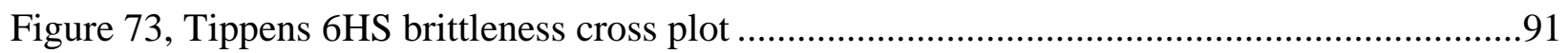

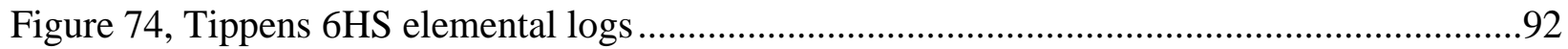

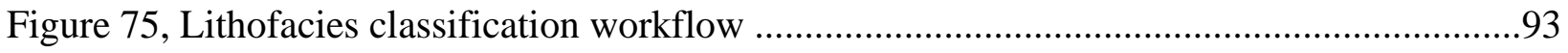

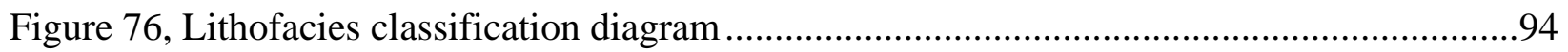

Figure 77, Upper Marcellus formation core features ..............................................................98

Figure 78, Middle Marcellus formation core features ...............................................................99

Figure 79, Lower Marcellus formation core features ..........................................................100

Figure 80, Thin section A1 ……….............................................................................101

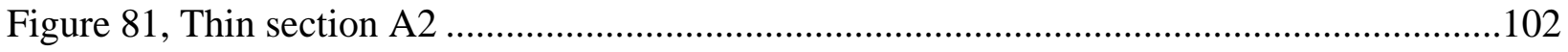

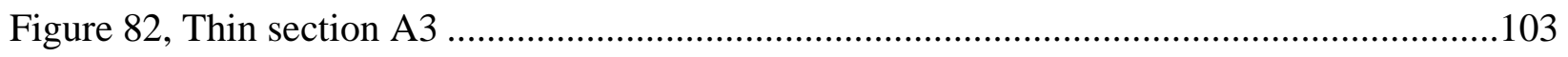

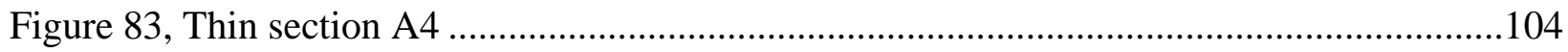

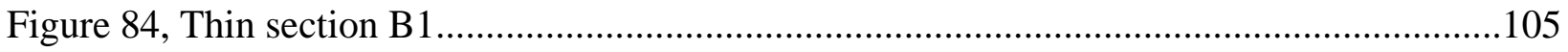




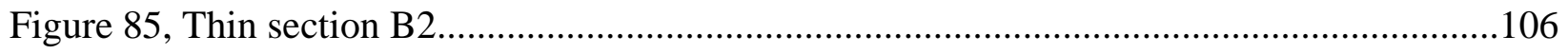

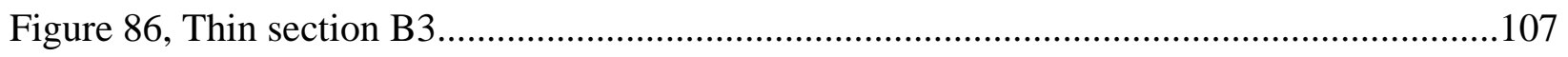

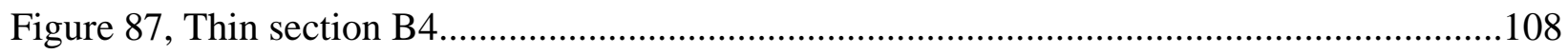

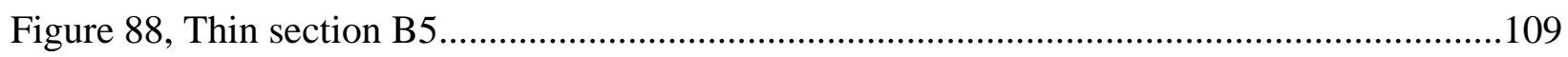

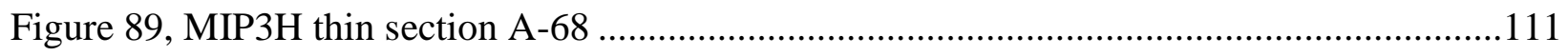

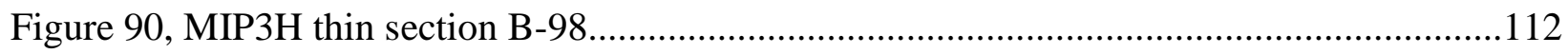

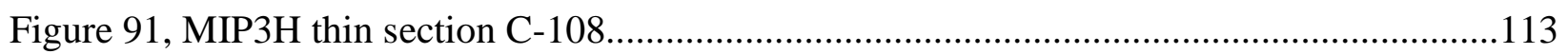

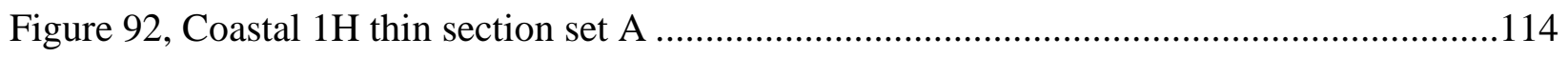

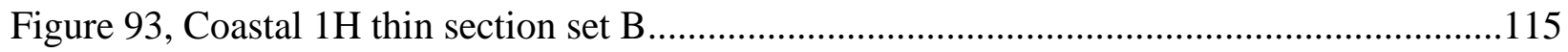

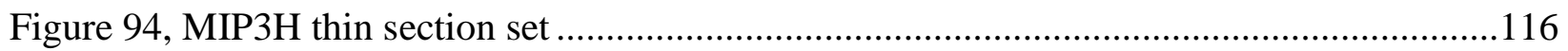




\subsection{INTRODUCTION}

Natural gas is an essential resource for American citizens to produce energy, find employment, practice science, and spur innovation. Since the natural shale gas boom began in 2007, the Marcellus Formation has proven to be the largest producer of dry shale gas (EIA, 2021a, Figure 1). Production really takes off after 2011 and current U.S. shale gas production is 71-73 billion cubic feet per day (Bcf/d). Currently, the Marcellus Formation is producing nearly 24.4 Bcf/d double that of the second most productive shale gas play, the Permian Basin. Also located within the Appalachian Basin is the deeper Utica Formation, which is the third highest producing source of shale gas in the United States at (7.3 Bcf/d). The two Appalachian basin shale gas reservoirs combined produce almost $45 \%$ of total shale gas production.

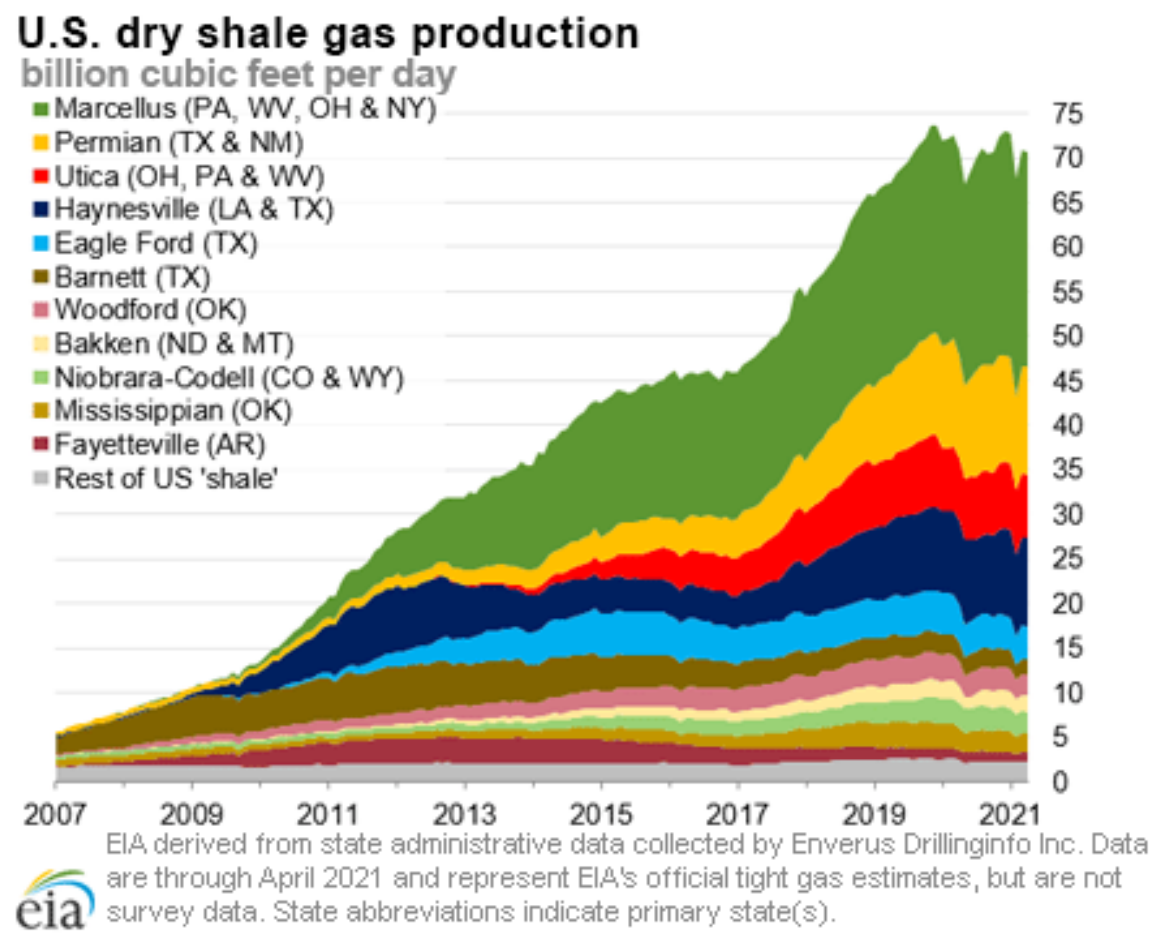

Figure 1. Data from the EIA showing various shale gas plays contribution to gas production. The Appalachian Basin holds the first and third most producing plays in the United States (EIA, 2021a). 
The United States Geological Survey believes that there is more than eighty trillion cubic feet of undiscovered natural gas remaining in the Marcellus Formation, indicating that there is an enormous amount of recoverable natural gas available (USGS, 2020). Currently natural gas is the most consumed fossil fuel resource for energy in Pennsylvania and Ohio, and second to coal in West Virginia (EIA, 2021b). Data from the Energy Information Administration suggests that yearly production of natural gas from tight/shale sources will increase to nearly 40 trillion cubic feet by 2050 (Figure 2). This would be an increase of about 10 trillion from the year 2020 over the course of 30 years.

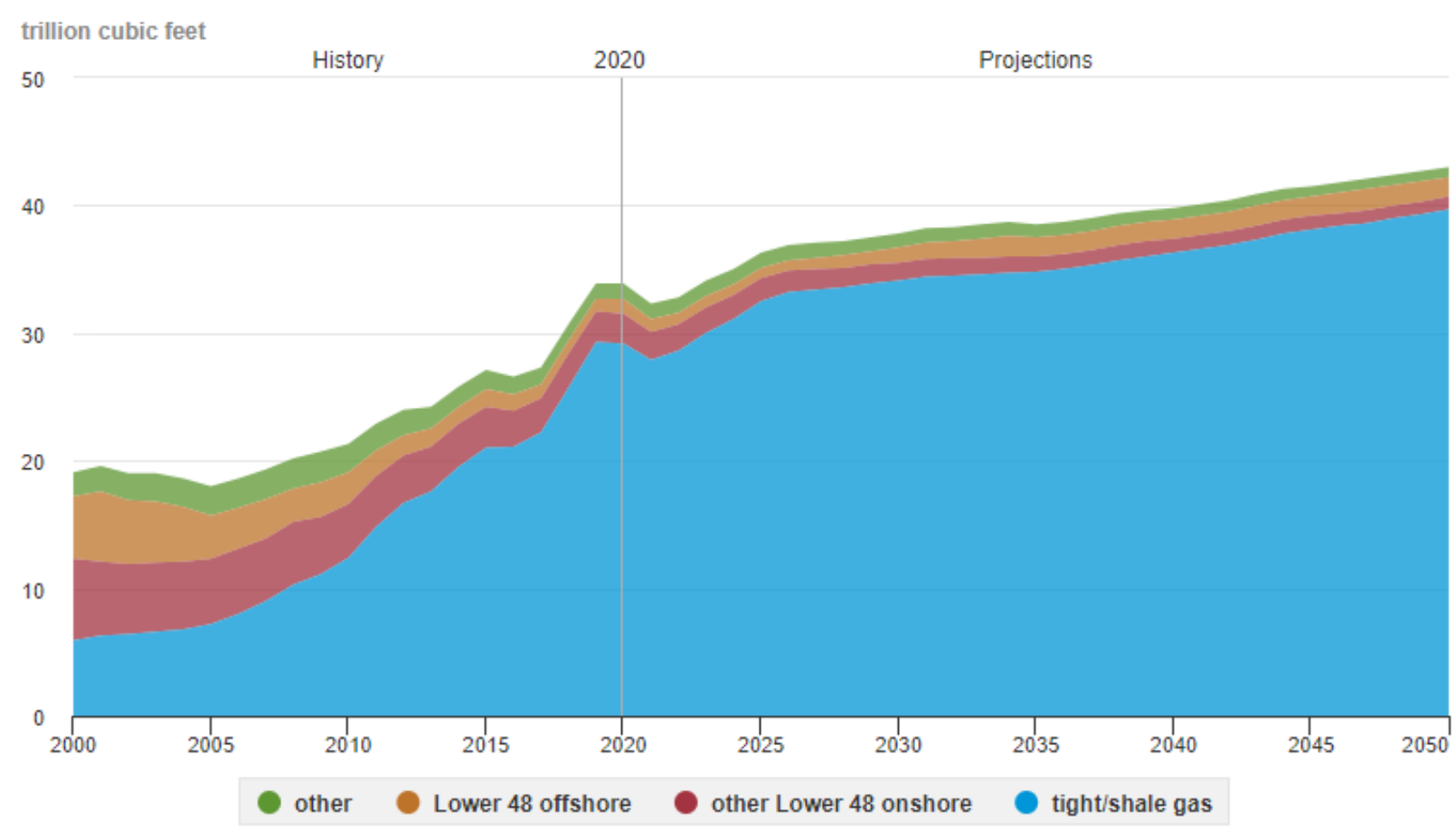

Figure 2. Gas production by type, shale and tight gas resources are expected to be the primary producer of natural gas through 2050 (EIA, 2021a).

Continued development of technology and research focused on efficient and safe shale gas production from the Appalachian Basin and growth of the natural gas industry, the United 
States can maintain this economic powerhouse. This geologic study interprets data of the Infinity Coastal $1 \mathrm{H}$ well and integrates it with data from various other wells in the Marcellus Formation. The results can contribute to a better understanding of the Marcellus Formation and further improvements in natural gas production in the Appalachian basin. It is important to study the Coastal $1 \mathrm{H}$ due to its unique geographic setting being on the cusp of the shallow Devonian foreland basin.

\section{Background of Well Data and Geology}

Infinity Natural Resources provided data from both the vertical pilot/observation well and the horizontal well of the Infinity Natural Resources Coastal $1 \mathrm{H}$. The wells were drilled and completed in 2010 and 2011 in the southeastern portion of Fayette County, Pennsylvania northeast of Morgantown West Virginia. The well is adjacent to the Chestnut Ridge anticline at the edge of the Appalachian Plateau and approaching the Allegheny Mountain Front (Figures 3 and 4). 


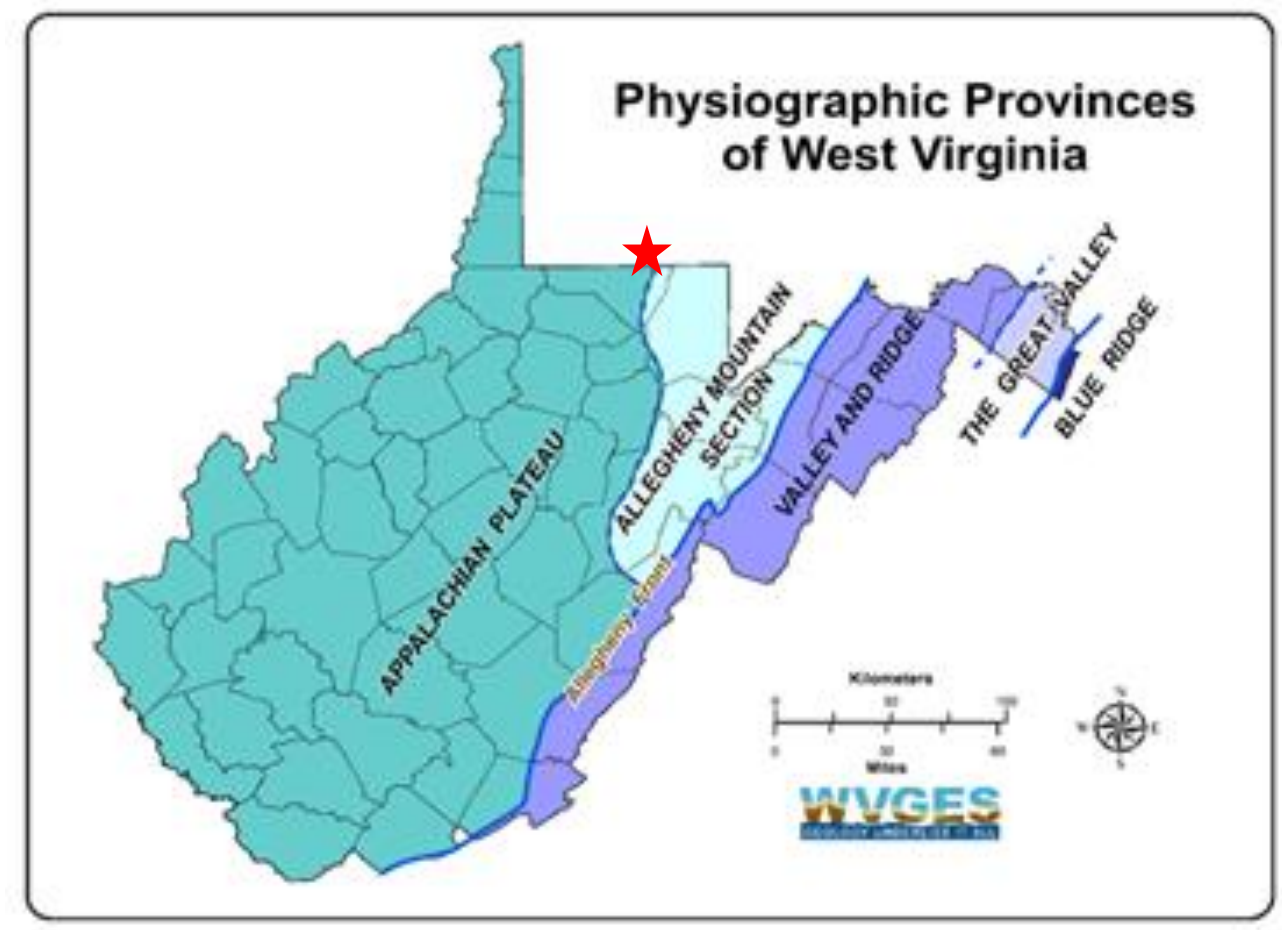

Figure 3. Map showing physiographic provinces in West Virginia, and location of the Infinity Natural Resources Coastal 1H well (red star) near the boundary of Appalachian Plateau with the Allegheny Mountain Front. Map modified from the West Virginia Geologic and Economic Survey (WVGES, 2020).

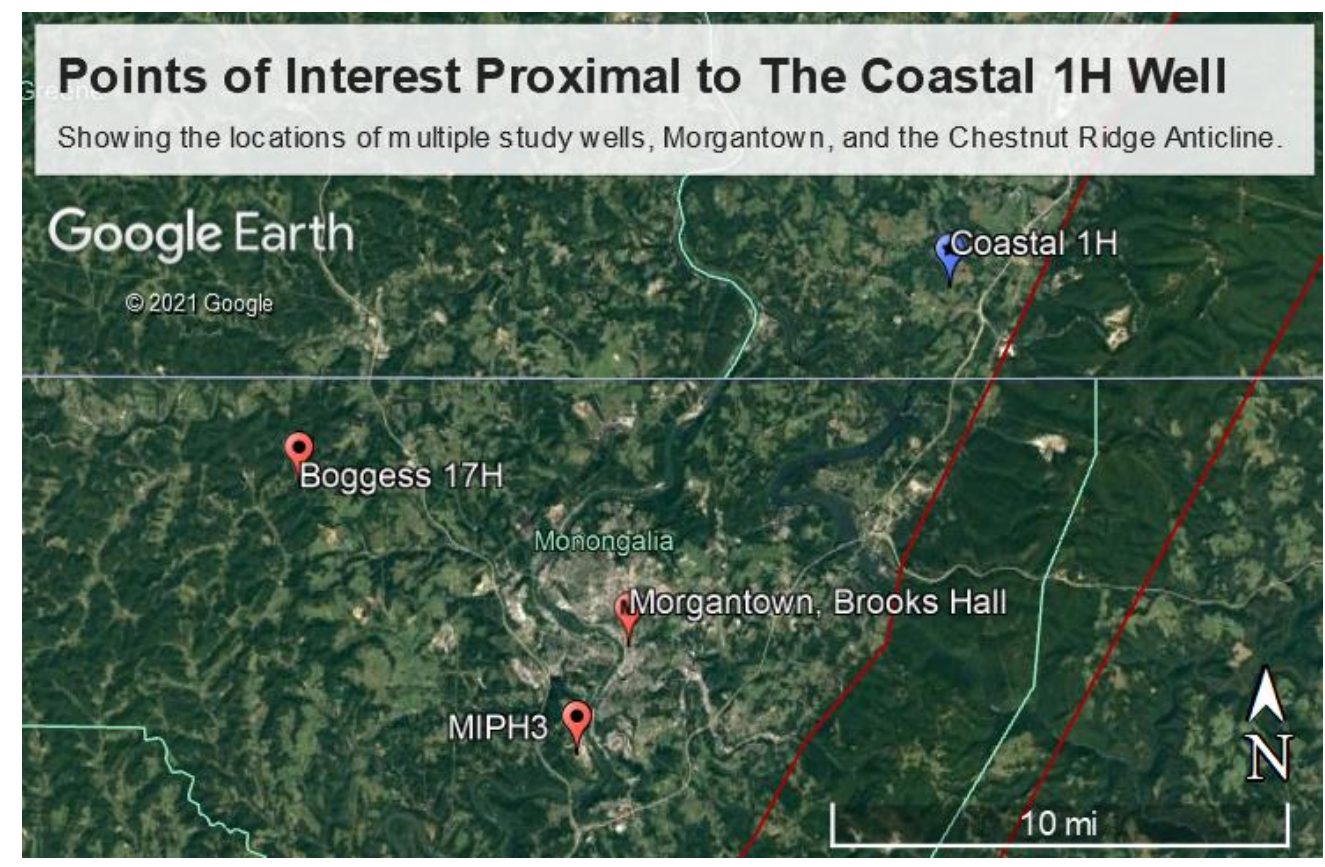

Figure 4. Map of locations relevant to this geologic study, outlining the general location of the Chestnut Ridge Anticline. Map created using Google Earth. 
The Coastal $1 \mathrm{H}$ well is located within a kilometer of the Chestnut Ridge Anticline, which defines the edge of Allegheny Mountain Front. The anticline is broad and asymmetrical, with an axial trend of northeast $30^{\circ}$ and variations in topographic uplift (Kerrigan, 2016). It spans over 125 miles and plunges $1^{\circ}$ to $2^{\circ}$ towards the northeast. The dip of the limbs of Chestnut Ridge Anticline varies but is around $15^{\circ}$ on its southeast and $10^{\circ}$ in the northwest. The various structural changes in this anticline are associated with the presence of the Rome Trough in the southwestern extent, and it is absent near the northeastern portion.

The Appalachian Foreland Basin is the host of the Marcellus Formation, which spans several states, including New York, Ohio, Pennsylvania, and West Virginia (Figure 8, EIA, 2017). The Appalachian Foreland Basin is asymmetrical, northeast trending, and at several locations more than 5 kilometers deep. Estimates put its extent to be above 100,000 square kilometers (Zagorski et al., 2017). The Hamilton Group contains the Marcellus Formation, which is located at the base and the Mahantango Formation. The Mahantango Formation occurs and is approximately 220 feet thick at the Coastal $1 \mathrm{H}$ well. The Mahantango consists of grey shale with some organic rich zones and occasionally interbedded limestone. Underlying the Marcellus Formation is Onondaga Limestone which is about 14 feet thick at the well.

In this research, the Marcellus is broken up into the informal upper, middle, and lower layers. The uppermost layer is about $30 \mathrm{ft}$ thick. The Purcell Limestone is shown as a drop in the gamma log and is less than $5 \mathrm{ft}$ thick. This member separates the upper shale from the middle shale. The middle shale (around $45 \mathrm{ft}$ in thickness) was produced towards the end of the wells lifespan and is underlain by the Cherry Valley Limestone, which is represented similarly to the Purcell Limestone. Lastly, the lower shale has a thickness of about 40ft and sits at the base where it has a gradational contact with the Onondaga Limestone. Most of the fracturing stages 
occurred within the Union Springs shale and it was the initial target formation to produce from.

A total of 200 feet of interval was cored from the vertical well, and currently is in the West Virginia University Petroleum and Natural Gas Engineering Department. Data collected from the vertical well includes FMI Image logs, Quad Combo logs, and various seismic tools. The Coastal $1 \mathrm{H}$ well underwent fracturing in 17 stages. Micro seismic data was recorded for stages 10 through 17 and was taken at a point within the vertical pilot/observation well.

The map below (Figure 5) is an illustration from Blakey (2008) of what the world may have looked like while the Marcellus Formation was being deposited. The tectonic history of the Appalachian basin consists of three orogenic events (Tankard, 1986). The earliest being the Taconic, followed by the Acadian, and ending with the Alleghenian. Thrusting and lithospheric flexure during the Paleozoic led to the formation of the Appalachian basin. Transitioning from a passive margin to a convergent boundary began with the Taconic mountain building event in which over thrusting led to subsidence. 


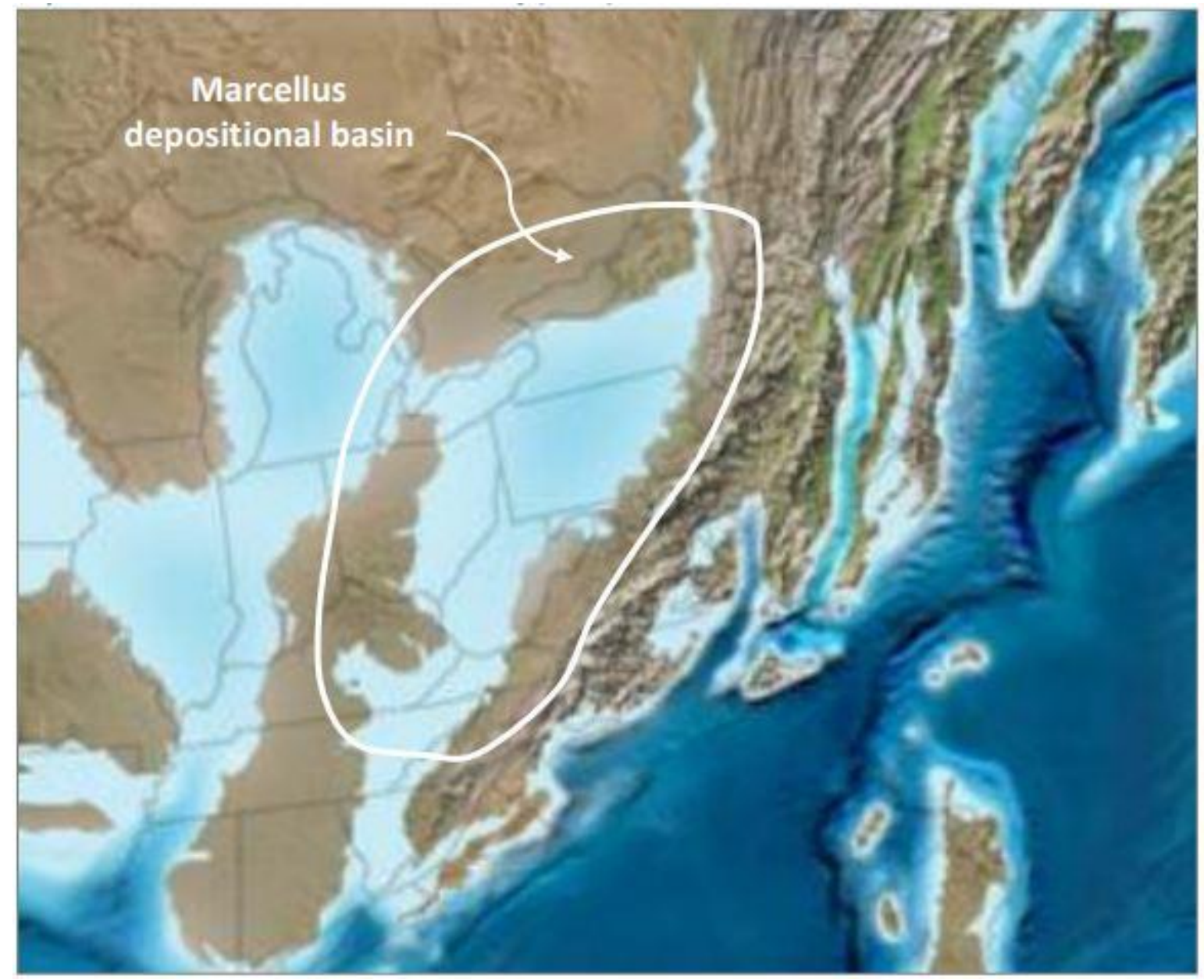

Figure 5. Geologic history map, indicating the location and setting of the Marcellus Depositional Basin (Blakey, 2008).

The tectonic regime became much more passive after the Taconic. The Acadian Orogeny is reported as having prolonged intervals of time in which fine-grained sediments could accumulate. This period of relaxation was a driving factor in the subsidence of the Appalachian foreland basin. During this subsidence, there was a rise in sea level. The eustatic sea level change altered the depositional characteristics present at the time. Thus, transitioning from a sandstone and carbonate dominated regime to one characterized by organic-rich shale. Over the course of 2 million years, organic matter accumulated within this shallow Devonian foreland basin and formed a series of shale and interbedded limestone units (Wang and Carr, 2013). The anoxic environments in which the shale of the Marcellus Formation formed prevented the 
organic matter from decaying (Boyce and Carr, 2009). Thus, making it rich in hydrocarbons. This portion of a paleogeographic map shows the onset of the depositional basin.

\subsection{METHODS}

The objective of this research is to interpret the reservoir characteristics of the Marcellus Formation. As one moves in a generally eastward direction, the Marcellus Formation tends to thin out. Being so close to the Allegheny Mountain Front may show a significantly thicker and/or more clastic rich section of the Marcellus. The data from Infinity Natural Resources is integrated with data from regional wells drilled in the Marcellus Formation, and places the study within a regional context across the Appalachian basin. Available logs include basic suites and advanced logs (e.g., ELAN, ECS, sonic, FMI logs). Understanding how the Marcellus varies across the region and its potential effect on production is important for continued development. The Coastal $1 \mathrm{H}$ in conjunction with data from the relatively nearby MSEEL wells at the MIP pad provides an interpretation of the geology in this transitional zone.

\section{Some research questions to answer:}

1) How do the individual sub-units of the Marcellus Formation differ? (depositional changes, small picture variability)

2) How does the Marcellus Formation change across The Appalachian Basin? (Big picture variability)

The first objective of this research is to determine stratigraphy of the Marcellus Formation. This requires analysis of the gamma, density, and resistivity logs. In the Marcellus, gamma logs indicate changes primarily in uranium related to changes in total organic carbon (TOC) and gas 
content (Schmoker, 1981; Wang and Carr, 2012). The density and resistivity logs illustrate changes in rock lithology and are important for finding interbedded typically thin limestone units between the upper, middle, and lower units. However, the Purcell Limestone in the Poseidon $8 \mathrm{M}$ well is significantly thicker, about 12 feet $(3.7 \mathrm{~m})$.

The petrophysical and core data available from 10 wells was arranged into individual groups covering geomechanical, XRD, lithological (elemental/mineralogical), spectral, and TOC, (Table 1). The geomechanical data consists of sonic logs and is important for delineating how the stress field is expressed. XRD, lithological, and spectral data enables us to interpret the compositional variation of the Marcellus Formation (chemostratigraphy). Data on TOC is essential to this research as it potentially relevant to industry.

\begin{tabular}{|l|c|c|c|c|}
\hline \multicolumn{1}{|c|}{ Well } & Geomechanical & Lithological & Spectral & TOC \\
\hline 1) Tippens 6HS & Yes & Yes & Yes & Yes \\
\hline 2) Goff 55 & Yes & Yes & & \\
\hline 3) Dunham 4H & & & Yes & Yes \\
\hline 4) Armstrong 1 & Yes & Yes & & Yes \\
\hline 5) Boggess 17H & Yes & Yes & Yes & Yes \\
\hline 6) St Whipkey 1 & & & & \\
\hline 7) MIP3H & Yes & Yes & Yes & Yes \\
\hline 8) Coastal 1H & Yes & Yes & Yes & Yes \\
\hline 9) Poseidon 8M & Yes & Yes & & Yes \\
\hline 10) Coldstream 1MH & & & Yes & \\
\hline
\end{tabular}

Table 1. Indicates what type of data is used for each of the wells is present. Data availability varies between the wells, with 6 categories to work from.

The available wells are from 3 states, Ohio, West Virginia, and Pennsylvania. A gamma log stratigraphic section was constructed with A (west) marked as the Tippens 6HS well (the only well in Ohio) and A' (east) the Coldstream 1MH well (the most northeastern Pennsylvania well) (Figures 6, 7 and 8). The state of West Virginia accounts for 5 wells while Pennsylvania 
consists of 4. Detailed log displays for individual wells used for the regional cross section are found in the Regional Correlation Appendix 1.

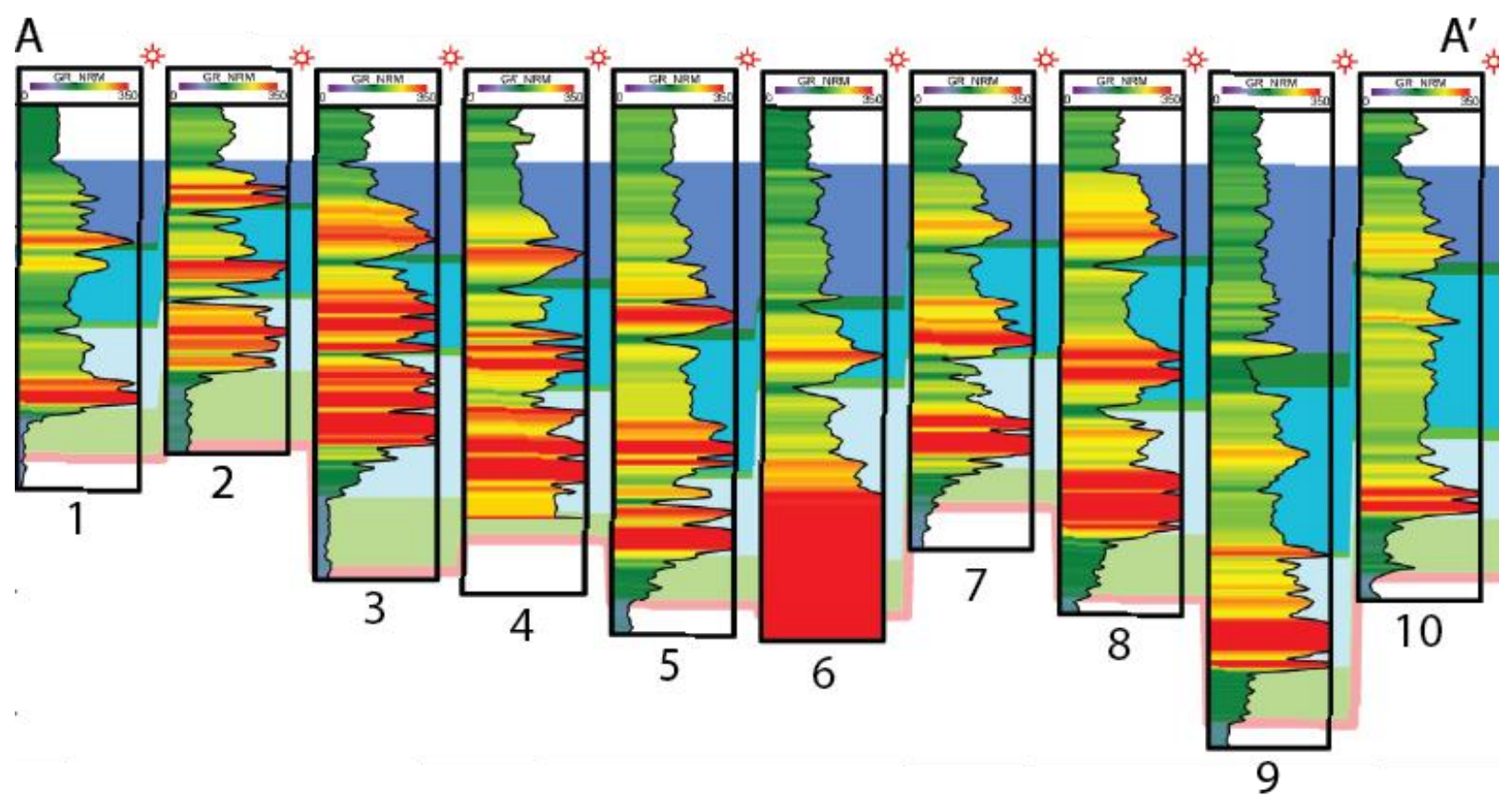

Figure 6. Stratigraphic section of all 10 wells included within this study, marked with A at the most western well and $\mathrm{A}^{\prime}$ at the most eastern well. 


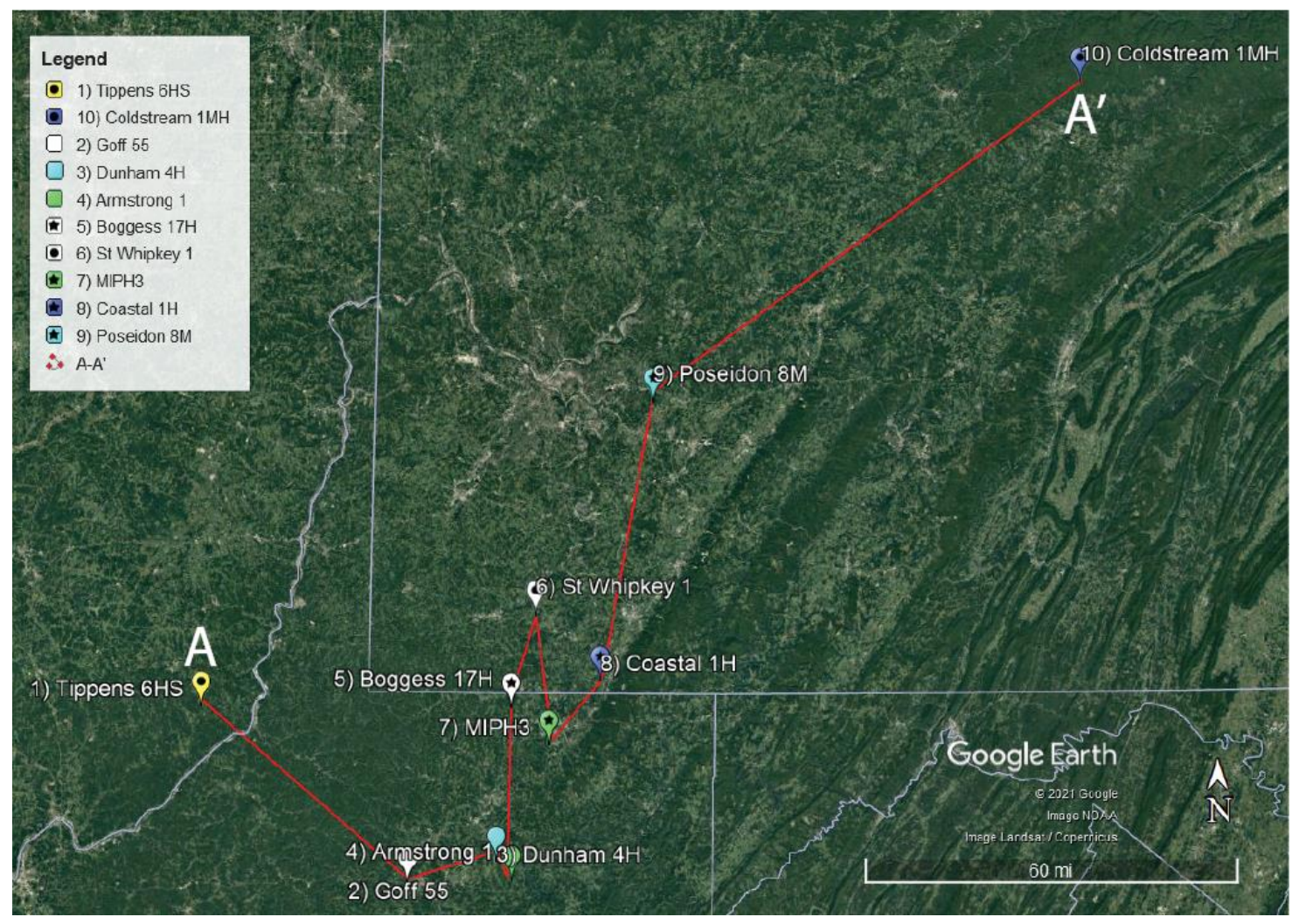

Figure 7. Map coinciding with the stratigraphic section above, showing the location of wells and marked with A-A'. 


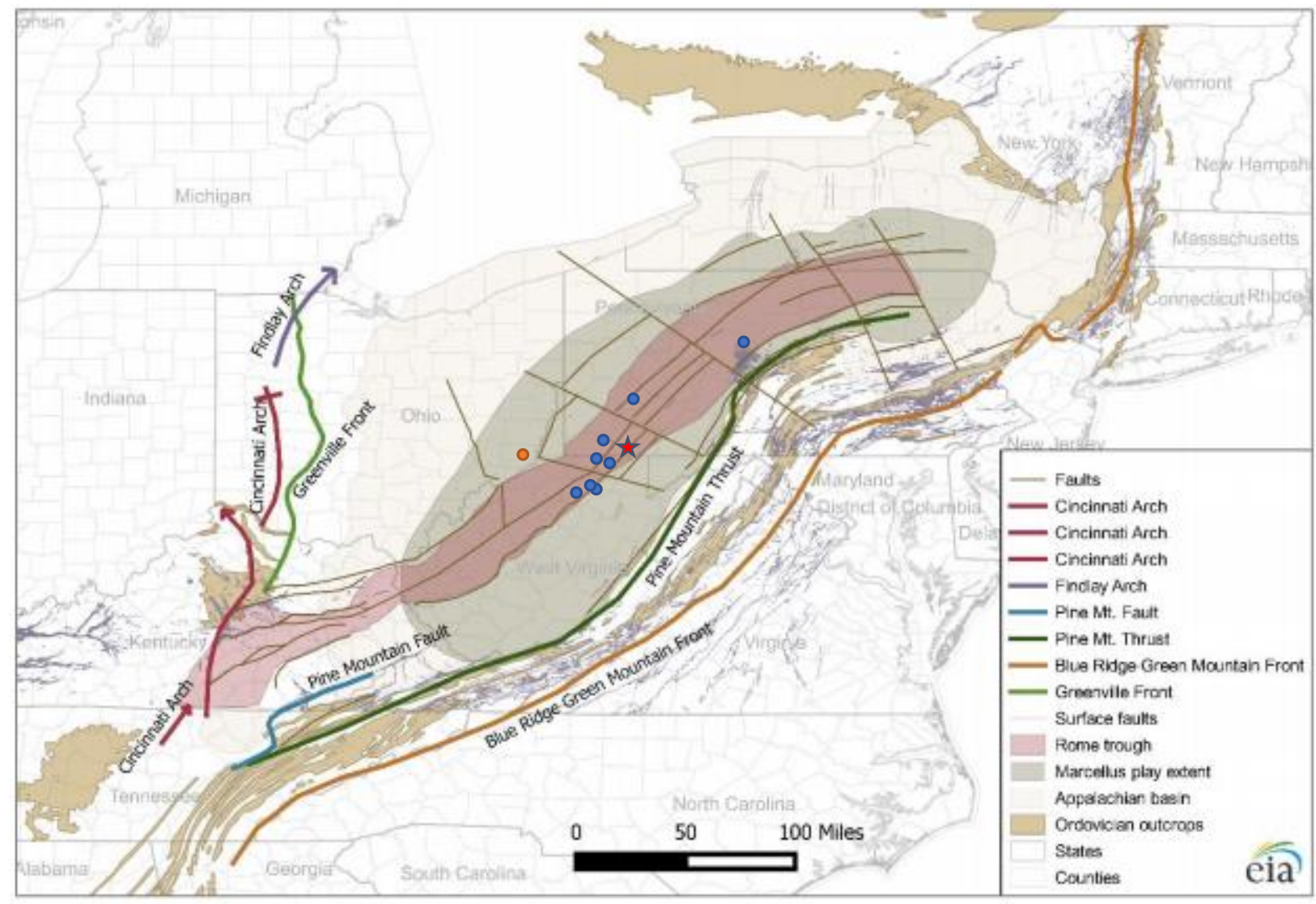

Figure 8. Map which illustrates the structural geology of the Appalachian Basin, with locations of all wells in this research paper, data for this map is from the EIA.

The Coastal $1 \mathrm{H}$ well (distinguished by a red star, Figure 8) is within the Rome Trough and separated from the other study wells by multiple basement faults (wells represented by blue dots). These faults are categorized as either those that strike parallel to the basin (regarding the Rome Trough) and those that are structural discontinuities perpendicular to the basin (EIA, 2017). The proximal location to the edge of the Rome Trough Allegheny Mountain Front may result in variations in reservoir characteristics such as organic-richness, mineralogy, geomechanical properties, and structure that could affect potential productivity. Only one of the study wells occurs outside of the Rome Trough, the Tippens 6HS, being in a wet gas zone (represented by an orange dot).

Before this research paper delves into data analysis, tops for the Marcellus Formation 
must be determined. To do this, seven tops are distinguished (Figure 9) and assigned various colors in cross sections. Shale units of the Marcellus occur in shades of blue, while limestone units coincide with green. Lastly, the top of the Huntersville Chert (contact with the Onondaga) is distinguished in the logs by a red line across the base.

\begin{tabular}{|l|l|}
\hline Stratigraphy & Color \\
\hline upper Marcellus & \\
\hline upper Limestone & \\
\hline middle Marcellus & \\
\hline lower Limestone & \\
\hline lower Marcellus & \\
\hline Onondaga & \\
\hline Huntersville & \\
\hline
\end{tabular}

Figure 9. Tops defined within the logs developed from Peta. Shales of the Marcellus Formation use shades of blue, while limestones use shades of green.

To determine variations in total organic carbon (TOC), data sources from 7 wells (Coastal 1H, MIP3H, Armstrong 1, Dunham 4H, Poseidon 8M, Tippens 6HS, Boggess 17H) are used. First, each set of data is normalized individually, using a min-max normalization. Utilizing the programing language, $\mathrm{R}$, scatterplots, and cross plots are made of the normalized data. This exhibits the variation in TOC for each well across its depth. Combination box and violin plots are made of the units and wells.

It becomes possible to mathematically compute geomechanical properties using the bulk density, DTCO, and DTSM wave logs. Applying the data from these logs into moduli equations such as Young's Modulus (YME) and Poisson's Ratio (PR) enables one to interpret properties such as strength and ductility. With this, the brittleness index of the Marcellus Formation can be estimated (Rickman et al., 2008). Like the TOC carbon data, the geomechanical information undergoes a min-max normalization. 
Through combining XRD and lithological data, it is possible to determine the elemental and mineralogical components present throughout the various wells. Lithological data is measured with multiple logging and mineralogy estimated with various processes, all measurements involved in this paper are in weight percent. The methods used to estimate mineralogy include ELAN, Spectrolith, Inelastic Processing, and Lithoscanner. For both types of data, there are three general groups created. The clay group, often composed of illite, smectite, and chlorite. The carbonate group, which generally consists of calcite and dolomite, though occasionally including siderite. Remaining data in the log files is added to the QFP group. The QFP group is mostly quarts, feldspars, and pyrite, though certain datasets may have measured for specific minerals, which are also included in the QFP group (if they are not clay or carbonate). Once these categories have been computed, ternary plots were created. These plots are based off the work done by Lazar et al., 2015, which establishes nomenclature guidelines (Figure 10). Initially a ternary plot is made of the compositional data for each well. This indicates how the overall composition of a particular well plots. Any wells that have both XRD and log-based lithology were used to create ternary plots to compare and calibrate between data types. This is important to understand how these measurements differ and if they're consistent. 


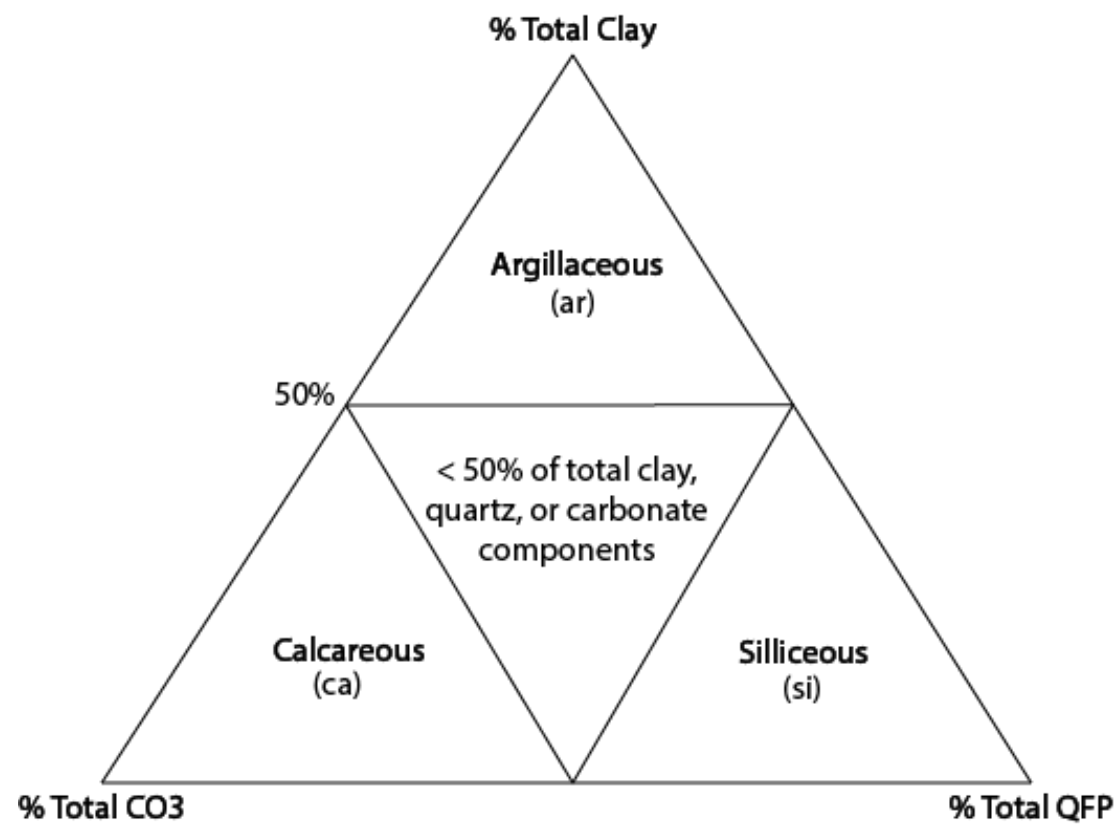

Figure 10. Nomenclature guidelines for fine grained sedimentary rocks, modified from Lazar et al., 2015. The siliceous group consists of quartz, feldspars, and pyrite.

One of the most industry relevant questions asked about the Marcellus Formation is "What is the contact with the Onondaga Limestone like'? To answer this, it is important to acknowledge the Tioga Ash Beds. These are very thin intervals in which ash was deposited while sediments of the Onondaga and lower Marcellus were accumulating. The Coldstream $1 \mathrm{MH}$ well has had its ash beds studied and marked, so it will serve as the control. To determine potential locations for these ash beds, the amount of thorium and uranium in parts per million (PPM) and the ratio of thorium to uranium.

\subsection{RESULTS}

\section{Determining Tops of the Focus Wells}

To distinguish the different rock types from one another, three types of logs are used (Figure 11). The first type is the gamma log which measures radioactivity to determine 
compositional changes and correlation (Asquith et al., 2004). The gamma ray log has been

normalized using a baseline shift and has an average value of 116.360 API.

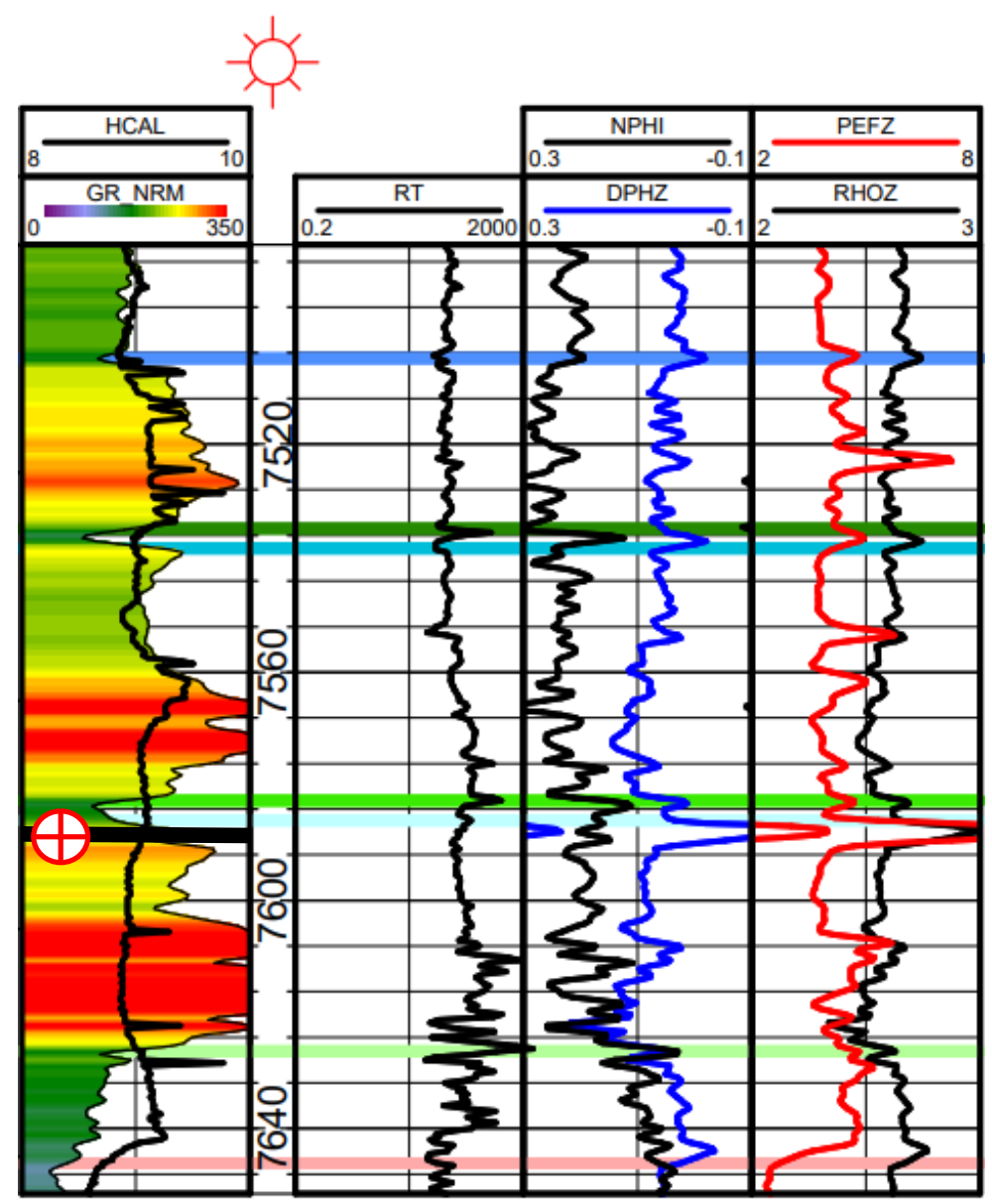

Figure 11. Log compilation of the Coastal 1H well consisting of gamma (GR_NRM), caliper (HCAL), resistivity (RT), neutron porosity (NPHI), density porosity (DPHI), photoelectric factor (PEFZ), and bulk density (RHOZ) logs. Tops are marked by color and coordinate with Figure 11. The initial target for production is marked by the red crosshairs on the left side of the gamma log, which is the landing point for the lateral well. These tops mirror the work done by Burnett Oil Company, the original owners of the Coastal $1 \mathrm{H}$ well. Their interpretations of the data led them to designate three shales within the Marcellus Formation.

Though by itself gamma-ray is not entirely fool proof, thus requiring the use of two other log types. For this thesis, density logs measured (mnemonics RHOZ, RHOB and ZDEN) implemented in the well bore measure density of the rock and fluids present. Lastly, the third type is neutron porosity logs identified as NPHI and CN (Figure 12). The neutron porosity log 
emits neutrons which are inhibited by the presence of hydrogen. This inhibition occurs due to the presence of fluids, indicating a level of porosity or bound water in the rock formation.

\begin{tabular}{|l|l|}
\hline Log Code & Log Explained \\
\hline GR_NRM & Normalized Gamma Ray \\
\hline RHOZ & HRDD Formation Density \\
\hline RHOB & Formation Density \\
\hline NPHI & Thermal Neutron Porosity \\
\hline ZDEN & Formation Bulk Density \\
\hline CN & Compensated Neutron Porosity \\
\hline
\end{tabular}

Figure 12. Log codes found in the figures created using Petra and their meaning.

To determine the location of the tops mentioned above, the MIP3H and Coastal $1 \mathrm{H}$ wells serve as controls for the data (Figure 13). The Coastal $1 \mathrm{H}$ is the focus well of this thesis, and the MIP3H is the nearest well, towards the west. All logs shown within this section are oriented in a west to east fashion as well. First, the gamma ray log, shows distinct drops in gamma radiation when measuring within limestone intervals. These interval seem to show gamma-ray values less than 150 API. Second, the density and neutron porosity logs will exhibit distinct distancing from one another when within a limestone section of the well bore. In an interbedded limestone unit, the density increases while the porosity decreases. In general, the way these logs respond to shales depends on the mineralogy and if fluids are present. Organic rich shales may show crossovers (indicated in yellow) between the two logs. For both wells, the upper and lower limestone units show the largest seperation between these two log types and occur beneath large spikes in gamma radiation. On average, the density log (RHOZ) increased to 2.65 and the neutron porosity $\log (\mathrm{NPHI})$ decreases to 0.15 . 


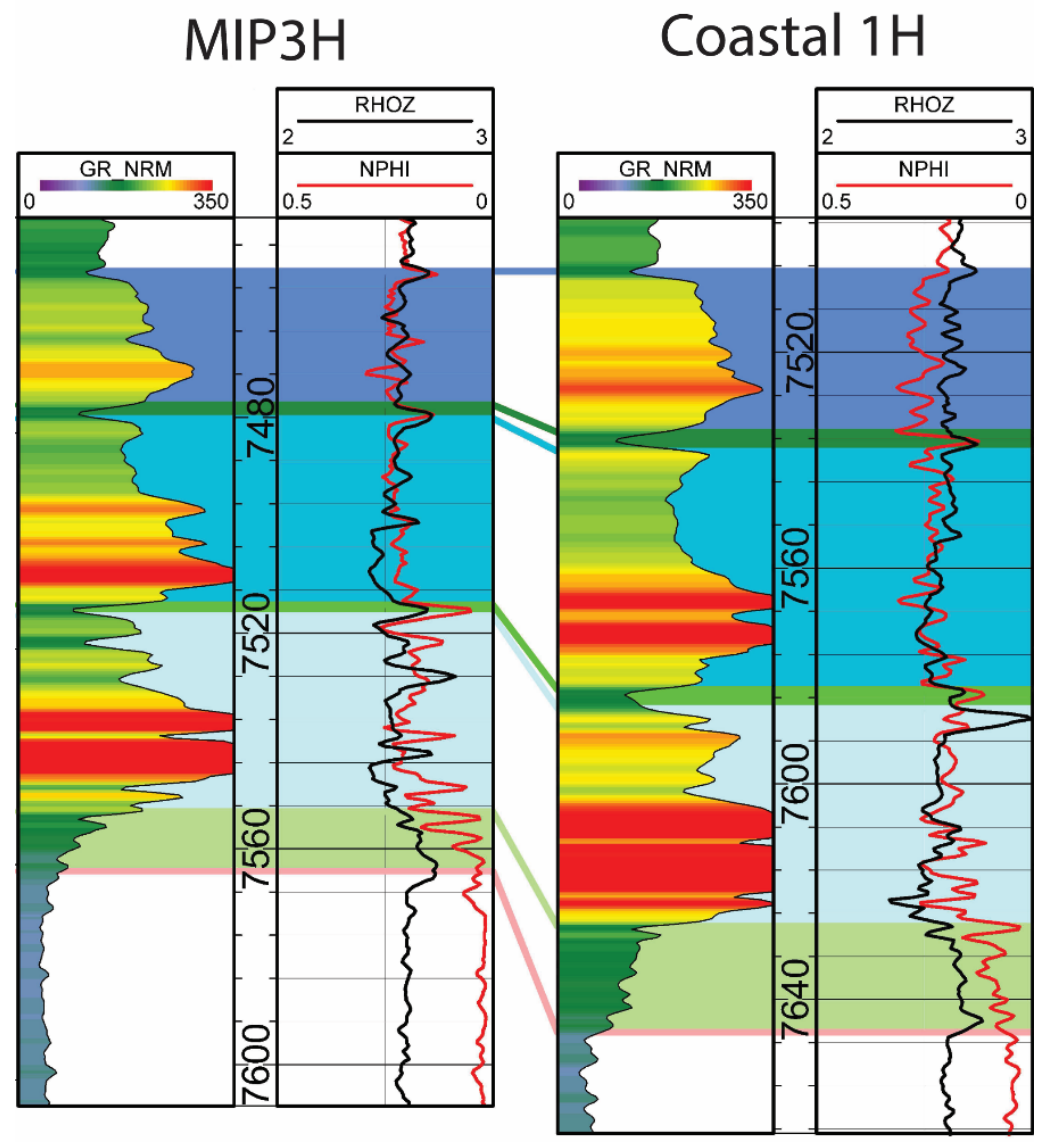

Figure 13. Cross section of the MIP3H and Coastal $1 \mathrm{H}$ wells, indicating the tops present and correlated using bulk density (RHOZ) and neutron porosity (NPHI).

\section{Coastal 1H Lithological Data Analysis}

Lithological data is important to distinguish characteristics of the Marcellus Formation. These characteristics, such as clay content, carbonate, or silicate, can be indicative of organic content in the formation. This data can be combined with interpretations of the core to better understand boundaries between units and how its effects stimulation. Lithological data is determined through methods such as elemental log analysis (ELAN) solutions using traditional and elemental logs, advanced mineralogic solutions using Elemental Capture Spectroscopy (ECS) such as Spectrolith, Inelastic Processing, Lithoscanner, and traditional XRD on available core samples. Ternary plots were made to show whole rock composition based upon Clay, QFP (quartz, feldspars, pyrites), and CO3 (carbonate). This allows us to look at data type and see 
how the tools measure the well bore differently or if biases occur during sampling. To create the figures of this section, I utilized the R programming language via Seong, 2019. 


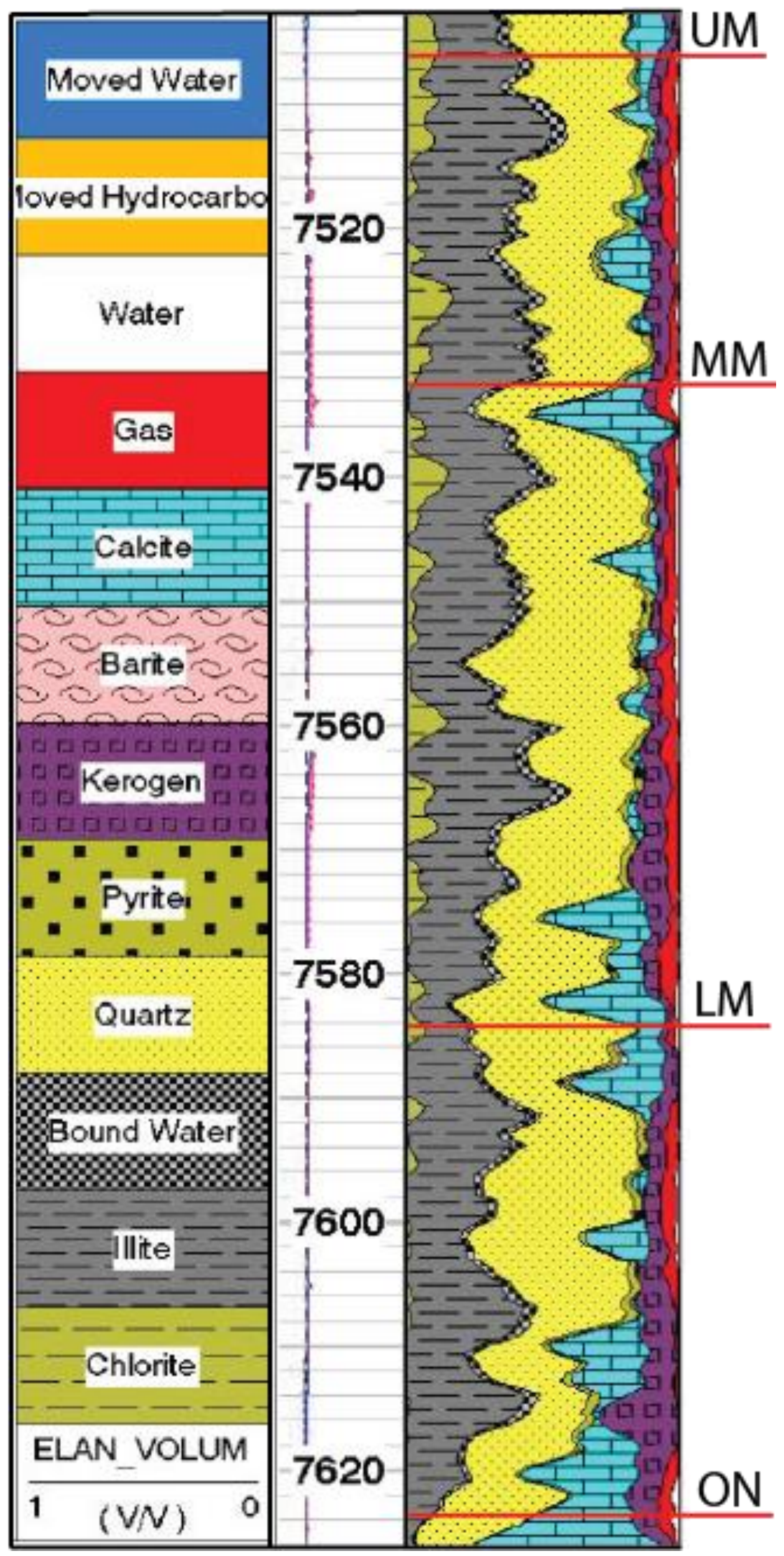

Figure 14. ELAN log data indicating lithological variations across the Marcellus Formation. 
This $\log$ (Figure 14) gives us a general look at the lithological variations with depth of the Marcellus Formation. Overall, it shows that chlorite, illite, and quartz make up most of the Marcellus Formation, with spikes of calcite occurring at the carbonate boundaries between the shale units. However, the lower Marcellus exhibits very little chlorite, higher amounts of kerogen, and even little to no gas present at a depth of $7615 \mathrm{Ft}$. Throughout the Marcellus Formation, large peaks in kerogen occur while calcite disappears entirely. These peaks in kerogen are found at the lower ends of each unit, with minor amounts of pyrite and moved hydrocarbons present. There does not appear to be any relation between lithology and water content, and barite is not present in the Marcellus Formation according to the log.

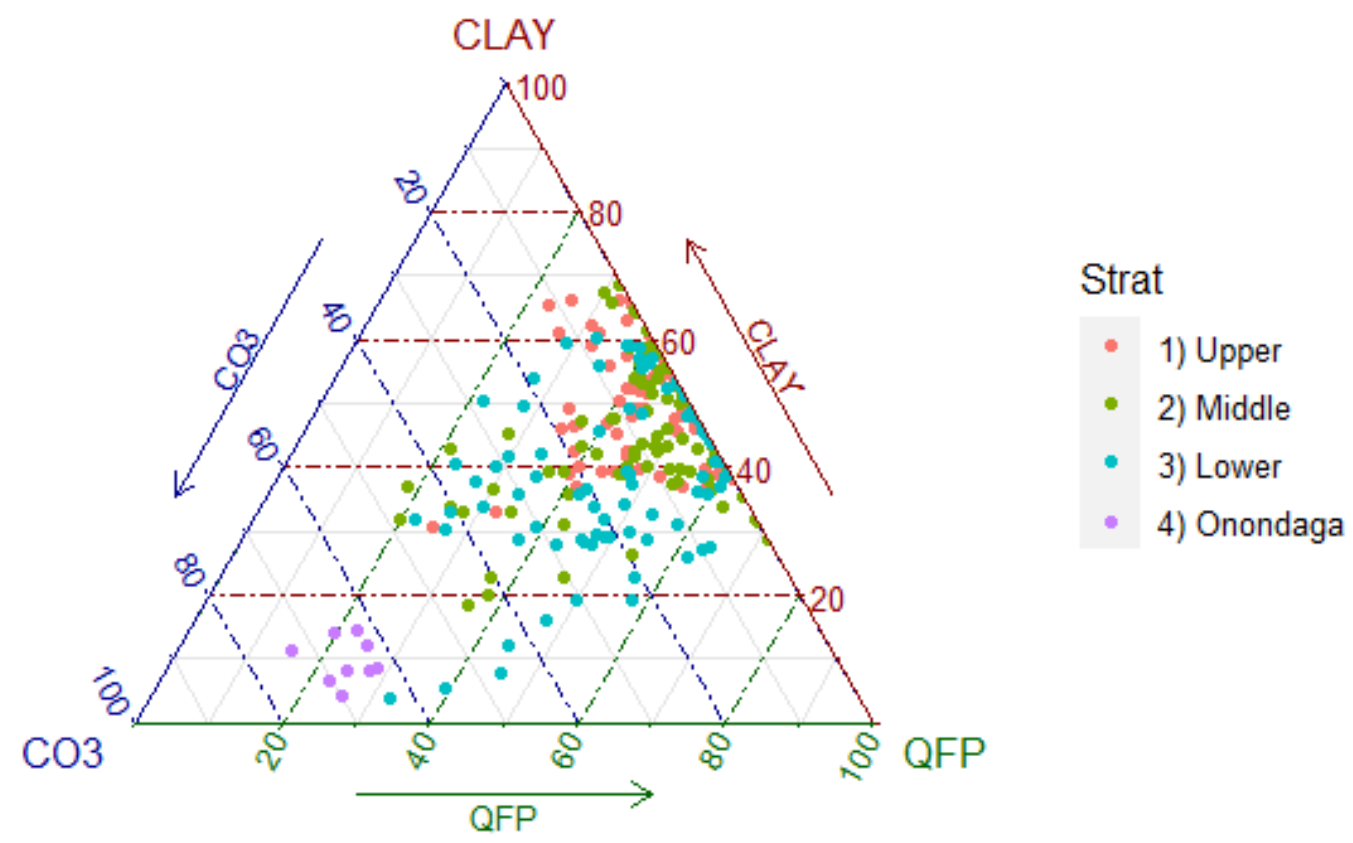

Figure 15. Coastal 1H ELAN whole rock ternary diagram indicating lithological variation based on stratigraphy. 


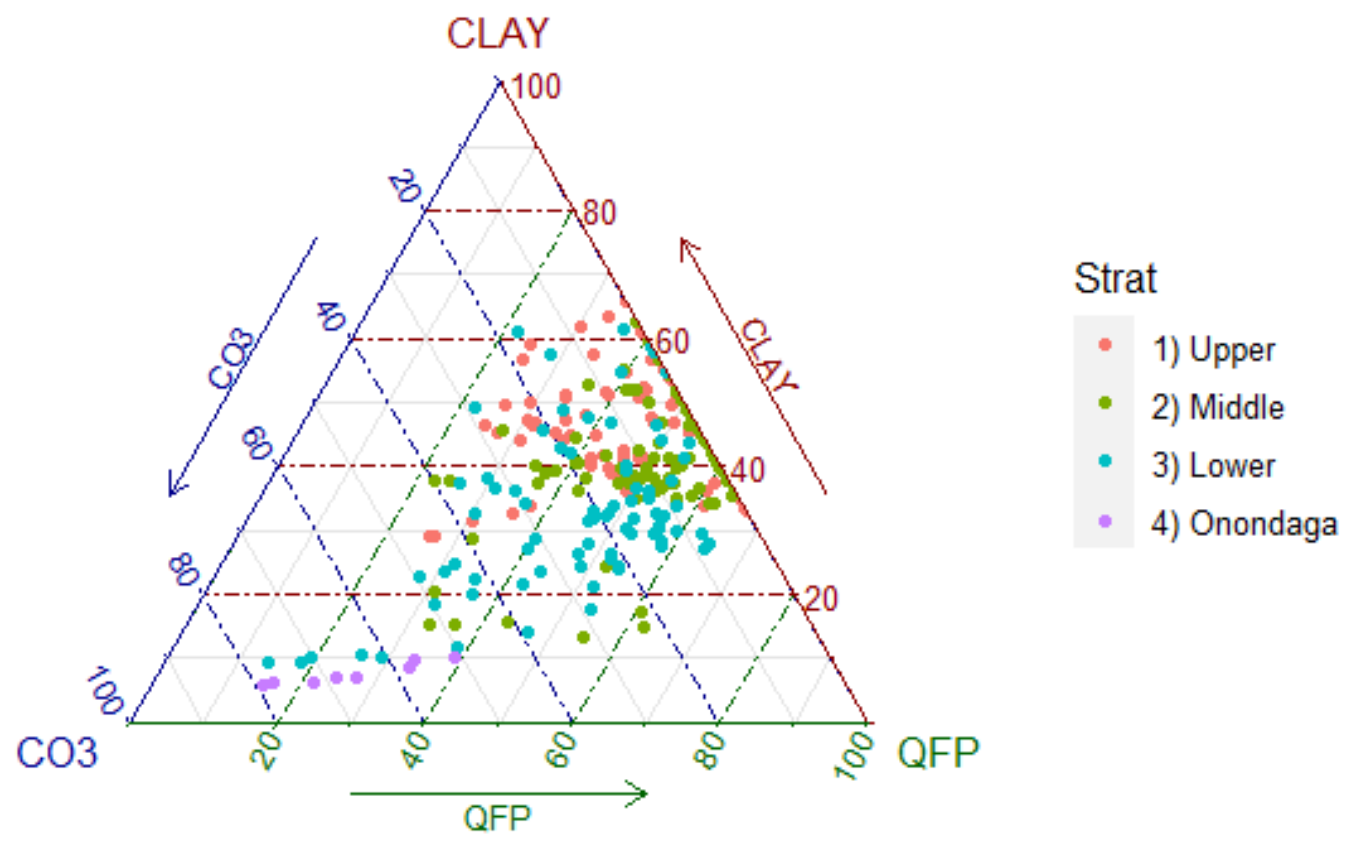

Figure 16. Coastal $1 \mathrm{H}$ Spectrolith whole rock ternary diagram indicating lithological variation based on stratigraphy.

Figures 15 and 16 show lithological data plotted onto whole rock ternary plots for the Infinity (Coastal 1H) well. Creating these graphs required using the coding language R (Seong, 2020). For this ternary diagram, the three axes are clay, CO3 (carbonate), and QFP (quartz, feldspar, and pyrite). Spectrolith utilizes neutron-induced gamma ray Spectroscopy to measure elemental and mineralogical data in well bores (Barson et al., 2005). This reports back data in ELAN weight percent and Spectrolith weight percent for the Coastal $1 \mathrm{H}$ well. Figure 15 and Figure 16 share similarities in their data clustering. The upper Marcellus for both Figures plot tightly right of center, with most points consisting of less than $20 \%$ carbonate and at about an equal proportion of Clay and QFP. The middle unit plots similarly to the upper, though it has more outliers, with some points measuring beneath $20 \%$ clay content. The lower unit has points spread-out across the ternary plot, with an increase in carbonate and QFP content. Lastly, the Onondaga unit in both figures is dominantly carbonate with less than $15 \%$ Clay and between 20- 
40\% QFP. Overall, as depositional occurs in the Marcellus Formation, it becomes more clay rich.

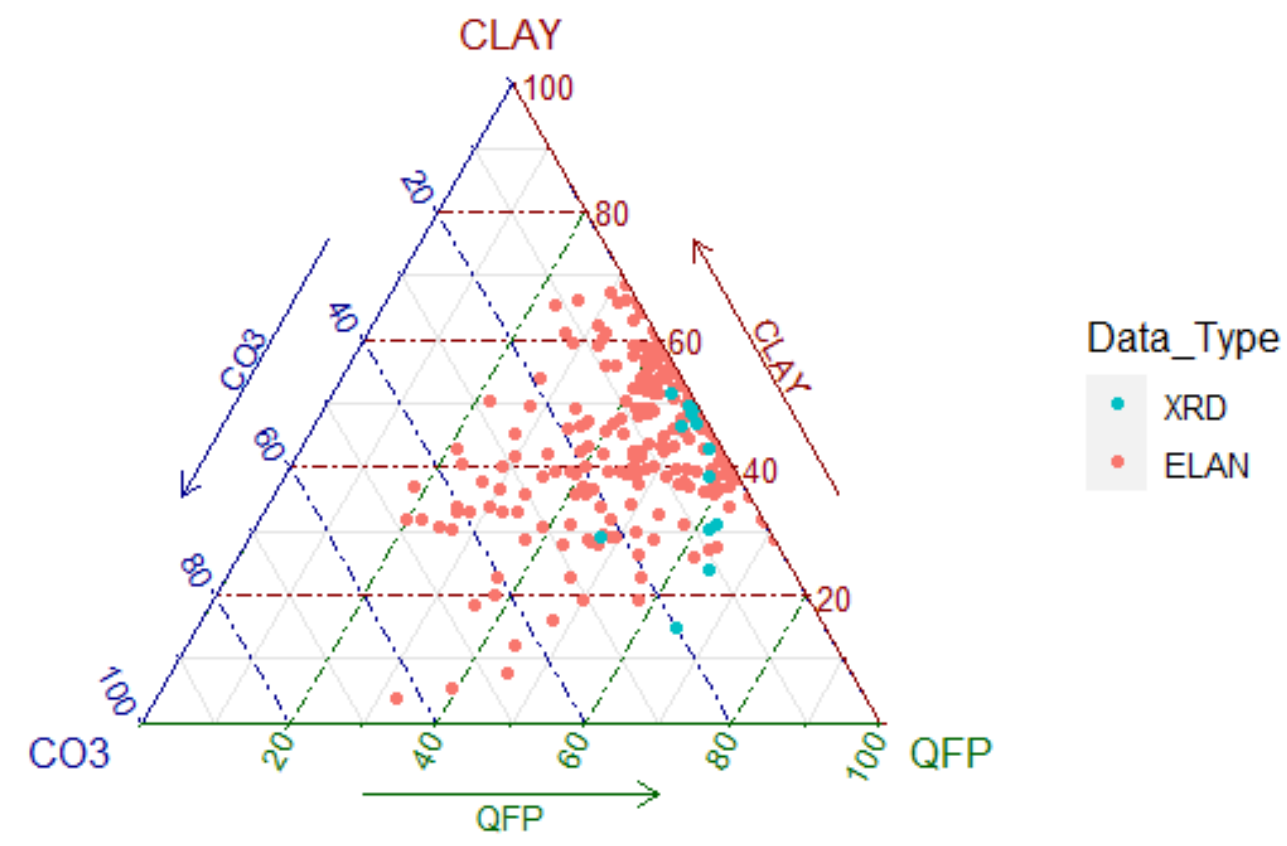

Figure 17. Coastal 1H XRD and ELAN ternary diagram indicating differences in measurement of lithology.

An important part of determining lithological composition is by comparing data types. For the Coastal 1H well (Figure 17), the XRD data indicates a decrease in clay content and an increase in silica. Both sets of data indicate this deviation from the Clay/CO3 Axis. This pattern is exhibited in Figures 15 and 16, as depth increases. Comparing data types also helps researchers understand if biases are present. The log data (ELAN) is measured at an interval in the well bore. The XRD data, however, is collected by sampling pieces of the rock core. For the Coastal $1 \mathrm{H}$ well, it becomes apparent that the XRD data is biased, as it plots exclusively to one side. It is not accurately representing the presence of carbonate in the Marcellus Formation. 


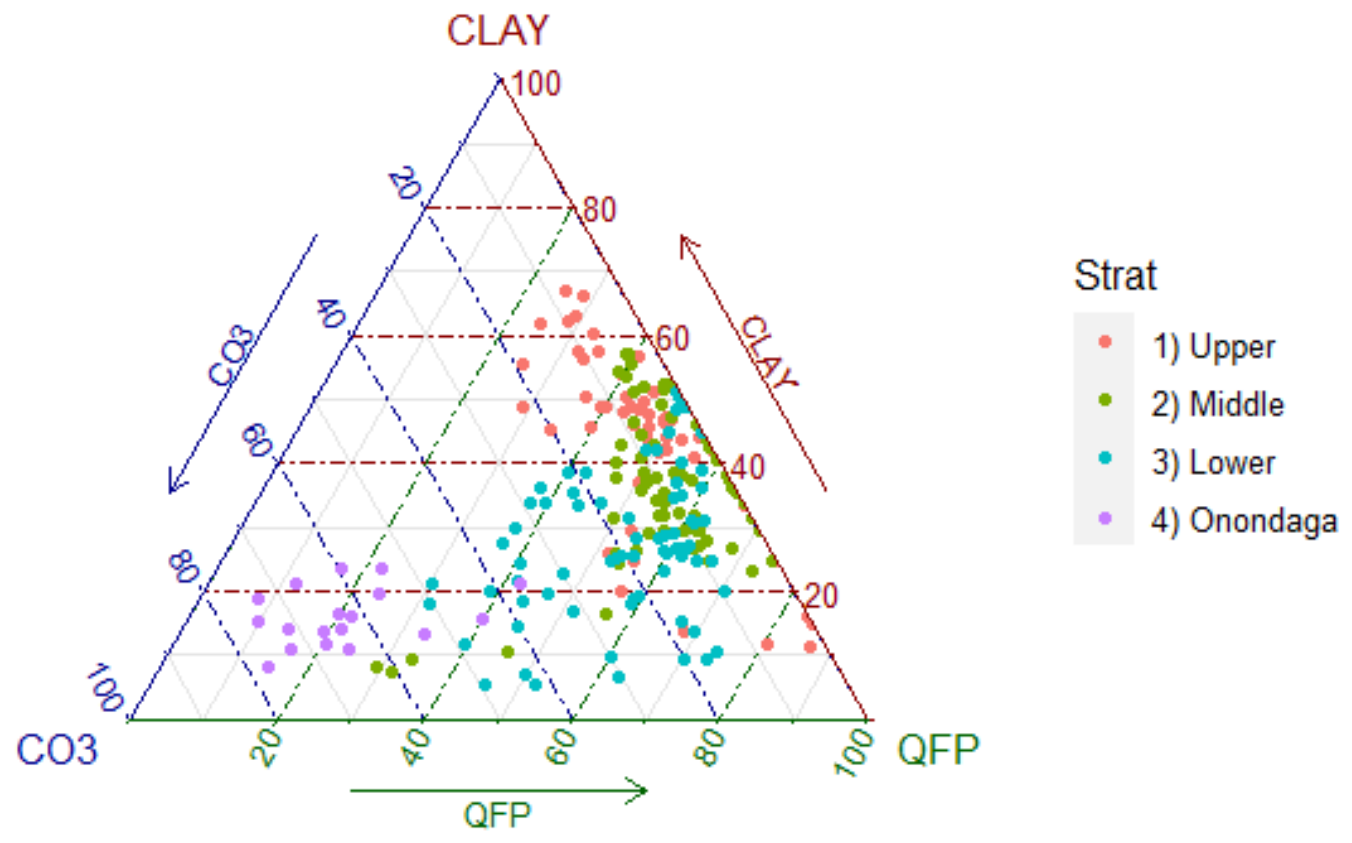

Figure 18. MIP3H ELAN whole rock ternary diagram indicating lithological variation based on stratigraphy.

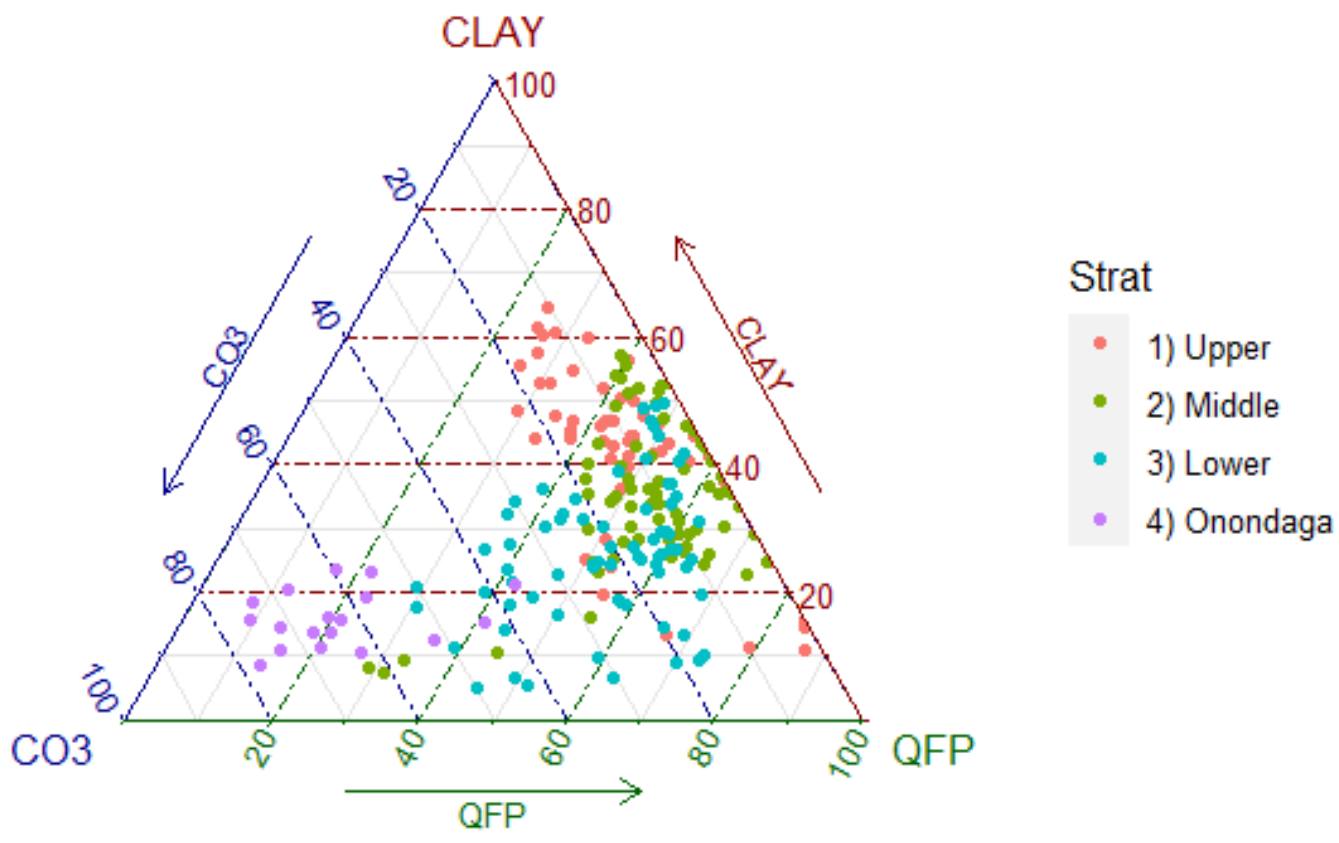

Figure 19. MIP3H Lithoscanner whole rock ternary diagram indicating lithological variation based on stratigraphy.

The MIP3H well utilizes Lithoscanner, which measures inelastic and capture spectra for high-definition Spectroscopy (Aboud et al., 2014). Figures 18 and 19 have identical plots to one 
another and exhibit similar patterns to that of the Coastal $1 \mathrm{H}$. The upper unit exhibits less than $20 \% \mathrm{CO} 3$ and about 50\% Clay/QFP, with some outliers indicating 80\% QFP. The middle unit mirror this, though favoring QFP content between $40 \%$ and $60 \%$. All points measure below $60 \%$ QFP for the lower unit and consistently become more CO3 rich. The Onondaga Formation has most points consistently plotting above $60 \% \mathrm{CO}$.

\section{Analyzing Total Organic Carbon of the Coastal $1 \mathrm{H}$ Well}

Total organic carbon (TOC) is an important parameter for evaluation of shale gas resources. Analyzing variations in TOC is important for identifying zones that may have the highest log-term productivity. Reporting for production of the Coastal $1 \mathrm{H}$ and MIP3H wells began in 2015, however, the MIP3H did not have gas production until 2016. Figures 20 and 21 below show the production for the first two years, with the first month of actual production separated, as well a log for total organic carbon. The Coastal 1H well consists of a TVD (true vertical depth) of 7064 feet and a MD (measured depth) of 14,226 feet, for an estimated lateral length of 7,162 ft. The MIP3H drilling design has a TVD of 7,413 feet and a MD of 13,836 feet, for an estimated lateral length of 6,423 feet. Overall, the Coastal $1 \mathrm{H}$ well produced 1,442,370 Mcf while the MIP3H produced 2,626,007 Mcf, more than 1 million more cubic feet in comparison. Normalized production of the two wells shows that the Coastal $1 \mathrm{H}$ accounts for 201,392 Mcf and the MIP3H produces 408,844 Mcf, per 1,000 feet of lateral. The MIP3H has the highest TOC values and the highest cumulative production over the first two years. 


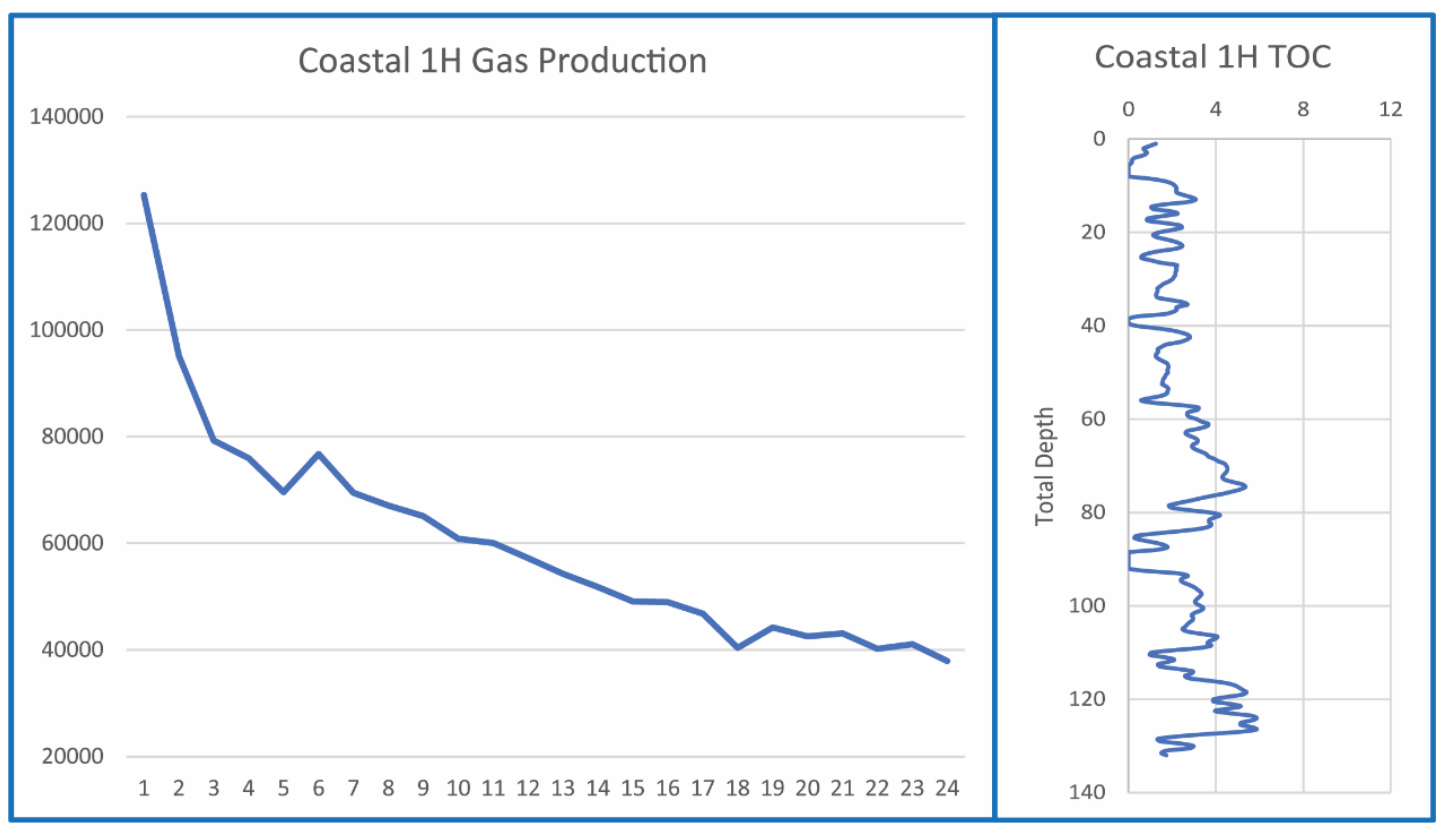

Figure 20. First two years (24 months) of gas production (in Mcf) and TOC log for the Coastal 1H Well.

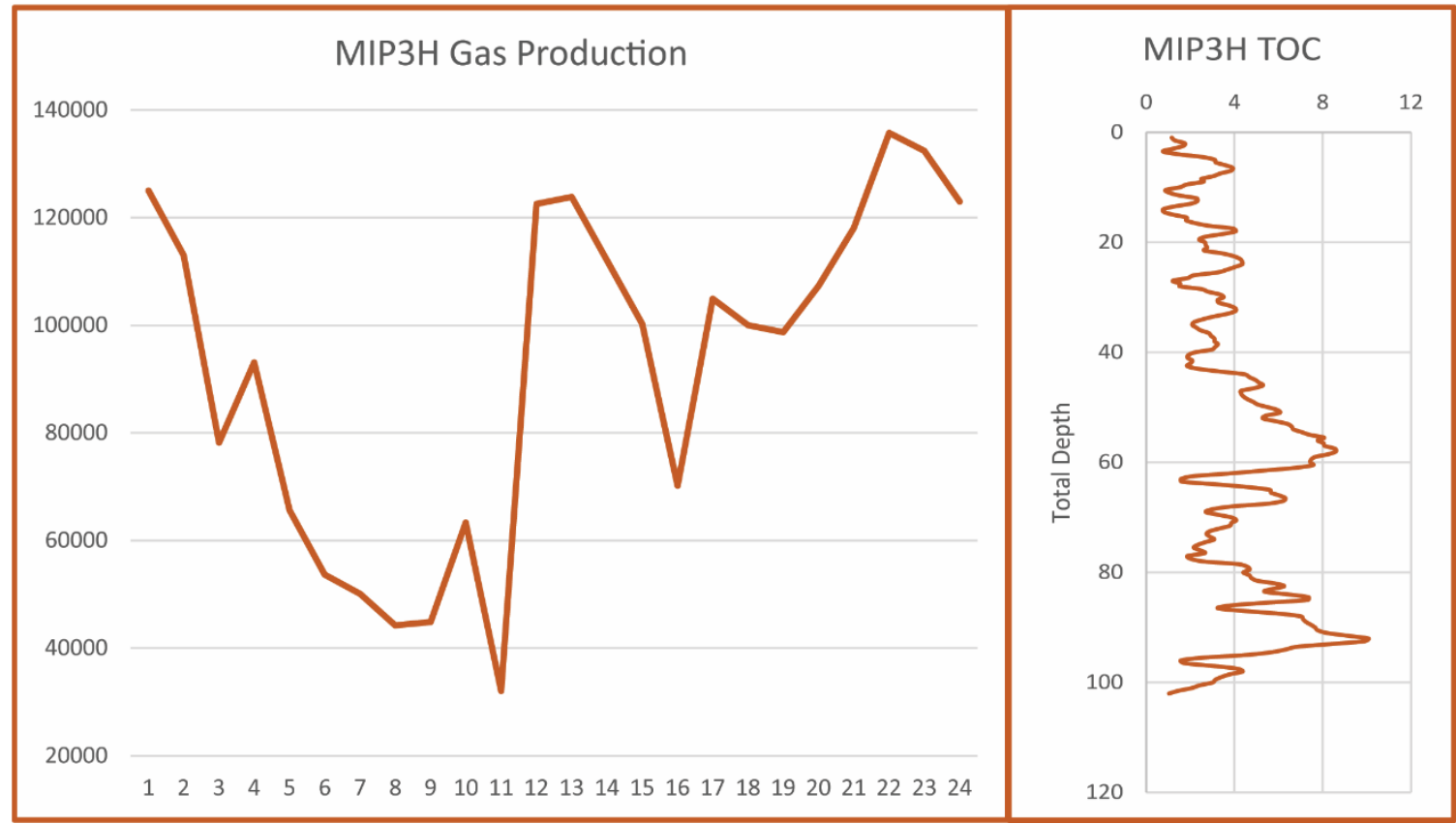

Figure 21. MIP3H gas production (in Mcf) for the first two years (24 months) and TOC log.

There are many methods employed by industry which measure total organic carbon.

These include Schmoker's, Terratek, Isotherm LECO (pyrolysis), and various well logging methods. Each of these are interpreted in the data and normalized amongst themselves.

Schmoker's utilizes the bulk density logs to estimate TOC (Alshakhs and Rezaee, 2019), while 
Terratek is a heterogenous rock analysis tool (Aboud et al., 2014). Lithoscanner measures mineralogy in rock formations and quantitatively estimates TOC (SLB, 2021). The graphs for normalized TOC in this section were developed using the coding language, $\mathrm{R}$.
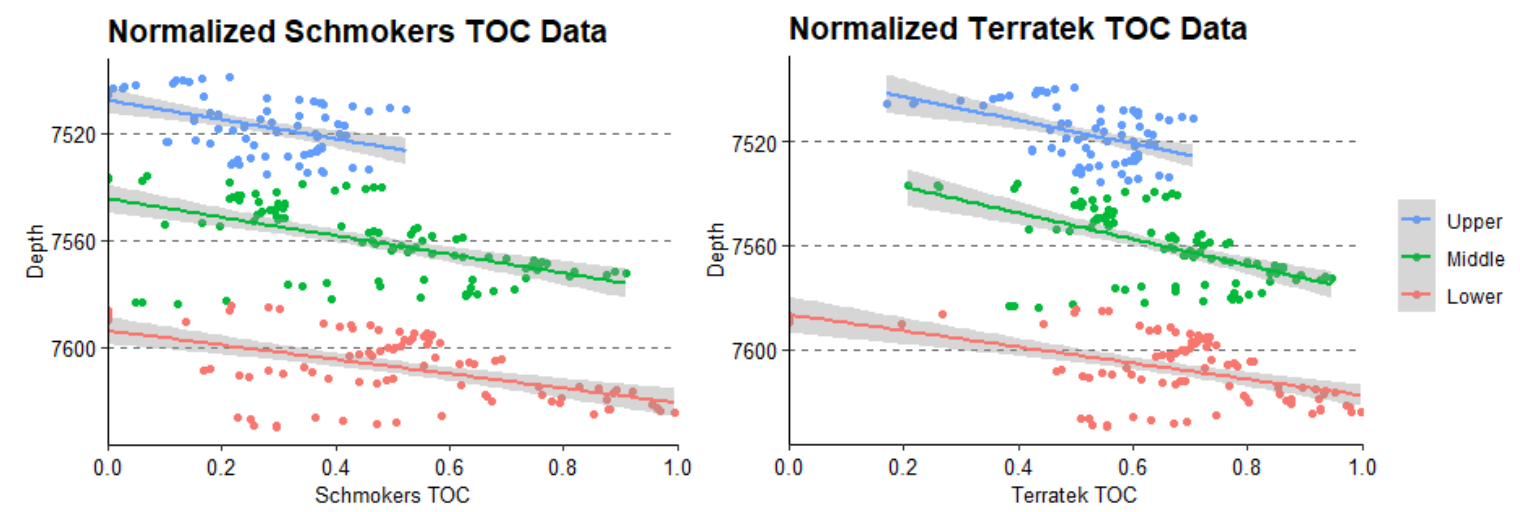

Figure 22. Coastal 1H TOC log data calculating TOC through both Schmoker's and Terratek methods.

The Infinity Natural Resources well (Coastal 1H) implemented two different methods of measuring TOC (Figure 22, Schmoker's and Terratek). Both graphs illustrate how TOC changes with depth in the upper, middle, and lower sections of the Marcellus Formation. Between the Schmoker's (left) and the Terratek (right) there are minor differences. The Terratek method measures higher amounts of TOC, with its data points being in tighter clusters. Both graphs exhibit the same patterns of increasing TOC with depth and the trend lines have nearly identical orientations. Cross plotting the measurements shows that the Terratek method has higher estimates of TOC at lower values a slight change in similarity occurs at about 0.5 ( $\mathrm{X}$ axis) and 0.7 (Y axis). At this point, the trend line and data intersect (Figure 23). 


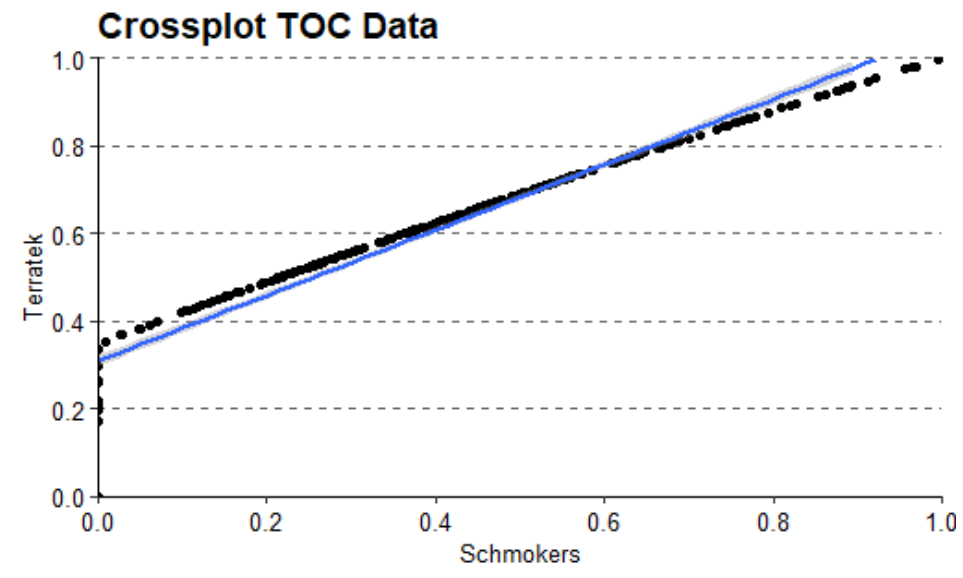

Figure 23. Coastal 1H TOC Cross plot of Schmoker's and Terratek methods.

The plot below (Figure 24) of the MIP3H well shows similar trends to the Coastal $1 \mathrm{H}$ well. The most notable difference being the much shallower trend line of the lower Marcellus. The confidence interval of this section is much broader at its ends as well, suggesting that while the data appears stable, it may be inconsistent at higher measurements.

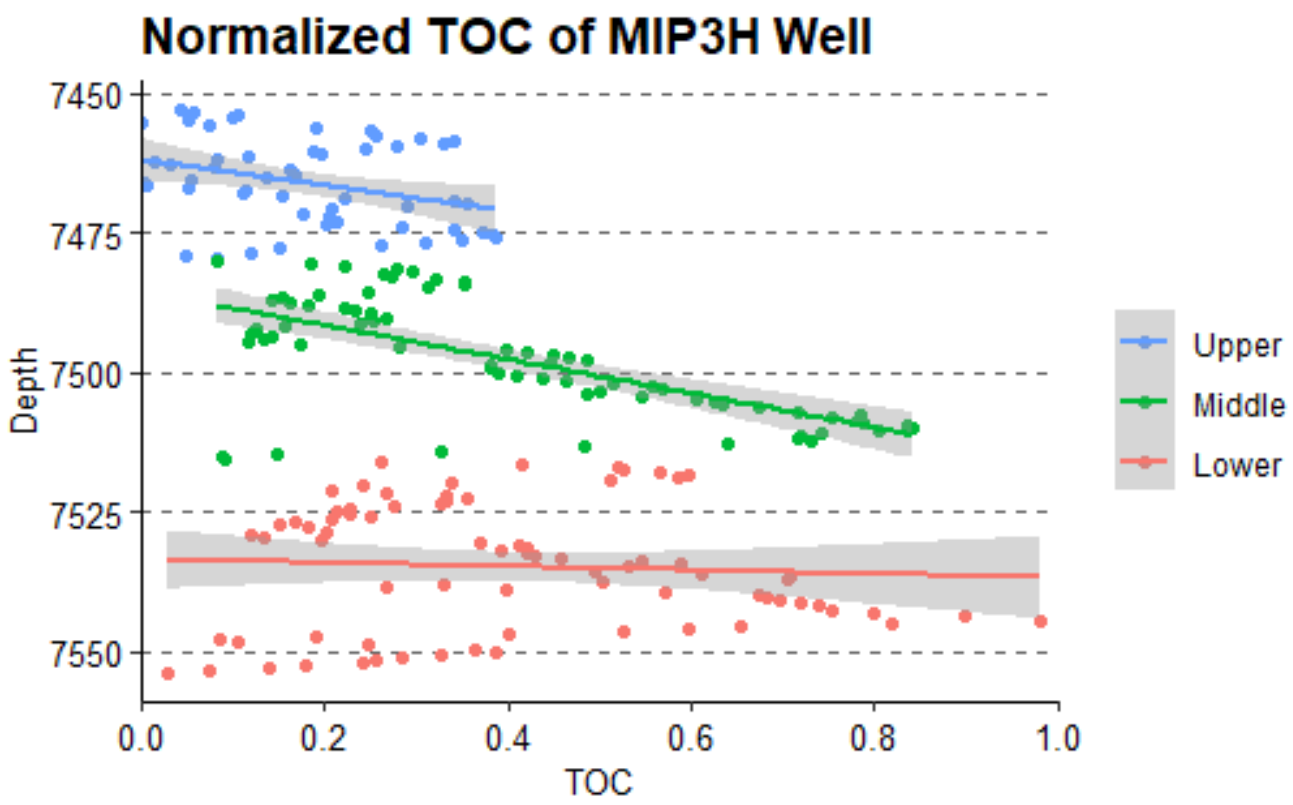

Figure 24. MIP3H TOC data per unit determined using the Lithoscanner log tool. 


\section{Interpreting Fractures and Geomechanics}

According to Zoback et al., (2003) stresses in the wellbore are defined in three ways. The first being the Sv, which is considered the vertical stress. The others are the SHmin and the SHmax, considered the minimum and maximum horizontal principal stresses. During drilling, how fractures occur is the result of changes in these stresses. Borehole breakouts and natural fractures occur within the direction of the minimum principal stress (SHmin), while drilling induced fractures are the result of the maximum principal stress (SHmax, Figure 25).

\begin{tabular}{|l|l|}
\hline Borehole Breakouts & SHmin \\
\hline Natural Fractures & SHmin \\
\hline Drilling Induced Fractures & SHmax \\
\hline
\end{tabular}

Figure 25. Types of fractures occurring within the well bore.

Rosette diagrams from the Coastal $1 \mathrm{H}$ well can visualize the positioning of these fractures. This enables one to determine the stress orientation of the well bore. Knowing this, it is possible to predict the way fracturing will occur and distinguish between fracturing types. 


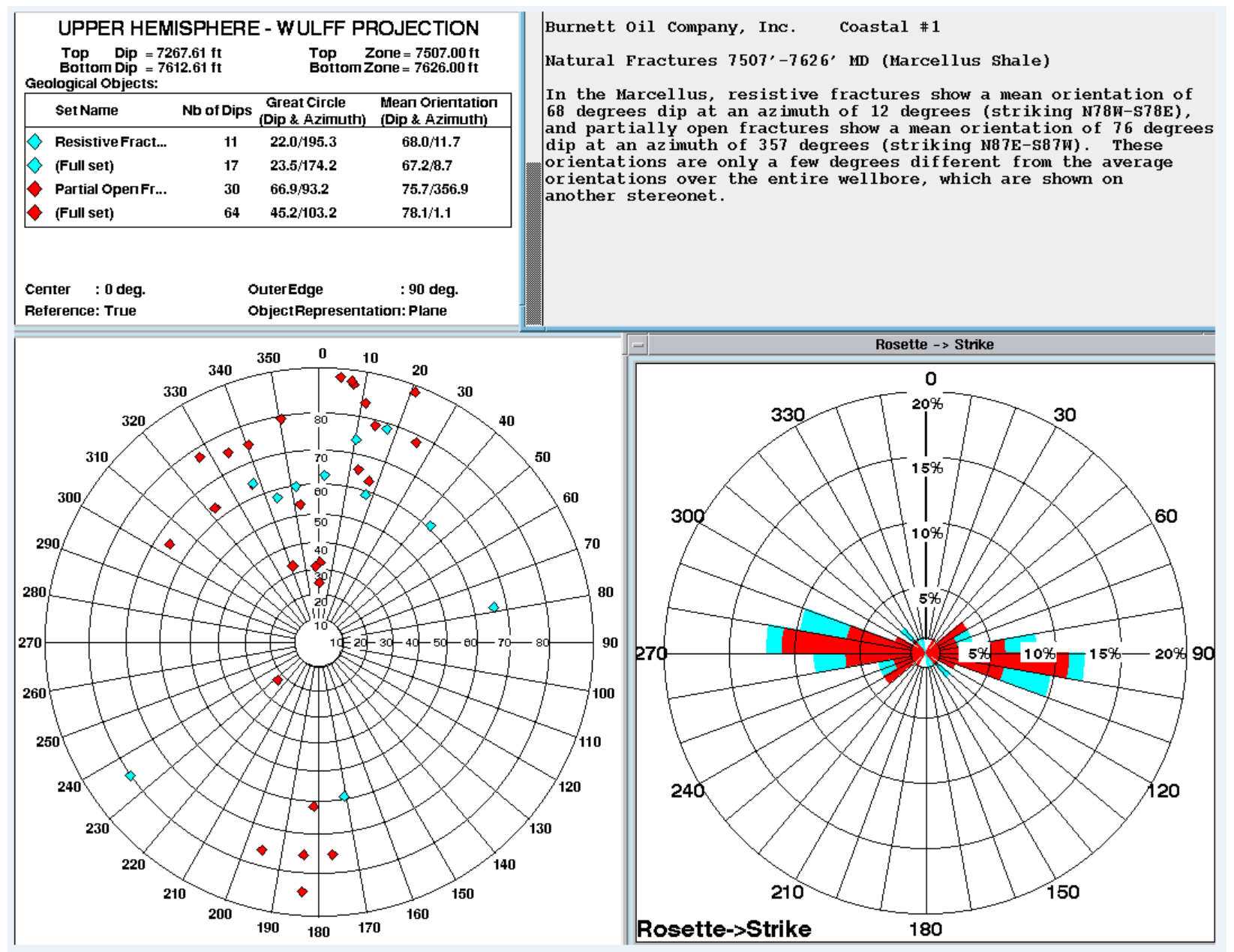

Figure 26. Rosette diagrams indicating positioning of resistive and partially open fractures in the Coastal $1 \mathrm{H}$.

The graph above (Figure 26) represents fracture types and orientation for the Marcellus

Formation of the Coastal $1 \mathrm{H}$ well. Looking at both resistive fractures and partial open fractures is important for delineating the stress field. The Coastal $1 \mathrm{H}$ accounts for a total of 42 of these fractures within the Marcellus Formation. The mean orientation for dip and azimuth of both fractures set are not equivalent. The partial open fractures have a greater dip by 7.7 degrees, and the total difference in azimuth is 14.8 degrees. The dip orientation graph on the left shows that resistive fractures consist of more outliers and less representatives, while both fracture types occur towards the north of the well bore (between 300 and 30 degrees). This difference is 
observable in the Rosette-Strike diagram on the right, where most of the data points fall between 80 and 110 degrees or 260 and 290 degrees.

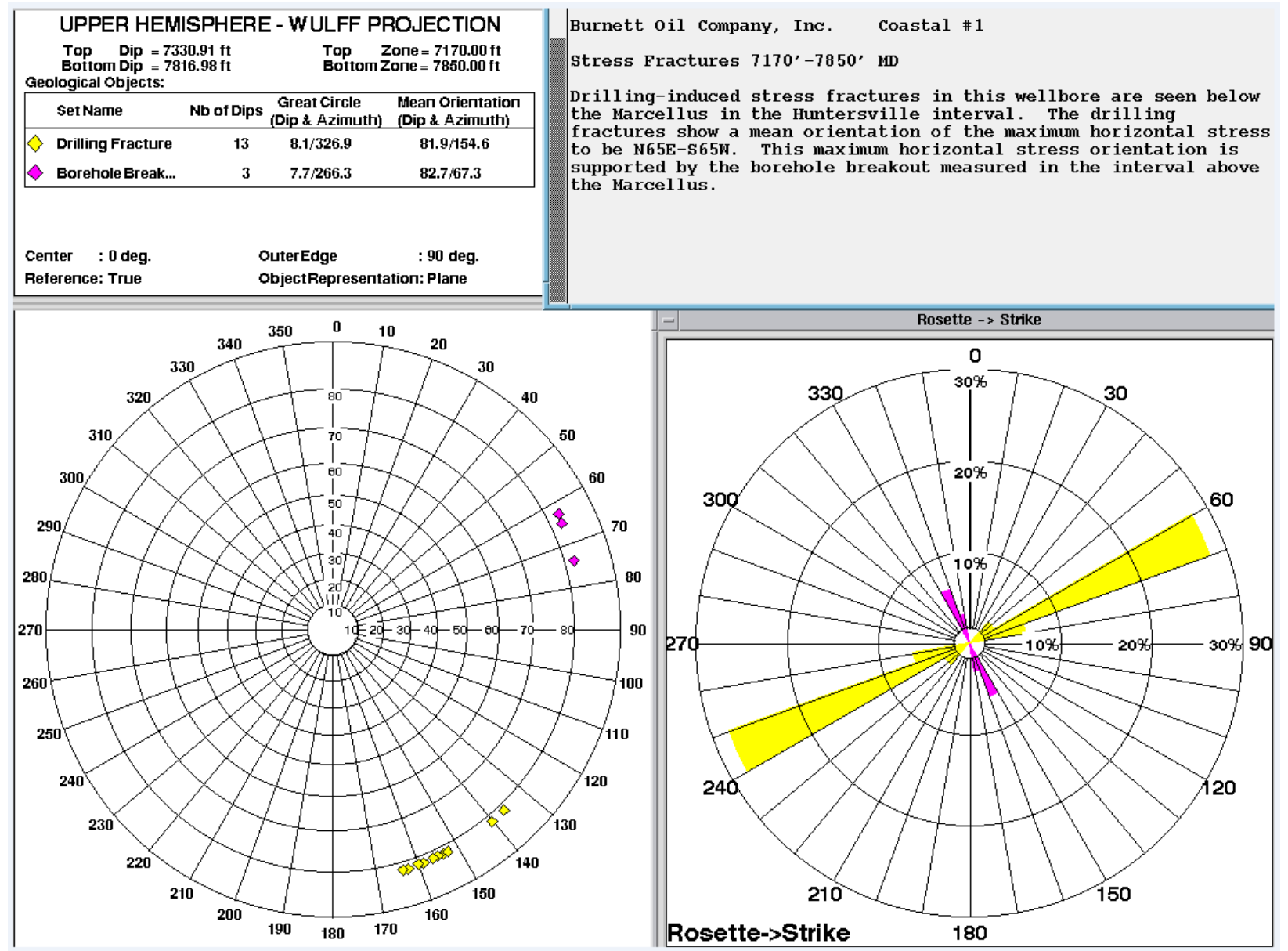

Figure 27. Rosette diagrams indicating positioning of drilling fractures and borehole breakouts in the Coastal $1 \mathrm{H}$.

In contrast to the resistive and partially open fractures, drilling induced fractures display a perpendicular relationship (Figure 27). There are few representatives for both types (16 total), which is indicative of proper drilling technique. The dip orientation graph has borehole breakouts occur between 50 and 75 degrees, while drilling fractures occur between 135 and 165 degrees. The drilling fractures have a similar orientation to the resistive and partial open fractures, with the strike between 60 and 70 or 240 and 250 degrees in the Rosette-Strike diagram. Borehole breakouts however, plot between 150 and 155 or 330 and 345 degrees. Both 
rosette-strike diagrams (Figure $24 \& 25$ ) indicate the direction of the SHmin (natural fractures, borehole breakouts) and the SHmax (drilling induced fractures). There is a difference of about 30 degrees between the natural fractures and borehole breakouts. 


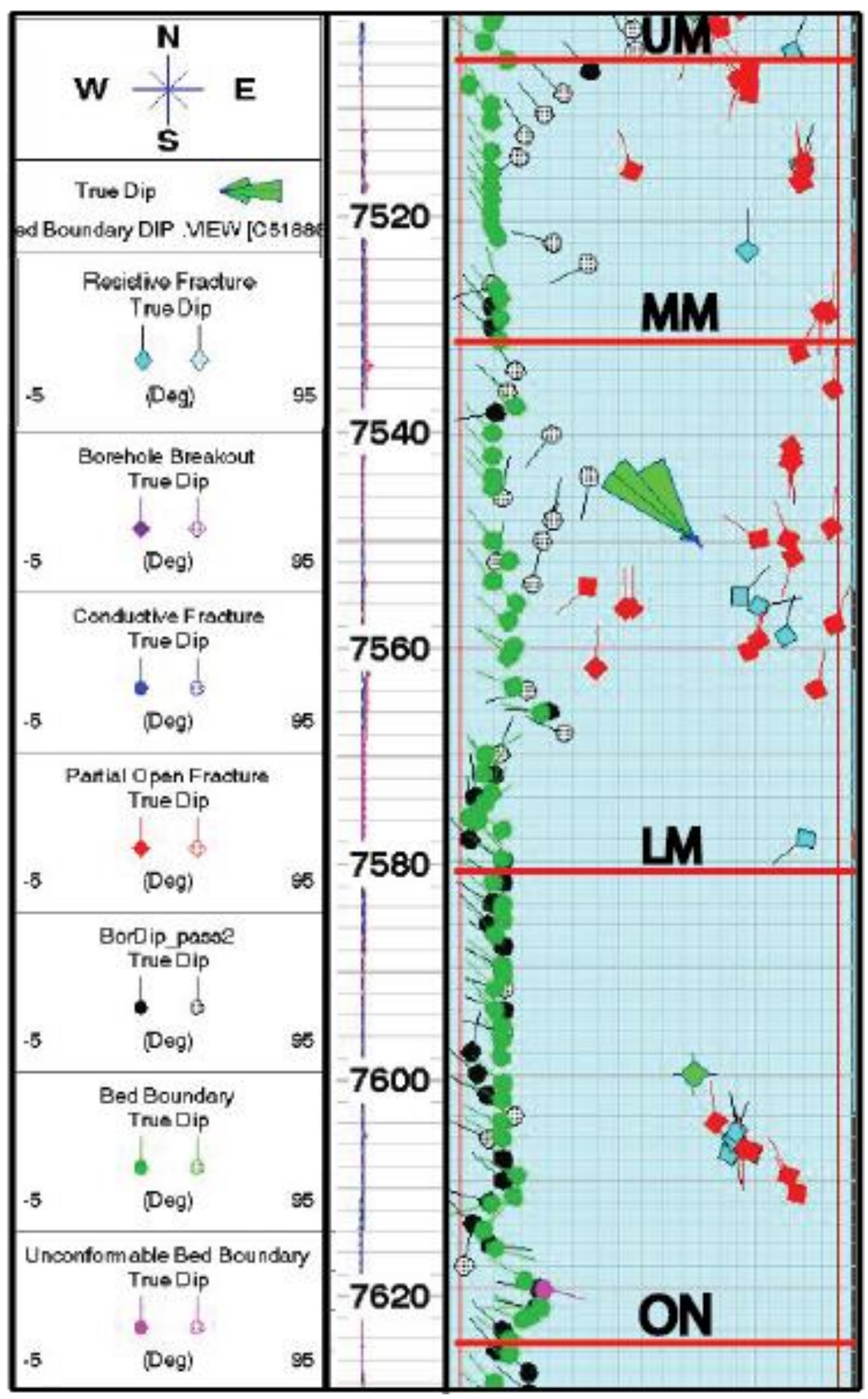

Figure 28. Modified FMI log using Adobe Illustrator, which indicates the position and angle of fractures occurring in the Marcellus Formation from the Coastal $1 \mathrm{H}$. 
The FMI log above (Figure 28) shows the location of fractures, dip orientation, and bed boundaries. The Marcellus Formation dips towards the north west and consists of one unconformable bed boundary near the base. According to the FMI log, no borehole breakouts occurred within the Marcellus Formation during drilling. However, the caliper log (HCAL, which measures borehole width, Figure 11), shows some variation in the size of the borehole within the Marcellus Formation. This size change could be attributed to small breakouts, occurring due to existing fractures, many of which have been photographed (Appendix 3, Figures 73-75). The core of the coastal $1 \mathrm{H}$ has many sections which are broken apart, like rubble. The upper Marcellus has 2 resistive fractures and sporadic partially open fractures. Though the partially open fractures seem to occur in small groups. The middle Marcellus consists of 4 resistive fractures, with 3 occurring proximal to one another. The partial open fractures are spread out, but they occur predominantly in the upper half of the middle Marcellus, with many found in groups of two. Lastly, the lower Marcellus has tightly clustered fractures that occur in the middle. A total of 9 fractures ( 3 resistive, 6 partially open) are found directly beneath a bed boundary. Thin section analysis of the Coastal $1 \mathrm{H}$ and MIP3H wells shows many fractures existed prior to drilling (Appendix 3, Figures 76-87). Mineral filled fractures are abundant throughout the Coastal $1 \mathrm{H}$ well. The orientation of these fractures varies, some seem to have occurred after drilling, possibly during the process of making the thin sections.

The goal of interpreting geomechanics is to determine the brittleness of the rock. Rock strength is an important characteristic to consider when drilling and hydraulically fracturing rock. Without knowing this, it may be difficult to create fractures properly and lead to inefficient production. Classifying rocks based upon geomechanical principles is possible using sonic logs, shear waves (DTSM), and Compressive waves (DTCO). To do this, the density logs are 
converted from $\mathrm{G} / \mathrm{cc}$ to $\mathrm{Kg} / \mathrm{m}^{\wedge} 3$, and the DTCO/DTSM logs are converted from Us/Ft to m/s. With these new values, it is possible to plug the data into equations for Youngs Modulus (YME) and Poisson's Ratio (PR).

Research conducted on the MSEEL pad in 2019 showed the Marcellus Formation consistently plotting in the "Weak-Brittle" region (Figure 30). This area is categorized mathematically as having a Youngs Modulus below 5 and a Poisson's Ratio beneath 0.25 . There are some outliers, but they do not seem to plot consistently with other formations. Generally, brittle rocks have a higher Youngs Modulus and a lower Poisson's ratio. Brittleness can be determined mathematically through methods by Rickman et al., (2008, Figure 29). To determine total brittleness (TotBrit), one must compute Youngs Modulus brittleness (YMBrit) and Poisson's Ratio brittleness (PRBrit). It should be noted that all the geomechanical data in this research has been normalized using the min-max method.

\begin{tabular}{|c|l|}
\hline Symbol & Value \\
\hline$\sigma$ & Bulk Density $\left(\mathrm{Kg} / \mathrm{m}^{\wedge} 3\right)$ \\
\hline $\mathrm{Vs}$ & Shear Wave $(\mathrm{m} / \mathrm{s})$ \\
\hline $\mathrm{Vp}$ & Compressive Wave $(\mathrm{m} / \mathrm{s})$ \\
\hline
\end{tabular}

Geomechanical Equations

$$
\begin{gathered}
Y M=\frac{\sigma V s^{2}\left(3 V p^{2}-4 V s^{2}\right)}{\left(V p^{2}-V s^{2}\right)} \quad \mid \quad P R=\frac{V p^{2}-2 V s^{2}}{2\left(V p^{2}-V s^{2}\right)} \\
\text { YMBrit }=\left(\frac{Y M-1}{8-1}\right) * 100 \quad \mid \quad \text { PRBrit }=\left(\frac{Y M-0.4}{0.15-0.4}\right) * 100
\end{gathered}
$$




$$
\text { TotBrit }=\left(\frac{\text { YMBrit }- \text { PRBrit }}{2}\right)
$$

Figure 29. Symbols, description, and equations for geomechanical properties.

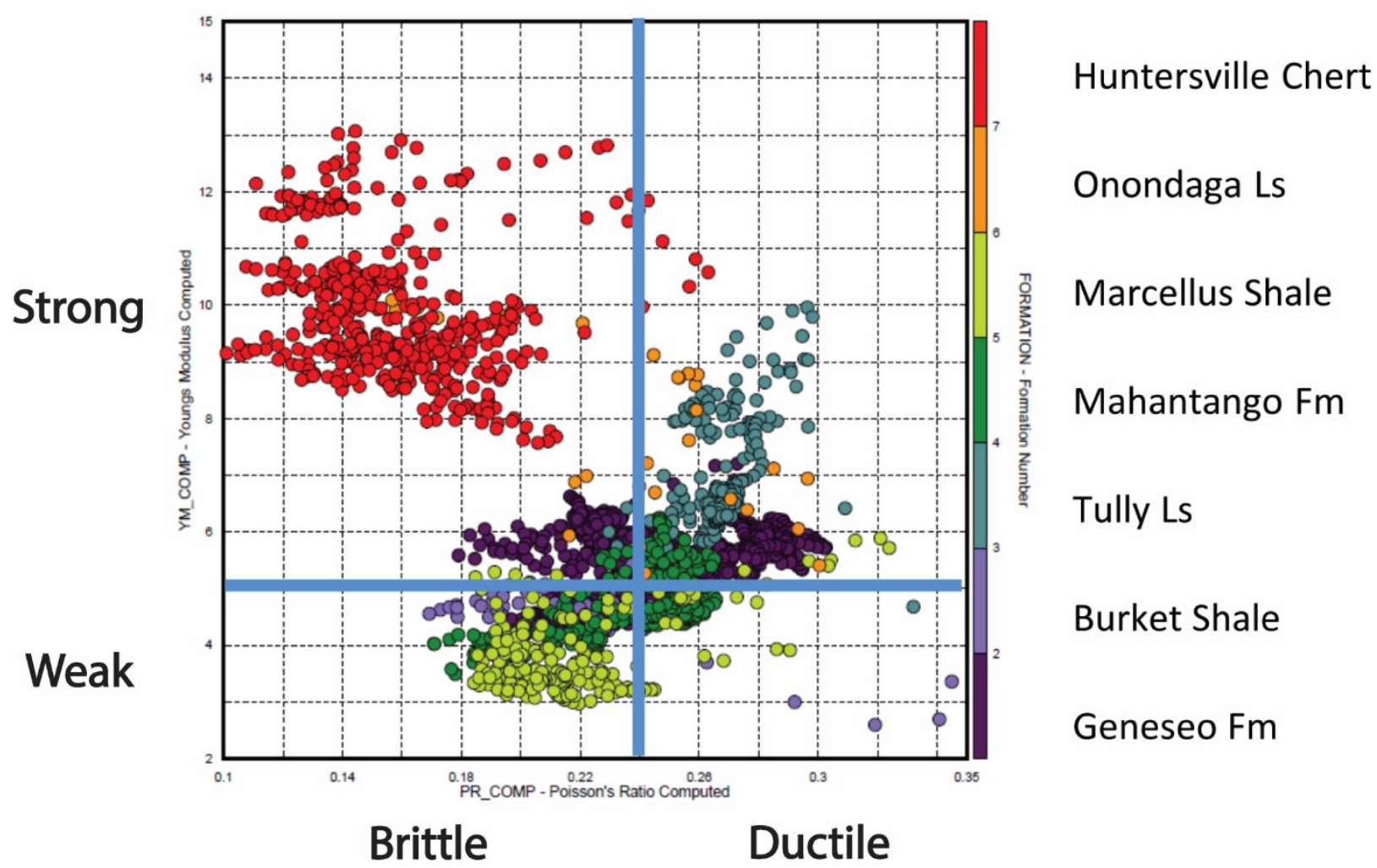

Figure 30. Brittleness plot of the MSEEL pad, showing where formations above and below the Marcellus plot in the four quadrants. Modified from Greiser and Bray, 2007.

The MSEEL well pad has had its geomechanical data interpreted across the well bore.

Figures 30 and 31 are modified from Grieser and Bray (2007) and indicates that the Marcellus Formation plots into the weak-brittle quadrant. There are some outliers which plot into the weak-ductile and strong-ductile quadrants as well. The Onondaga however, plots into the strong-ductile and strong-brittle quadrants. The data for the Onondaga Formation is much more spread out and is less consistent than other formations represented in this figure. This may be a result of varying lithology, possible due to the presence of clay minerals. 


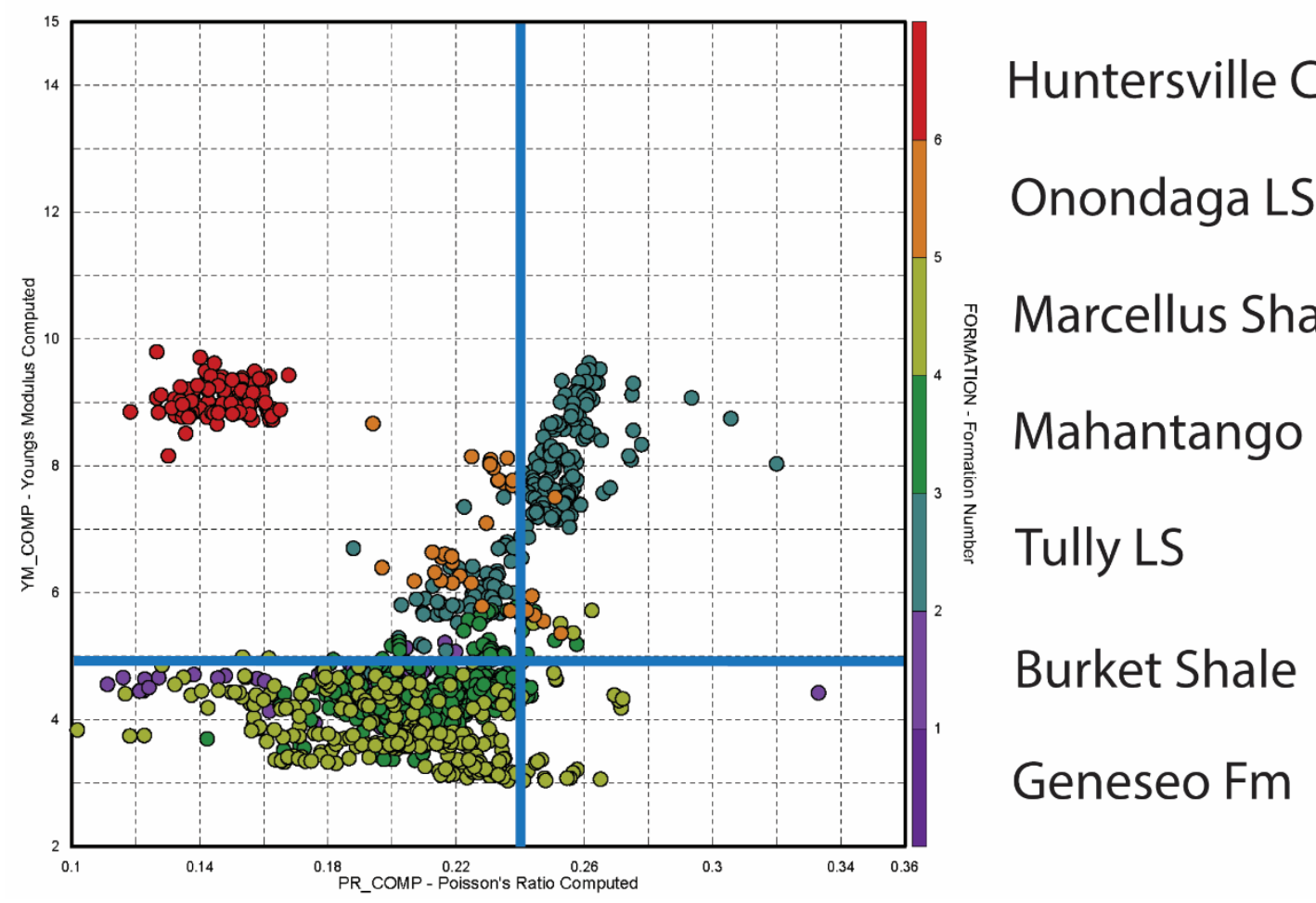

Figure 31. Brittleness plot of the Coastal $1 \mathrm{H}$ Well, showing where formations above and below the Marcellus plot in the four quadrants.

The MIP3H well is the closest to the Coastal $1 \mathrm{H}$, so understanding how it plots in relation to the Coastal 1H (and other wells) is important for determining their similarity. It also shows whether the new information is consistent with previous research. The loess curve is a nonparametric strategy for applying a smooth curve within a set of data as a part of regression analysis. This enables researchers and statisticians to determine trends in data. The loess curve is applied by unit in the Young's Modulus and Poisson's Ratio cross plots. 


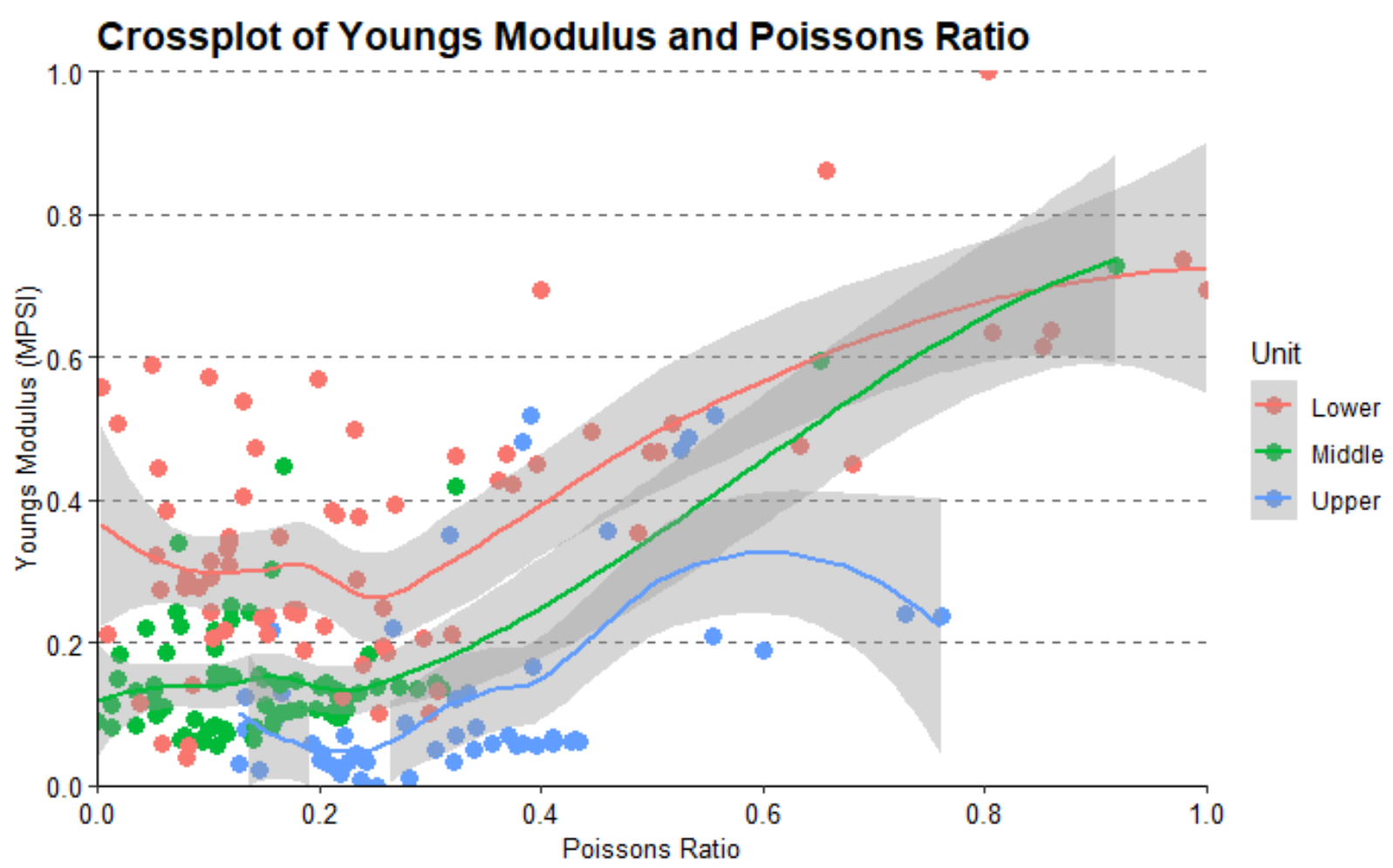

Figure 32. MIP3H cross plot between Young's Modulus and Poisson's Ratio with loess curves.

As Figure 32 suggests, the MIP3H well of the MSEEL pad plots consistently in the weak-brittle quadrant. The three loess curves exhibit similar patterns, with low and tighter confidence intervals in this quadrant. Like the Coastal 1H, as depth increases, so does Youngs Modulus. Though for the MIP3H well, it is less apparent if the Poisson's Ratio is decreasing with depth. 


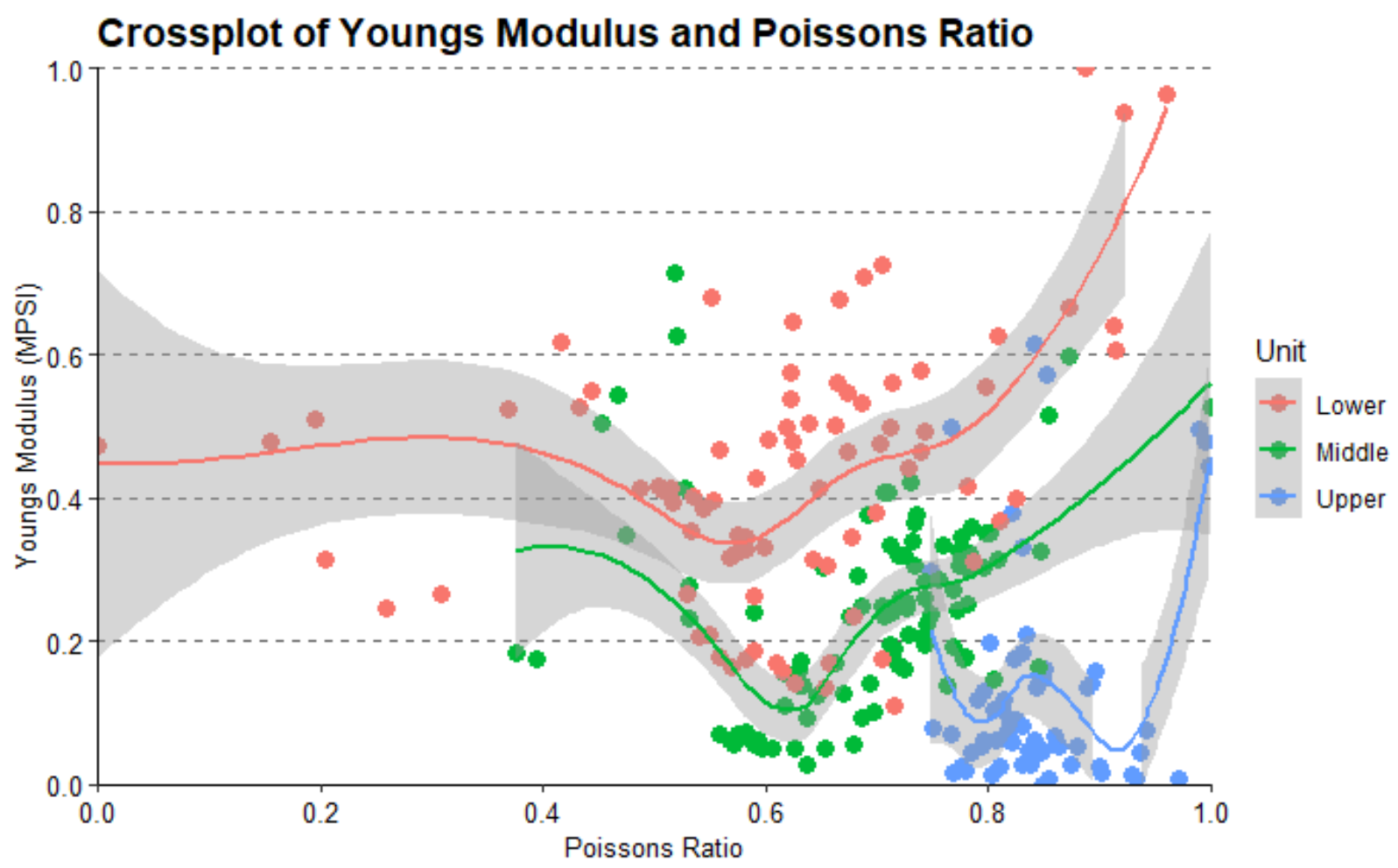

Figure 33. Coastal $1 \mathrm{H}$ cross plot between Youngs Modulus and Poisson's Ratio with loess curves.

The Coastal $1 \mathrm{H}$ well, while being near the MIP3H, is significantly different when normalized (Figure 33). It seemingly plots on the other end of the spectrum. The coastal $1 \mathrm{H}$ well exhibits a consistently higher Poisson's Ratio, with the upper unit plotting almost exclusively above 0.8 . The middle and lower units share similar patterns in their Loess Curves, with troughs occurring at around 0.6 along the $\mathrm{X}$ axis. As depth increases, Youngs Modulus increases and Poisson's Ratio decreases. Overall, the Coastal $1 \mathrm{H}$ well plots within the weakductile quadrant.

\section{Marcellus-Onondaga Transition}

Spectral well log data has enabled geologists to delineate elemental components of reservoirs in the Marcellus Shale. Through the well bore, special sensors are sent down to measure the gamma radiation emitting from the rock. The spectral components of this gamma 
measurement are broken down into 3 elements. Uranium (measured in PPM), which is a major indicator for the presence of organic material such as Kerogen. Potassium (measured as a percentage, because it is very small), which is important for determining lithological variations in mineral groups. But the most important element for this project is Thorium.

Thorium (measured in PPM) is essential to this project because it is an elemental component of minerals found in ash beds. This is attributed to the presence of biotite and feldspar present in these types of rock (Yanni, 2010). According to Hayward (2012), the presence of pyrite is associated with these ash deposits as well. These ash beds were deposited around 400 million years ago across the eastern United States (VanMeter, 2014). In West Virginia and certain parts of Pennsylvania, they are known as the Tioga Bentonite. In terms of Stratigraphy, this formation generally occurs between the Marcellus Shale and the Onondaga limestone, though the beds have been identified in portions of the lower Marcellus as well. The thickness of the Tioga Bentonite varies, and it is not a continuous formation, appearing sporadically across several states. It is important to know where the ash beds are for three reasons. The first is that it serves as a key indicator in geologic time, given the vary narrow window in which it was deposited. The second is because it outputs higher gamma radiation it could be mistaken for deposits of organic material and be targeted for gas production. Lastly, it helps to understand the contact between the Marcellus Formation and the Onondaga Limestone.

Determining where the ash bed may be is a difficult without rock core to look at. Since Thorium and Uranium both cause higher spikes in the gamma log, the Tioga Bentonite can be identified by observing changes in the log. At the depth where the ash beds are expected (which varies between wells), the gamma log will still have higher values but show a significant drop in the concentration in Uranium. Subsequently, this will also the show the inverse in the Thorium 
log. The Coldstream 1MH well has had multiple ash beds identified and serves as the basis for interpreting these peaks. Thorium and the thorium/uranium ratio are the 2 primary logs being used to determine the presence of ash beds. But the elemental components of biotite and feldspars may be detectable as well, further proving that ash beds are present. To determine their presence, $\operatorname{logs}$ for iron $(\mathrm{Fe})$, aluminum $(\mathrm{Al})$, and silicon $(\mathrm{Si})$ are included based off the chemical compositions of these minerals (Figure 34).

\begin{tabular}{|l|l|}
\hline Mineral & Chemical Composition \\
\hline Biotite & $\mathrm{K}\left(\mathrm{Mg}, \mathrm{Fe}_{3}\left(\mathrm{AlSi}_{3} \mathrm{O}_{10}\right)(\mathrm{F}, \mathrm{OH})_{2}\right.$ \\
\hline Orthoclase & $\left(\mathrm{KAlSi}_{3} \mathrm{O}_{8}\right)$ \\
\hline Albite & $\left(\mathrm{NaAlSi}_{3} \mathrm{O}_{8}\right)$ \\
\hline Anorthite & $\left(\mathrm{CaAl}_{2} \mathrm{Si}_{2} \mathrm{O}_{8}\right)$ \\
\hline Pyrite & $\left(\mathrm{FeS}_{2}\right)$ \\
\hline
\end{tabular}

Figure 34. Chemical compositions of minerals associated with ash beds.

It also important to note that these ash beds were not deposited with organic material present in them. Areas where both logs respond highly could indicate changes in the depositional environment or influences such as bioturbation which mix the sediment together (Hayward, 2012), ash bed 5 of Figure 34 is an example of a reworked ash. 


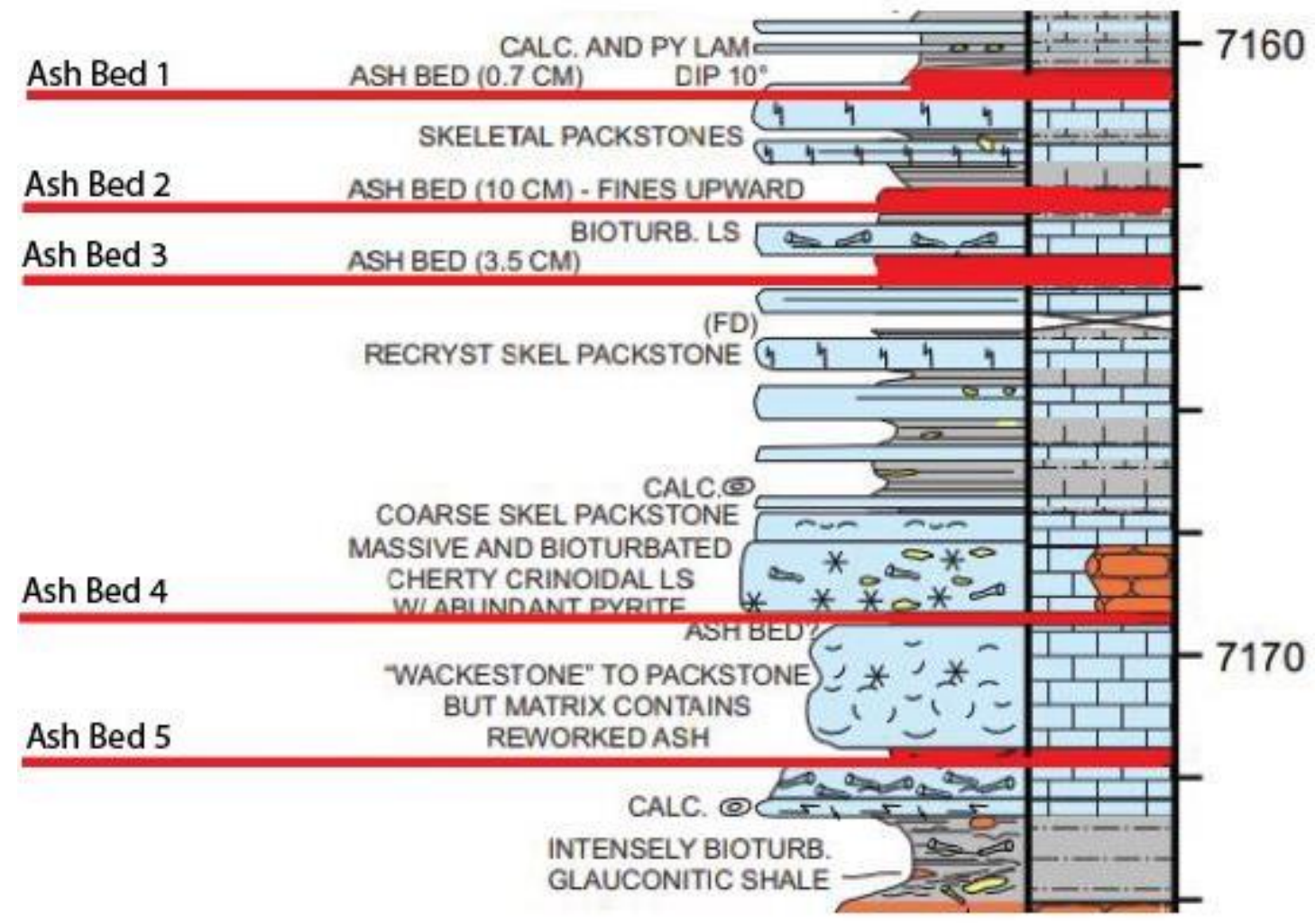

Figure 35. Section of the core description for the Coldstream 1MH well, which indicates the location of ash beds. Five ash beds have been identified within the Onondaga Limestone.

This stratigraphic column is of the Coldstream 1MH well (Figure 35), where multiple ash beds have been identified. This will serve as a guide for interpreting the logs of the Coastal $1 \mathrm{H}$ well. Between the lower Marcellus and the Onondaga, 5 ash beds are present in the Onondaga Formation. The largest ash bed is \#2, which is about $10 \mathrm{~cm}$, while the smallest is ash bed 1 at $0.7 \mathrm{~cm}$. Ash beds 4 and 5 are less defined than the ones above. Ashbed 4 is uncertain and ash bed 5 is considered reworked. 


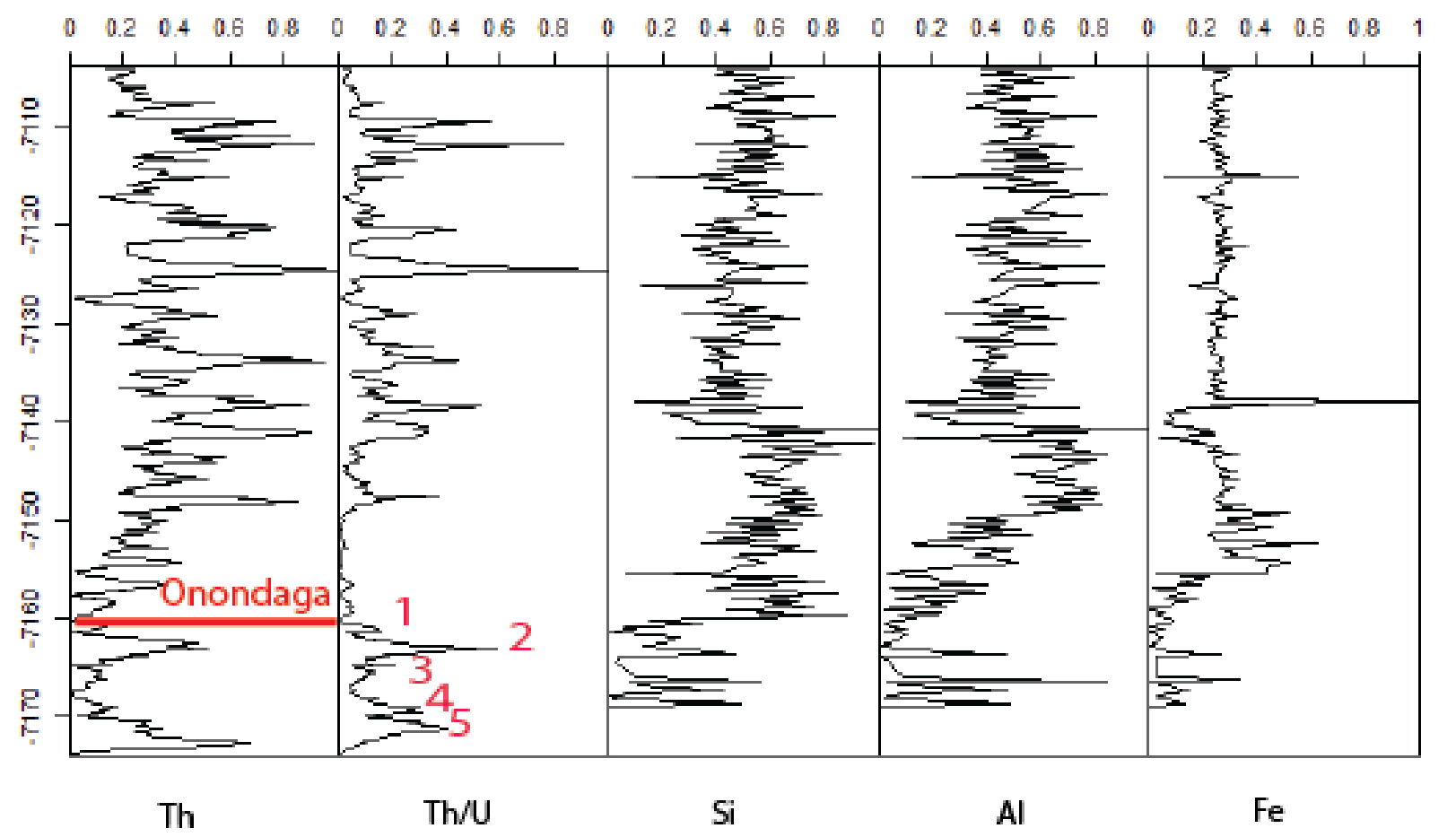

Figure 36. Thorium, thorium/uranium ratio, silicon, aluminum, and iron logs for the Coldstream $1 \mathrm{MH}$ well, indicating peaks in $\mathrm{Th} / \mathrm{U} \operatorname{logs}$.

Each of the 5 ash beds correlate to peaks in the Onondaga formation (Figure 36).

Surprisingly, ash beds 4 and 5 have significantly larger peaks in the Th/U log than ash beds 1 and 3. The logs for $\mathrm{Si}, \mathrm{Al}$, and $\mathrm{Fe}$ all show peaks within the Onondaga that correlate to the ash beds. The data set for the elemental data does not exceed $7170 \mathrm{ft}$ in depth, making it impossible to determine if these peaks occur with ash bed 5 as well. 


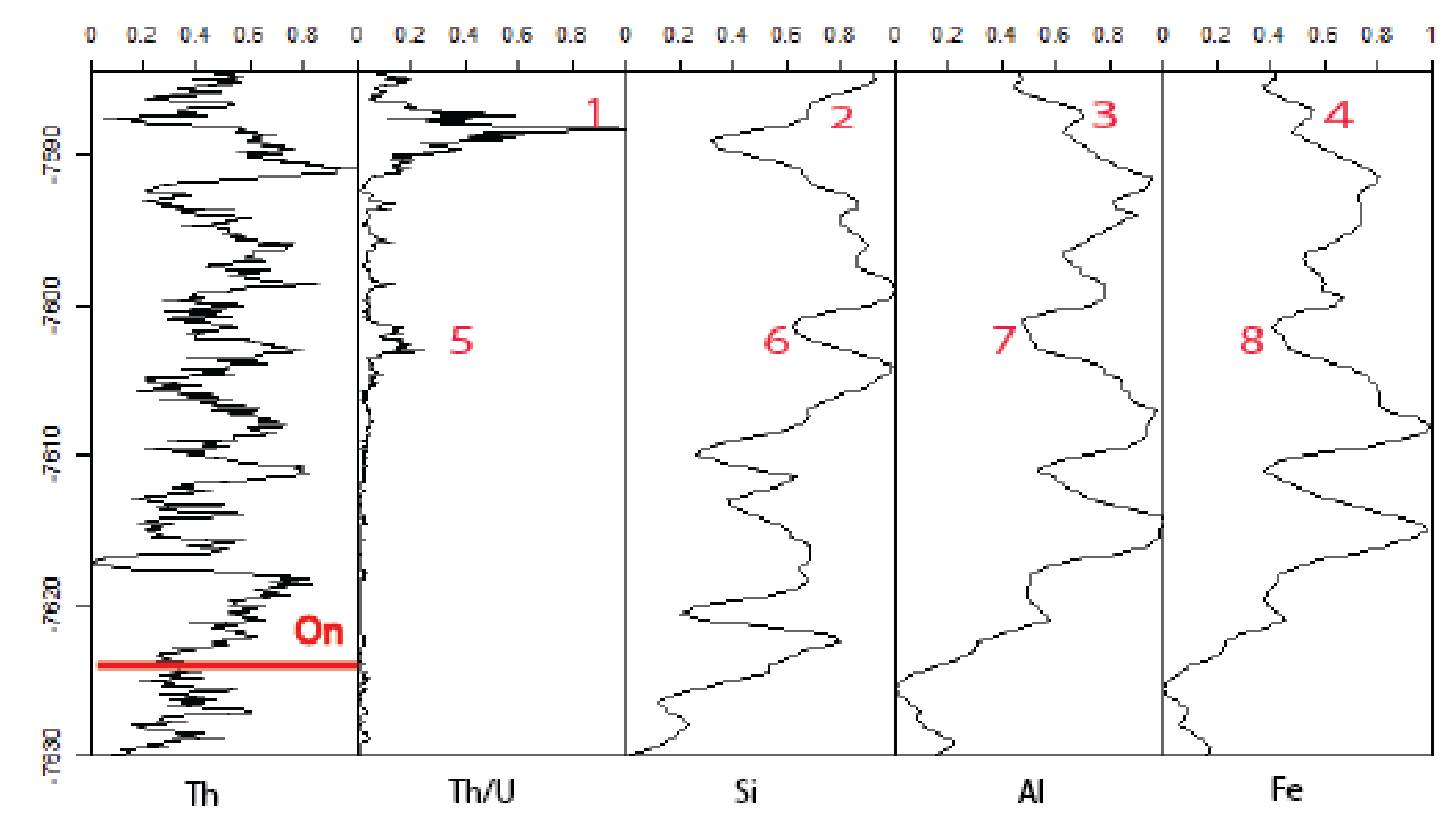

Figure 37. Coastal 1H spectral and elan well logs with peaks marked that may indicate the presence of ash beds.

These logs were developed using Python and serve to illustrate the spectral and elemental components of the lower Marcellus and Onondaga Formation (Figure 37). The Coastal 1H well has 2 noticeable peaks in the $\mathrm{Th} / \mathrm{U}$ ratio log. Peak one occurs at the top of the upper Marcellus and peak five occurs at about $7604 \mathrm{ft}$ in depth. Peak one is associated with noticeable peaks (2, 3, and 4) in the $\mathrm{Si}, \mathrm{Al}$, and Fe logs. Peak 5 however, does occurs with troughs in the logs at the same depth. These troughs do exhibit somewhat similar values as peaks 2 and 4, with a total difference less than 0.15 . The difference between peak 3 and its corresponding trough is nearly double, at 0.3 . 


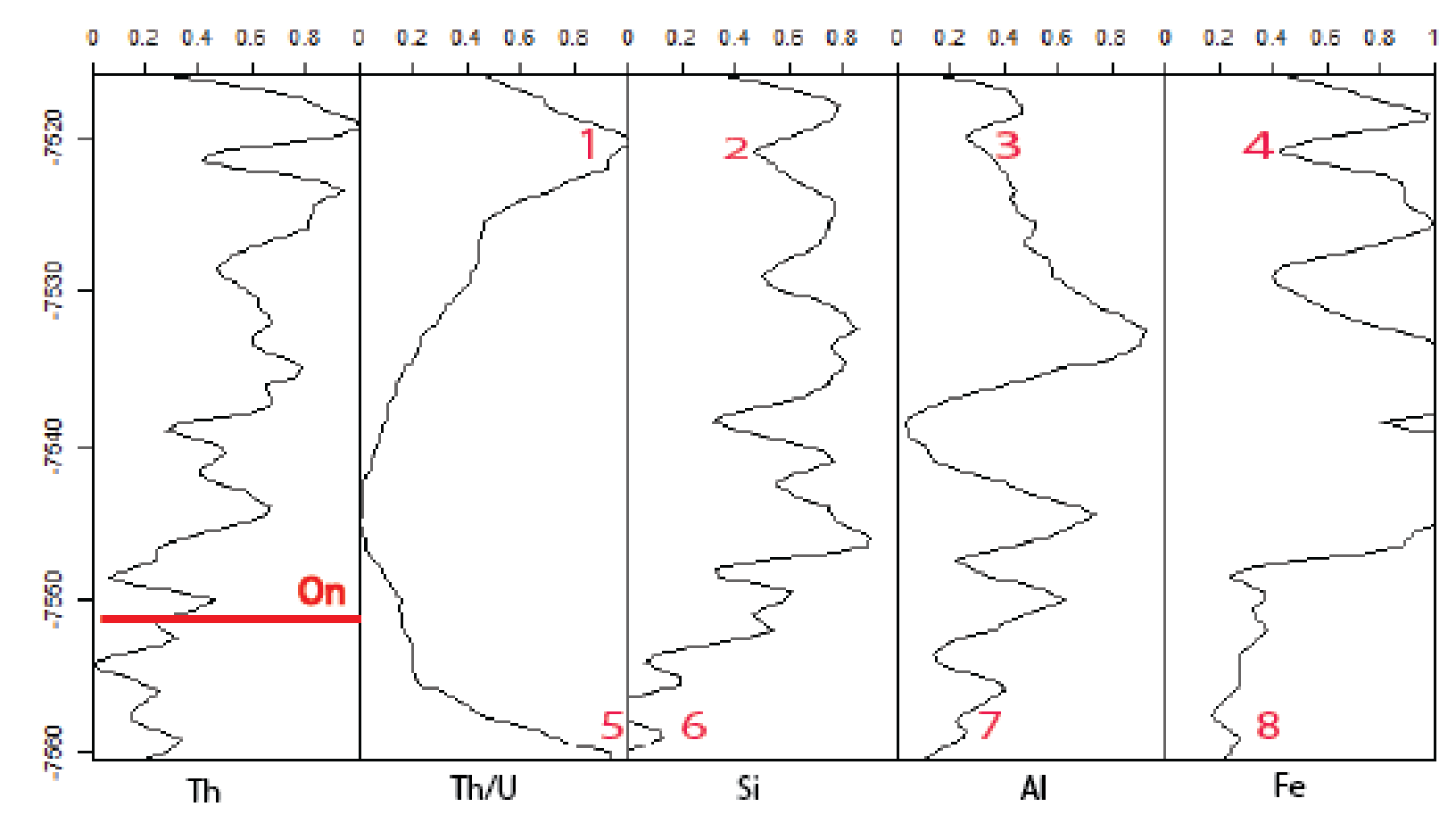

Figure 38. MIP3H spectral and elan well logs with peaks marked that may indicate the presence of ash beds.

The MIP3H well experiences peaks in two places within the Th/U ratio log (Figure 38). One peak occurs at the top of the lower Marcellus and the other at the base of the Onondaga. The upper peak experiences troughs like the Coastal $1 \mathrm{H}$ well. While the lower peak coincides with multiple peaks in the $\mathrm{Si}, \mathrm{Al}$, and $\mathrm{Fe} \operatorname{logs}$.

\subsection{Discussion}

\section{Marcellus Formation differences in Lithological Data}

The Ternary diagrams indicate that as depth increases, the percentage of silica content increases. Each of the ternary diagrams depicted data points becoming less condensed from the Clay axis and gradually increase in silica and carbonate content towards the Onondaga formation. The only exception would be the data from the Tippens 6HS well. These ternary diagrams seem to indicate that most of the wells became more clay rich as deposition occurs. However, this could be attributed to the small sample pool collected, as it makes it difficult to 
discern. The Boggess $17 \mathrm{H}$ well is the only well with data points of the Onondaga Formation in the $\mathrm{CO} 3$ corner. Most of the Onondaga data points indicate sixty to eighty percent carbonates, with outliers favoring an increase in quartz, feldspars, and pyrite (QFP).

When it comes to data type, consistency and pattern varies depending on the well. Overall, XRD data seems to bias and heavily affected by the number of samples taken. The Coastal $1 \mathrm{H}$ well has few data points and shows a predominantly clay and QFP rich Marcellus Formation, in contrast to the ELAN log data. While there are distinctions between how each data type (XRD, ELAN, Spectrolith, and Inelastic Processing) portrays the Marcellus Formation, these differences are not consistent across wells. For example, ELAN log data of the Armstrong 1 well indicates more clay present than the Spectrolith data, while Goff 55 well shows the opposite.

\section{Interpreting Total Organic Carbon of the Marcellus Formation}

Figures $39 \& 40$ show the accumulation of all normalized TOC data for each of the units present in the Marcellus through combination box and violin plots. The box plots display a fivenumber summary as the minimum, first quartile, median, third quartile, and maximum. The violin plots operate like the box plots, except that they indicate the probability density of the data. With few exceptions, the lower Marcellus is usually the richest in organic material. With deposition, the Marcellus formation becomes less organically productive. 


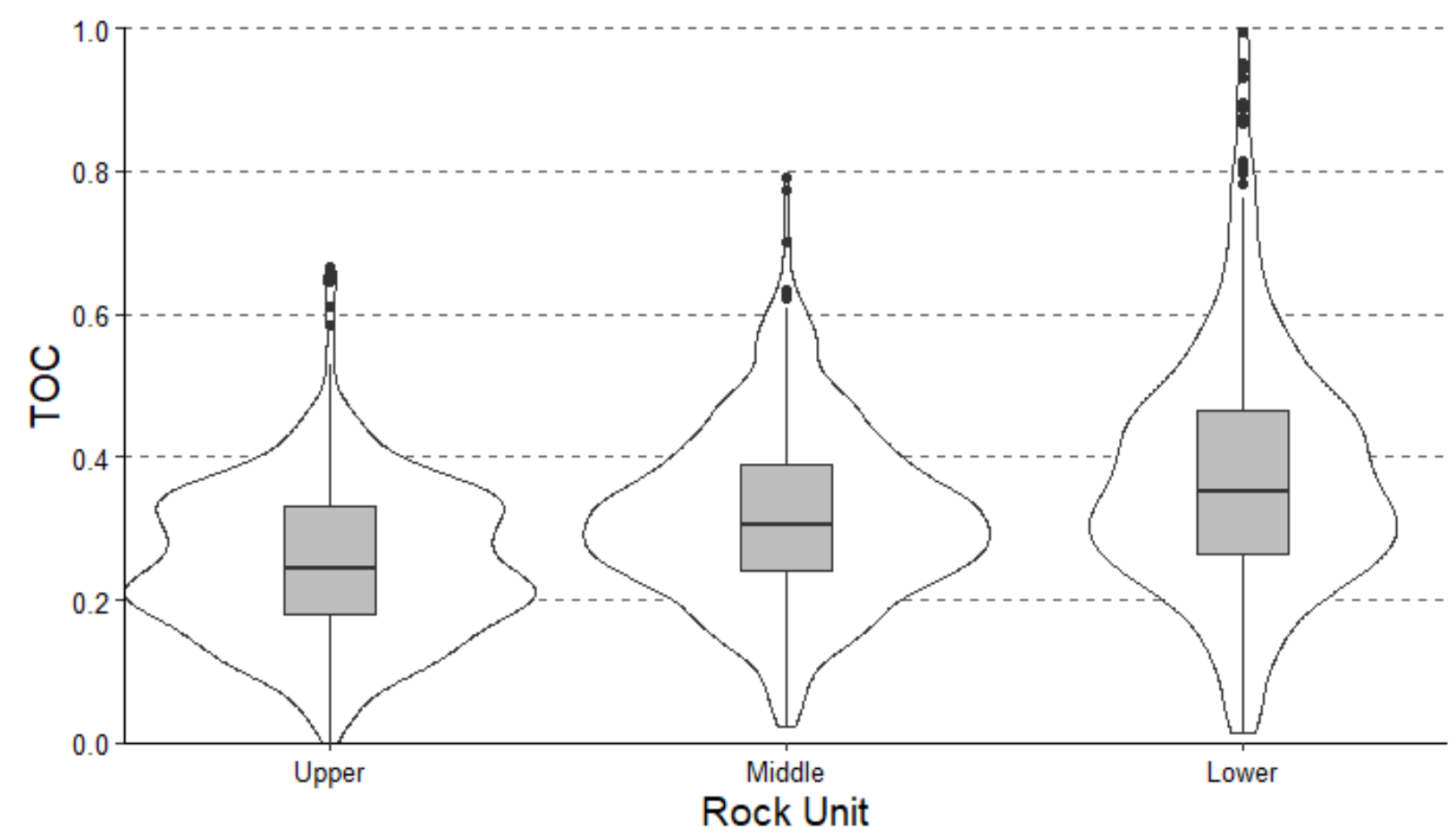

Figure 39. Combination box and violin plots showing cumulative TOC data of all wells, per unit.

Each of the units have their median occur between 0.2 and 0.4 TOC (Figure 39). The base of the upper unit first quartile range occurs at about 0.19 TOC. The peak of the lower unit third quartile range is about 0.45 TOC. As depth increases the violin plots grow longer along the $\mathrm{Y}$ axis, but thin along the $\mathrm{X}$ axis. The first and third quartiles are larger with depth as well. The upper unit is unique as it has two peaks in probability density. The larger peak occurs at 0.21 TOC and the lower peak is at 0.35 TOC. The middle and lower units have their probability density peaks at 0.3 TOC. 


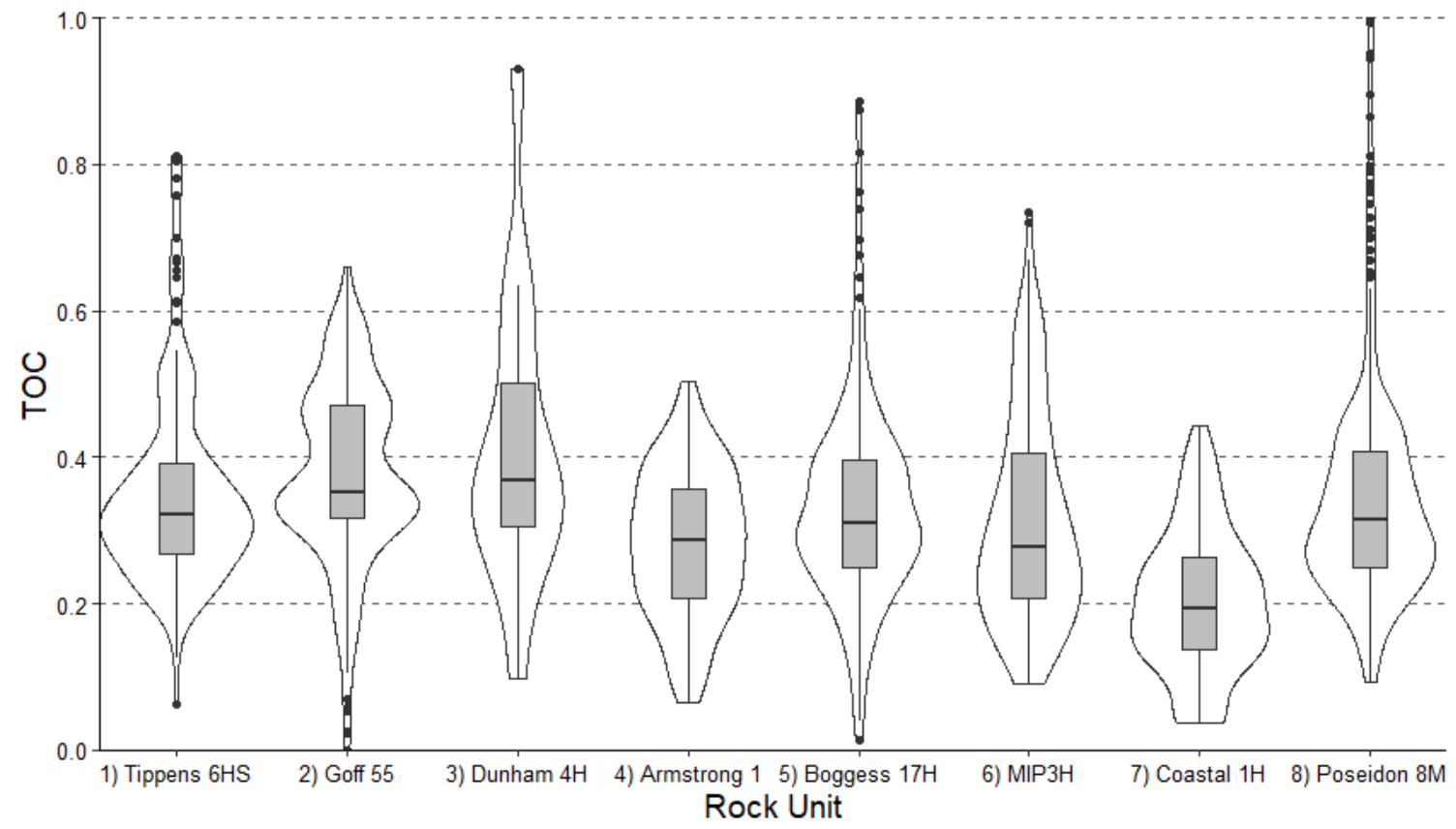

Figure 40. Combination box and violin plots showing cumulative TOC data of all wells, per well.

Breaking the data down into individual wells is important for understanding regional variation. The wells of Figure 40 are arranged from west (Tippens 6HS) to east (Poseidon 8M). The most outliers occur in the Tippens $6 \mathrm{HS}$, Goff 55, Boggess $17 \mathrm{H}$, and Poseidon $8 \mathrm{M}$ wells. The Goff 55 well exhibits the greatest difference between two peaks in probability density, and it has the most outliers towards the minimum. In terms of straight-line distance, the Tippens 6HS and Poseidon $8 \mathrm{M}$ wells are 103080 and 73880 meters from the Coastal $1 \mathrm{H}$ well. This is important to note because there are two clusters of wells. Southwest of the Coastal 1H well about 50000 meters away are the Goff 55, Dunham 4H, and Armstrong 1 wells. Within 25000 meters of the Coastal $1 \mathrm{H}$ well are the Boggess $17 \mathrm{H}$ and MIP3H. Within both clusters, an increase in TOC occurs westward from the most eastern well. The Coastal 1H and Armstrong 1 (most eastern) both exhibit similar distributions, having tighter spreads, higher probability distribution peaks, and no outliers. The MIP3H and Dunham $4 \mathrm{H}$ wells cover a broader range, a narrower first quartile, and 
few outliers towards the top. Of the two clusters, the Boggess $17 \mathrm{H}$ and Goff 55 wells (most western) have the most outliers, and both exhibit two peaks in probability density.

\section{Variation in Brittleness of the Marcellus Formation}

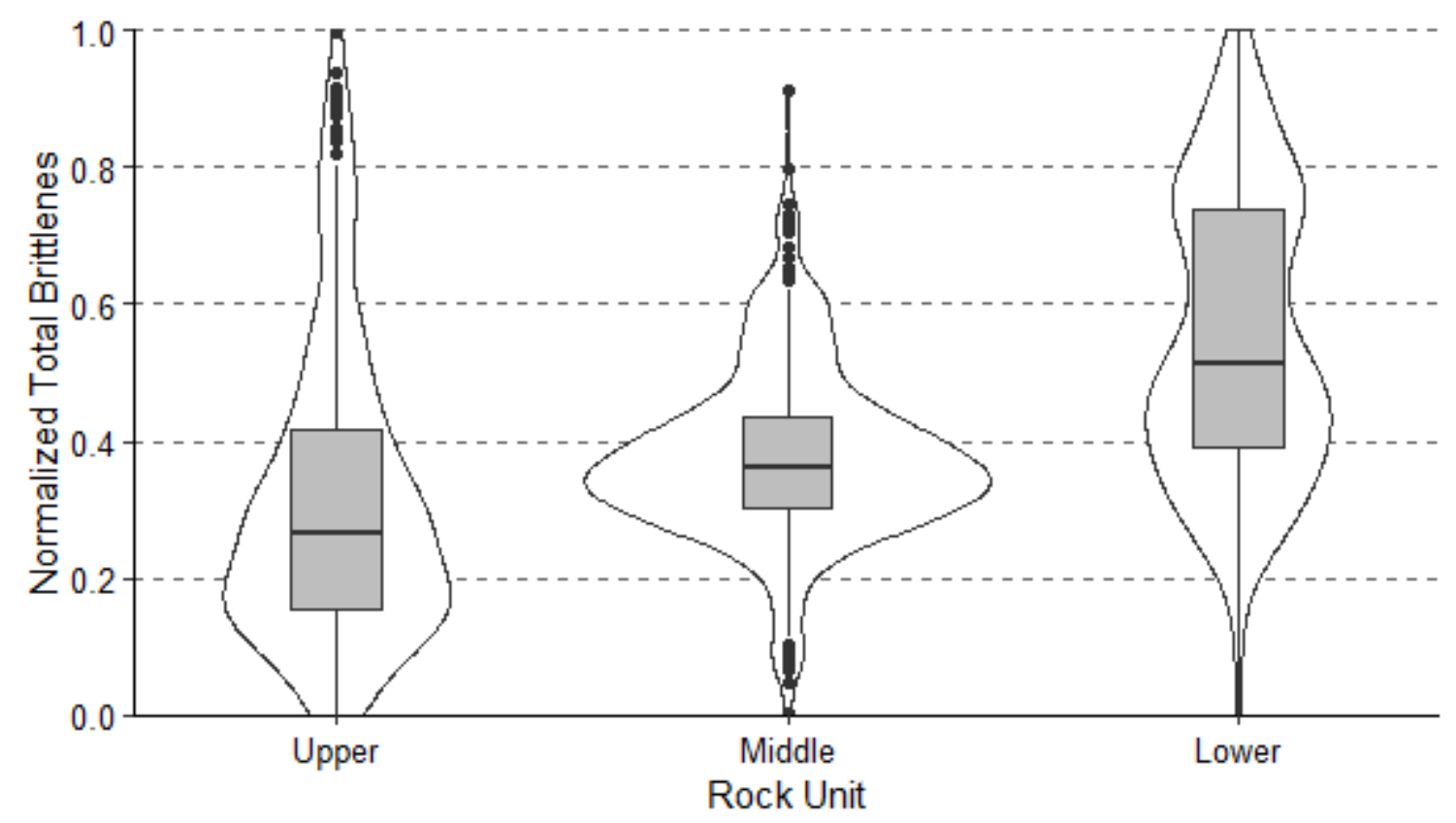

Figure 41. Combination box and violin plots showing cumulative brittleness values of all wells for each unit.

Figure 41 consists of combination violin and boxplots, which show measurements of normalized total brittleness. The data is broken down into each unit and consists of every well in the geomechanical research. At first glance, it becomes apparent that each unit exhibits a unique pattern. The upper unit is widest at its base ( 0.2 brittleness). The boxplots are wide, with the median at about 0.3 brittleness. The upper unit has many outliers at its top, where the violin plot is narrowest. The middle unit shows the widest overall and is consistent with its median (about 0.375 brittleness). It has the smallest boxplot amongst the three units. However, it as many outliers on both ends, where it narrows. The lower unit has no outliers plotted on either end, even when it narrows at the base. It does consist of two peaks, one at 0.4 and the other at 0.8 
brittleness. The boxplot is the largest of three units, and it has a median of about 0.5 brittleness. The graph does illustrate that brittleness increases with depth.

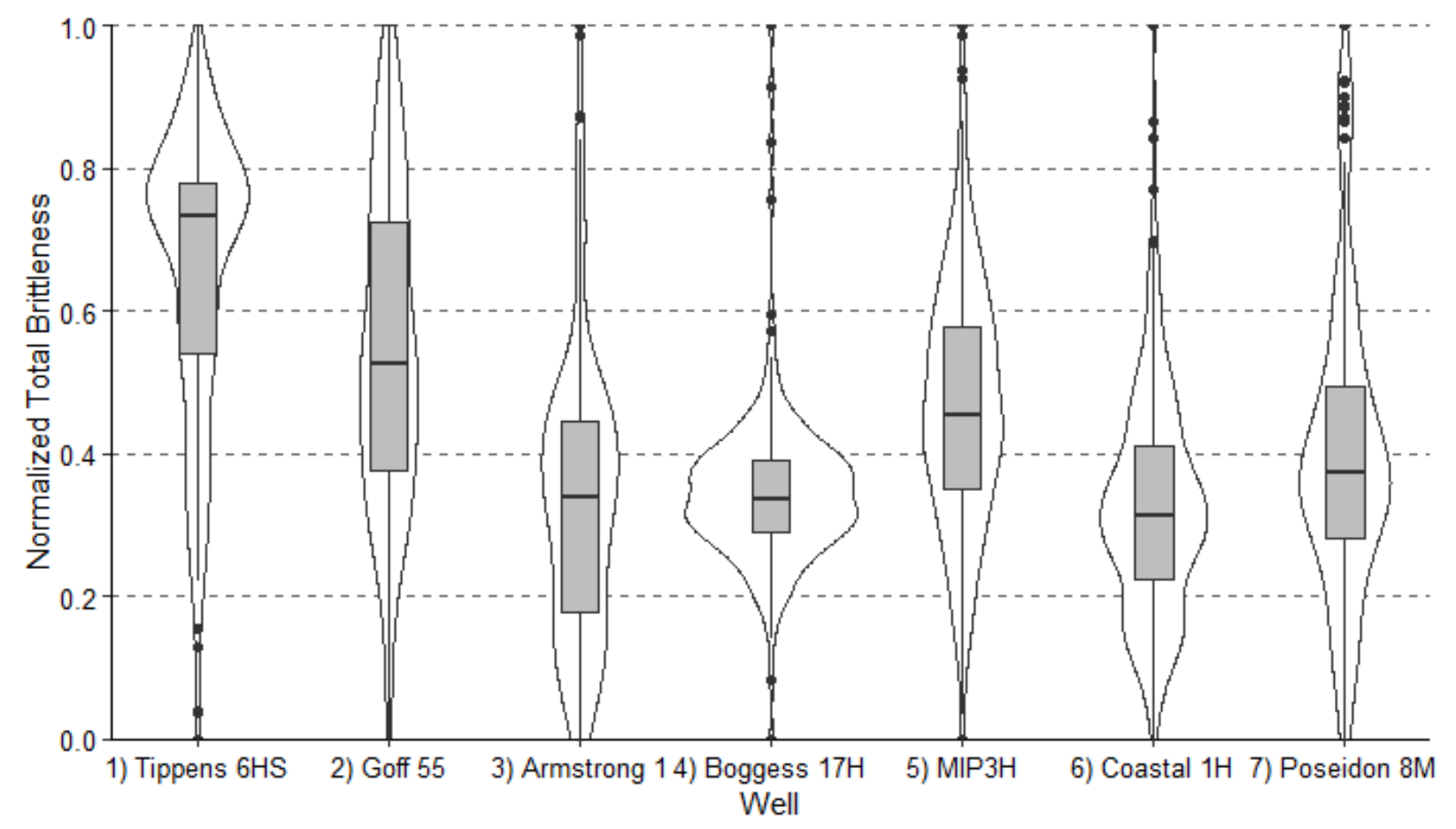

Figure 42. Combination box and violin plots showing cumulative brittleness values for each well.

Observing the individual brittleness plots of the study wells indicates significant variation, even among wells that are proximal to one another (Figure 42). The Tippens 6HS is the most brittle well, with its median at about 0.8. It does have a larger first quartile, which is attributed to the presence of outliers towards its base. The Goff 55 well seems to the second most brittle well, though its data seems to spread out evenly. It is unexpected that the Armstrong 1 plots so differently from the Goff 55 well, given how close they are to one another. The violin plots for both wells are at their widest between 0.4 and 0.5 , though the Armstrong 1 well has outliers towards the top. The Boggess 17H, MIP3H, and Coastal 1H wells are all proximal to another and plot somewhat consistently. While it is the only well with outliers on both ends, the 
Boggess $17 \mathrm{H}$ has the widest violin plot and smallest interquartile range amongst all the wells. The MIP3H well is the third most brittle and has a uniform shape to its violin plot. The Coastal $1 \mathrm{H}$ and Poseidon $8 \mathrm{M}$ are the most consistent amongst all the wells. Both have medians between 0.3 and 0.4 , possess similar shaped violin plots, and have evenly distributed interquartile ranges.

\section{Defining the Marcellus Onondaga Contact}

The Coldstream 1MH well appears to serve as an excellent control for determining the presence of ash beds. The spectral and elemental data are measured at intervals small enough to detect very small changes in rock composition. Unfortunately, the elemental data was not recorded past the third ash bed. The other wells of this dataset did not seem to be reliable for this method. All the other wells (Coastal 1H, MIP3H, Boggess 16H, Dunham 4H, and Tippens 6HS) have measurements taken at broader intervals (usually taken every half foot). This makes it difficult to determine with certainty if the Tioga Bentonite ash beds are located at where peaks are seen in the logs. The Dunham $4 \mathrm{H}$ well does have a narrower measurement window showing distinct peaks in the Onondaga Formation, but does not have elemental data to correlate with. The MIP3H and Boggess $16 \mathrm{H}$ wells show similar patterns in the Th and $\mathrm{Th} / \mathrm{U} \operatorname{logs}$.

\subsection{Conclusions}

The separate members of the Marcellus Formation have unique characteristics but depositional and geomechanical changes are present throughout the natural gas play. Based on the data available from selected wells across the Appalachian basin, in general the Coastal $1 \mathrm{H}$ well shares similarities to the other wells producing from the Marcellus. However, there are several differences that may be attributable to changes in the depositional environment due to the location along the transition between the Appalachian Plateau and Allegheny Mountain Front. 
This well is found in one of the deeper portions of the Marcellus and is more than 20 feet $(6 \mathrm{~m})$ thicker than the MIP3H. The Coastal $1 \mathrm{H}$ well is the closest well of this study to the Acadian mountains, the original sediment source.

The Coastal $1 \mathrm{H}$ shows some of the lowest TOC and brittleness amongst the study wells. Though it is important to remember that data quality is not uniform. Wells were drilled at different times, the earliest being 2009, and analyzed using various methods. In comparison to the MIP3H, they are alike in terms of lithology, although the MIP3H is more organic rich and brittle. TOC and brittleness do not show a strong relation to one another. The trend lines of Figures 43 and 44 have shallow slopes and highly scattered data points. The slope of the Coastal $1 \mathrm{H}$ trend line increases by 0.35 , while the MIP3H increases by 0.1 .

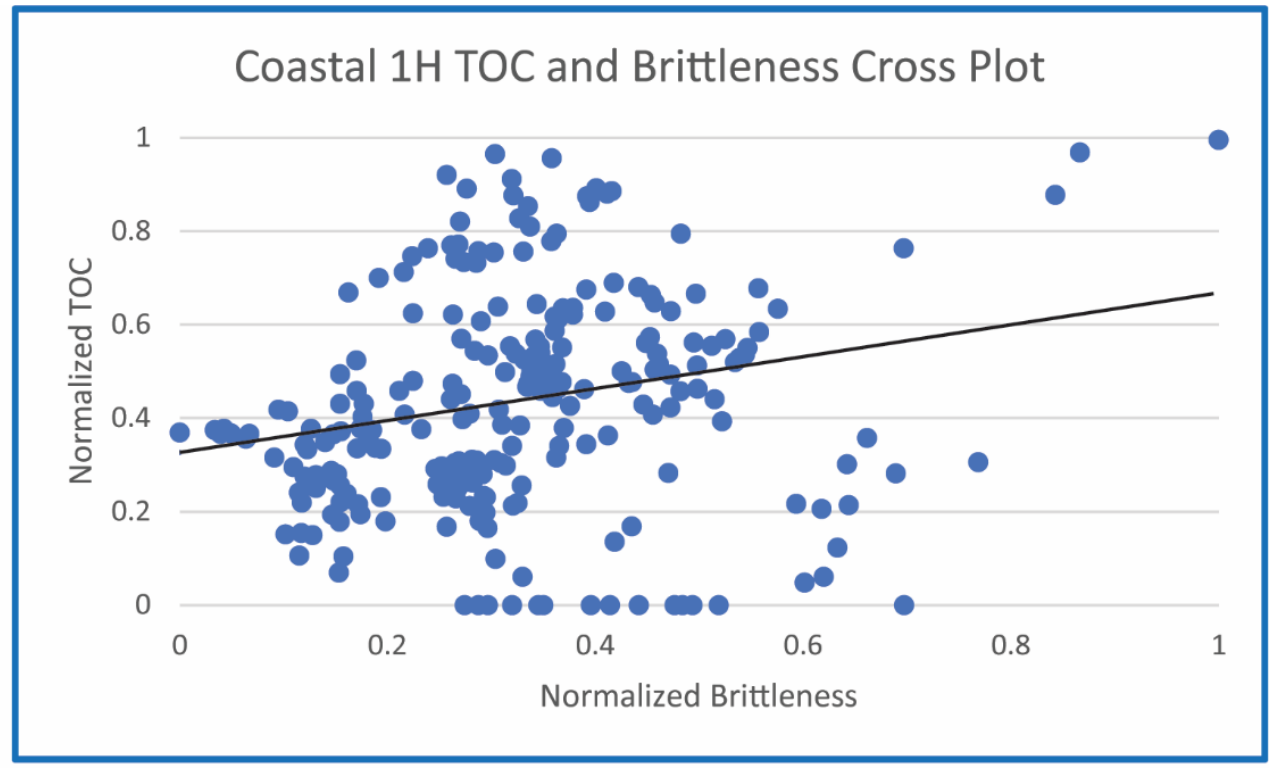

Figure 43. Coastal $1 \mathrm{H}$ cross plot of TOC and brittleness, containing a trend line which increases from 0.3 to 0.65 . 


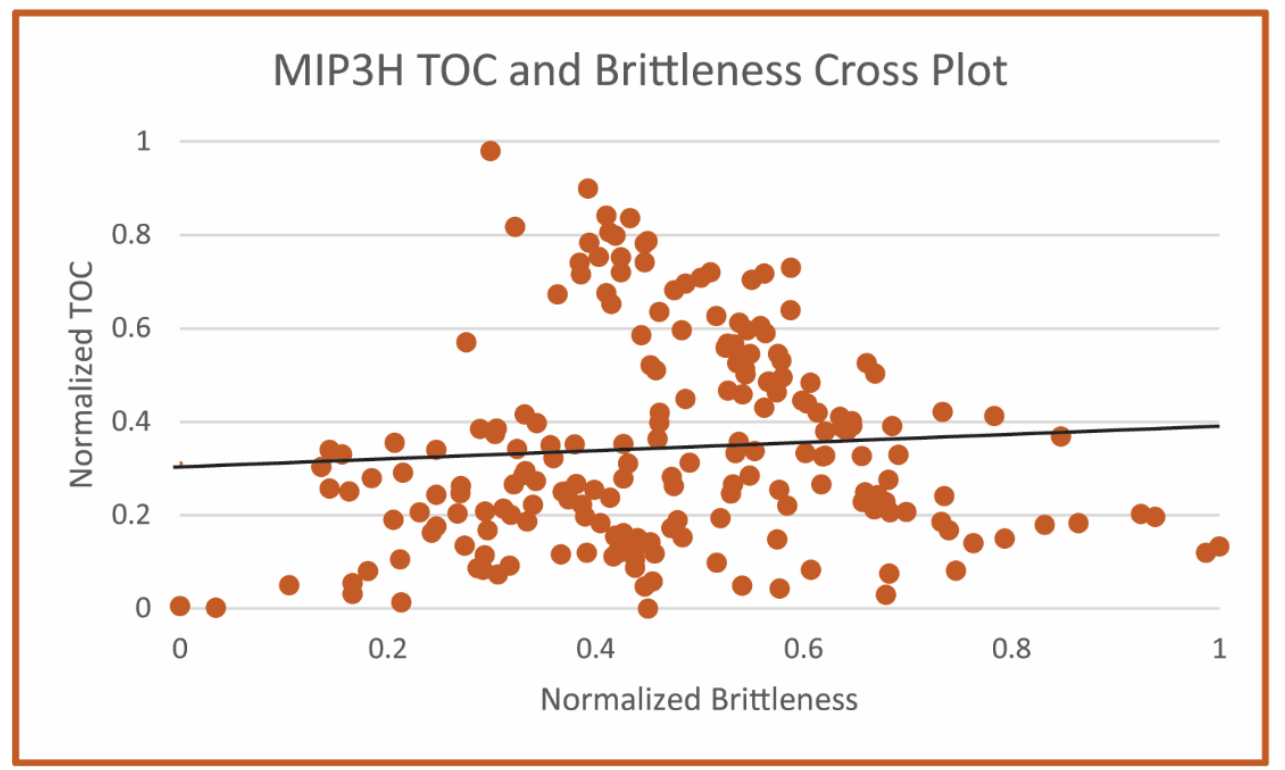

Figure 44. TOC and brittleness cross plot for the MIP3H well, with trend line that increases from 0.3 to 0.4.

The Boggess $17 \mathrm{H}$ well is consistent with both the Coastal $1 \mathrm{H}$ and MIP3H wells when it comes to the lithological ternary diagrams. However, the upper unit is shown to have about $10 \%$ more silica content (Appendix 1, Figures 46, 47, and 48). Like the Coastal 1H and MIP3H, the Boggess $17 \mathrm{H}$ well indicates an increase in total organic carbon with depth (Appendix 1, Figure 49). Though, the middle Marcellus consists of the steepest increase amongst all the wells. In terms of geomechanical properties, The Boggess $17 \mathrm{H}$ well is inconsistent with both the Coastal $1 \mathrm{H}$ and MIP3H plots, increasing in strength and ductility with depth (Appendix 1, Figure 50). There is a trough which occurs at approximately 0.6 along the $\mathrm{x}$ axis that is consistent with the Coastal 1H well. The Boggess $17 \mathrm{H}$ well elemental logs plot consistently with the MIP3H well, having peaks in the thorium/uranium ratio log at the top and bottom (Appendix 1, Figure 51).

The Purcell (the upper limestone) is the thickest in the Poseidon 8M well (Appendix 1, Figures 52, 53, and 54). The ternary diagram indicates that the Purcell consists of about 30-40\% carbonate, with the data clustering slightly below center of the diagram. Interestingly, the larger upper limestone (The Purcell Formation) of the Poseidon 8M well is consistent with the entire 
Marcellus Formation. Each unit shows an increase in total organic carbon with depth (Appendix 1, Figure 55). The Poseidon $8 \mathrm{M}$ well is the most consistent with the Coastal $1 \mathrm{H}$ well. In the upper Marcellus, the Poseidon 8M well is weak and ductile, as depth increases do does strength and brittleness (Appendix 1, Figure 56).

Ternary diagrams for the Goff well indicate that it decreases in QFP with deposition (Appendix 1, Figures 58, 59, and 60). South of Morgantown, the Goff 55 well is the most alike the MIP3H in terms of geomechanical properties (Appendix 1, Figure 61). The loess curves exhibit the same shapes, and the Marcellus formation is consistently weak and brittle, with some portions being strong and ductile.

The Dunham 4H well does not have enough data to accurately assess total organic carbon (Appendix 1, Figure 62). The confidence intervals for this plot are wide, and the data is sporadic. There are 4 notable peaks within the thorium/uranium ratio log of the Dunham $4 \mathrm{H}$ well, though logs measuring silicon, aluminum, and iron are not available (Appendix 1, Figure $63)$.

With depth, the Armstrong 1 well shows an increase in QFP (like the nearby Goff 55 well) and consists of the most unique Onondaga formation (Appendix 1, Figures 64, 65, and 66). The Armstrong 1 well is different from the Coastal $1 \mathrm{H}$ in that both the upper and lower sections indicate a decrease in organic content with depth (Appendix 1, Figure 67). The Armstrong 1 starts off weak and ductile in the upper Marcellus and becomes stronger and brittle with depth (Appendix 1, Figure 68).

Lastly, the Tippens 6HS well is drilled into the wet gas zone, outside of the Rome Trough. The lithological data of this well is sparse, and plots sporadically. The Onondaga formation is 
inconsistent with all previous wells, making it difficult to be confident in the lithological data available for the Tippens 6HS (Appendix 1, Figures 70 and 71). The Tippens 6HS well shows an overall increase in total organic carbon with depth, however, the middle Marcellus seems to flat line (Appendix 1, Figure 72). Lastly, the Tippens 6HS is the most inconsistent well in terms of its geomechanical properties (Appendix 1, Figure 73). The upper unit of the Marcellus Formation may be the strongest, having multiple data points in the strong ductile quadrant. The lower and middle Marcellus plot exhibit a decrease in strength and ductility with depth. While the Tippens $6 \mathrm{HS}$ measurement intervals are broad, there are 2 sets of peaks which may indicate the presence of ash beds, found just above and below the Onondaga contact (Appendix 1, Figure 74).

When it comes to data type, XRD is does not correlate well with the other methods available (ELAN, Spectrolith, or Inelastic Processing). It is likely that a sampling bias occurs as the number of samples is limited and most XRD measurements occur within one unit (usually the lower Marcellus) of the Marcellus Formation, for any given well. Overall, organic productivity decreases as deposition occurs. The Marcellus Formation is most organic rich in the lower Marcellus, though this can change depending on the well. Generally, strength of the Marcellus Formation decreases with deposition. Though brittleness and ductility seem more dependent on lithological factors. Identifying thorium present in ash beds has the potential to be beneficial in defining the Onondaga contact, however, it requires narrow measurement intervals.

Fractures are accounted for through FMI logs, core photos, and thin sections. There are 42 resistive or open fractures within the Marcellus Formation of the Coastal $1 \mathrm{H}$ well. According to the rosette-strike diagram, these fractures have an average dip between 68 and 76 degrees, with an azimuth between 356 and 11.7 degrees. Drilling induced fractures and borehole 
breakouts occur along planes perpendicular to one another, shown by the rosette-strike diagram. Within the bore of the Coastal $1 \mathrm{H}$ well, drilling induced fractures have strikes which run SW-NE while the strikes of borehole breakouts are NW-SE. However, there were not any borehole breakouts accounted for in the Marcellus Formation. Patterns are noticeable in the distribution of these fractures. While both have outliers, resistive and partially open fractures tend to occur in groups.

Photos and thin sections were taken of features within the rock core as a part of Appendix 3 (Figures 77-91). The upper Marcellus (Figure 77) shows large mineral filled fractures occurring vertically and obliquely (images 2,3 , and 6). In image 6 of Figure 76 the upper limestone has a large vertical mineral filled fracture with rock broken apart around it. On the other hand, Figure 78 of the middle Marcellus has thin mineral filled fractures (images 1, 2, 4, and 5), these occur both horizontally and vertically. Images 5 and 6 of the middle Marcellus have vertical mineral filled fractures that occur proximal to mineral filled bedding planes. The lower Marcellus Formation has mostly vertical mineral filled fractures (images 1 and 3, of Figure 79), with image 1 showing vertical mineral filled fractures occurring within a concretion.

Thin sections A1 through A4 are taken at various depths within the upper and middle Marcellus Formation. Figure 80 is of thin section A1, which shows thin, horizontal filled fractures occur in between layers of clay and calcite. Open fractures occur proximal to calcite filled fractures in Figure 81 (thin section A2), consisting of both vertical and horizontal fractures. Unfilled fractures occurring parallel to the calcite filled fractures are connected to thin unfilled fractures which occur along cleavage planes. Fractures of thin section A3 (Figure 82) consist of both unfilled and mineral filled fractures, with horizontal fractures branching off vertical fractures. The fractures of Figure 83 (thin section A4) show unfilled, and mineral filled 
horizontal fractures. The remaining thin sections (B1 through B5) are taken at depths within the lower Marcellus Formation. Figure 84 and 87 (thin section B1 and B4) have thin, horizontal unfilled fractures splitting apart skeletal grains. Two types of fractures occur within thin section B2 (Figure 85). The first type are open fractures that occur parallel or perpendicular to the second type, which consists of vertical calcite filled fractures. Some of the open fractures cut across cleavage plains of the calcite filled fractures. This is like Figure 86 (thin section B3), where thin unfilled fractures occur proximal to large calcite filled vertical fractures. The calcite filled fractures exhibit lenses, sharp 90 degree turns, and are disconnected sporadically. The thin unfilled fractures will occur within and connect the calcite filled fractures. The final Coastal $1 \mathrm{H}$ thin section (Figure 88, thin section B5) exhibits similar fracturing to Figure 80 (thin section A1), as thin, unfilled horizontal fractures occur between layers of clay and calcite (skeletal bedding). The MIP3H has two thin sections which exhibit fracturing, A-68 and C-108 (Figures 89 and 91). Within thin section A-68, one horizontal fracture occurs which is sporadically mineral filled. Two fractures are found within thin section C-108, one filled with calcite and the other an opaque mineral (likely pyrite or organic content). The calcite filled fracture is horizontal and connects to the opaque vertical fracture.

The information presented in this research encompasses multiple areas with key information for natural gas development. Within the study area, these gas reserves are not homogenous. This thesis addresses areas such as total organic carbon (TOC), geochemistry, and geomechanics which are each important in their own way. Low levels of TOC may indicate that an area isn't profitable to drill into. Geochemistry is paramount understanding lithological variations across the basin. Lastly, without a proper understanding of geomechanics, drilling methods and measurements from well logging tools will suffer. If one were to conduct research 
on other natural gas wells, this thesis may serve as a broad source of information. Looking forward, the Marcellus Formation will likely be the target for further research. Various interest groups have predicted a gradual yet increasing demand for natural gas through 2050. As data becomes more available and methods for production improve, scientific inquiry is inevitable. 


\subsection{References}

AAPG, 2015, LECO Method in Estimating Richness, American Association of Petroleum Geologists, https://wiki.aapg.org/LECO_method_in_estimating_richness\#: :text=The\%20 LECO $\% 20$ method $\% 20$ of $\% 20$ estimating,replaced $\% 20$ by $\% 20$ Rock $\% 2$ DEval $\% 20$ pyrolysis, accessed May 7, 2020.

Aboud, M., Badry, R., Grau, J., Susan, H., Hamichi, F., Horkowitz, J., Hemingway, J., Macdonald, R., 2014, High Definition Spectroscopy - Determining Mineralogic Complexity, Oilfield Review, https://www.slb.com/-/media/files/oilfield-review/4spectroscopy-3-english, accessed March 23, 2020.

Alshakhs, M., \& Rezaee, R., 2019, A new method to estimate total organic Carbon (TOC) content, an example FROM Goldwyer Shale formation, the Canning basin, https://benthamopen.com/FULLTEXT/TOPEJ-10-118, accessed May 1, 2021.

Asquith, G., Krygowski, D., Henderson, S., \& Hurley, N., 2004, Gamma Ray Log, GeoScience World, https://pubs.geoscienceworld.org/books/book/1891/chapter/ 107121149/Gamma-Ray-Log, accessed March 23, 2020.

Barson, D., Christensen, R., Decoster, E., Grau, J., Herron, M., Herron, S., 2005, Spectroscopy: The Key to Rapid, Reliable Petrophysical Answers, Oilfield Review, https://www.researchgate.net/publication/289842216_Spectroscopy_The_Key_to_Rapid_ Reliable_Petrophysical_Answers, accessed March 23, 2020.

Blakey, R., 2008, Middle Devonian North American Paleogeography: Northern Arizona University, https://deeptimemaps.com/, accessed January 13, 2020 
BLS, 2020, From the barrel to the pump: the impact of the COVID-19 pandemic on prices for petroleum products : Monthly Labor Review, U.S. Bureau of Labor Statistics, https://www.bls.gov/opub/mlr/2020/article/from-the-barrel-to-the-pump.htm, accessed January 10, 2021.

Boyce, M., and Carr, T., 2009, Lithostratigraphy and Petrophysics of the Devonian Marcellus Interval in West Virginia and Southwestern Pennsylvania, accessed April 11, 2020.

Clemente, J., 2020, U.S. Natural Gas Beats Covid-19. Forbes. https://www.forbes.com/sites/judeclemente/2020/12/06/us-natural-gas-beats-covid19/?sh=555d76f42318, accessed February 13, 2021.

EIA, 2017, U.S. Energy Information Administration (EIA), Marcellus play: Geology Review, https://www.eia.gov/maps/pdf/MarcellusPlayUpdate_Jan2017.pdf , accessed July 5, 2021.

EIA, 2021a, U.S. Energy Information Administration - EIA - Independent Statistics and Analysis. Where our natural gas comes from - U.S. Energy Information Administration (EIA). (2021). https://www.eia.gov/energyexplained/natural-gas/where-our-natural-gascomes-from.php, accessed July 13, 2021.

EIA, 2021b, U.S. Energy Information Administration - EIA - Independent Statistics and Analysis. State Energy Profile Overview - U.S. Energy Information Administration (EIA). https://www.eia.gov/state/, accessed July 5, 2021. 
Grieser, W. V., and Bray, J. M., 2007, Identification of production potential in unconventional reservoirs. OnePetro, from https://onepetro.org/SPEOKOG/proceedingsabstract/07POS/All-07POS/SPE-106623-MS/141732, accessed March 9, 2021.

Hayward, Jessica M., 2012, Zircon Geochronology of Ash Beds in the Marcellus Shale of the Appalachian Basin, Graduate Theses, Dissertations, and Problem Reports. 138, https://researchrepository.wvu.edu/etd/138, accessed April 24, 2020.

Kerrigan, R., 2016, Structural Geology of the Southwestern Section of the Appalachian Plateau, University of Pittsburgh - Department of Energy and Earth Resources, from https://rjkerrigan.com/CR-Structure/2016,\%20Kerrigan,\%20FCOPG,\%20Structural \%20Geology\%20of\%20the\%20Allegheny\%20Plateau.pdf', accessed June 24, 2020.

Kovski, A., 2021, Sixty-day oil and gas leasing moratorium ordered on federal lands, waters. Oil \& Gas Journal, https://www.ogj.com/general-interest/government/article/14196031/60dayoil-and-gas-leasing-moratorium-ordered-on-federal-lands-waters, accessed February 3, 2021.

Lash, G., Engelder, T., 2011, Thickness trends and sequence stratigraphy of the Middle Devonian Marcellus Formation, Appalachian Basin: implications for Acadian foreland basin evolution: American Association of Petroleum Geologists, v. 95, p. 61-103, accessed June 24, 2020.

Lazar, R., Bohacs, K., Macquaker, J., Schieber, J., Demko, T., 2015, Capturing Key Attributes of Fine-Grained Sedimentary Rocks in Outcrops, Cores, and Thin Sections: Nomenclature 
and Description Guidelines, Journal of Sedimentary Reach, v. 85, p. 230-246, https://pubs.geoscienceworld.org/sepm/jsedres/article/85/3/230/145457/ Capturing-Key-Attributes-of-Fine-Grained, Accessed June 24, 2020.

SLB, 2021, Lithoscanner: High-Definition Spectroscopy Service, Schlumberger https://www.slb.com/reservoir-characterization/surface-and-downhole-logging/wirelineopenhole-logging/litho-scanner-spectroscopy, accessed March 9, 2021.

McKeon, D., Roscoe, B., \& Stoller, C., 2008, Patent Us5045693a - carbon/oxygen well logging method and apparatus, https://patents.google.com/patent/US5045693, accessed May 07, 2021.

Rickman, R., Mullen, M., Petre, E., Grieser, B., Kundert, D., 2008, A practical use of Shale Petrophysics for Stimulation Design Optimization: All Shale Plays are Not Clones of the Barnett Shale, SPE International, https://www.onepetro.org/conference-paper/SPE115258-MS, accessed April 11, 2020.

Sanger, D. E., Krauss, C., \& Perlroth, N., 2021, Cyberattack Forces a Shutdown of a Top U.S. Pipeline, The New York Times, https://www.nytimes.com/2021/05/08/us/politics/cyberattack-colonial-pipeline.html, accessed May 8, 2021.

Schmoker, J.W., 1981, Determination of organic-matter content of Appalachian Devonian shales from gamma-ray logs, AAPG Bulletin 65, 1285-1298, accessed March 14, 2020. 
Seong, K., 2020, Hands-on Exercise 8: Creating Ternary Plot with R. RPubs.

https://rpubs.com/tskam/ternary_plot, accessed August 20, 2021.

Tankard, A. J., 1986, On the depositional response to thrusting and lithospheric flexure: Examples from the Appalachian and Rocky Mountain basins, in P. A. Allen and P. Homewood, eds., Foreland basins: Special Publications of the International Society of Sedimentologists, v. 8, p. 369-392, accessed April 11, 2020.

USGS, 2020, How much gas is in the Marcellus Shale, United States Geological Survey, https://www.usgs.gov/faqs/how-much-gas-marcellus-shale?qt-news_science_ products=0\#qt-news_science_products, accessed April 11, 2020.

VanMeter, J., 2014, Regional Mapping and Reservoir Analysis of the Middle Devonian Marcellus Shale in the Appalachian Basin, Graduate Theses, Dissertations, and Problem Reports. 634.https://researchrepository.wvu.edu/etd/634

Wang, G., and Carr, T., 2012, Methodology of organic-rich shale lithofacies identification and prediction: A case study from the Marcellus Shale in the Appalachian Basin, Elsevier LTD, Computers and Geosciences 49, p. 151-163, https://www.researchgate.net/publication/256938764_Methodology_of_organicrich_shale_lithofacies_identification_and_prediction_A_case_study_from_Marcellus_Sh ale_in_the_Appalachian_basin, accessed April 11, 2020.

Wang, G., and Carr, T., 2013, Organic-rich Marcellus Shale Lithofacies Modeling and 
Distribution Pattern Analysis in the Appalachian Basin, AAPG Bulletin, v. 97, p. 21732205, https://pubs.geoscienceworld.org/sepm/aapgbull/article/97/12/2173/133266, accessed April 11, 2020.

West Virginia Geological and Economic Survey, 2020, Map of Physiographic Provinces of West Virginia (WVGES), https://www.wvgs.wvnet.edu/www/maps/pprovinces.htm, accessed February 23, 2020.

Yanni, A., 2010, Subsurface Stratigraphy and Petrophysical Analysis of the Middle Devonian Interval, Including the Marcellus Shale, of the Central Appalachian Basin; Northwestern Pennsylvania, Graduate Theses, Dissertations, and Problem Reports. 3077. https://researchrepository.wvu.edu/etd/3077

Zagorski, W., Emery, M., and Ventura, J., 2017, The Marcellus Shale Play: Its Discovery and Emergence as a Major Global Hydrocarbon Accumulation: American Association of Petroleum Geologists, v. 113, p. 55-90, accessed June 24, 2020.

Zoback, M., Barton, C., Brudy M., Castillo, D., Finkbeiner, T., Grollimund, B., Moos, D., Peska, P., Ward, C., Wiprut, D., 2003, Determination of Stress Orientation and Magnitude in Deep Wells, International Journal of Rock Mechanics and Mining Sciences, v. 40, p. 1049-1076, https://www.sciencedirect.com/science/article/ pii/S1365160903001175, accessed April 11, 2020. 


\subsection{Appendices}

\section{Appendix 1: Regional Correlation}

Using the methods described earlier, the 10 wells are broken down into three separate groups. The near group (Figure 44) consists of the Boggess $17 \mathrm{H}$, the MIP3H, and the Poseidon 8M. A cluster of wells to the south of Morgantown is considered the far group (Figure 56). These wells consist of the Goff 55, Dunham 4H, and Armstrong 1. The final set of wells is considered the outlier group (Figure 68), which includes the Tippens 6Hs, St Whipkey 1, and the Coldstream $1 \mathrm{MH}$. The near group is consistent with the Coastal $1 \mathrm{H}$ and does not consist of any distinct data issues. The Poseidon $8 \mathrm{M}$ is not that close to the Coastal $1 \mathrm{H}$, but it does occur at a similar place along the Marcellus Formation's eastern extent. It also consists of a large upper limestone unit commonly referred to as the Purcell Limesone. 


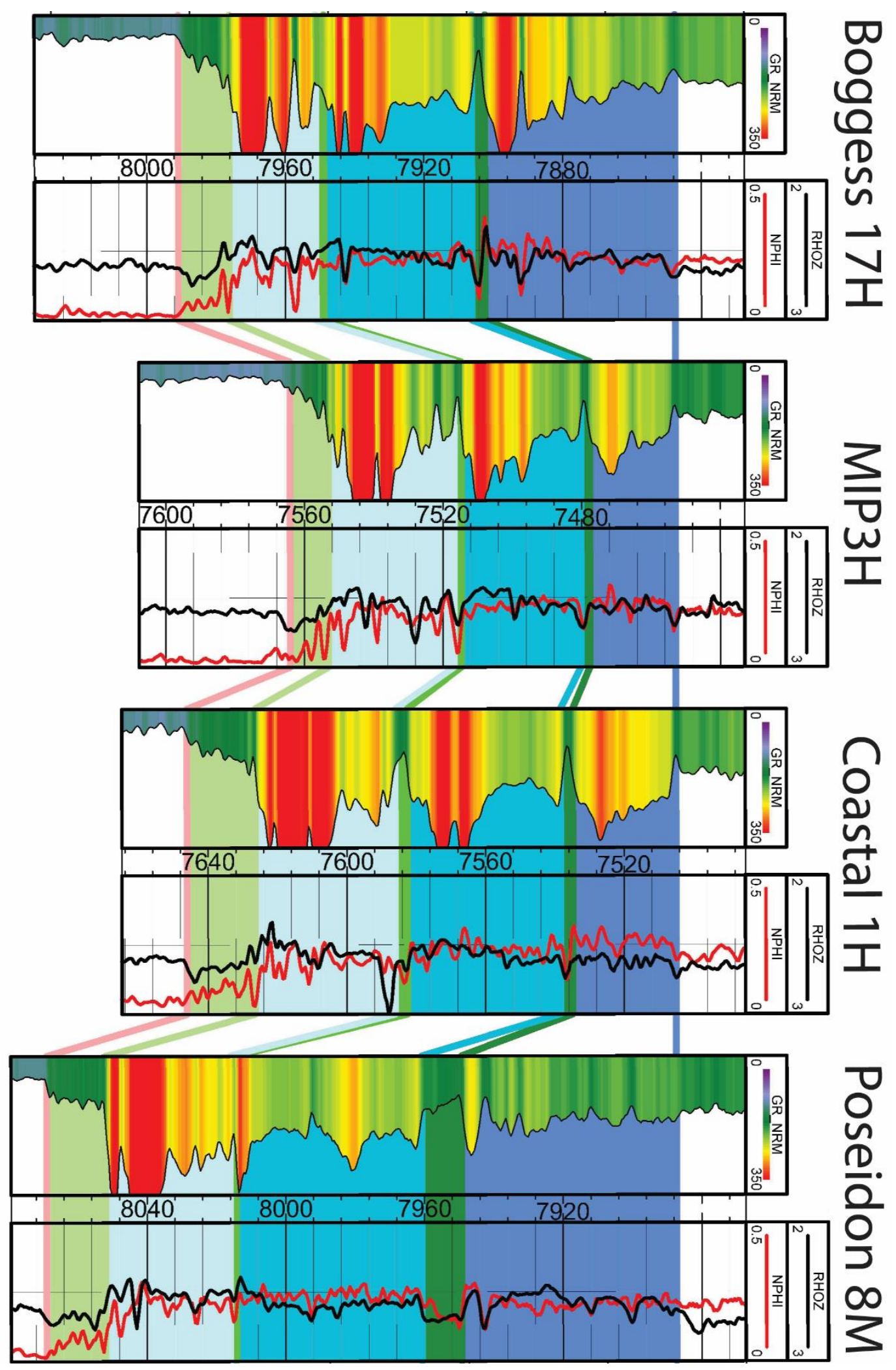

Figure 45. Petra logs indicating stratigraphy of the near group wells, the Coastal $1 \mathrm{H}$ well falls between the MIP3H and Poseidon 8M logs. 


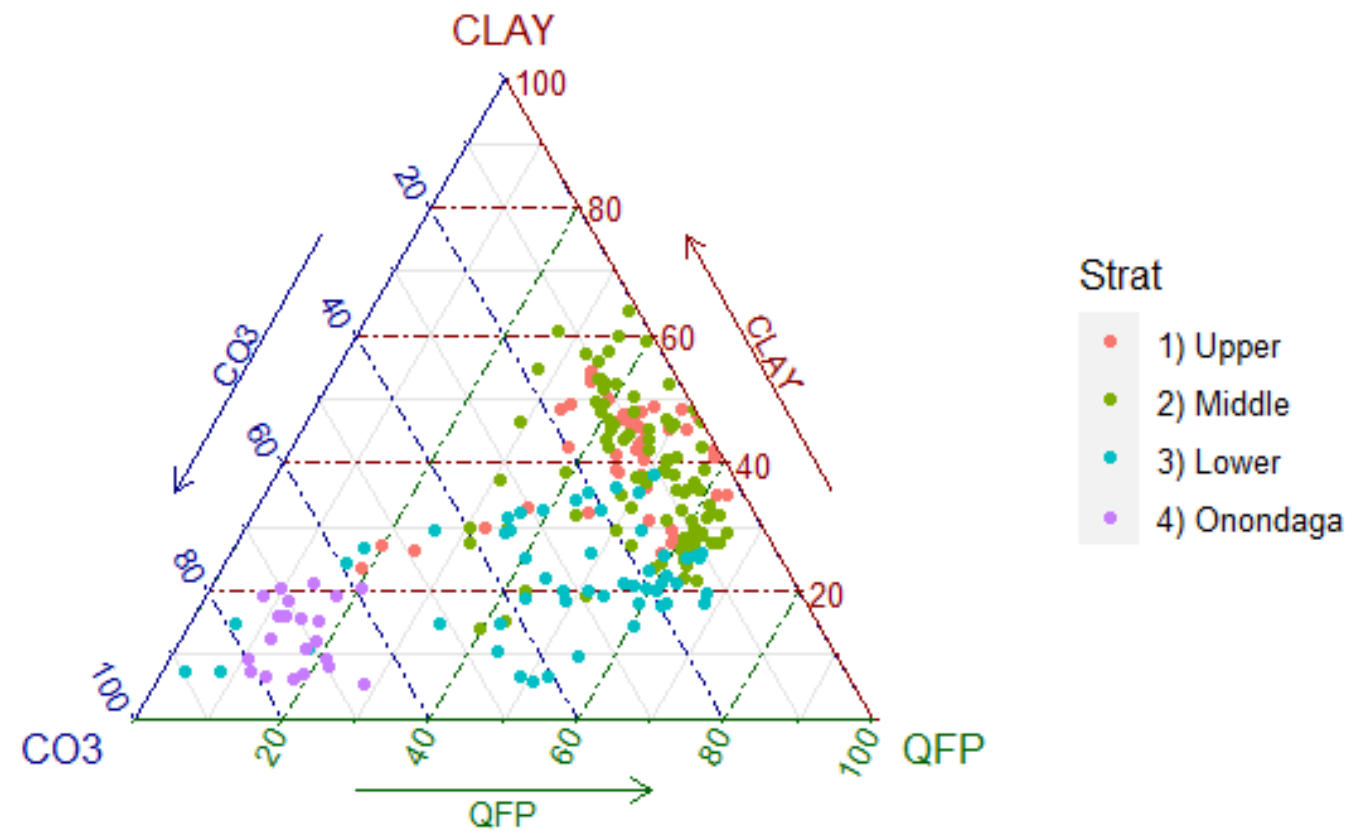

Figure 46. Boggess $17 \mathrm{H}$ ELAN whole rock ternary diagram indicating lithological variation based on stratigraphy.

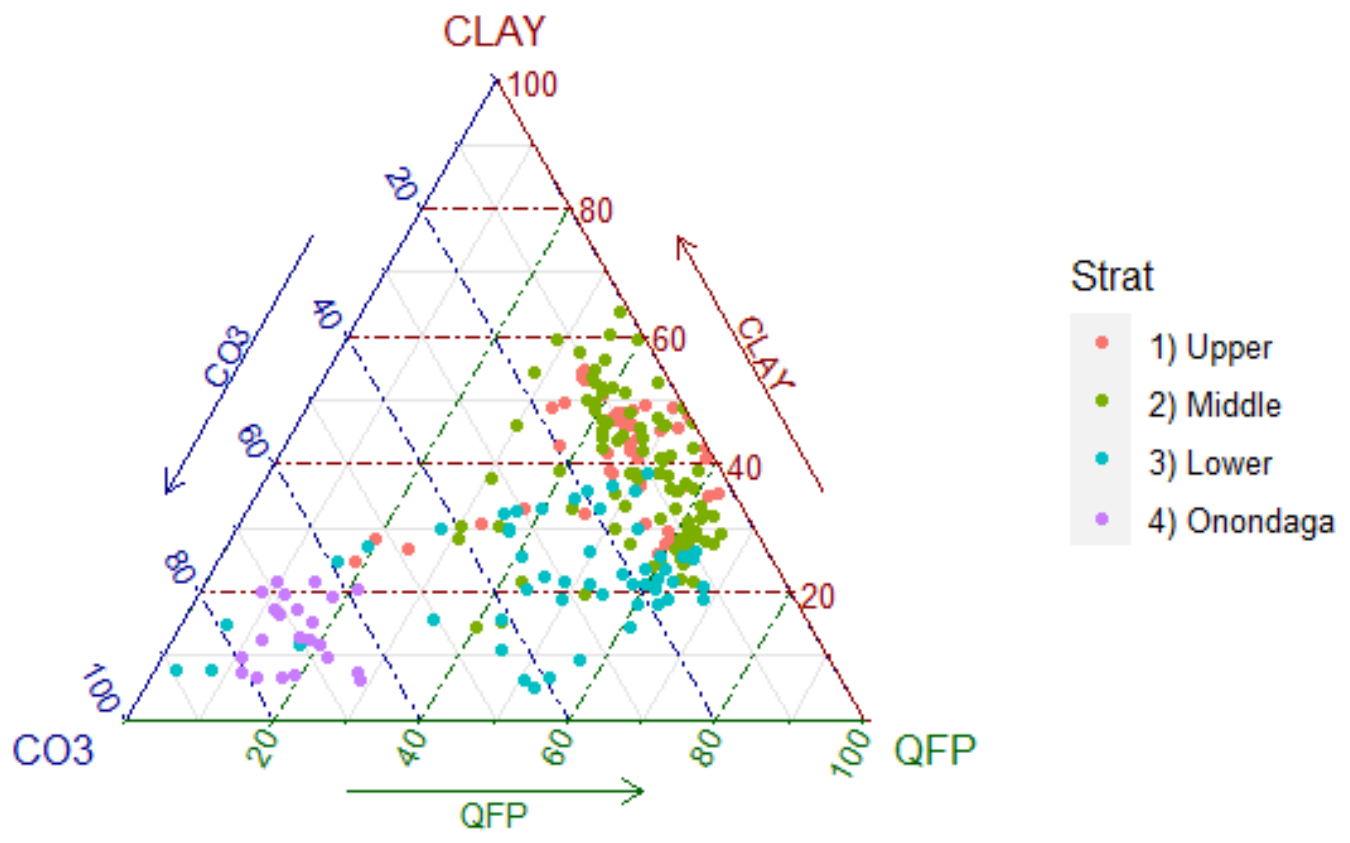

Figure 47. Boggess $17 \mathrm{H}$ Inelastic whole rock ternary diagram indicating lithological variation based on stratigraphy. 
Like the MIP3H, Figures 46 and 47, plot identical to one another. The Boggess 17H implements Inelastic Processing to determine mineralogical composition by measuring near and far inelastic gamma ray spectra (Mckeon et al., 2008). Compared to the Coastal 1H and MIP3H, the upper unit of the Boggess $17 \mathrm{H}$ is shown to have more QFP content. The upper unit clusters at about 55\% QFP, with outliers plotting towards higher amounts of CO3 and QFP. Most of the points for the middle unit plot between 30 and $60 \%$ clay content, with less than $20 \% \mathrm{CO}$. The lower unit has no points above 40\% Clay, favoring more QFP content with some spread towards the $\mathrm{CO} 3$ corner. Like all previous wells, the Onondaga shows carbonate most points plotting above $60 \% \mathrm{CO} 3$.

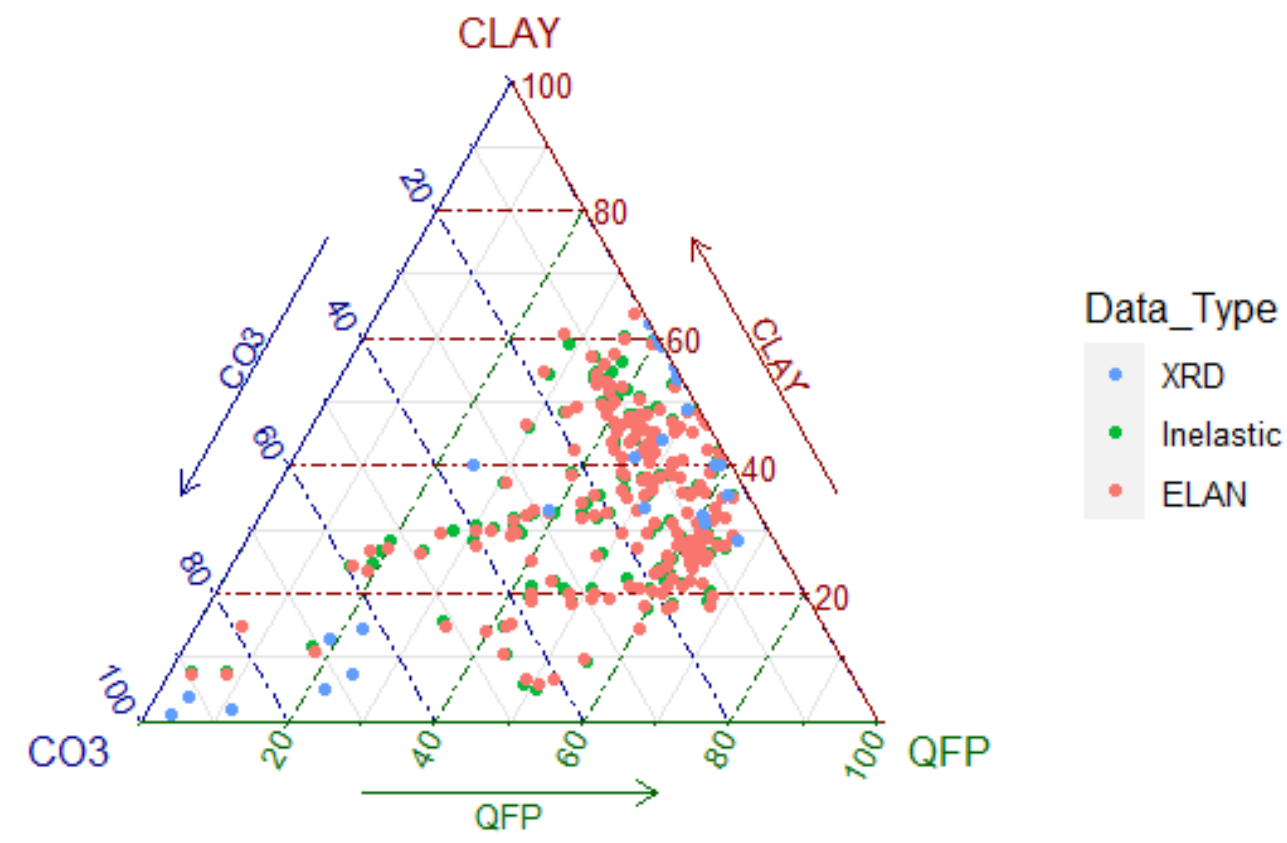

Figure 48. Boggess 17H XRD, inelastic, and ELAN ternary diagram indicating differences in measurement of lithology.

Two unique characteristics are present in the Boggess $17 \mathrm{H}$ well data (Figure 48). First, the inelastic and ELAN measurements are nearly identical. The most variation occurs with outliers as the data becomes richer in CO3. Second, the XRD data is abundant and with the most 
data available. The presence of datapoints in the $\mathrm{CO} 3$ corner suggests intermittent high limestone units between the upper, middle, and lower sections. It also indicates that some of these XRD measurements may have been taken in the lower-Onondaga transitionary zone. While less distinct, in comparison to Figures 46 and 47, the XRD data follows the same trend as previous wells.

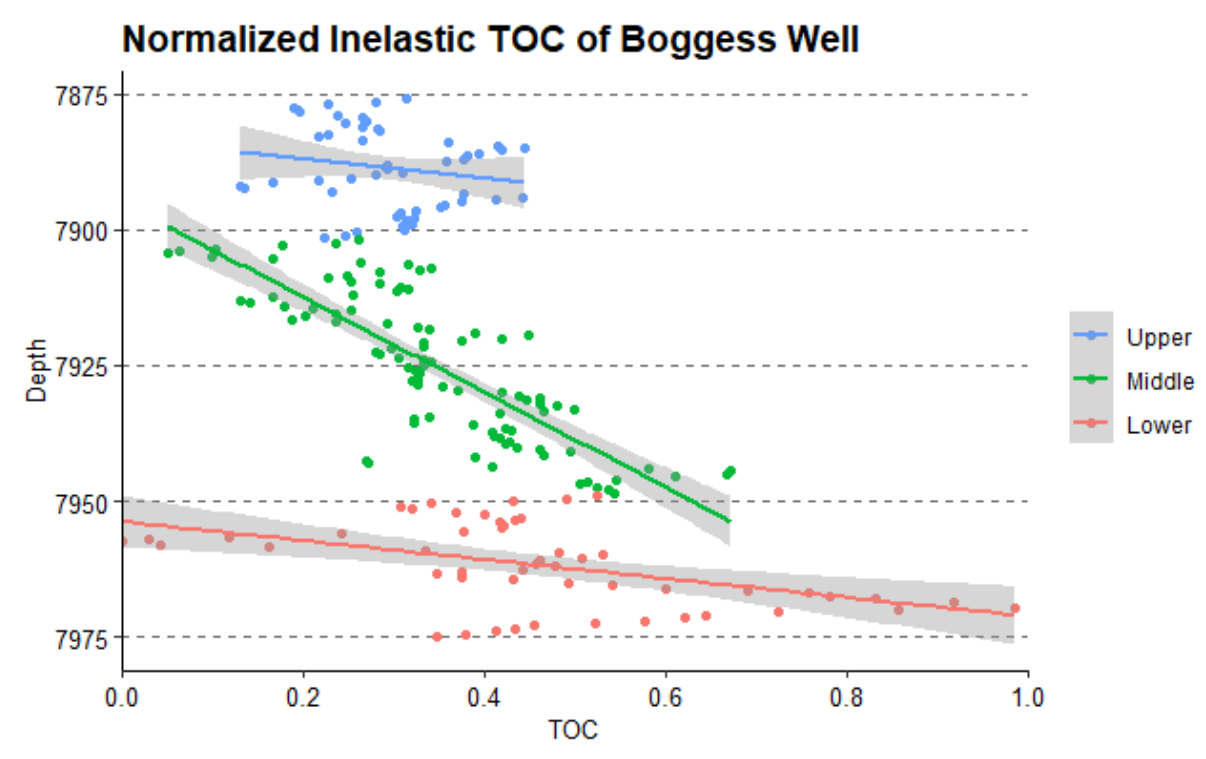

Figure 49. Boggess 17H TOC data calculated through Inelastic Processing logging tool.

The Boggess 17H well utilizes Inelastic Processing to measure levels of TOC (Figure 49). The Upper and Lower units exhibit similar trends in TOC as of other wells, with moderate increases in TOC with depth. However, the Middle unit increases in TOC steeply with depth. Of the three units, its confidence interval is the narrowest as well. 


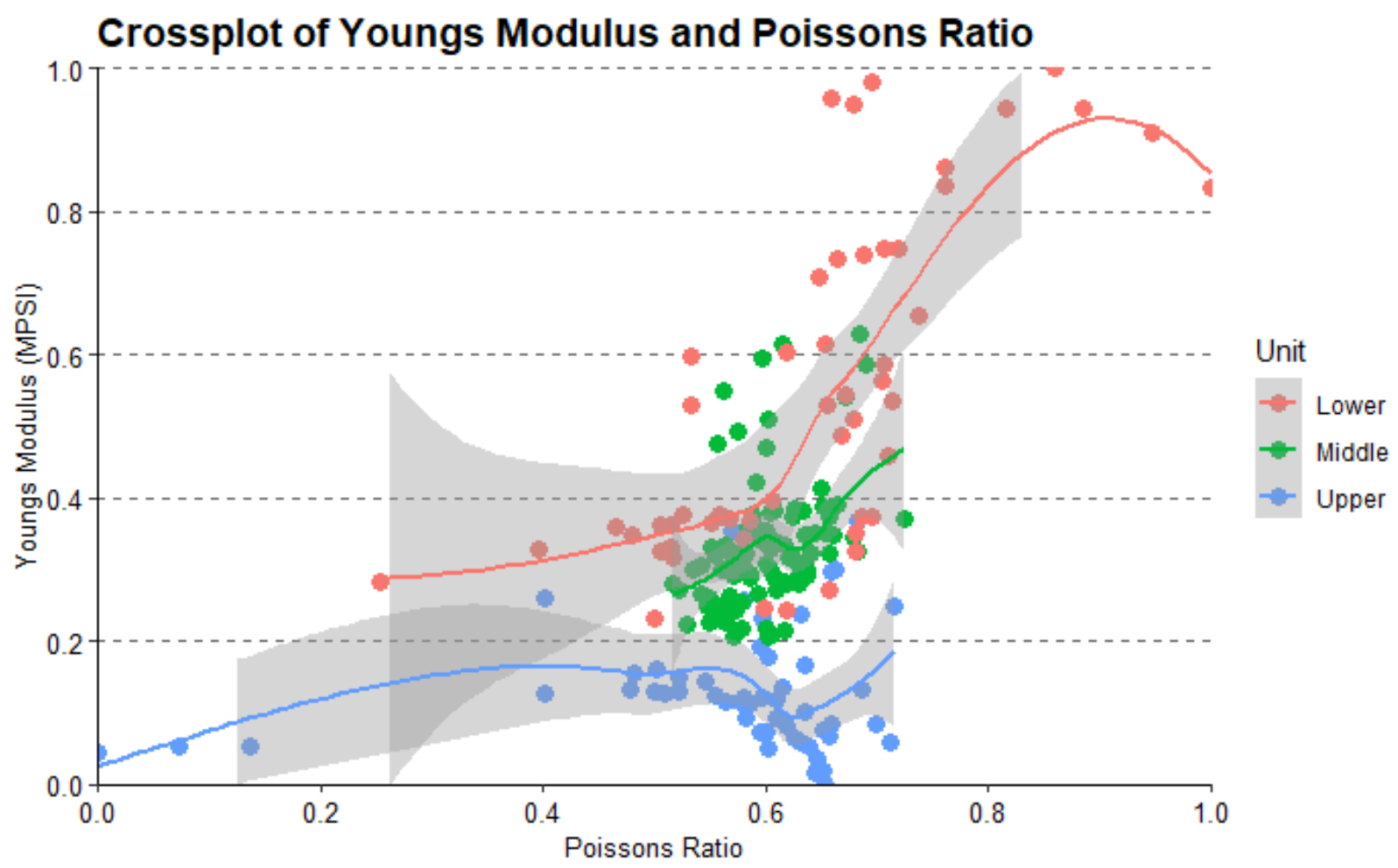

Figure 50. Boggess 17H cross plot between Youngs Modulus and Poissons Ratio with loess curves.

The Boggess 17H well doesn't plot similarly to the Coastal 1H or the MIP3H (Figure 50). Though like the coastal $1 \mathrm{H}$, there does seem be troughs in the Loess Curve at about 0.6 Poisson's Ratio. The lower and upper curves seem to mirror one another, with tail ends in opposite corners of the graph. The middle unit is unique as its Loess Curve is short and the data heavily clustered. The Boggess 17H is like the MIP3H in that Youngs Modulus increases with depth, but Poisson's Ratio doesn't seem to decrease. In fact, most of the data point seemed stacked between 0.5 and 0.7 along the $\mathrm{X}$ axis. The Boggess $17 \mathrm{H}$ well mostly plots in the weak-ductile quadrant, with the lower unit plotting a bit more in the strong-ductile quadrant. 


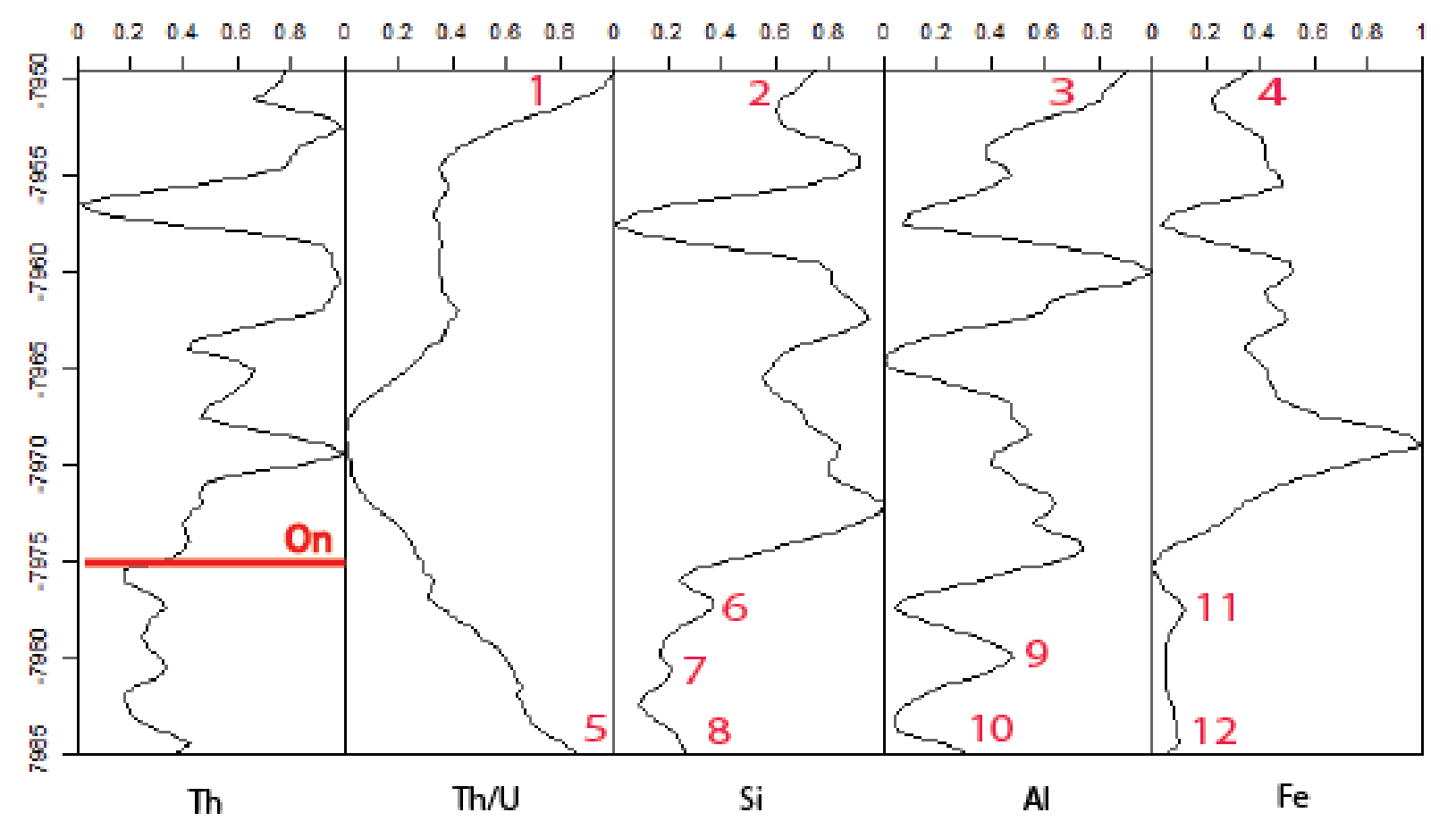

Figure 51. Boggess $17 \mathrm{H}$ spectral and elan well logs with peaks marked that may indicate the presence of ash beds.

The Boggess $117 \mathrm{H}$ well logs exhibit similar patterns to the MIP3H logs. Like the MIP3H, there are peaks in the Th/U log at the top and bottom (Figure 51). Peaks 1 through 4 do not exhibit any pattern, with high amounts of Si and Al. Peak number 5 at the base of the Onondaga Formation is associated with a steadily increasing Th/U ratio. Throughout this climb, peaks 6 through 12 occur sporadically. 


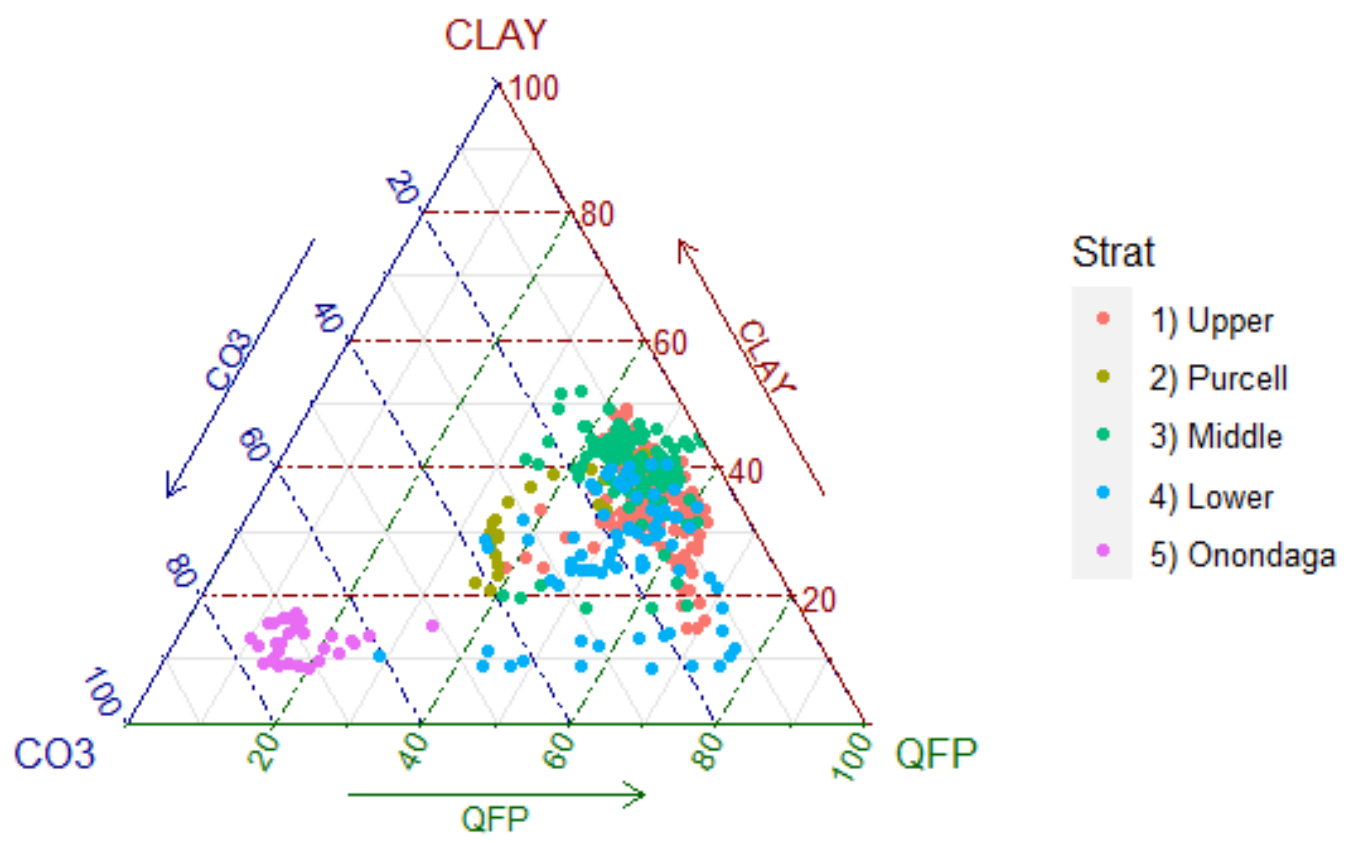

Figure 52. Poseidon 8M ELAN whole rock ternary diagram indicating lithological variation based on stratigraphy.

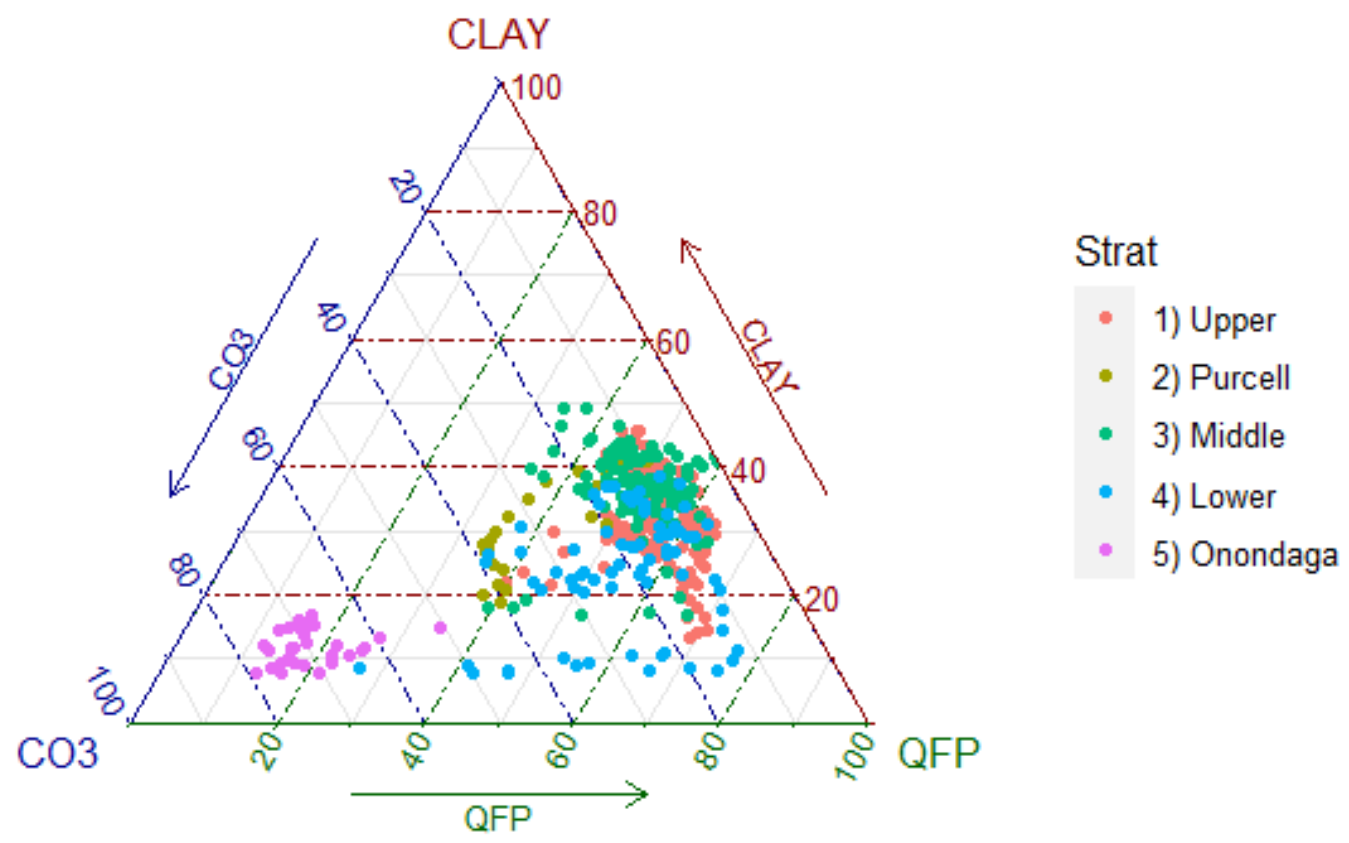

Figure 53. Poseidon $8 \mathrm{M}$ Inelastic whole rock ternary diagram indicating lithological variation based on stratigraphy. 
The Poseidon 8M (Figures 52 and 53) is unique amongst the dataset because it contains a thick upper limestone layer, known as the Purcell. This well implements Inelastic Processing and plots almost identical to each other. For the upper unit, both graphs show tight clusters between 20 and $40 \%$ clay content, with less than $20 \%$ CO3. The Purcell, while CO3 rich, consists of a cluster of points at about $30 \%$ clay, and 50\% CO3/WFP. The tightest cluster is found in the middle unit, where most points are located at about $30-40 \%$ clay. The lower unit plots consistently in the QFP corner, with points spread out beneath $40 \%$ clay and CO3. There is a tight group of points in the Onondaga, with most indicating more than $60 \% \mathrm{CO} 3$.

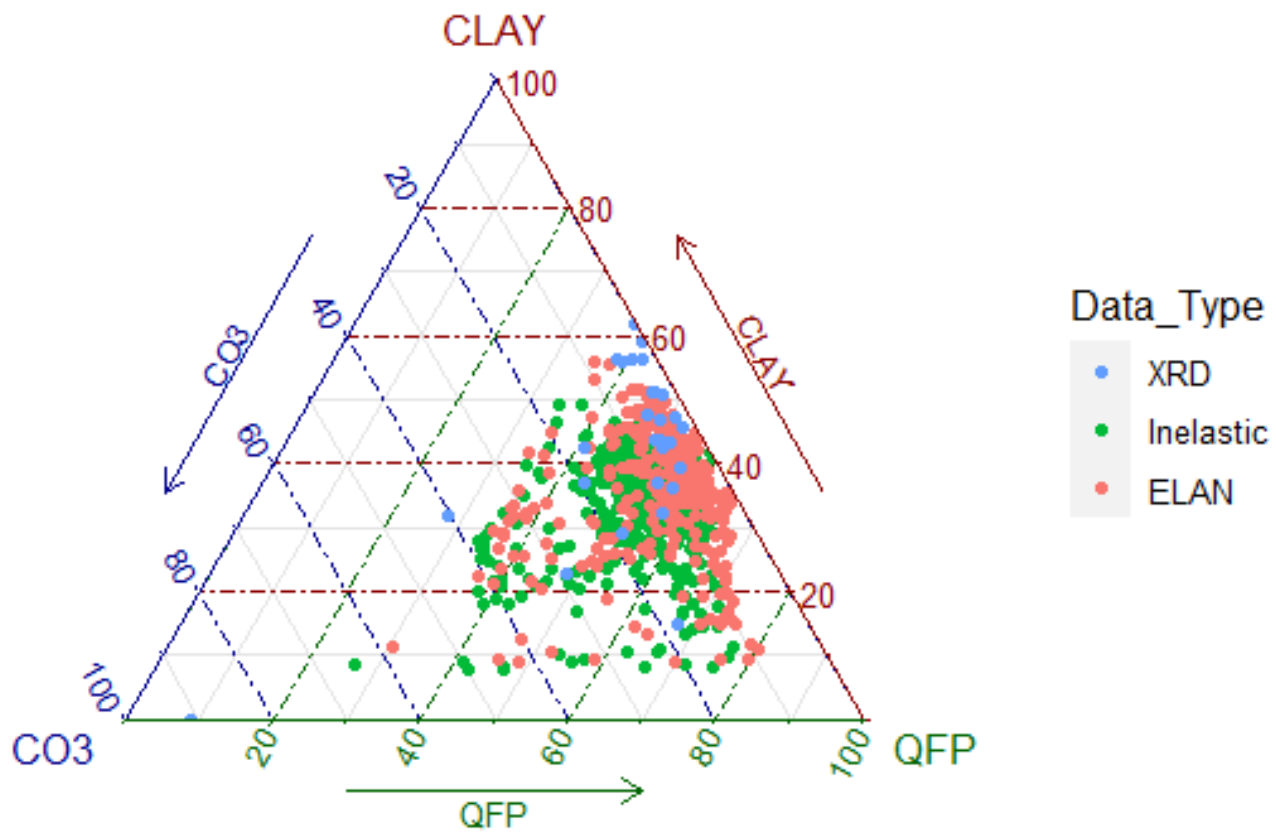

Figure 54. Poseidon $8 \mathrm{M}$ XRD, Inelastic, and ELAN ternary diagram indicating differences in measurement of lithology.

The Poseidon 8M well (Figure 54) illustrates how these measurement tools differ. The Inelastic measurements consists of more CO3, plotting between 80 and 90\% QFP/Clay, excluding outliers. In contrast, the ELAN weight measurements tend to plot between $90 \%$ and $100 \%$ QFP/Clay. A similar curve to that of the Coastal $1 \mathrm{H}$ well occurs within the XRD data. As depth 
increases, the XRD data plots further away from the Clay/QFP axis and increases in $\mathrm{CO} 3$ content.
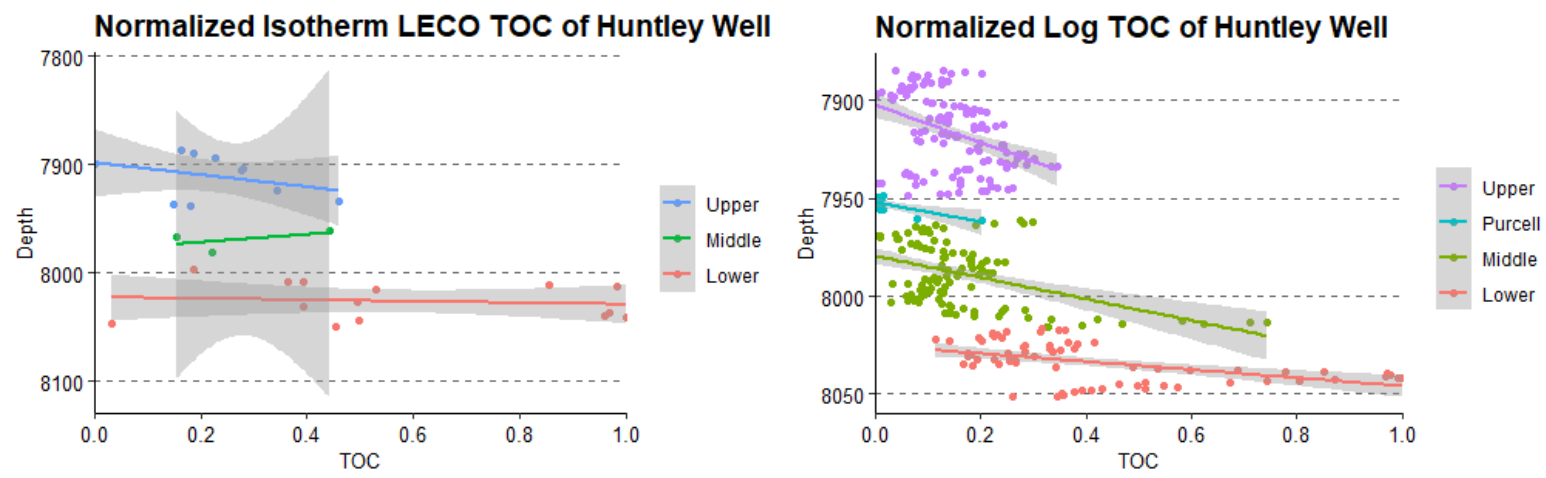

Figure 55. Poseidon 8M TOC data determined through LECO source rock analyzer and a logging tool.

Isotherm LECO and logging tools were used to measure TOC in the Poseidon 8M well (Figure 55). This well is unique because it consists of a thick upper limestone section known as the Purcell. The LECO data did not consist of any measurements within this section. For the log data, each trend line indicates an increase in TOC with depth. The confidence intervals are tight, except at the deeper end of the middle section. The Isotherm LECO consists of fewer data points and shallower trend lines. The middle section exhibits a decrease in TOC with depth and has a wide confidence interval. 


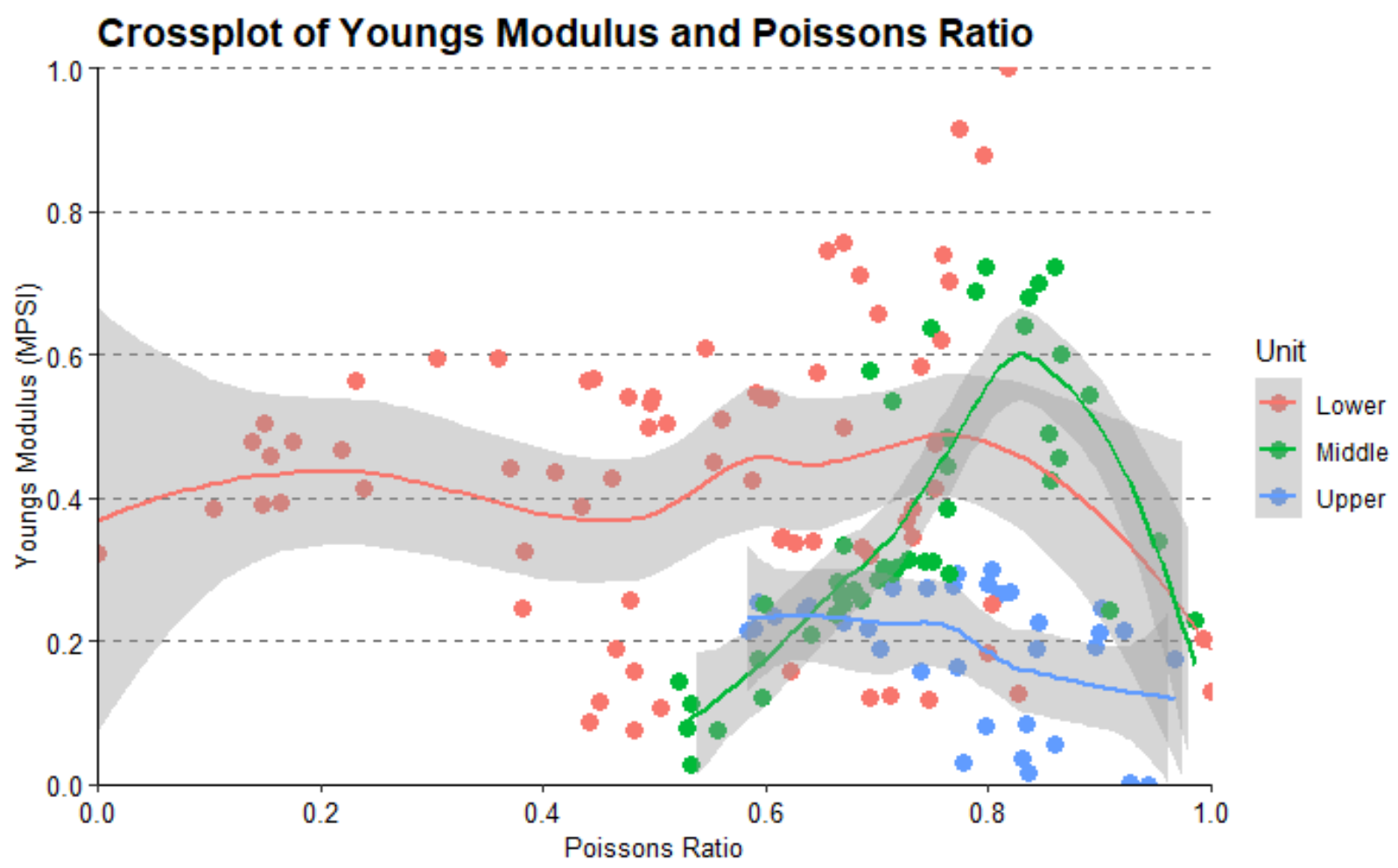

Figure 56. Poseidon $8 \mathrm{M}$ cross plot between Youngs Modulus and Poisson's Ratio with loess curves.

The cross plot of the Poseidon 8M well exhibits some unique features (Figure 56). Like the Armstrong 1 well, the upper unit plots in the weak ductile quadrant, with a similarly shaped Loess Curve. The middle unit, however, has a large peak at about 0.8 along the $\mathrm{X}$ axis. It is the only unit with a trend like this amongst all the wells. While the upper and middle units mostly plot in the weak-ductile quadrant, the lower unit plots along both lower quadrants (ductile and brittle). The plot does appear to show the inverse relationship between Youngs Modulus and Poisson's Ratio across the units. 


\section{The Far Group}

The far group shows an increase in depth to the east (Figure 57). Between the Goff 55 (top depth of $7160 \mathrm{ft}$ ) and Armstrong 1 (top depth of $7680 \mathrm{ft}$ ) Wells, there is a difference of 520 $\mathrm{ft}$ in depth. In comparison, the Boggess 17H, MIP3H, Coastal 1H, and Poseidon 8M wells consist of a difference of about $400 \mathrm{ft}$, with the wells shallowing towards the center. While the selected tops are consistent with the methods used on the Coastal $1 \mathrm{H}$ well, the Dunham $4 \mathrm{H}$ well presents one issue. Near the base of the well bore, there is some sort of tool failure which prevents it from operating effectively. Making it difficult to determine the exact location of the lower Marcellus and Onondaga contact. The Dunham 4H well accounts for density and neutron porosity differently too, considering them ZDEN and $\mathrm{CN}$ respectively. 


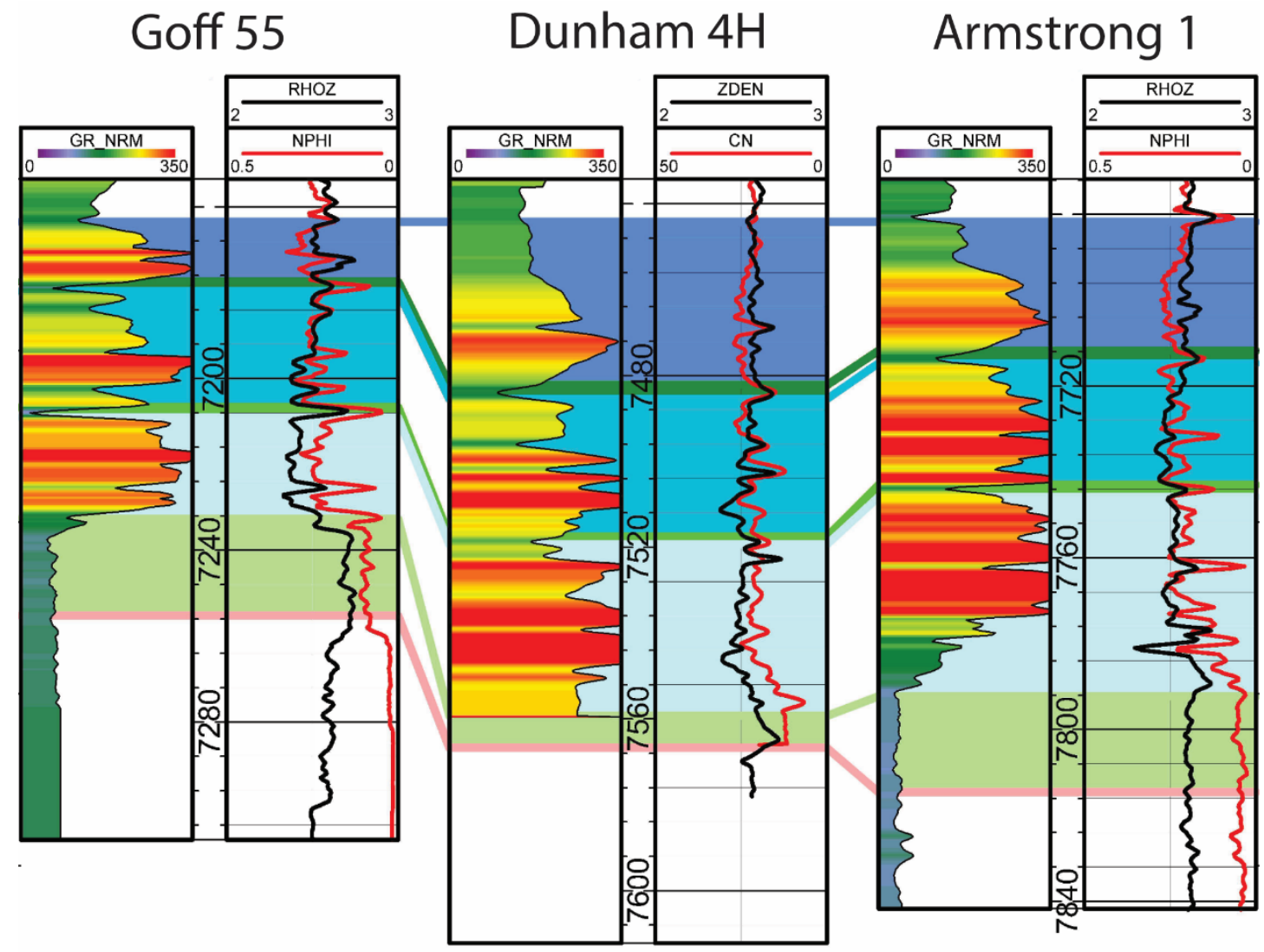

Figure 57. Logs for the far group of wells which include the Goff 55, Dunham 4H, and the Armstrong 1.

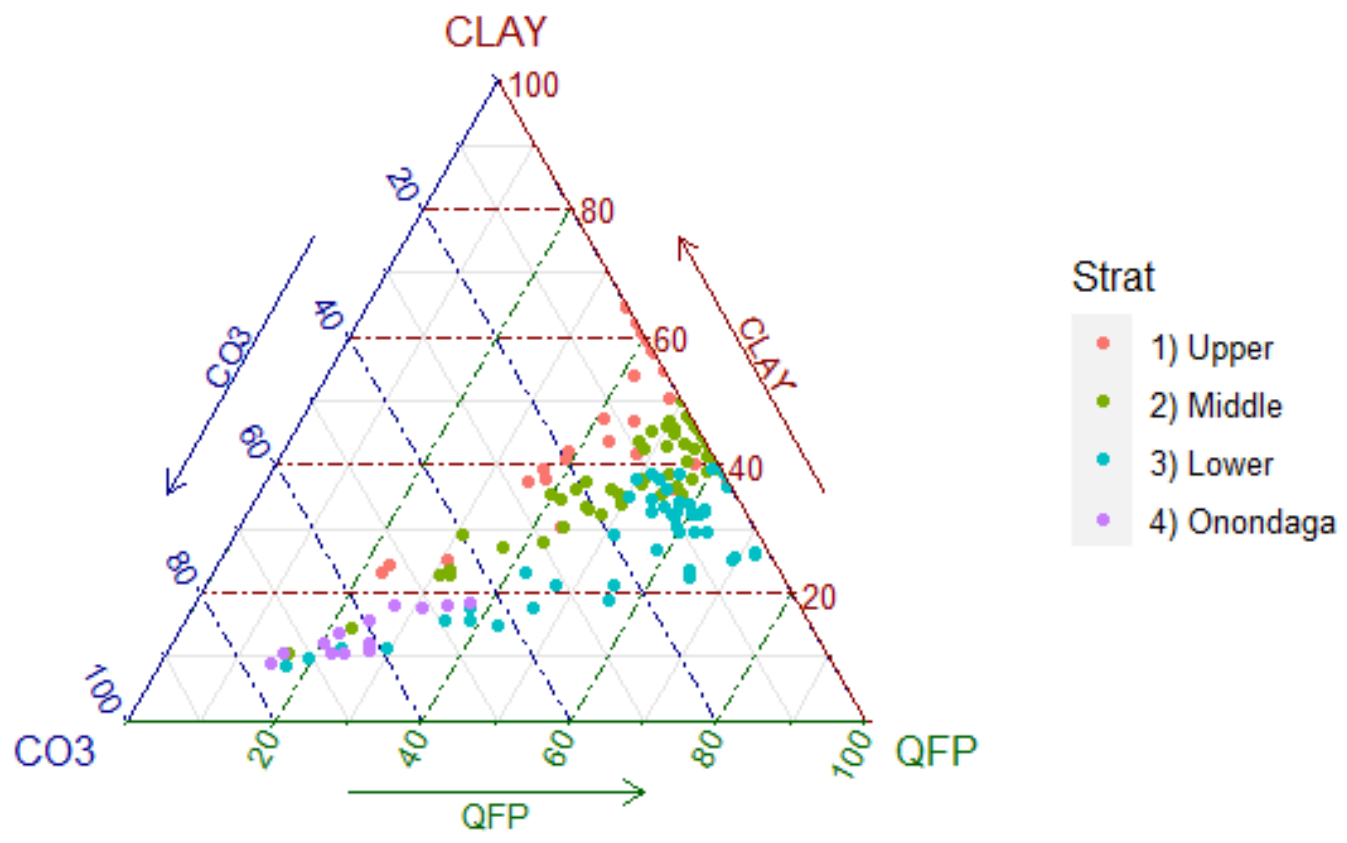

Figure 58. Goff 55 ELAN whole rock ternary diagram indicating lithological variation based on stratigraphy. 


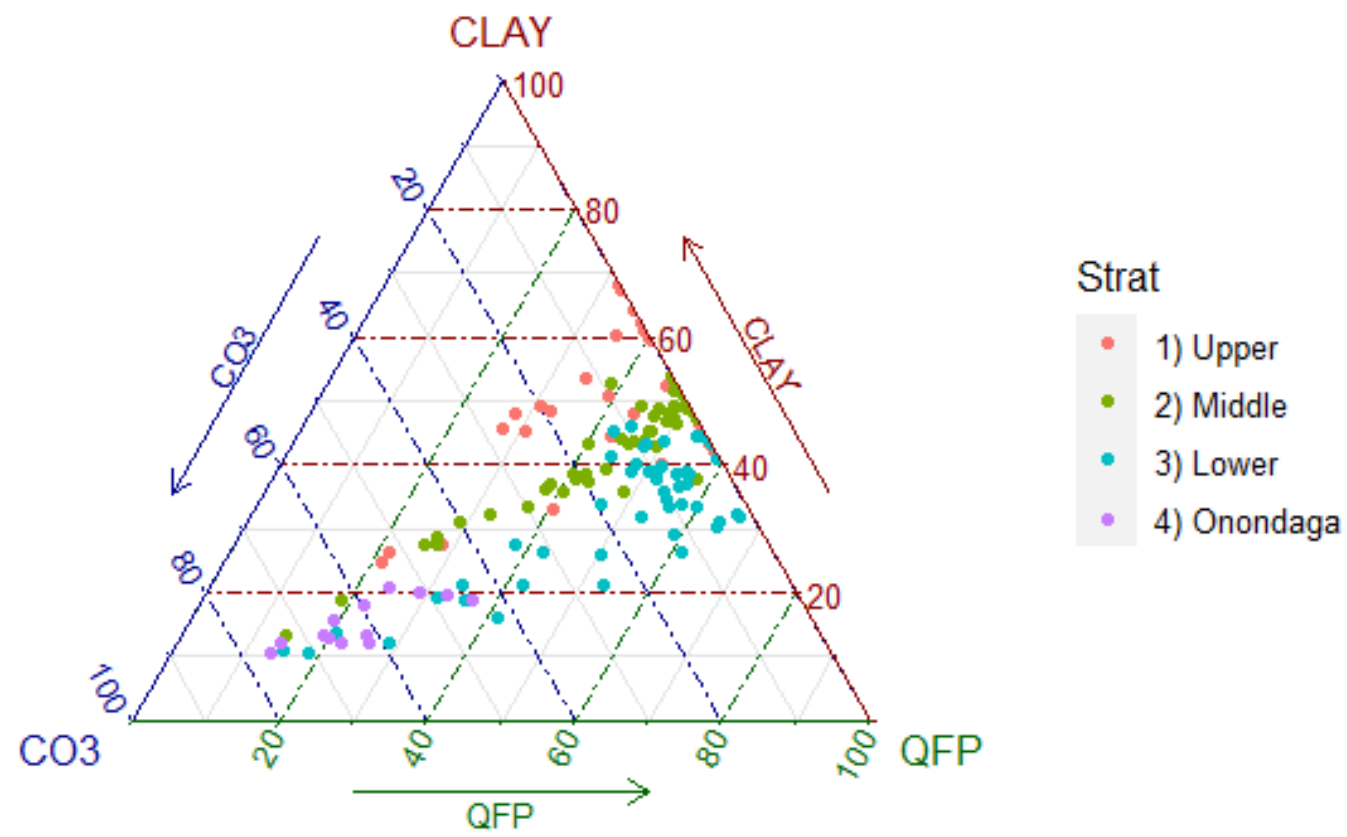

Figure 59. Goff 55 Spectrolith whole rock ternary diagram indicating lithological variation based on stratigraphy.

The Goff 55 (Figures 58 and 59) has nearly identical plots between ELAN and Spectrolith weight measurements. The upper unit has most points plot above $40 \%$ Clay, though it does contain many $\mathrm{CO} 3$ rich outliers. There is a similar pattern amongst the middle and lower units as well. The middle unit has tight clusters between $40 \%$ and $50 \%$ clay, while the lower clusters between $30 \%$ and $40 \%$ clay. Both have $\mathrm{CO} 3$ rich outliers with some plotting like the Onondaga. 
Lastly, the Onondaga appears to plot consistently with previous wells (except for the Armstrong 1), having points between 40 and $80 \% \mathrm{CO} 3$.

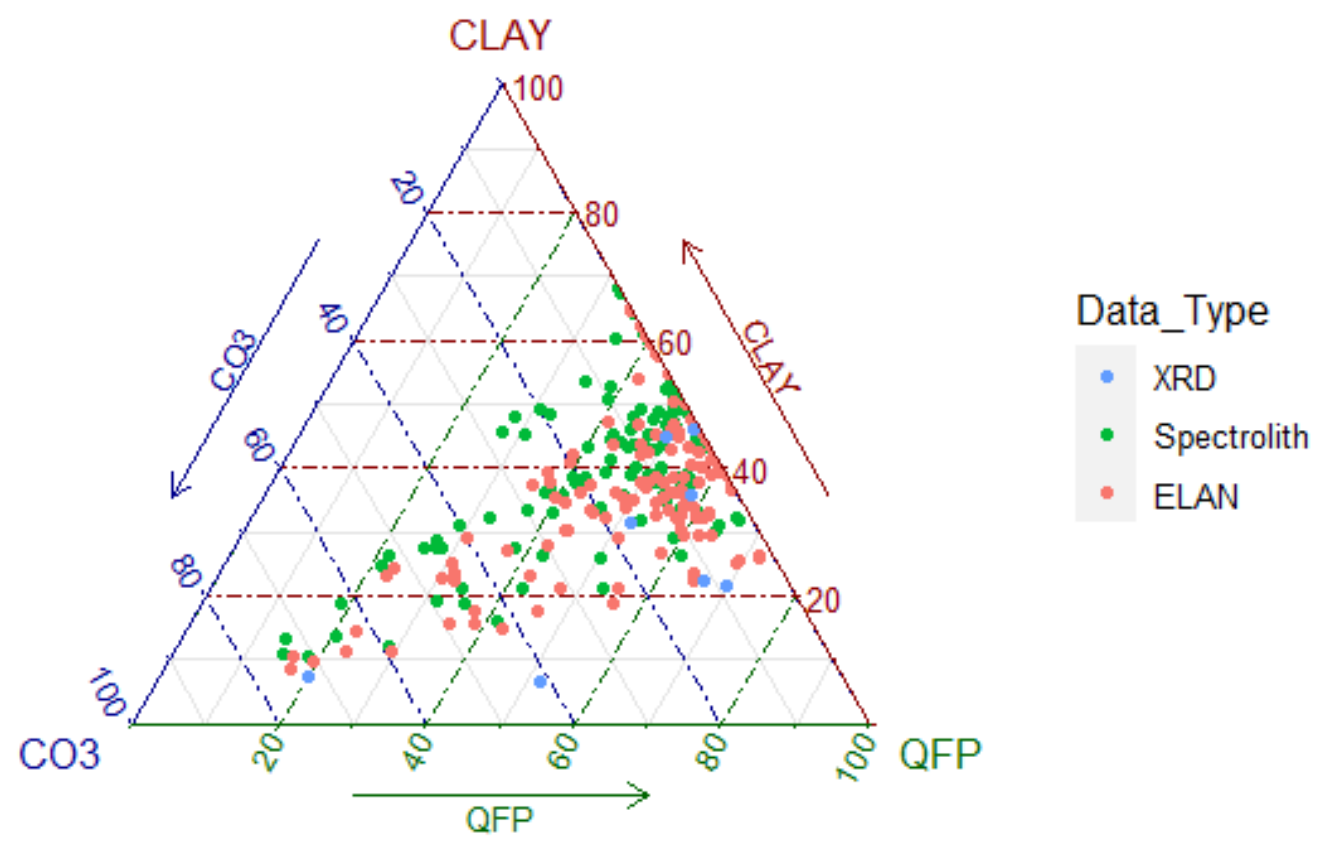

Figure 60. Goff $55 \mathrm{XRD}$, Spectrolith, and ELAN ternary diagram indicating differences in measurement of lithology.

In contrast to the Poseidon 8M well, the Goff 55 well (Figure 60) implements Spectrolith instead of Inelastic Processing. While the Inelastic Processing method favored a carbonate rich interpretation, the Spectrolith measurements consists of a clay rich interpretation in comparison to the ELAN data. The deviation occurs about $50 \%$ on the Clay/QFP axis, with this trend continuing towards the $\mathrm{CO} 3$ corner. The XRD data is consistent with previous interpretations, plotting highly in clay content initially and increasing in CO3 with depth, curving away from the Clay/QFP axis. 


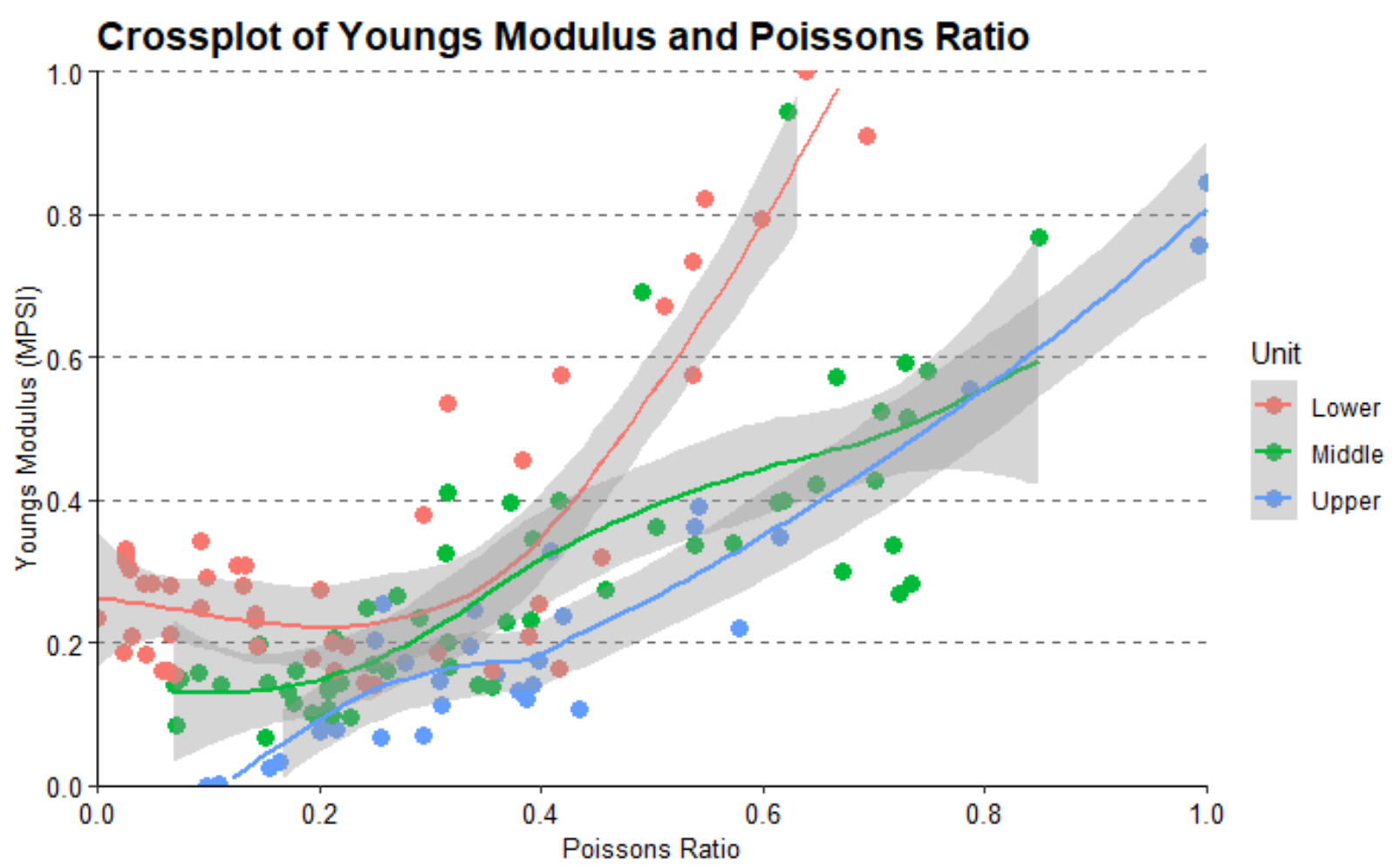

Figure 61. Goff 55 cross plot between Youngs Modulus and Poisson's Ratio with loess curves.

The Goff 55 well is consistent with the MIP3H, with most of its data plotting the weakbrittle quadrant (Figure 61). Like the MIP3H, it has outliers which expand into the weak-ductile and strong-ductile quadrants. The Loess Curves of each unit are similar, with tight confidence intervals. It does follow the inverse relationship between the two measurements and depth. 

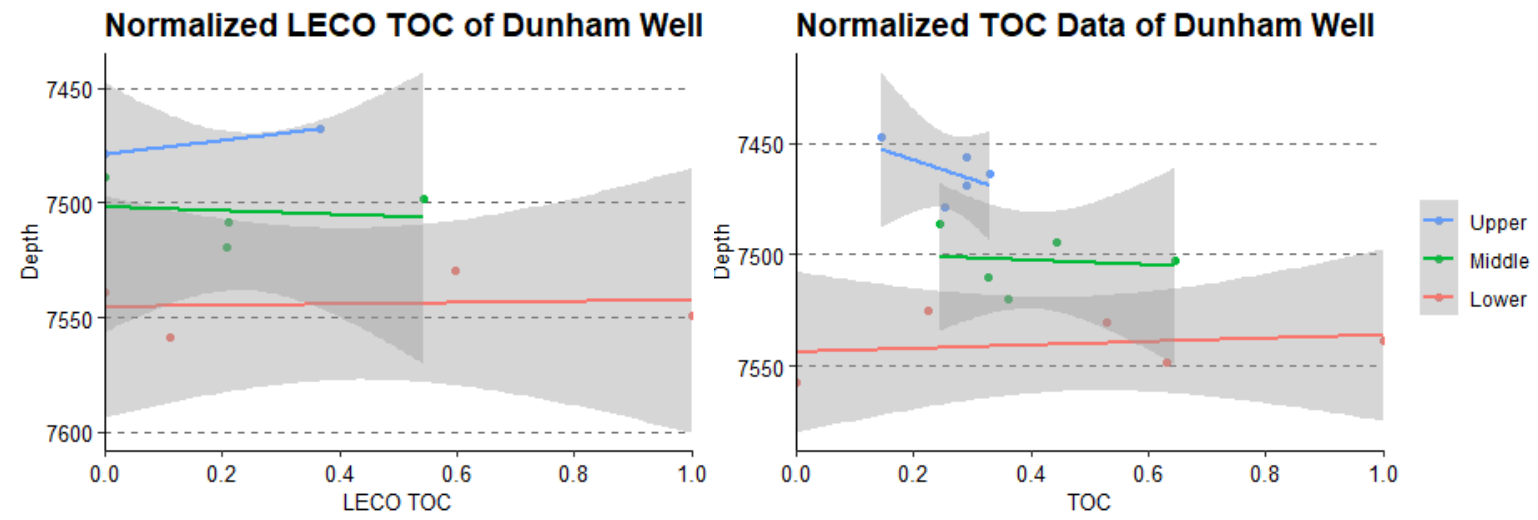

Figure 62. Dunham 4H TOC data determined through LECO source rock analyzer and a logging tool.

One of the issues with the dataset is a lack of measurements available. For the Dunham 4H well, measurements were collected through a logging tool and a LECO carbon analyzer (Figure 62). There are many difference between the two graphs. The upper section of the LECO measurements suggests a decrease in TOC with depth, while the log data indicates the opposite. Both the upper and middle sections show tighter groupings in the log data. The confidence intervals are wide for both graphs, but a bit tighter in the log data too. 


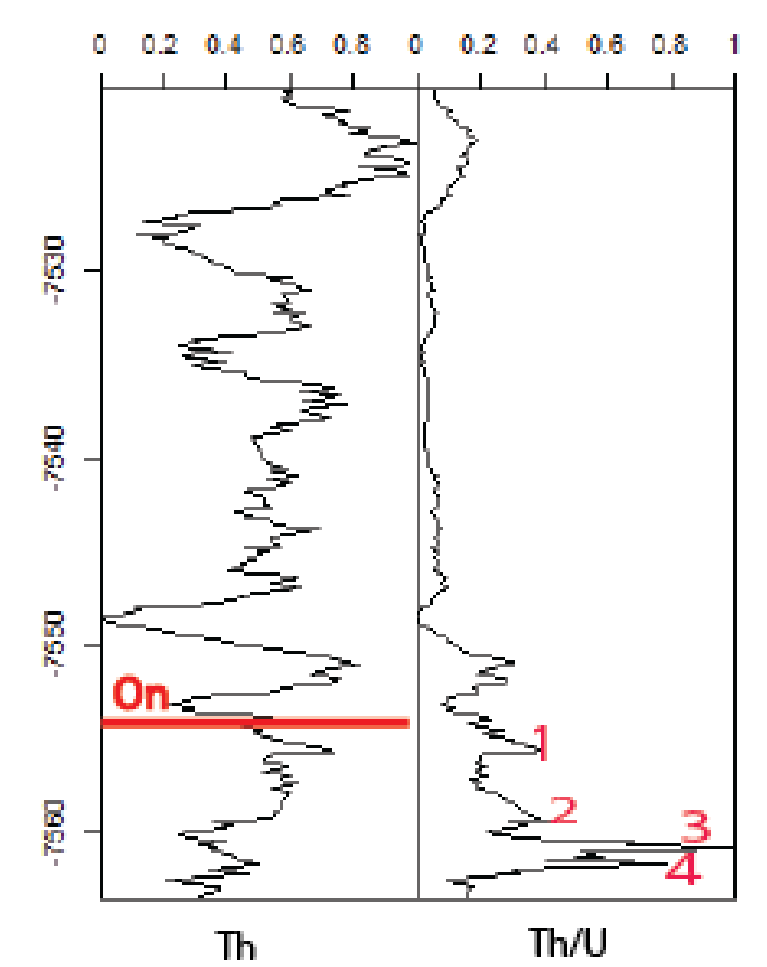

Figure 63. Dunham 4H spectral well logs with peaks marked that may indicate the presence of ash beds.

The Dunham 4H well does not have elemental composition logs to interpret (Figure 63). Though the $\mathrm{Th} / \mathrm{U}$ ratio log does exhibit at least 4 notable peaks, with two of those peaks valued at more than 0.7. There is a peak in the ratio log at the top of the lower Marcellus, but it is less than 2.0 and somewhat gradual in comparison to peaks 1 through 4. 


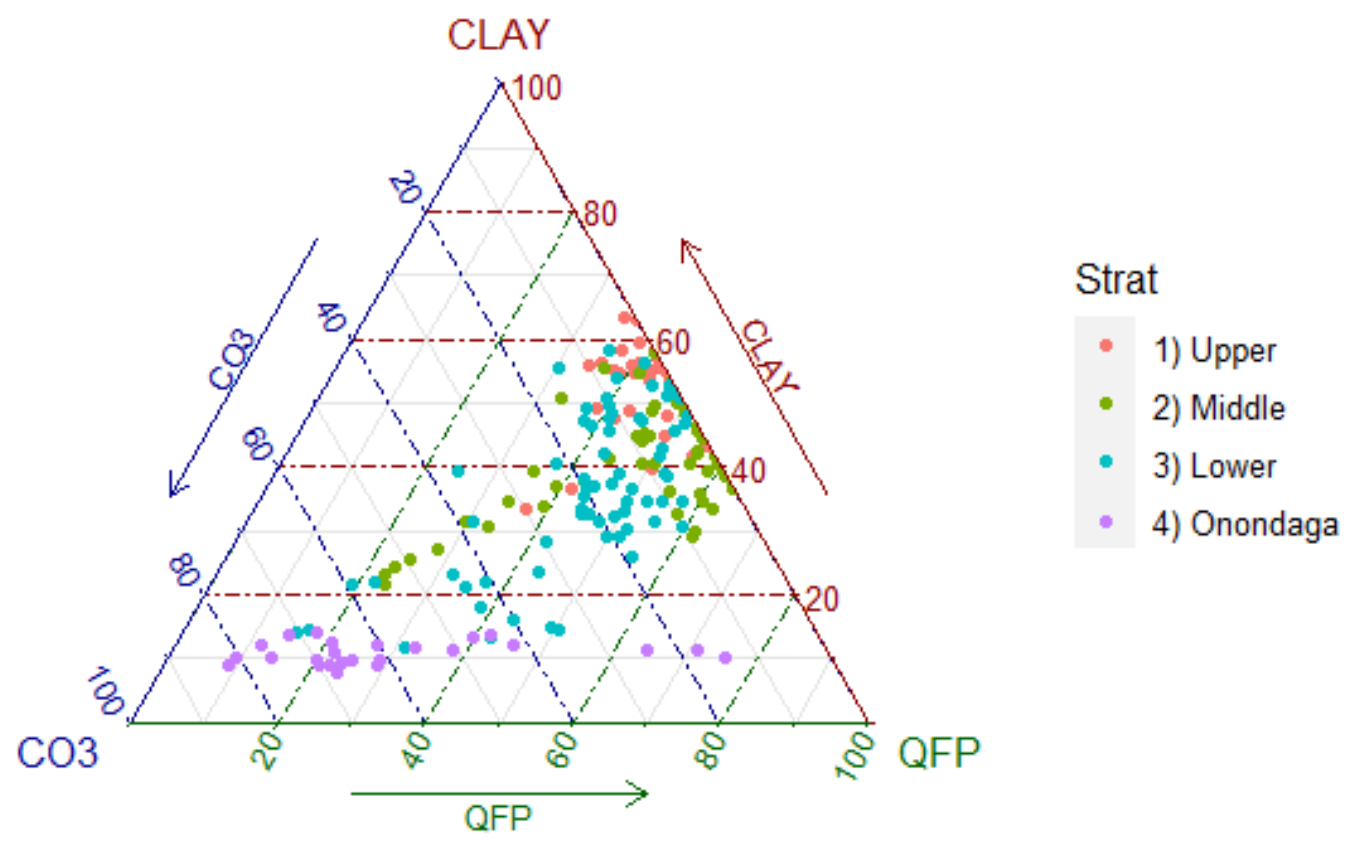

Figure 64. Armstrong 1 ELAN whole rock ternary diagram indicating lithological variation based on stratigraphy.

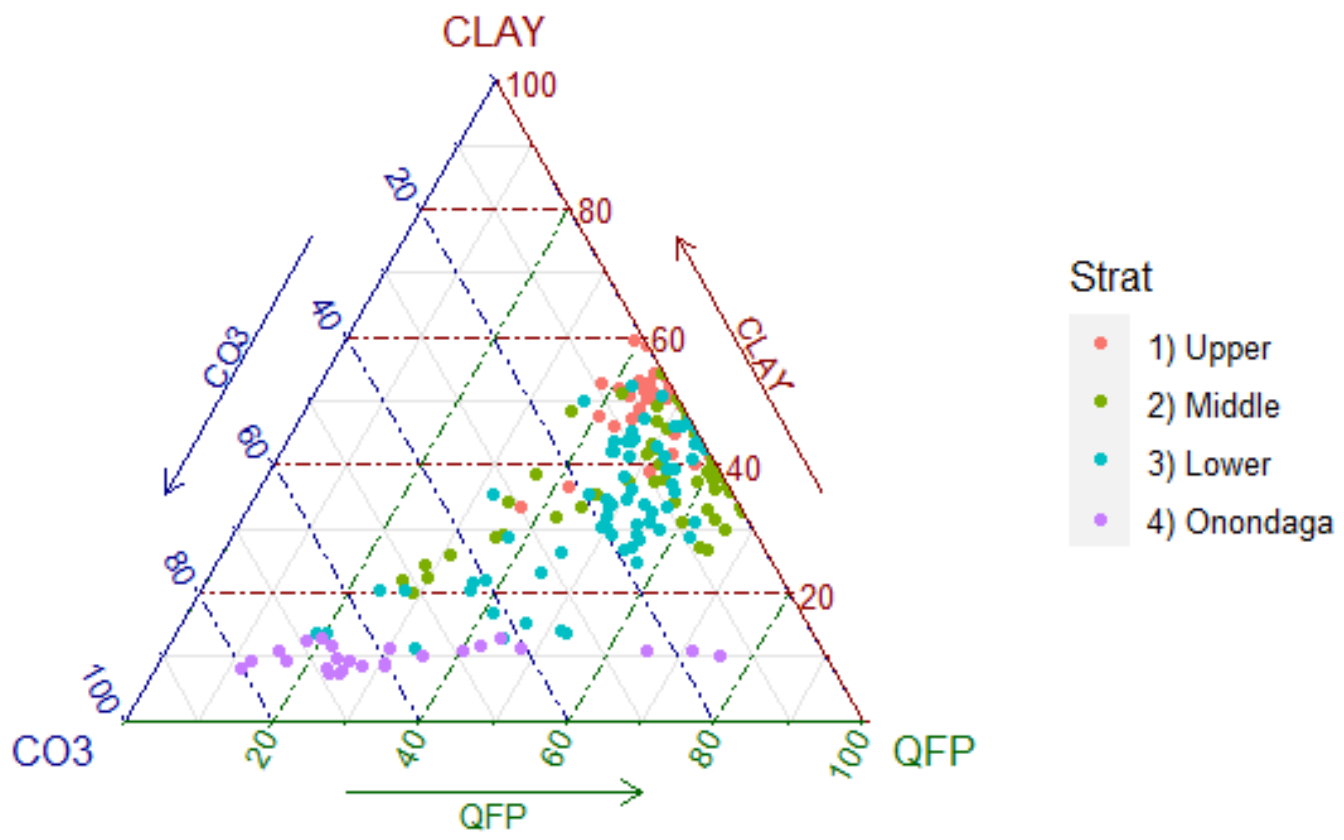

Figure 65. Armstrong 1 Spectrolith whole rock ternary diagram indicating lithological variation based on stratigraphy. 
The Armstrong 1 well (Figures 64 and 65) utilizes Spectrolith, like the Coastal 1H well. There are slight variations between the ELAN and Spectrolith weight measurements, though they are subtle. The upper unit plots tightly at about 55\% Clay content, with less than $15 \% \mathrm{CO}$. The data exhibits clusters between $30 \%$ and $50 \%$ clay content for the middle unit, with less than $10 \%$ CO3. The lower unit mostly plots between $30 \%$ and $50 \%$ clay content, with outliers plotting towards the $\mathrm{CO} 3$ corner. The Onondaga for this graph is the most unique. While all points indicate about $10 \%$ clay content, they spread across the CO3 and QFP axis.

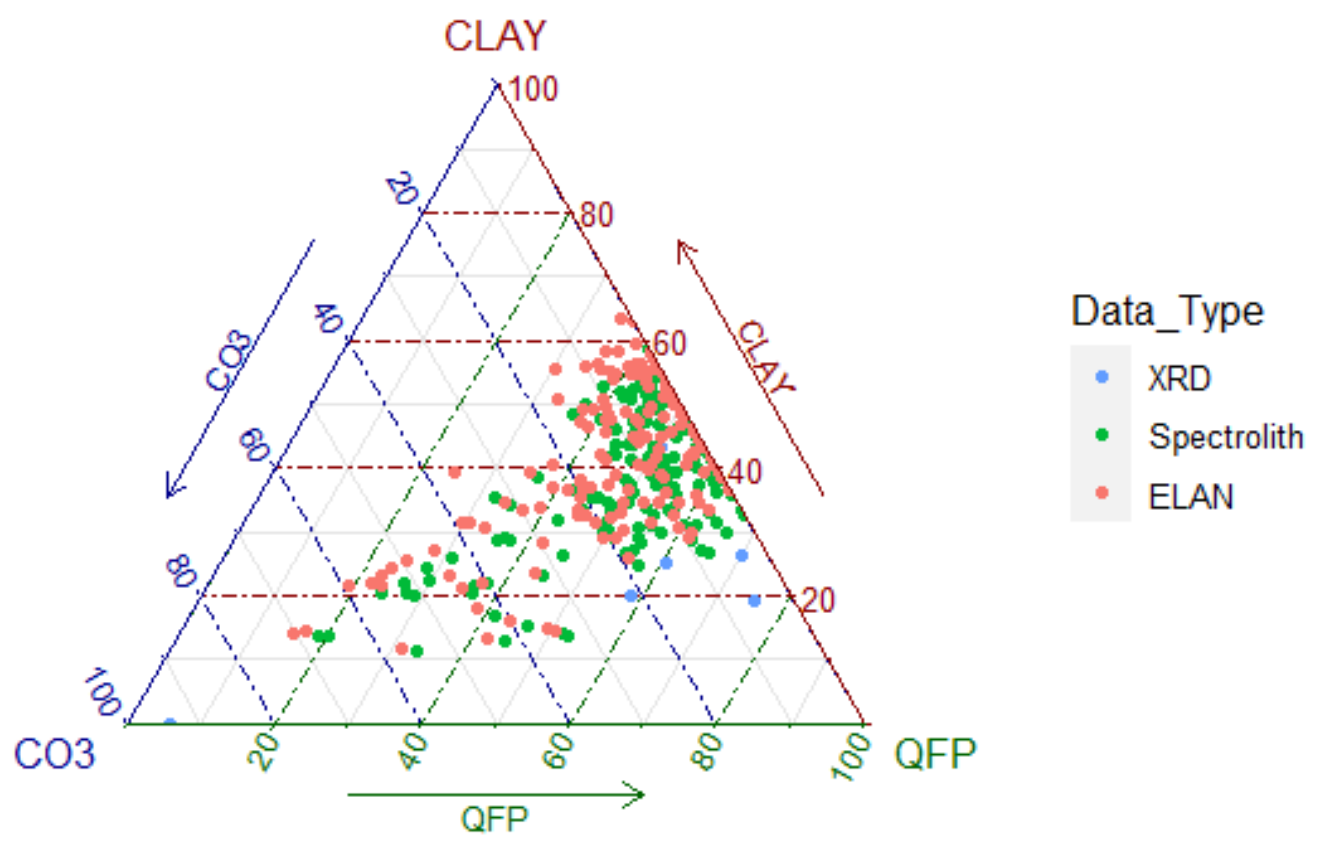

Figure 66. Armstrong 1 XRD, Spectrolith, and ELAN ternary diagram indicating differences in measurement of lithology.

The Armstrong 1 data is the least reliable when it comes to inspecting the XRD data (Figure 66). There are few measurements taken, and they do not seem to plot with any sort of consistency. The Spectrolith and ELAN weight measurements nearly identical though. It seems 
that the Spectrolith favors a clay-CO3 rich interpretation in comparison to the ELAN. This does contradict the Figure 18 (the Goff 55 well), which exhibits the opposite distribution.
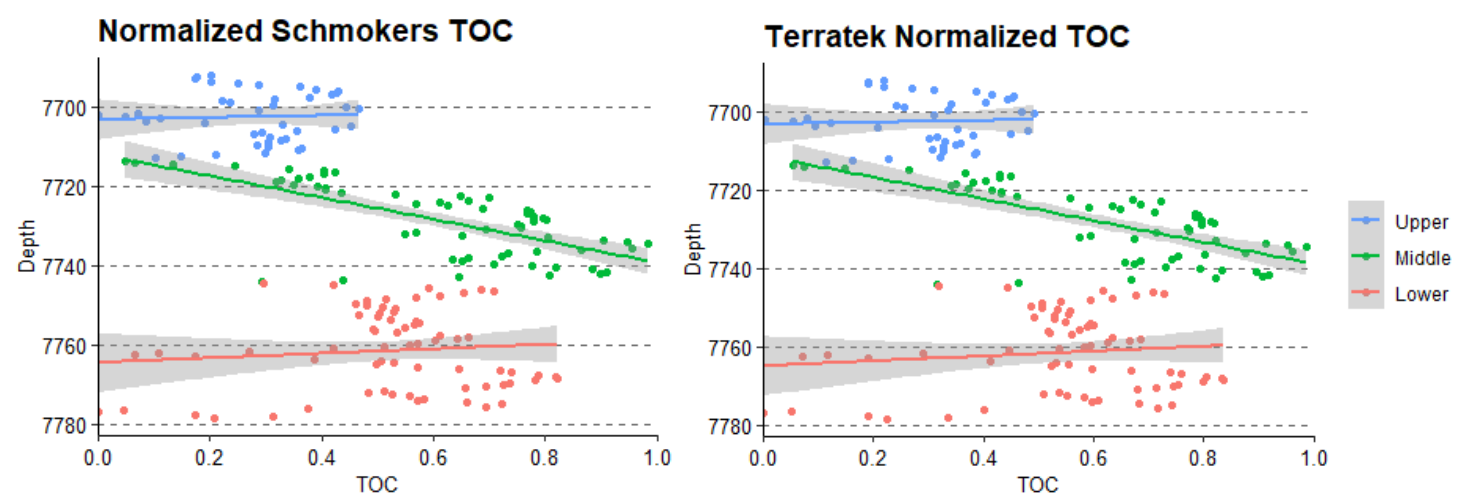

Figure 67. Armstrong 1 TOC log data calculating TOC through both Schmoker's and Terratek methods.

Similar to the Coastal 1H, the Armstrong 1 well utilizes Schmoker's and Terratek to measure TOC (Figure 67). Though the data between the two measurements is nearly identical. Trend lines of the Armstrong 1 well exhibit a slight decrease in TOC with depth in both the upper and lower sections, while the middle section consists of a steep increase in TOC with depth. 


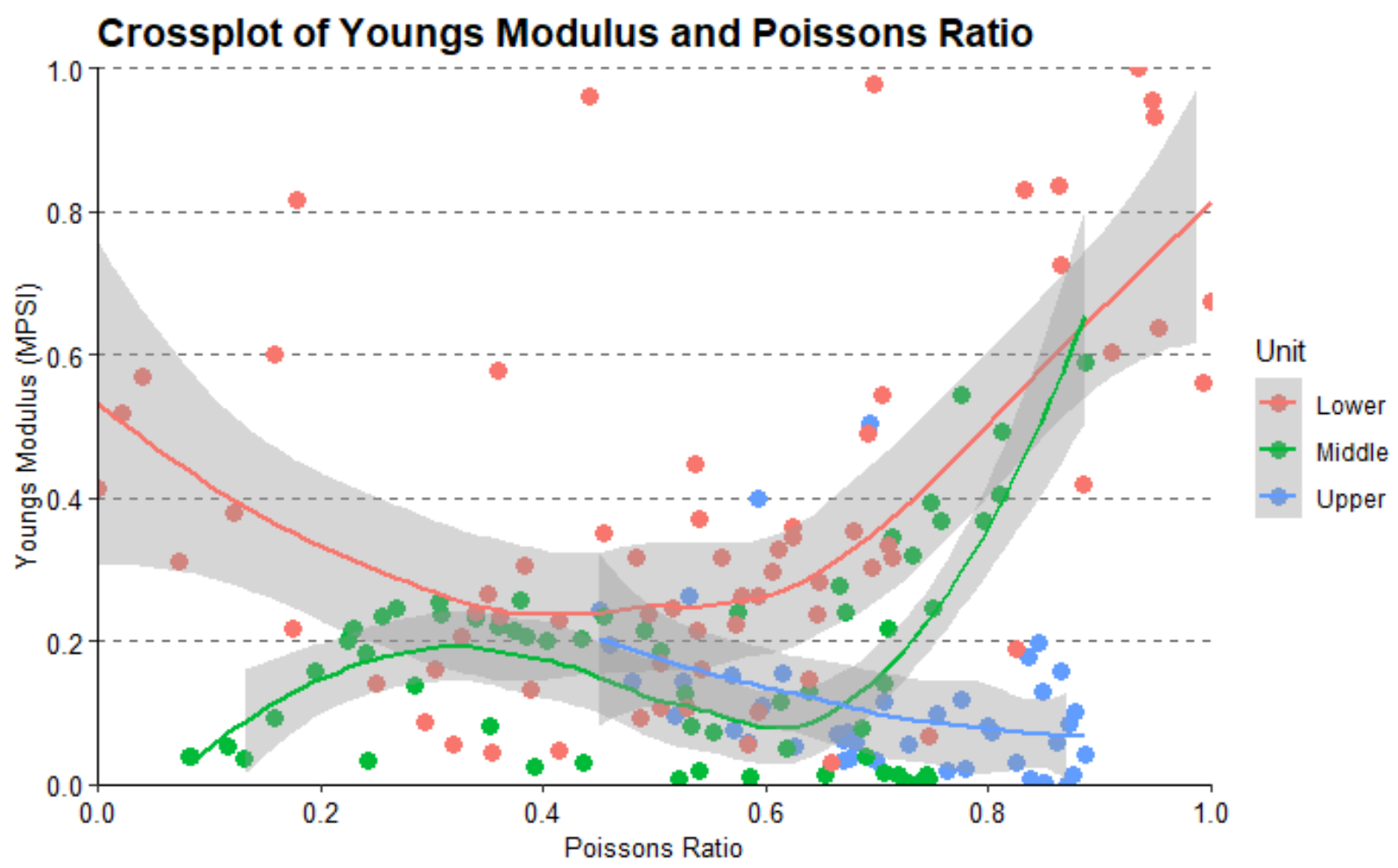

Figure 68. Armstrong 1 cross plot between Youngs Modulus and Poisson's Ratio with loess curves.

The Armstrong 1 well plot is the most like the Coastal 1H (Figure 68). Though its loess curves are much smoother. The middle unit does exhibit a trough at about 0.6 on the $\mathrm{X}$ axis like previous wells and it does possess a similar pattern to the middle unit of the Coastal $1 \mathrm{H}$. It also seems to exhibit the inverse relationship between Youngs Modulus and Poisson's Ratio with depth. This is the only well with a nearly straight loess curve, exhibited within the upper unit. Overall, this well plots within the weak-ductile quadrant. 


\section{The Outlier Group}

The outlier group has a number of issues which make it difficult to accurately determine tops (Figure 69). This also makes it difficult to use the data from these wells for deeper analysis. The Tippens 6HS well is in Ohio, part of the wet gas window of the Marcellus Formation. The neutron porosity $\log (\mathrm{NPHI})$ was not implemented in this target zone of the well bore. This limits the intrpretation of tops to the gamma log (GR_NRM) and bulk density log (RHOZ). At the upper and lower interbedded limestone units, the gamma log decreases while density log does increases. This is consistent with interpretations of lithology in the other wells. While proximal to the Coastal $1 \mathrm{H}$ well, the St Whipkey 1 well is considered an outlier due to the many issues it has with data. From the log, one can see that an error occurred near the Onondaga contact, making it difficult to determine its location. The same problem is obserable in both the density and neutron porosity logs and occurs with most of the data accompanying this well. Due to this, the St Whipkey 1 well is left out of this research paper. Lastly, the Coldstream $1 \mathrm{MH}$ is the most eastern well, located in Clearfield County of north eastern Pennsylania. It does exhibit similar characteristics to other wells in this study and consists of the highest average normalized gamma value (135 API). However, the density (RHOB) and neutron porosity (NPHI) logs are unique in that they do not come near eachother whatsoever in the log. The differences between these logs which indicate the presence of interbedded limestone units is still observable and consistent with the normalized gamma log (GR_NRM). 


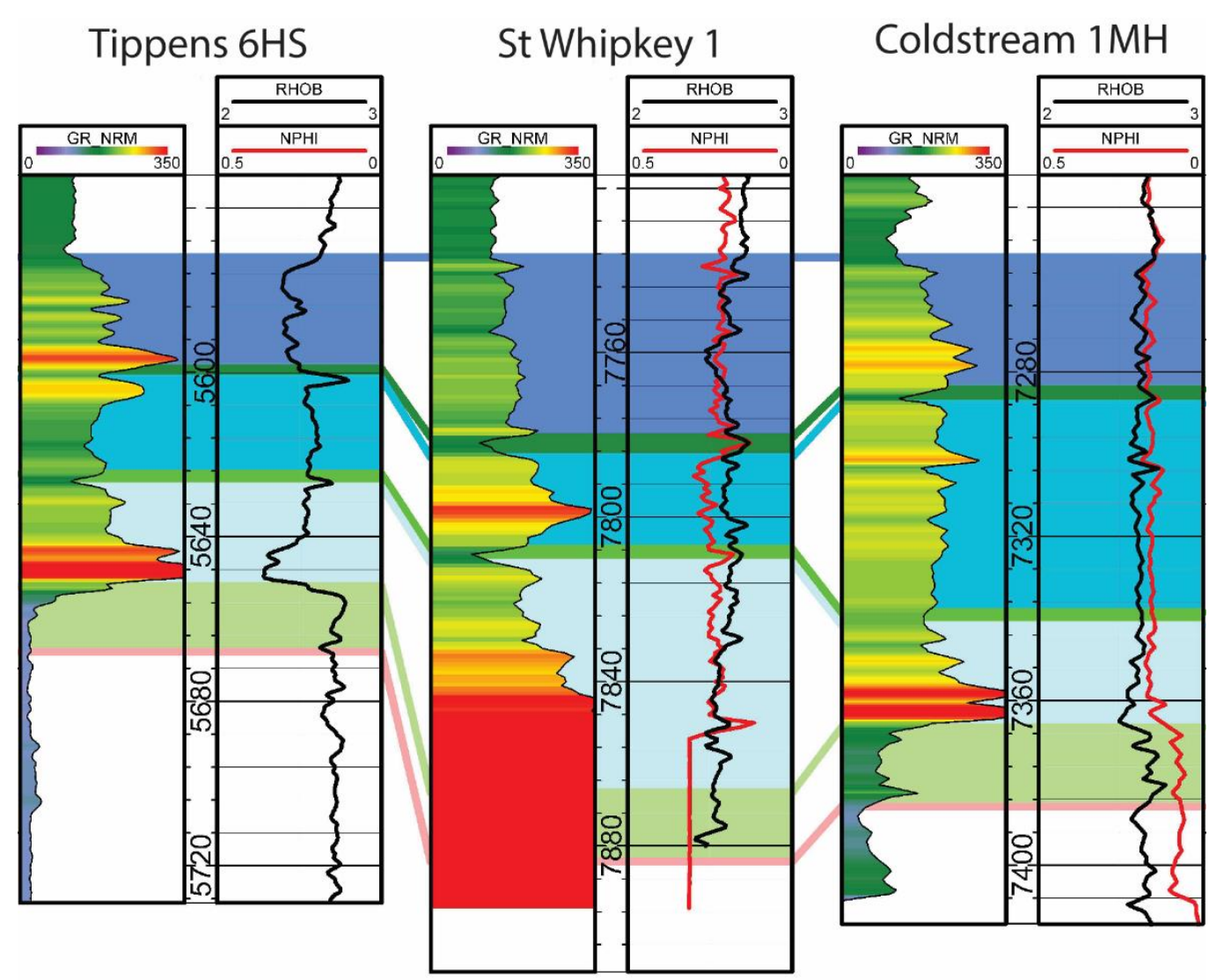

Figure 69. The outlier wells are represented by individual wells, without being correlated between one another. The Tippens 6HS is the most western well and the Coldstream 1MH is the most eastern. The St Whipkey 1 well is considered an outlier due to issues with data quality. 


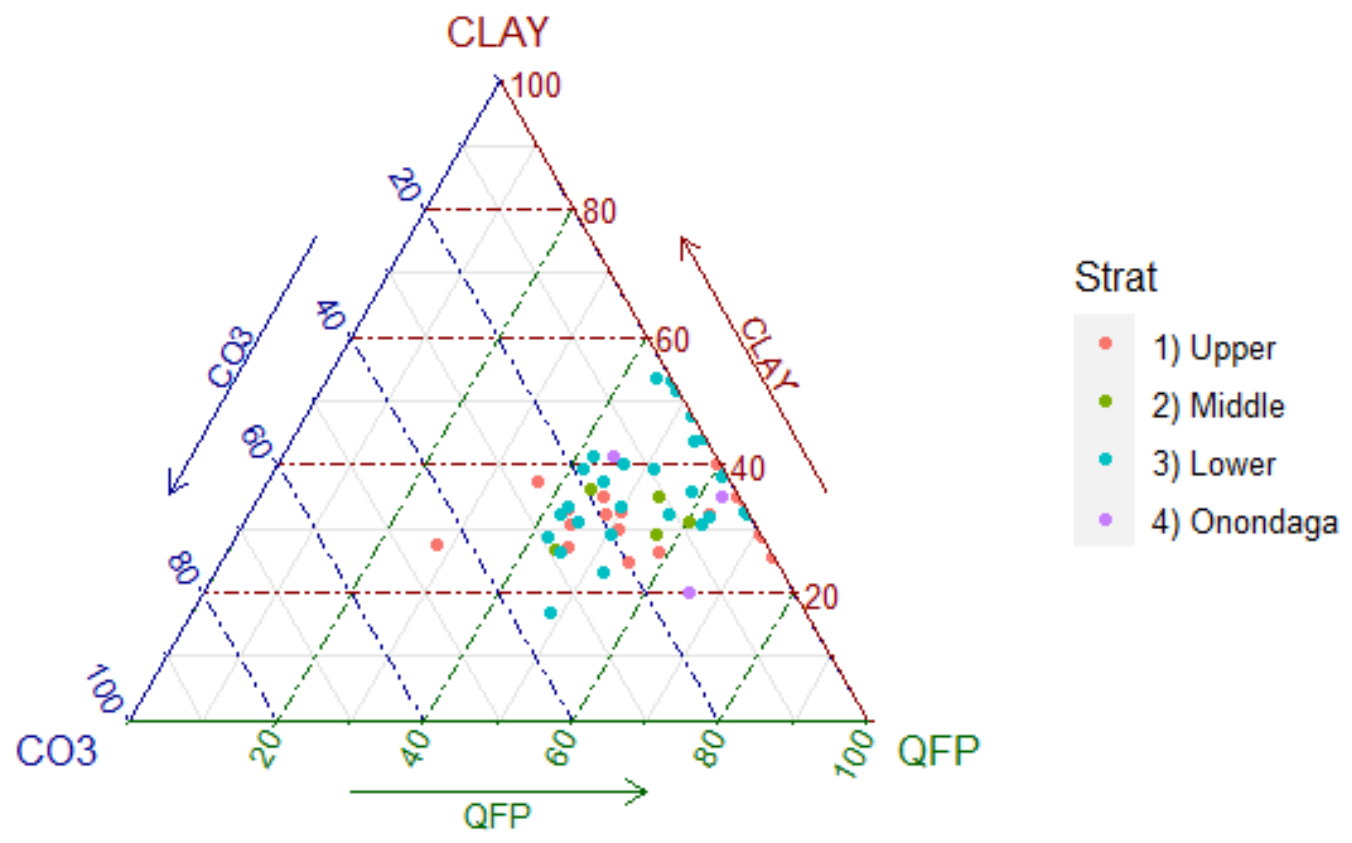

Figure 70. Tippens 6HS ELAN whole rock ternary diagram indicating lithological variation based on stratigraphy.

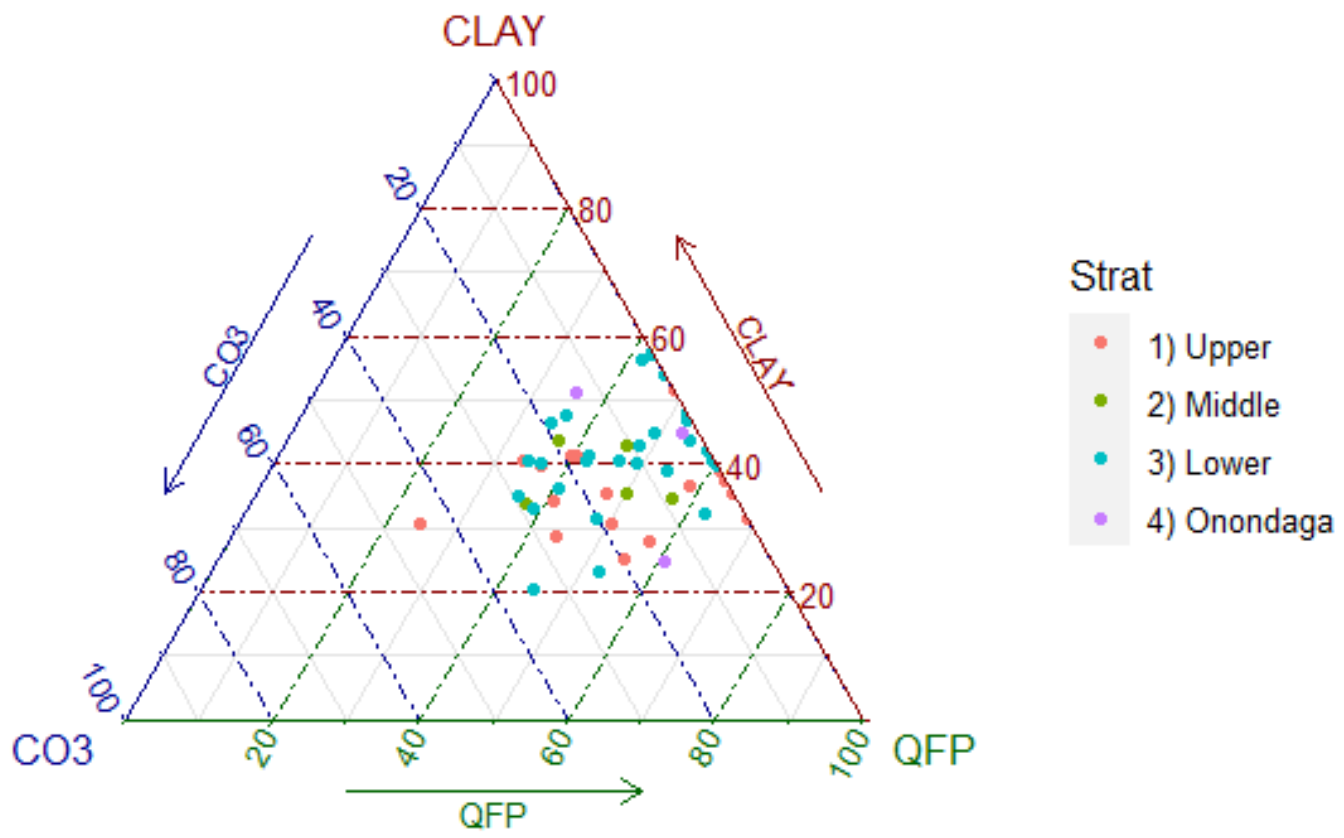

Figure 71. Tippens 6HS Spectroltih whole rock ternary diagram indicating lithological variation based on stratigraphy. 
The Tippens 6HS well (Figures 70 and 71) has the fewest data points to make interpretations from. It has inconsistent plotting, with the Onondaga formation lacking in CO3. Overall, it is hard to make interpretations of the data and would likely require a third source of data to determine composition.
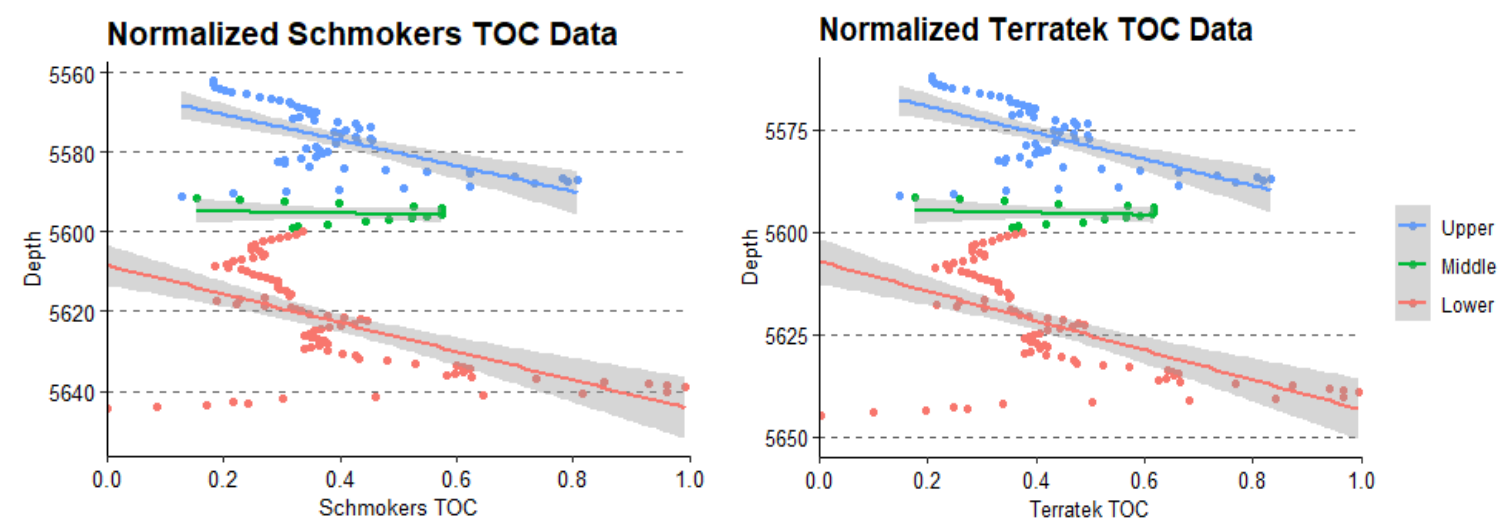

Figure 72. Tippens 6 HS TOC log data calculating TOC through both Schmoker's and Terratek methods.

Like the Coastal $1 \mathrm{H}$ and Armstrong 1 well, the Tippens 6HS well implements Schmoker's and Terratek to measure TOC (Figure 72). However, the measurements for both methods plot identical to one another like the Armstrong 1 well. The upper and lower sections exhibit steep trend lines, indicating an increase in TOC with depth. Like other wells, the confidence intervals at their widest when the measurements are higher. The middle section appears relatively stable, with nearly no change in TOC with depth. 


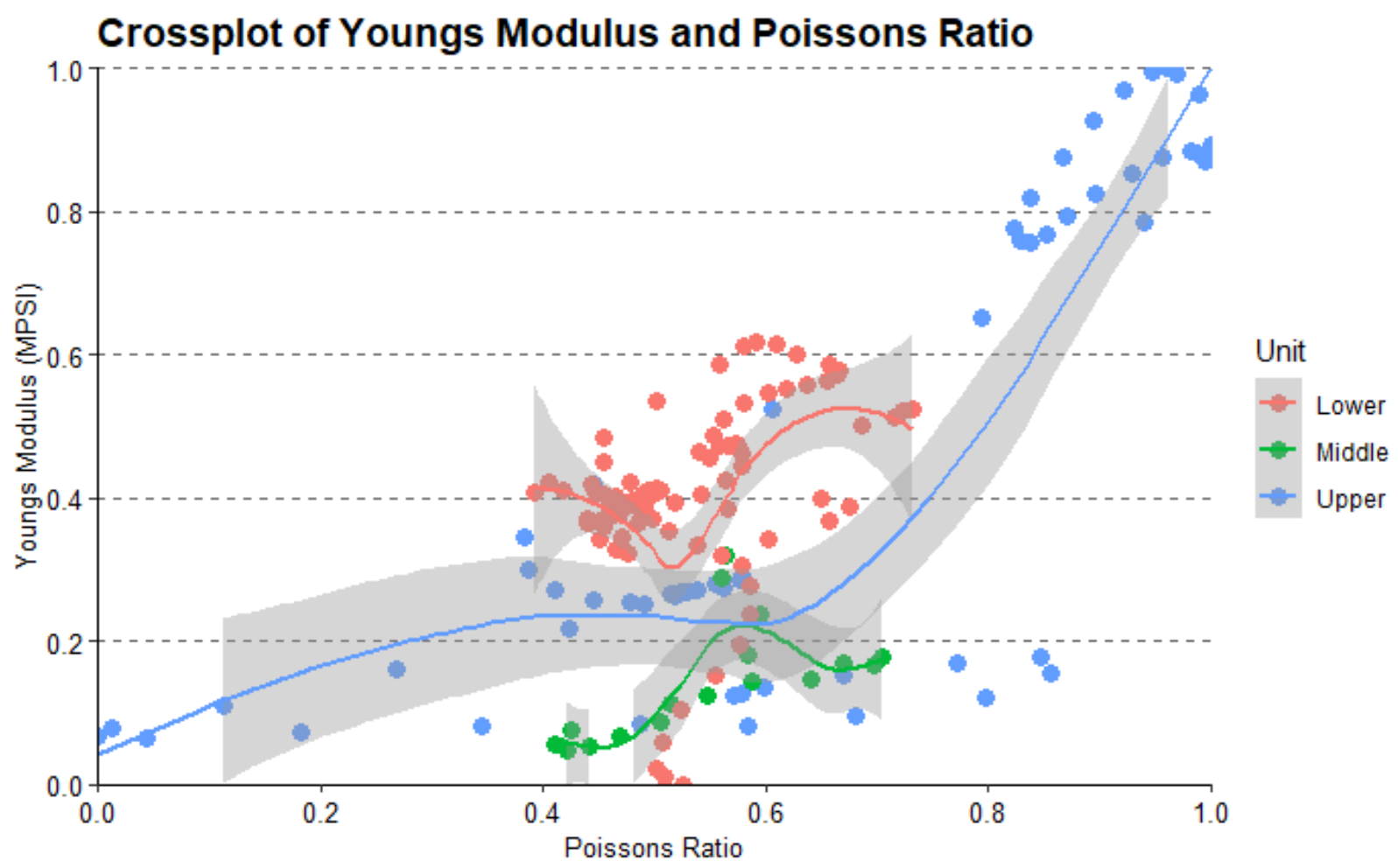

Figure 73. Tippens 6HS cross plot between Youngs Modulus and Poisson's Ratio with loess curves.

The Tippens 6HS well is the most unique of this set because it is the farthest west and the shallowest well (Figure 73). This is the only well where the loess curve of the middle unit is plotting beneath the upper unit. In fact, the upper unit seems to have data points spread inconsistently across the plot. A bit more than half of the data plots within the weak-brittle and weak-ductile quadrants, though a large cluster of data is within the strong-ductile quadrant. This is peculiar given how tight the lower- and upper-units plot, along with the similarity to their Loess Curves. Both exhibit troughs at about 0.5 and peaks at about 0.6 along the $\mathrm{X}$ axis. 


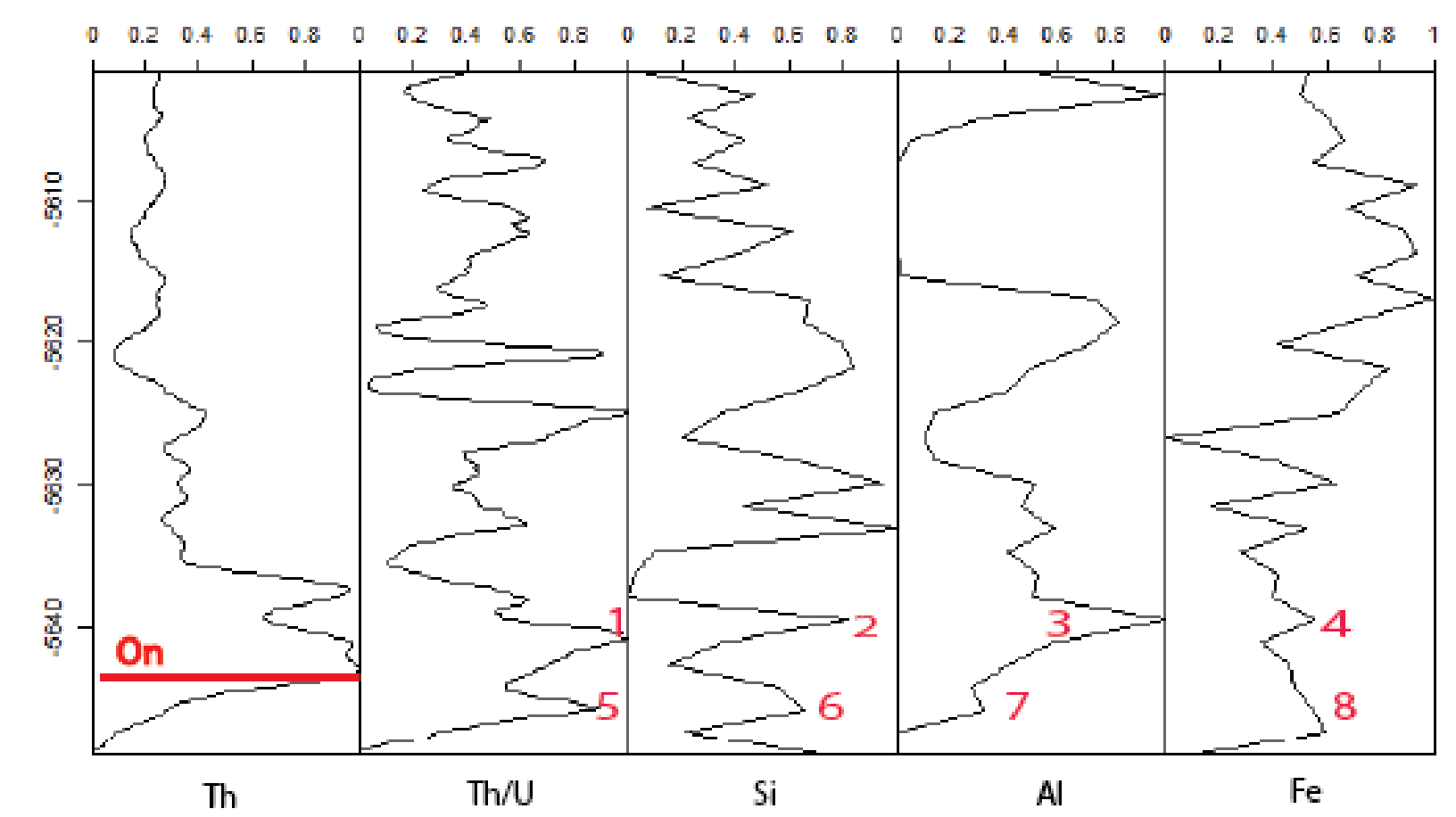

Figure 74. Tippens 6HS spectral and Elan well logs with peaks marked that may indicate the presence of ash beds. There are 8 notable peaks found within the Tippens 6HS well, occurring in two sets (Figure 74). Peaks 1 through 4 occurs right above the Onondaga Formation contact while peaks 5 through 8 occur right beneath the contact. Both sets of peaks exhibit similar levels of Si and Fe, with a difference of 0.6 in the $\mathrm{Al} \log$. 


\section{Appendix 2: Lithofacies Classification}

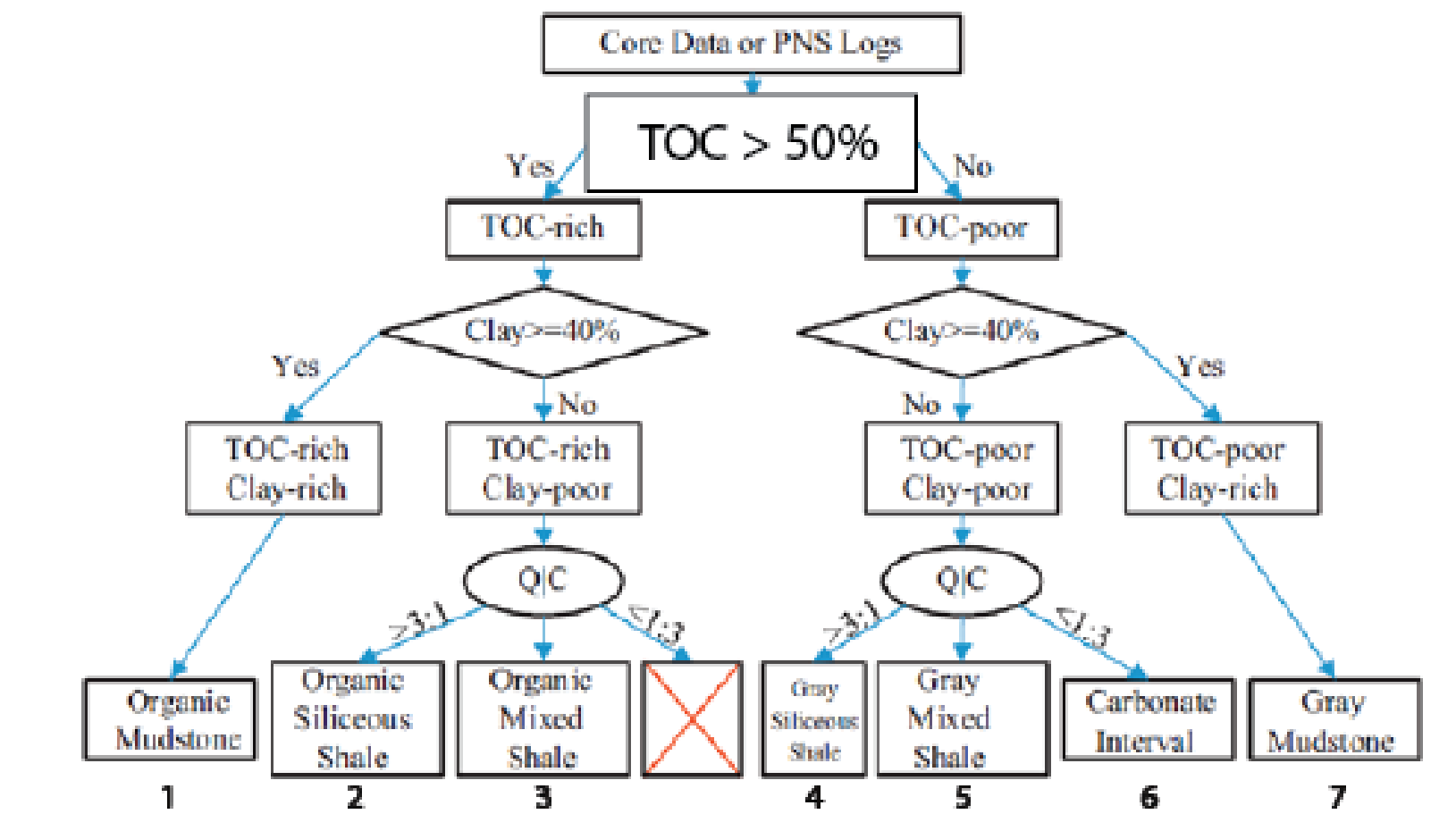

Figure 75. Shale lithofacies classification workflow modified from Wang and Carr, 2012. Total organic carbon (TOC) richness is considered above 50\% (through a min-max normalization), while originally $6.5 \%$ of the raw data. 
Figure 76. Shale lithofacies classification from log data, based on figure 70, separated into 4 sections.

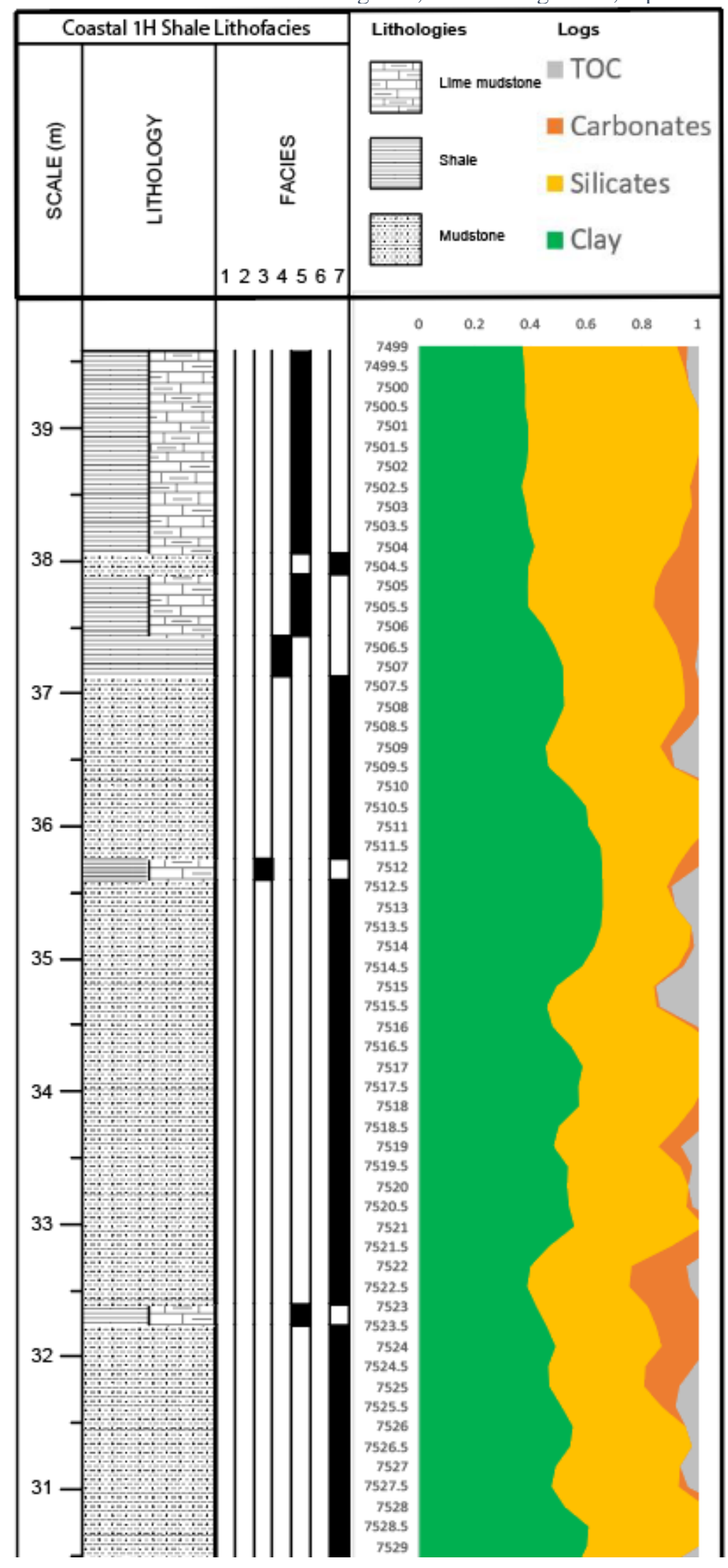




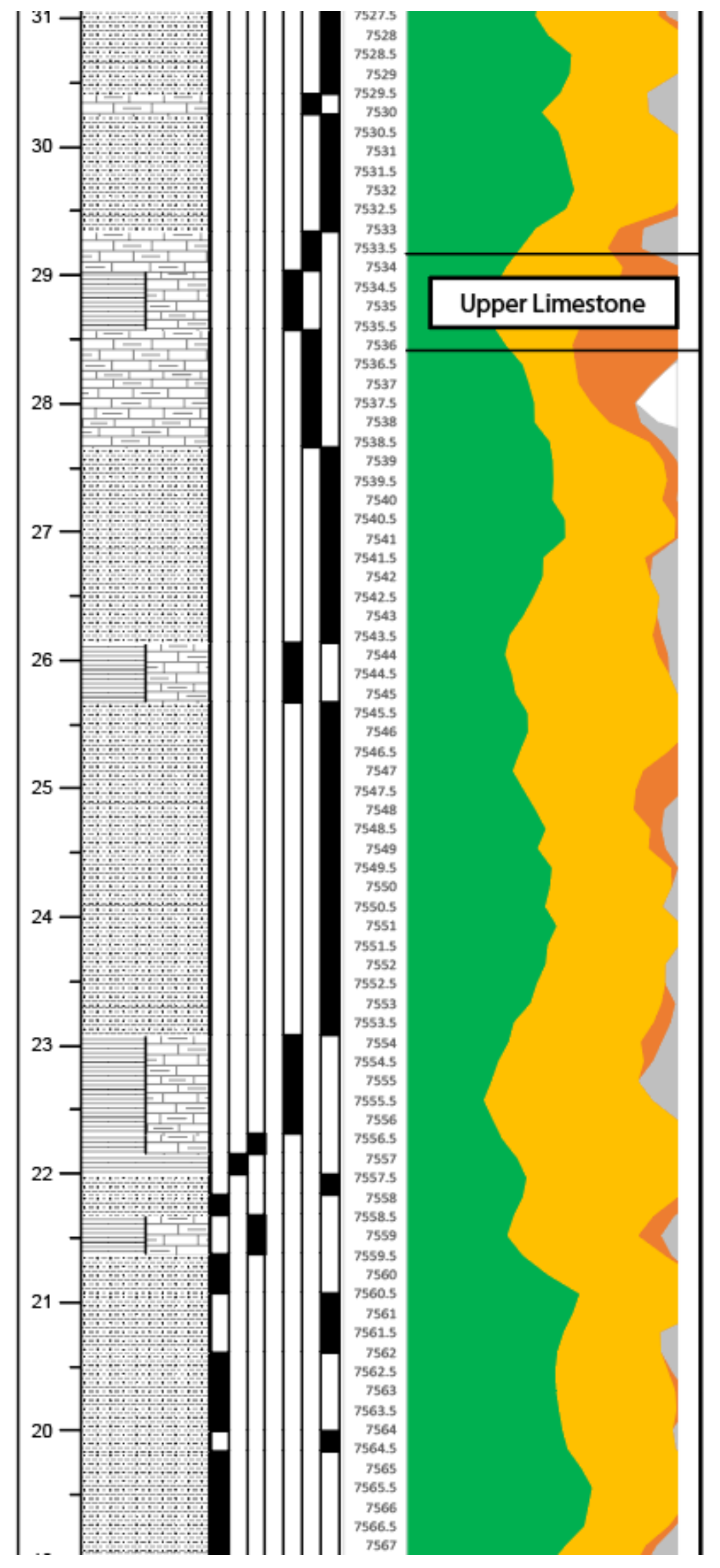




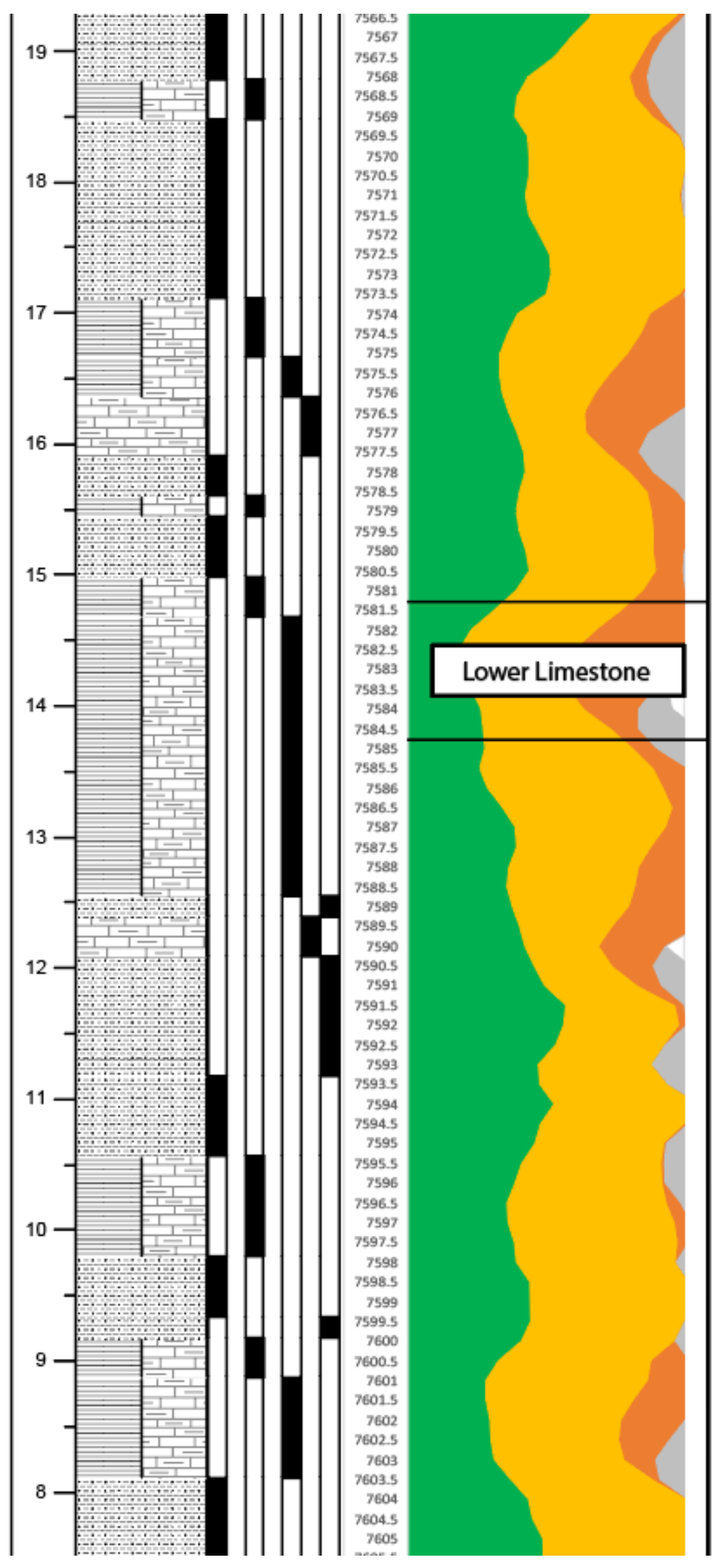




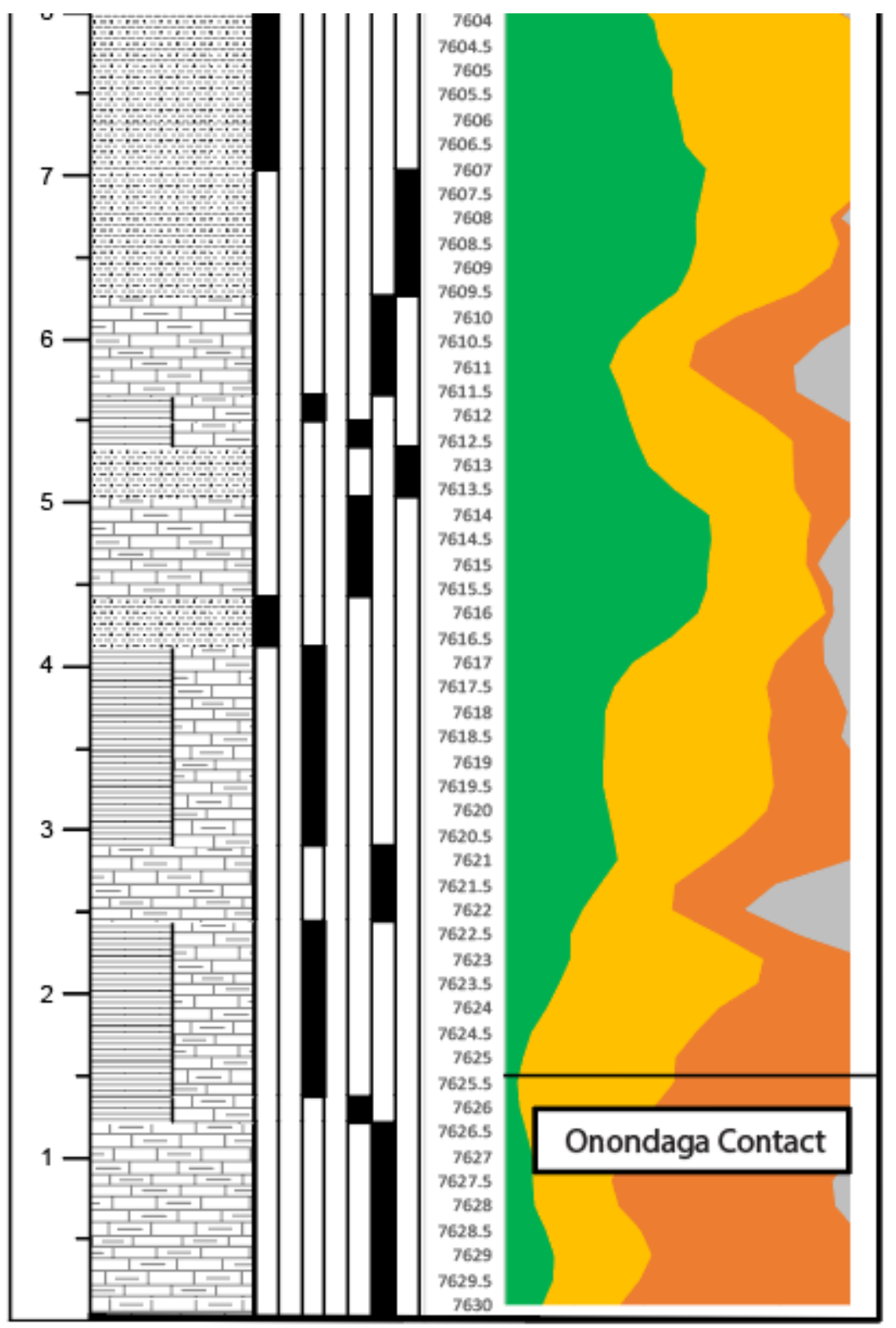




\section{Appendix 3: Core and Thin Section Observations}
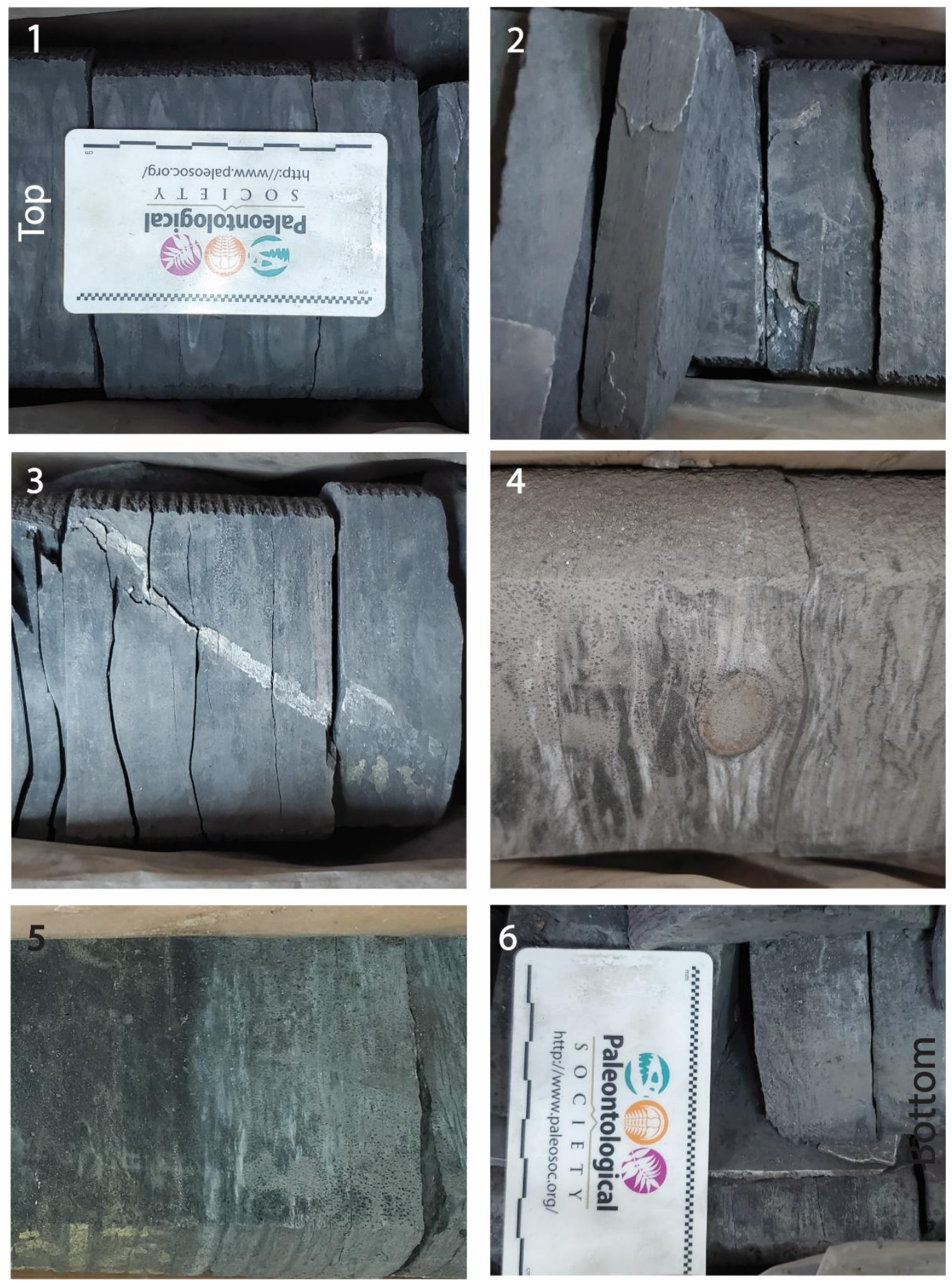

Figure 77. Photos of features from the rock core of the upper Marcellus. Image 1 was taken at a depth of $7510 \mathrm{ft}$. Image 2 was taken at a depth of $7517 \mathrm{ft}$. Image 3 was taken at a depth of $7520 \mathrm{ft}$. Image 4 was taken at a depth of $7524 \mathrm{ft}$. Image 5 was taken at a depth of $7532 \mathrm{ft}$. Image 6 was taken at a depth of $7535 \mathrm{ft}$. 

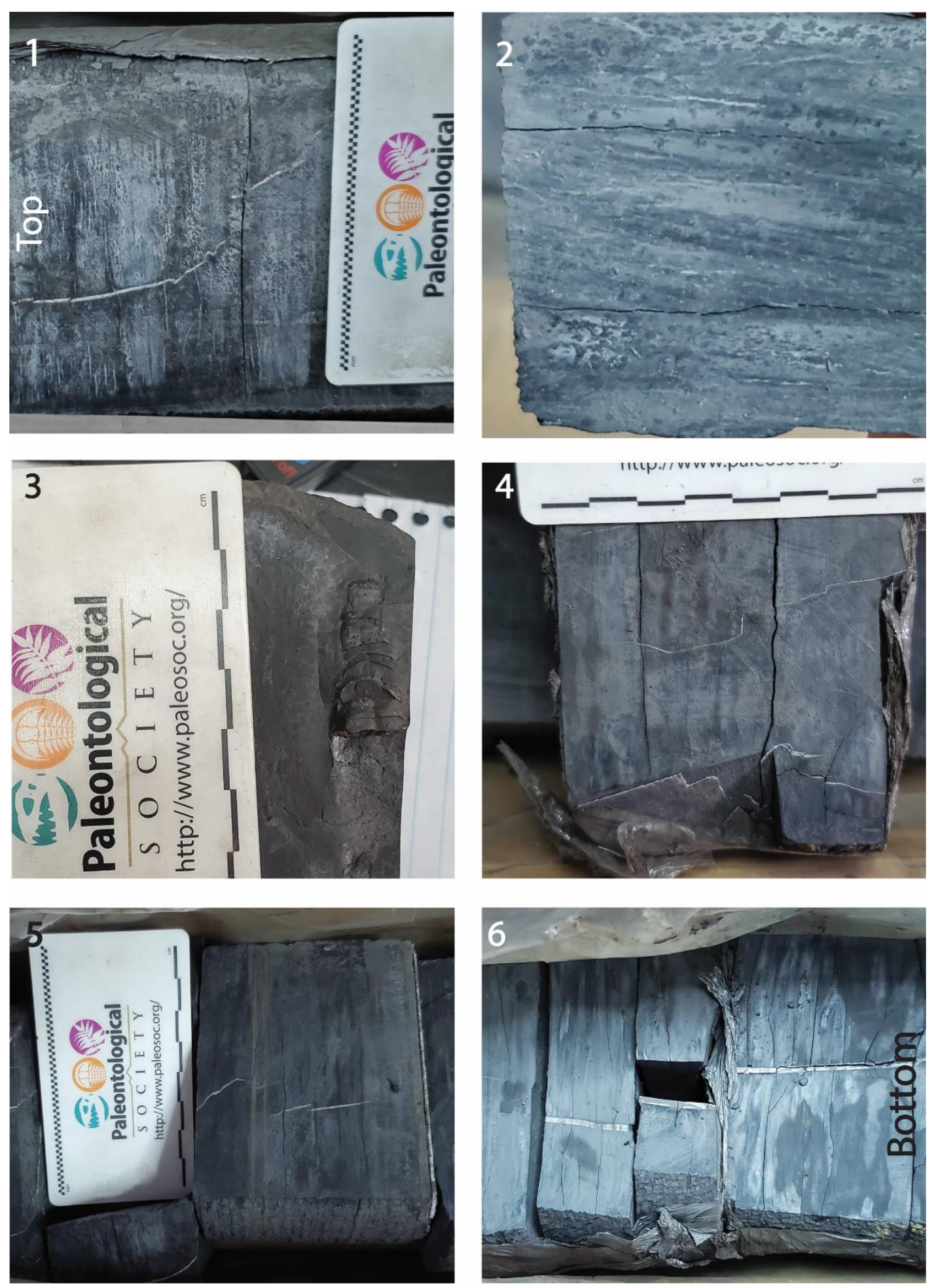

Figure 78. Photos of features from the rock core of the middle Marcellus. Image 1 was taken at a depth of $7545 \mathrm{ft}$. Image 2 was taken at a depth of $7547 \mathrm{ft}$. Image 3 was taken at a depth of $7557 \mathrm{ft}$. Image 4 was taken at a depth of $7561 \mathrm{ft}$. Image 5 was taken at a depth of $7562 \mathrm{ft}$. Image 6 was taken at a depth of $7570 \mathrm{ft}$. 

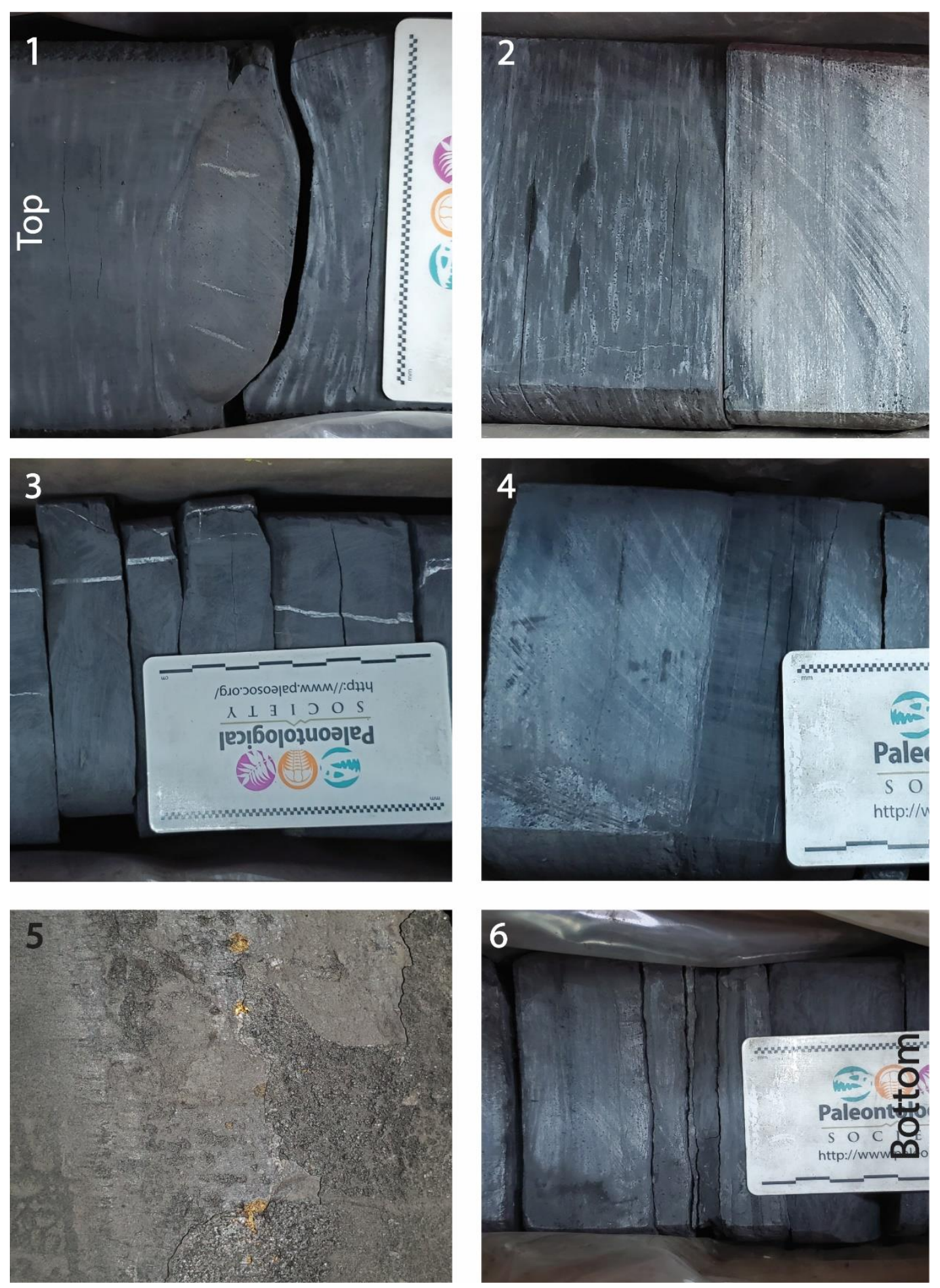

Figure 79. Photos of features from the rock core of the lower Marcellus. Photos of features from the rock core of the middle Marcellus. Image 1 was taken at a depth of $7585 \mathrm{ft}$. Image 2 was taken at a depth of $7613 \mathrm{ft}$. Image 3 was taken at a depth of $7621 \mathrm{ft}$. Image 4 was taken at a depth of $7625 \mathrm{ft}$. Image 5 was taken at a depth of $7627 \mathrm{ft}$. Image 6 was taken at a depth of $7629 \mathrm{ft}$ 

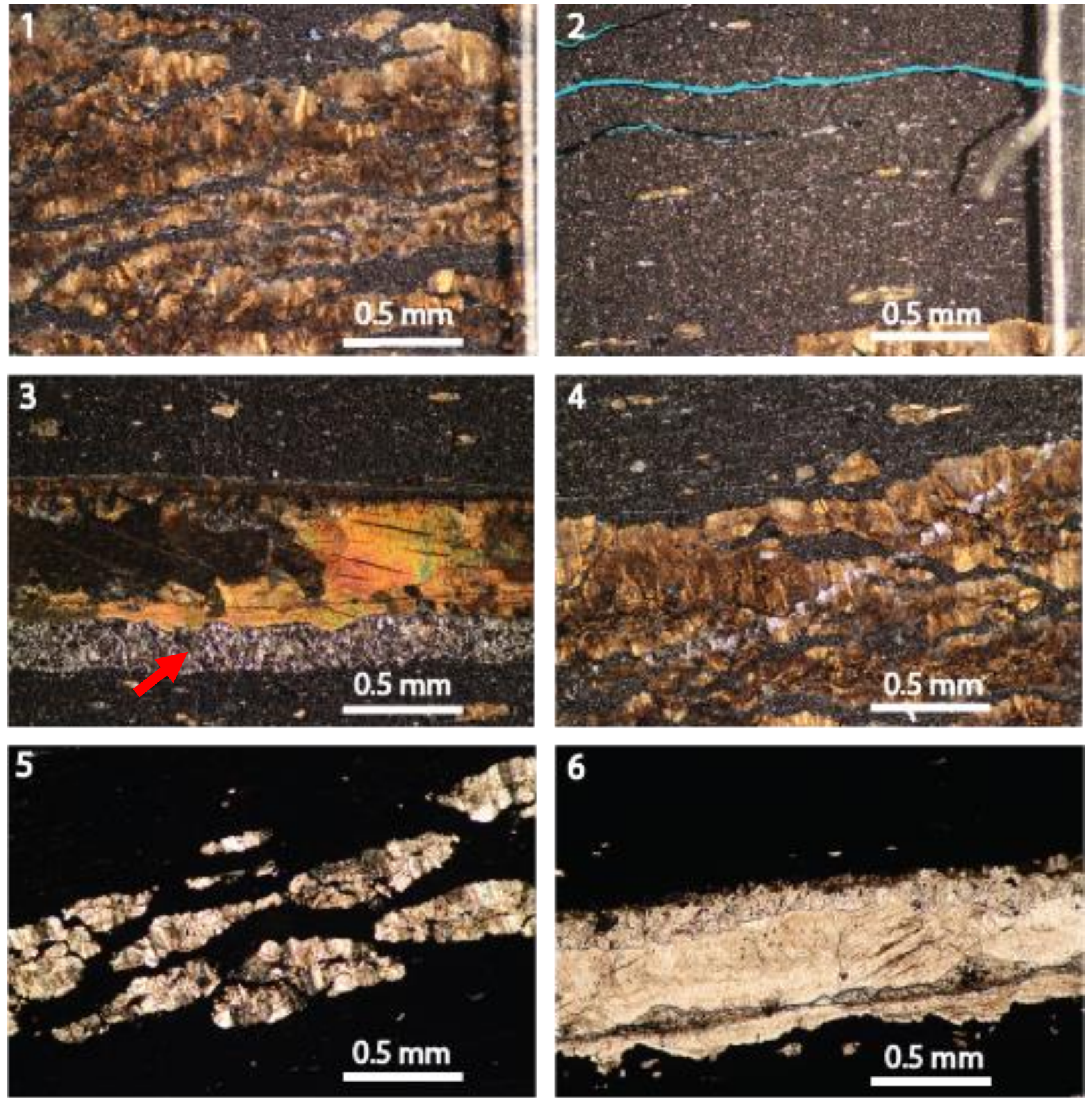

Figure 80. Thin Section A1, taken at a depth of 7515 feet. These thin sections show interbedded layers of clay shale and calcite. Image one is of interbedded calcite and clay, with thin horizontal fractures occurring between these layers. Image 2 is of a shale rich layer just above image 1, which shows larger horizontal fractures. Image 3 is of a calcite filled layer under cross polarized light, with what appears to be a layer of gypsum beneath it (indicated by a red arrow). Like image 1, image 4 shows interbedded calcite and clay, with thin horizontal fractures or laminations. With reflective light turned off, images 5 and 6 show calcite features, 5 being broken apart and 6 uniform. The differences between these images could be related to bioturbation. 

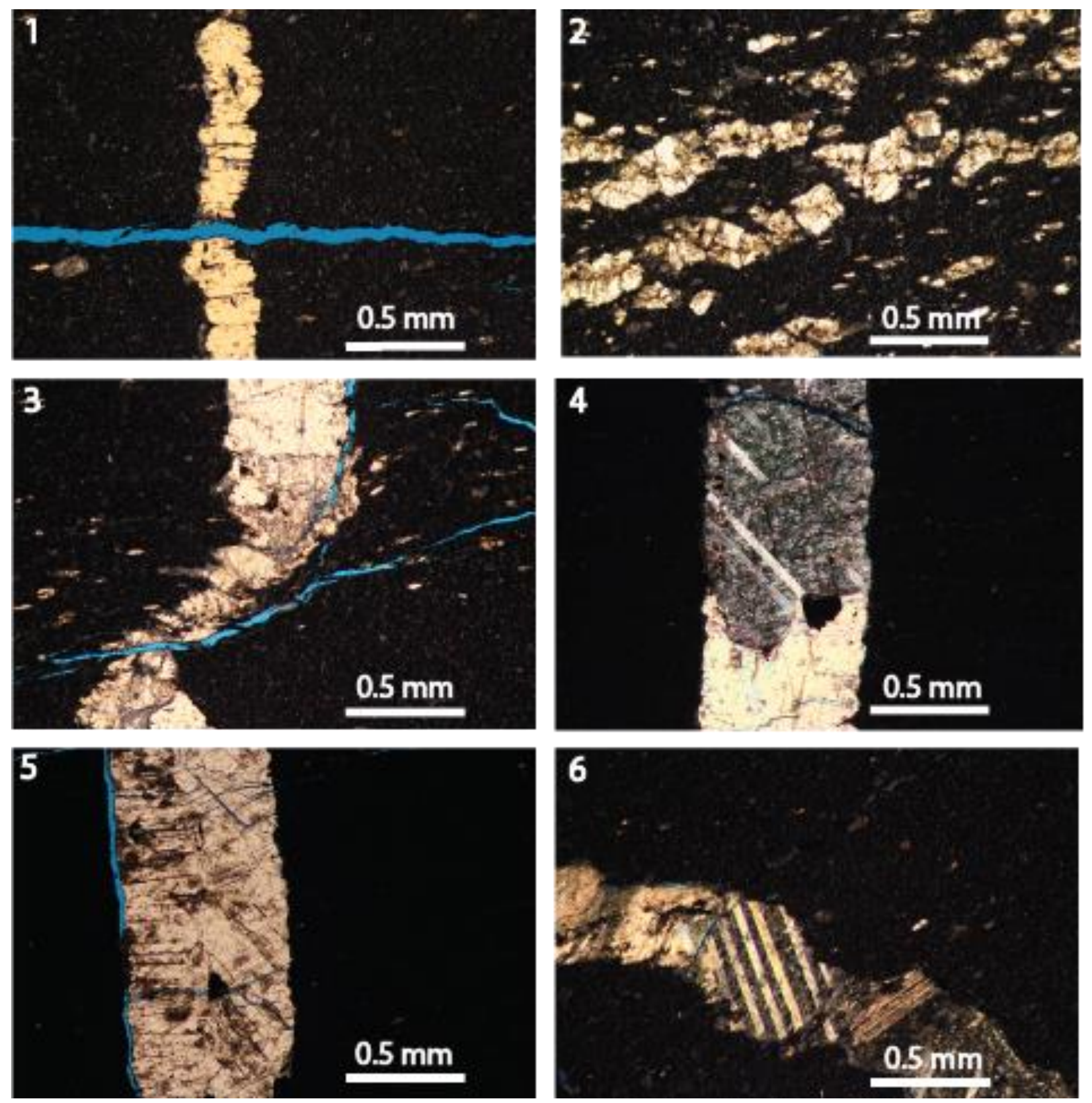

Figure 81. Thin Section A2, taken at a depth of 7563 feet. The first image is of a vertical calcite filled fracture cut across by an open horizontal fracture. The second image is of mixed shale and calcite grains, with minor amounts of pyrite. The third image shows a vertical calcite filled fracture with both horizontal and vertical open fractures within it. Though the vertical open fracture does not cut through the calcite. Under cross polarized light, the fourth image displays calcite twinning. It also consists of calcite grains and fossils on either side of the filled fracture. The fifth image is of a vertical calcite filled fracture, that has a vertical unfilled fracture running along its left side. More unfilled fractures can be seen within the crystalline structure. Lastly, the sixth image shows a somewhat horizontal calcite filled fracture, with twinning present. 

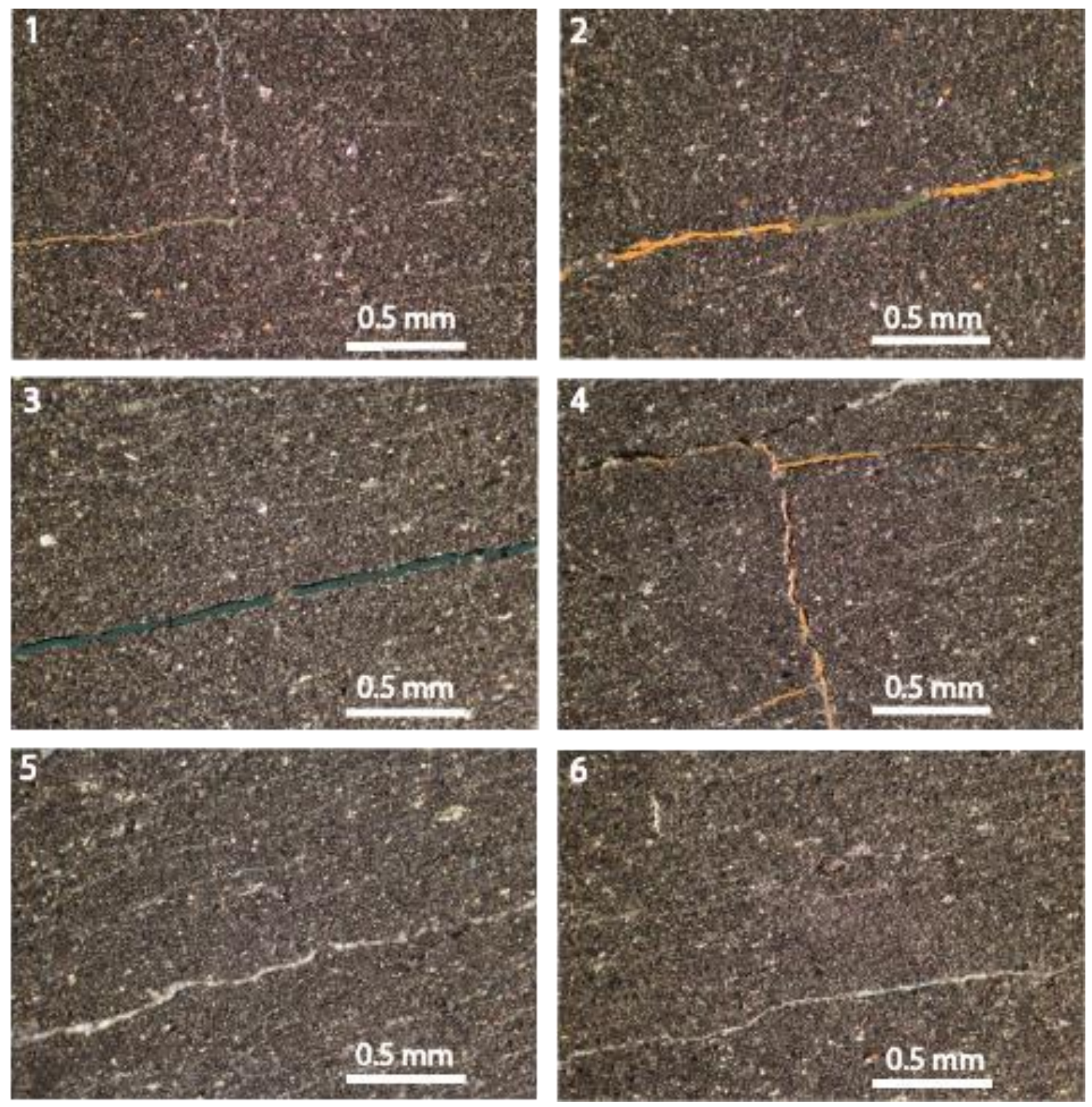

Figure 82. Thin Section A3, taken at a depth of 7570 feet. Images one through six are similar, though each show variations in fracturing. Within this thin section, very thin horizontal mineral filled fractures are present, with thicker unfilled ones occurring sporadically. These large unfilled fractures can be horizontal (image 3) or vertical. Images 5 and 6 may be of fractures, though it's possible they are thin laminations of silt. 

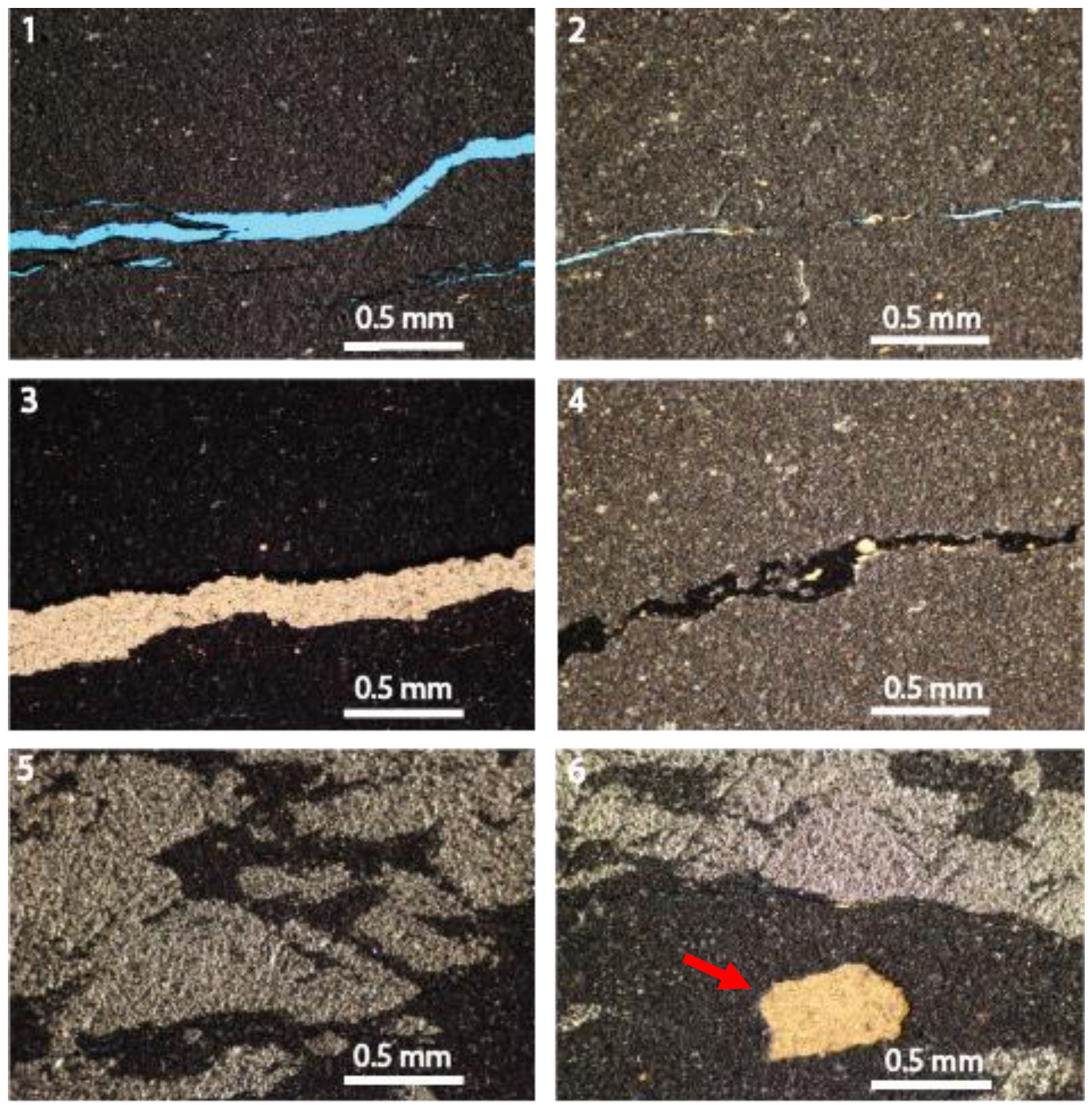

Figure 83. Thin Section A4, taken at a depth of 7572 feet. Just beneath thin section A3, the fractures occurring in this thin section are much larger. Predominantly these fractures are horizontal, and mineral filled though sporadic unfilled fractures are present. Image 3 shows a filled horizontal fracture, which may consist of fine-grained quartz. Images 5 and 6 show two minerals, one is presumed to be gypsum and an arrow points to what is possibly finegrained quartz. 

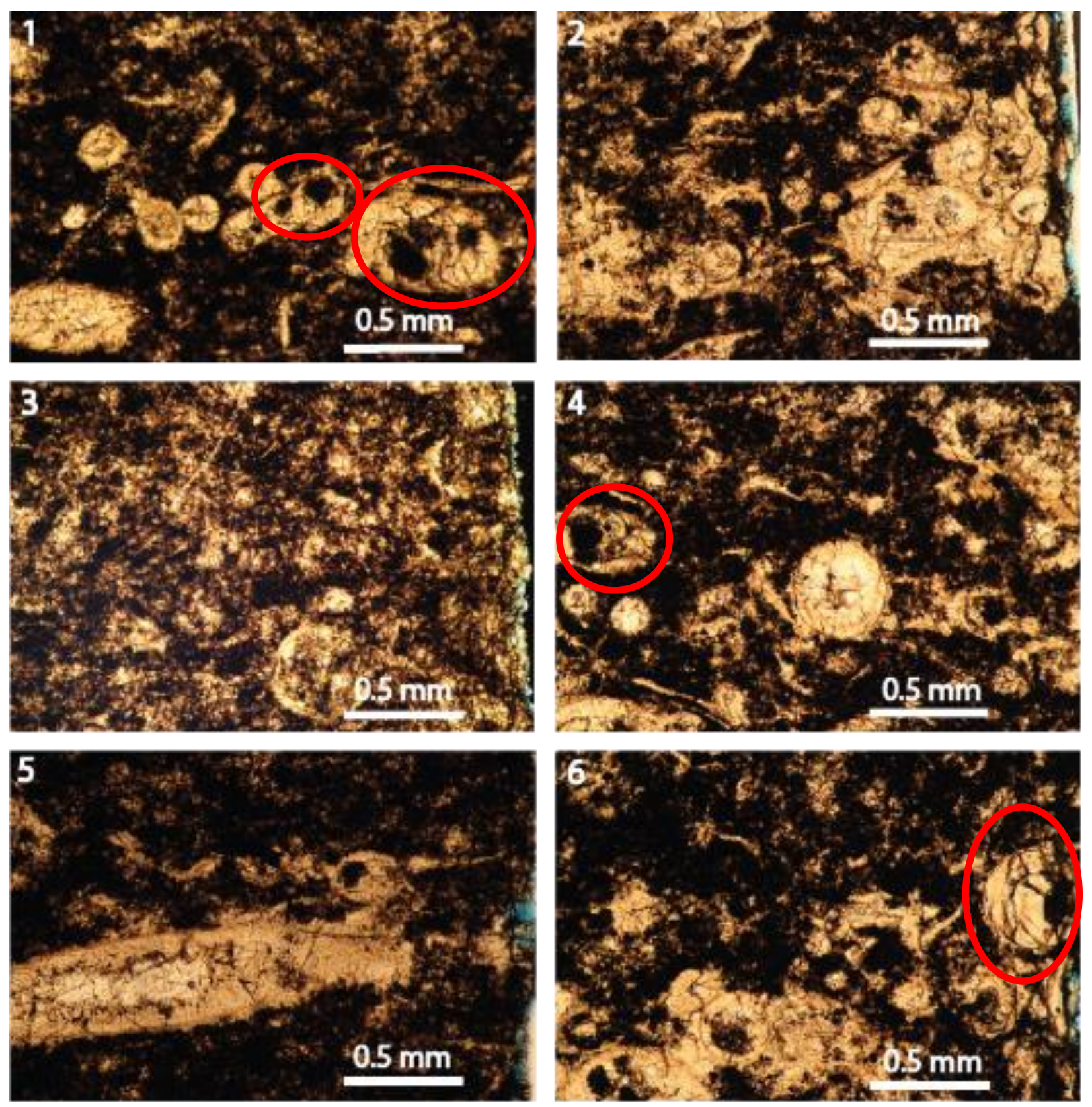

Figure 84. Thin Section B1, taken at a depth of 7613 feet. Images one through six are of various fossils and structures found throughout the thin section. Skeletal grains are abundant, mixed sporadically within the shale matrix. Shell fragments are often attributed to being the remains of mollusks. Image 1 shows red circles encompassing fossil grains with partial pyritization. Some of the circular skeletal grains found in images 2, 3, and 4 may be bryozoan. Image 3 shows an abundance of calcite grains. Image 5 is of a large conical skeletal grain, which may be a sponge spicule. In image 6, a red circle outlines the partial remains of skeletal fragment which resemble cephalopods or gastropods. 

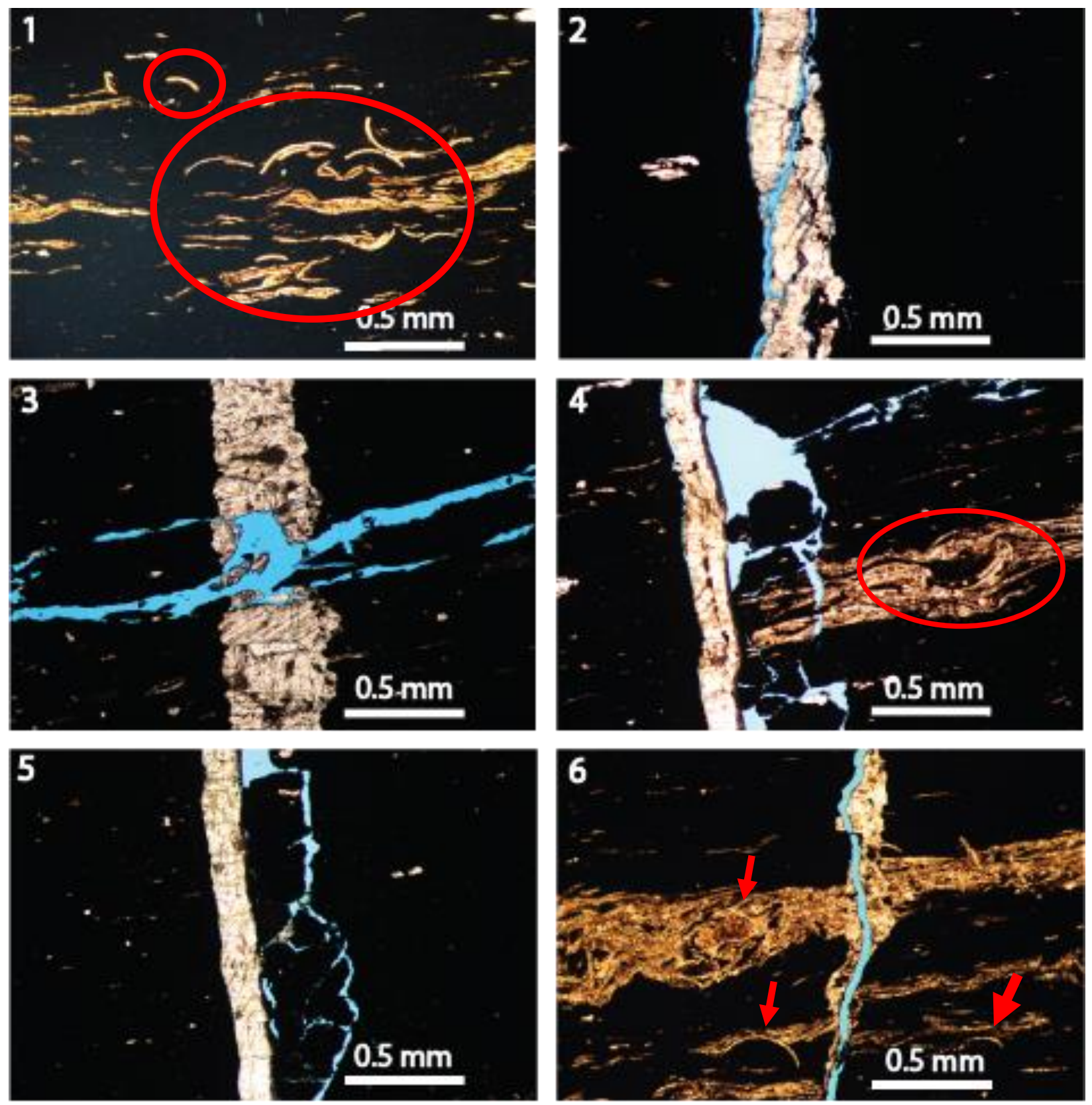

Figure 85. Thin Section B2, taken at a depth of 7622 feet. These images are of skeletal grains, unfilled and filled fractures. Image one is of skeletal grains like shell fragments (indicated by red circles) intermixed amongst the shale matrix. Some of the shell fragments exhibit features like that of mollusks. Image two shows multiple vertical fractures occurring within one larger calcite filled fracture. Like image 2, image 3 is of horizontal unfilled fractures cutting across a vertical mineral filled fracture. Image 4 consists of the vertical fracture intersecting with a layer of shell fragments, with large open pore spaces. Image 5 shows unfilled fractures occurring parallel to the calcite filled fracture. The last image is of an open fracture cutting through horizontal layers of skeletal fragments. 

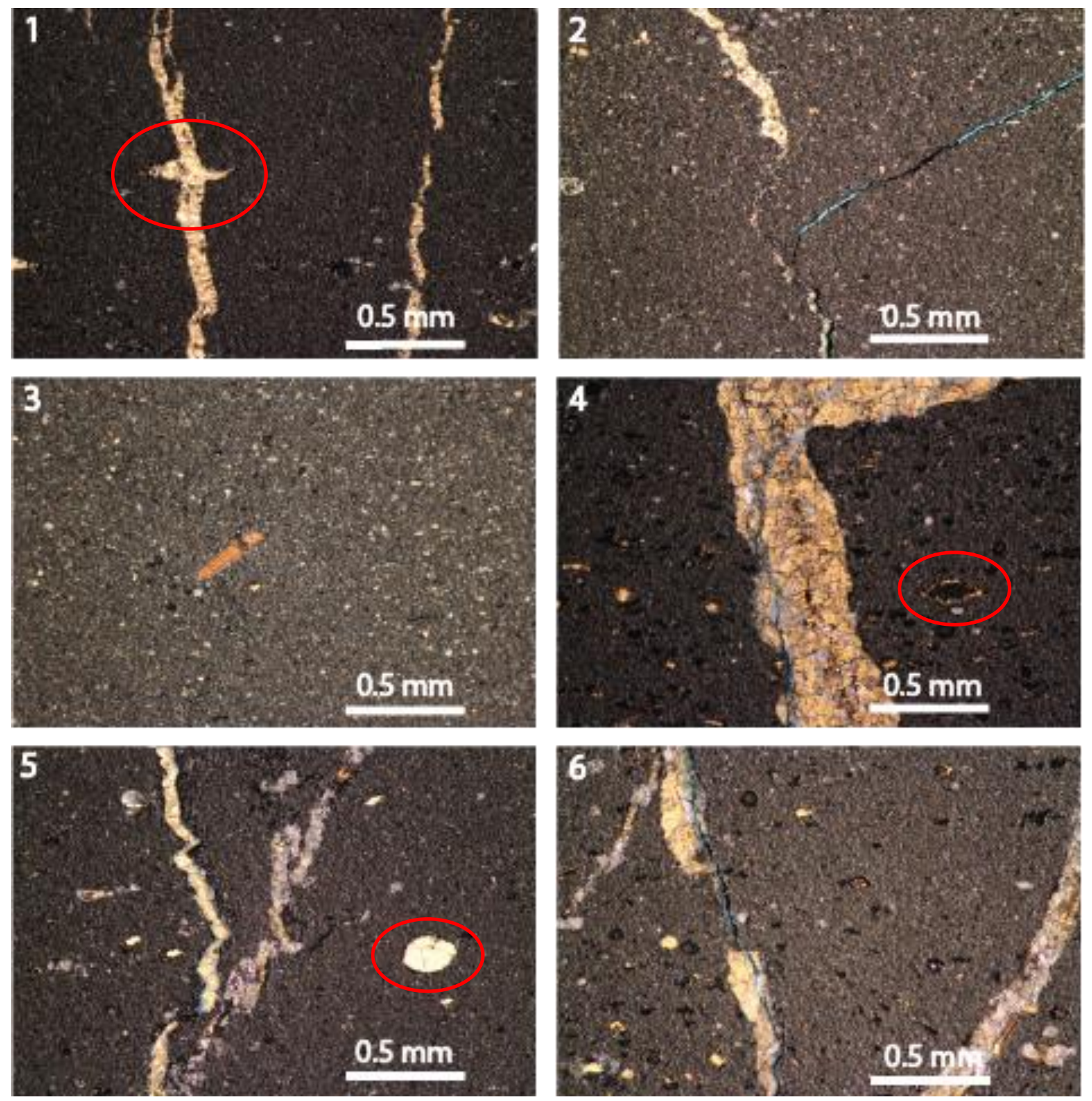

Figure 86. Thin Section B3, taken at a depth of 7626 feet. The first image is of two vertical calcite filled fractures, circled in red is a calcite lens along the filled fracture. The second image is of a vertical, calcite filled fracture which connects with a diagonal unfilled fracture. The third image is of a crystalline grain, possible fossiliferous. Image 4 is a calcite filled fracture which exhibits a nearly 90 degree turn from horizontal to vertical. There is a thin unfilled fracture within the filled fracture. The red circle indicates the location of mineral replacement, possible of a calcite grain. Images 5 and 6 are of two vertical fractures which are filled with different minerals. The mineral on the left is filled with calcite, is disconnected often, and has an unfilled fracture within it or alongside it. The fracture on the right appears to consist of fine quartz grains and minor amounts of calcite. 

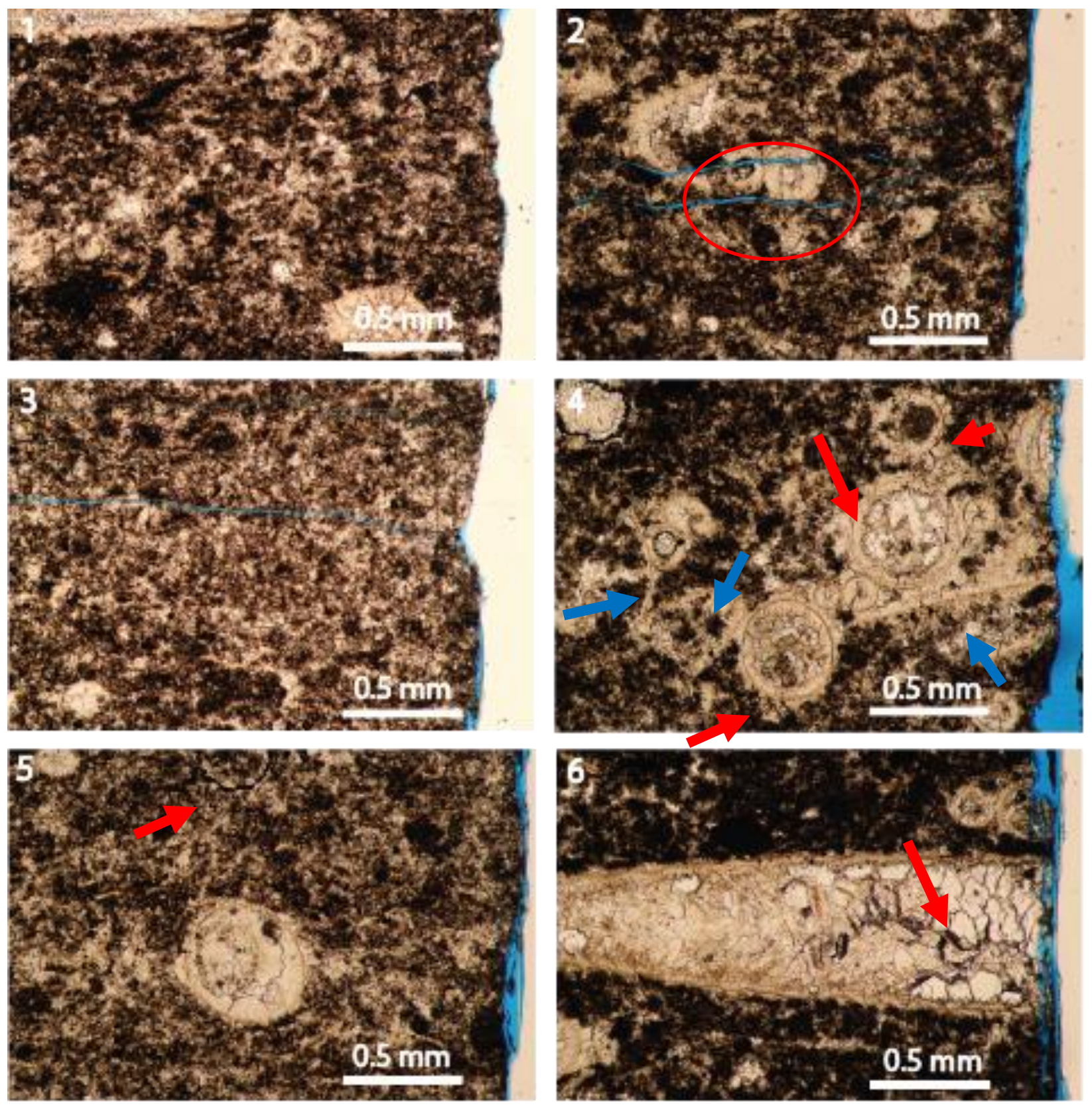

Figure 87. Thin Section B4, taken at a depth of 7628 feet. Each of the images in this thin section show an abundance in skeletal remains and calcite grains. Organic content and pyrite are present within the skeletal grains and matrix. Horizontal, unfilled fractures occur within images 2 and 3, with the fractures of image 2 cutting across crinoid fossils (circled in red). Image 4 shows multiple circular shell fossils (red arrows), possibly of algae or bryozoans. Shell fragments (blue arrows) seem to occur as well amongst the circular fossils, possibly mollusks or spinocyrtia. Image 5 is of a single shell fossil. Image 6 consists of a fossilized tentaculites, with mineral replacement indicated by an arrow. 

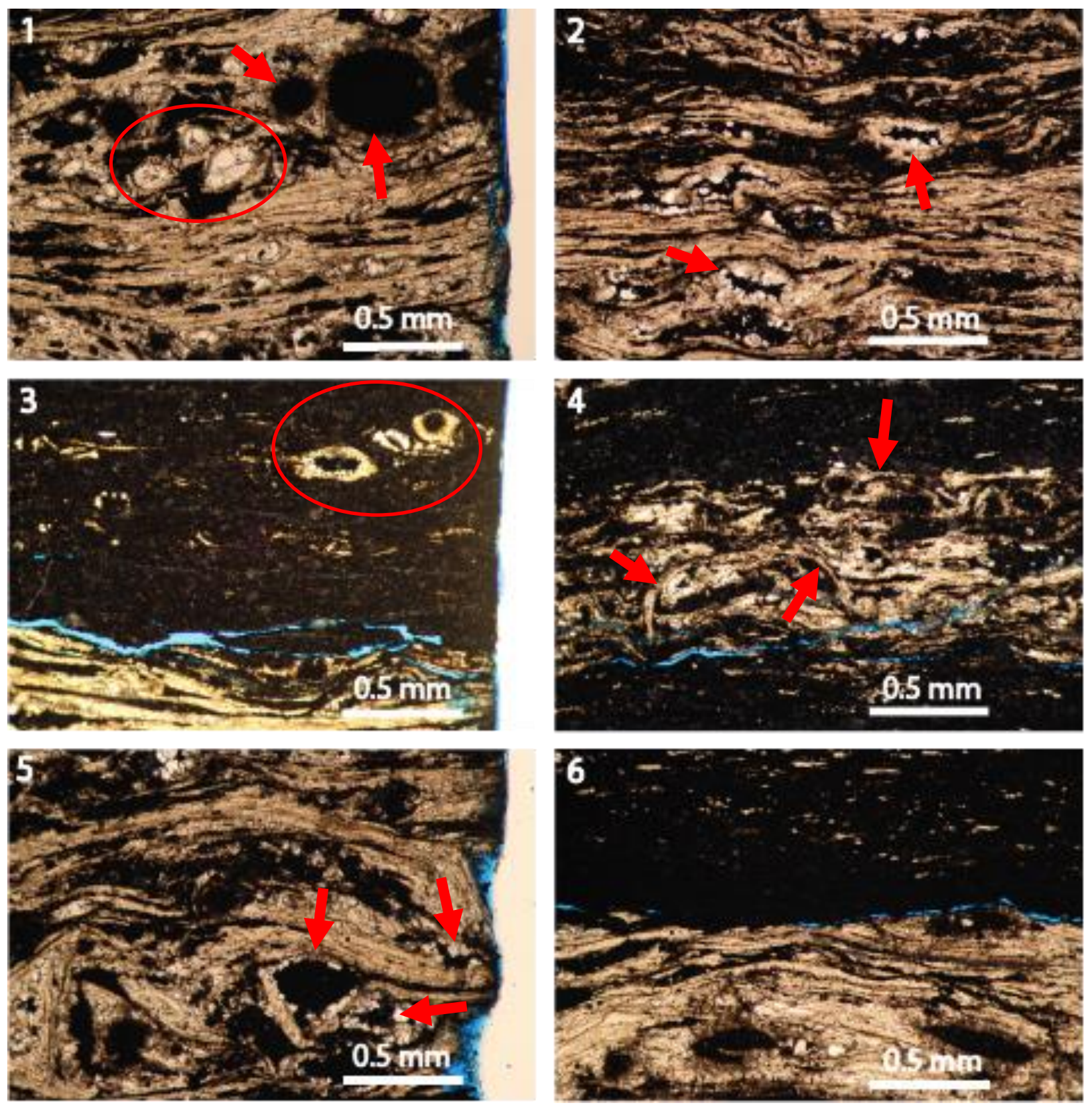

Figure 88. Thin Section B5, taken at a depth of 7630 feet. The images of this set are of layered carbonate and organic shales, with skeletal fragments present. In image one, skeletal fragments are outlined by a red circle and large opaque circles are pointed to by red arrows. Image 2 consists of layered calcite, with arrows pointing to opaque areas where minerals have precipitated. Image 3 consists of a shale layer, with an open fracture separating it from a calcite layer. There are three grains circled in red which resemble skeletal grains. Thin laminations occur in image 4, they resemble shell fragments and are pointed to by red arrows. Like image 2, image 5 shows more of the of the opaque areas with crystallization occurring on the outside edge. Lastly, image 6 shows the contact between a shale and calcite layer with an open fracture separating the two layers. 


\section{MIP3H Thin Sections}

Thin sections were also prepared from the MIP3H well. These thin sections were derived from core plugs taken within the well bore. There are three thin sections, each exhibiting unique features from one another. A-68 is of a dark shale with a pyrite band across it. The next thin section, B-98 represents a fossiliferous shale, with abundant carbonate grains present. Lastly, C108 is the deepest thin section, taken after the largest spike in gamma radiation of the lower Marcellus Formation. C-108 seems to represent a calcite rich section of the well. 

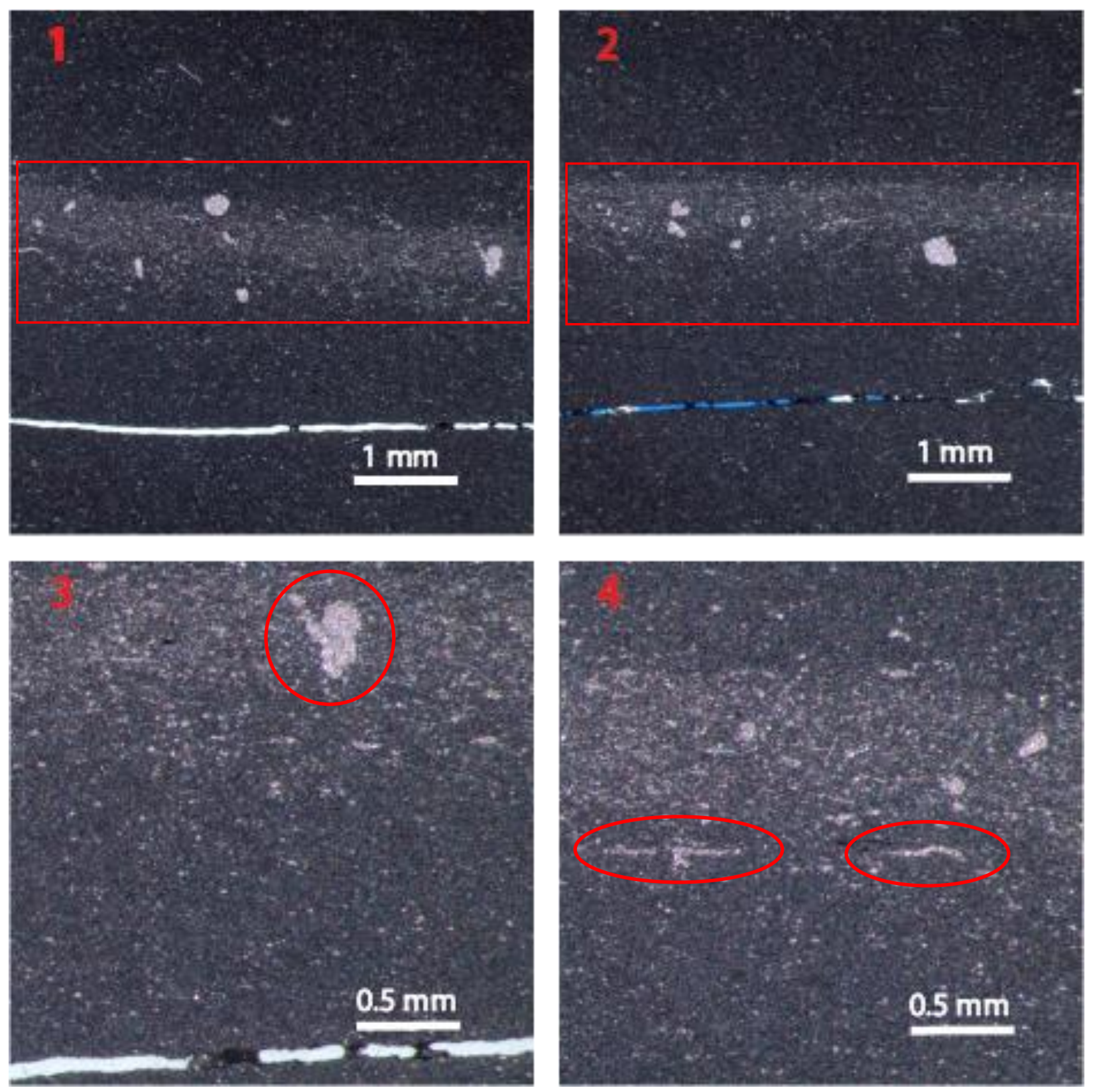

Figure 89. Thin section A-68, taken at a depth of $7512 \mathrm{Ft}$. This thin section shows a light-colored band, containing pyrite and the shapes of skeletal grains (images 1 and 2). Fractures are filled with calcite cement and clay sized grains (opaque grains in fracture). Most of the rock is composed of indiscernible clay sized grains. Image 3 has a large pyrite grain; irregular shape seems to suggest it formed from precipitation. Image 4 is of thin pyrite laminations, that resemble the shape of shell fragments. This would suggest that the original materials been replaced by pyrite. 

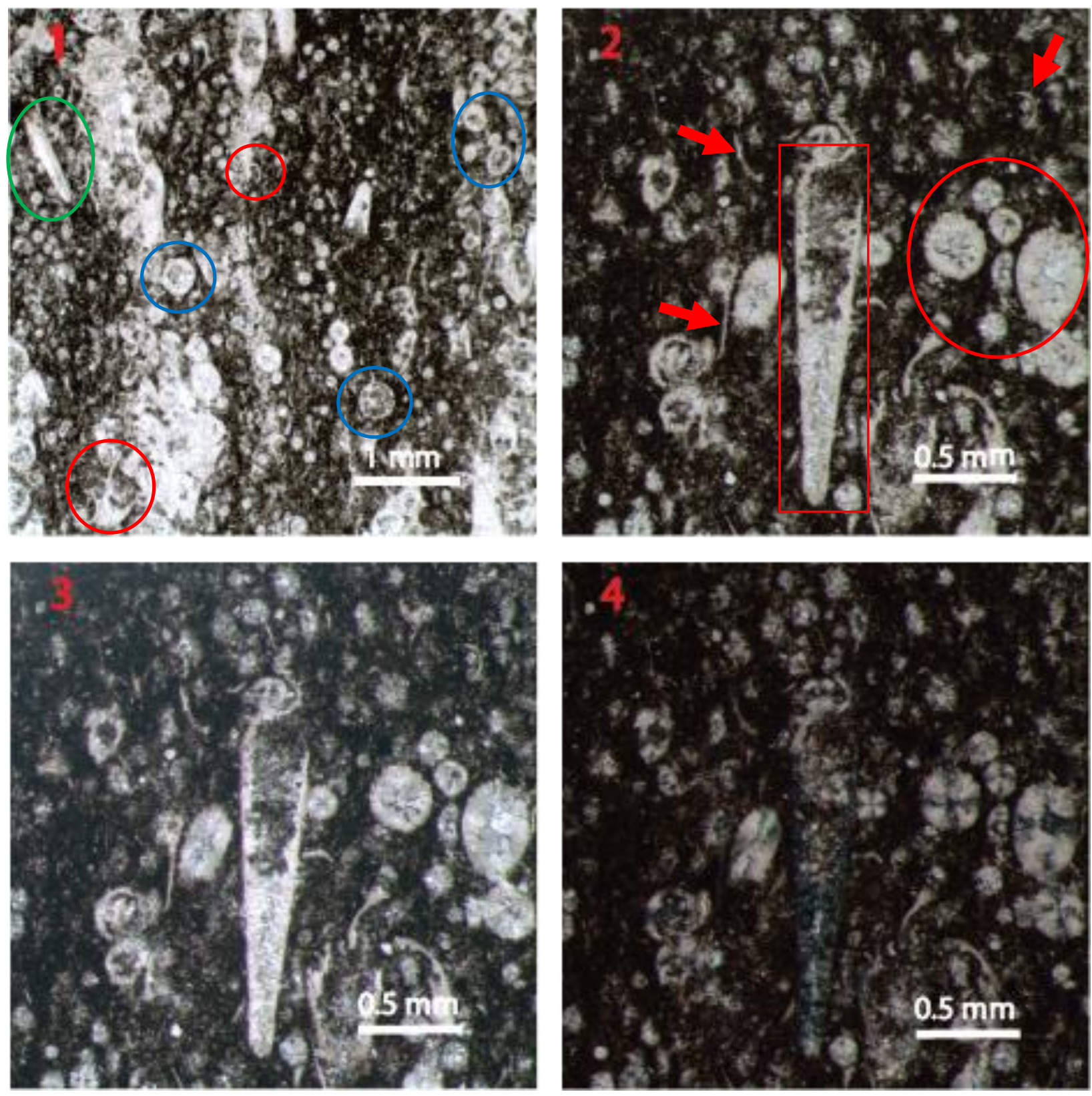

Figure 90. Thin section B-98, taken at a depth of 7541 Ft. Thin section B-98 shows numerous fossils present in the Marcellus Formation. Image 1 shows numerous circular calcite grains, possibly skeletal remains (indicated by a blue circle). Thin laminations that resemble shell fragments are circled in red. Lastly, within the green circle is a conical fossil which is may be a sponge spicule. Image 2 consists of thin laminations (red arrows) and circular calcite grains (red circle), both may be skeletal grains. In the center of image 2 is a conical skeletal grain known as tentaculites (red rectangle). 

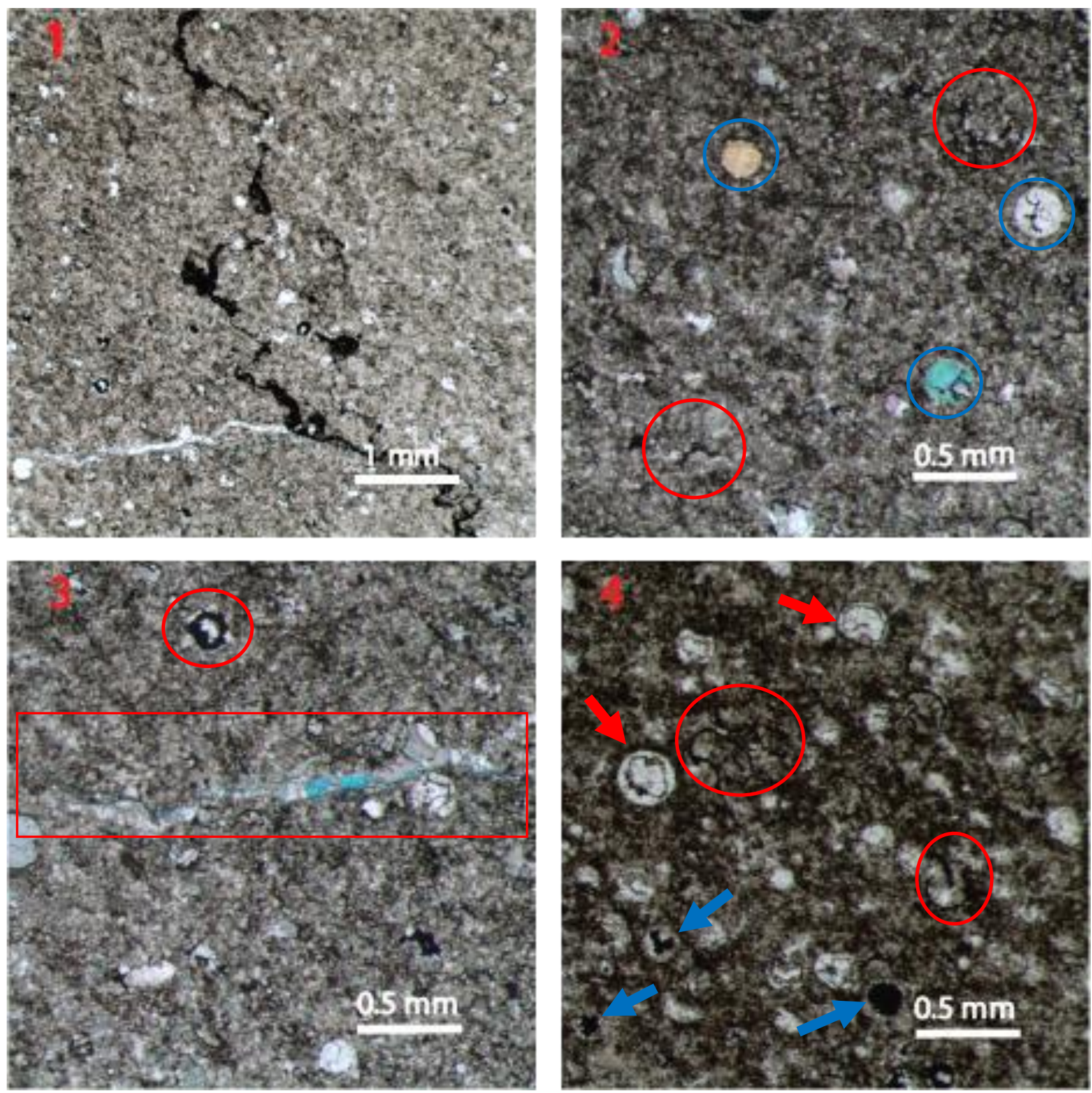

Figure 91. Thin section C-108, taken at a depth of $7551 \mathrm{Ft}$. The lowest thin section, C-108 shows both fossils and calcite filled fractures. Image one is of a calcite vein, with surrounding channel porosity (not fabric selective) that is connected into the opaque grains which resemble a channel. Possible that the opaque grains are the accumulation of pyrite crystals or organic grains. Image 2 is in cross polarized light, indicating variation in orientation of circular calcite grains (Indicated by blue circles). Skeletal remains circled in red occur as opaque grains, suggesting replacement of the original calcite. In image 3, within the red square is the horizontal calcite filled fracture is shown in cross polarized light. Image 4 points several features which resemble skeletal grains. The red arrows indicate the presence of circular calcite grains that have thin opaque outlines within them. These outlines look like the opaque

laminations circled in red. Lastly, the blue arrows point to three circular calcite grains at various levels of replacement. 


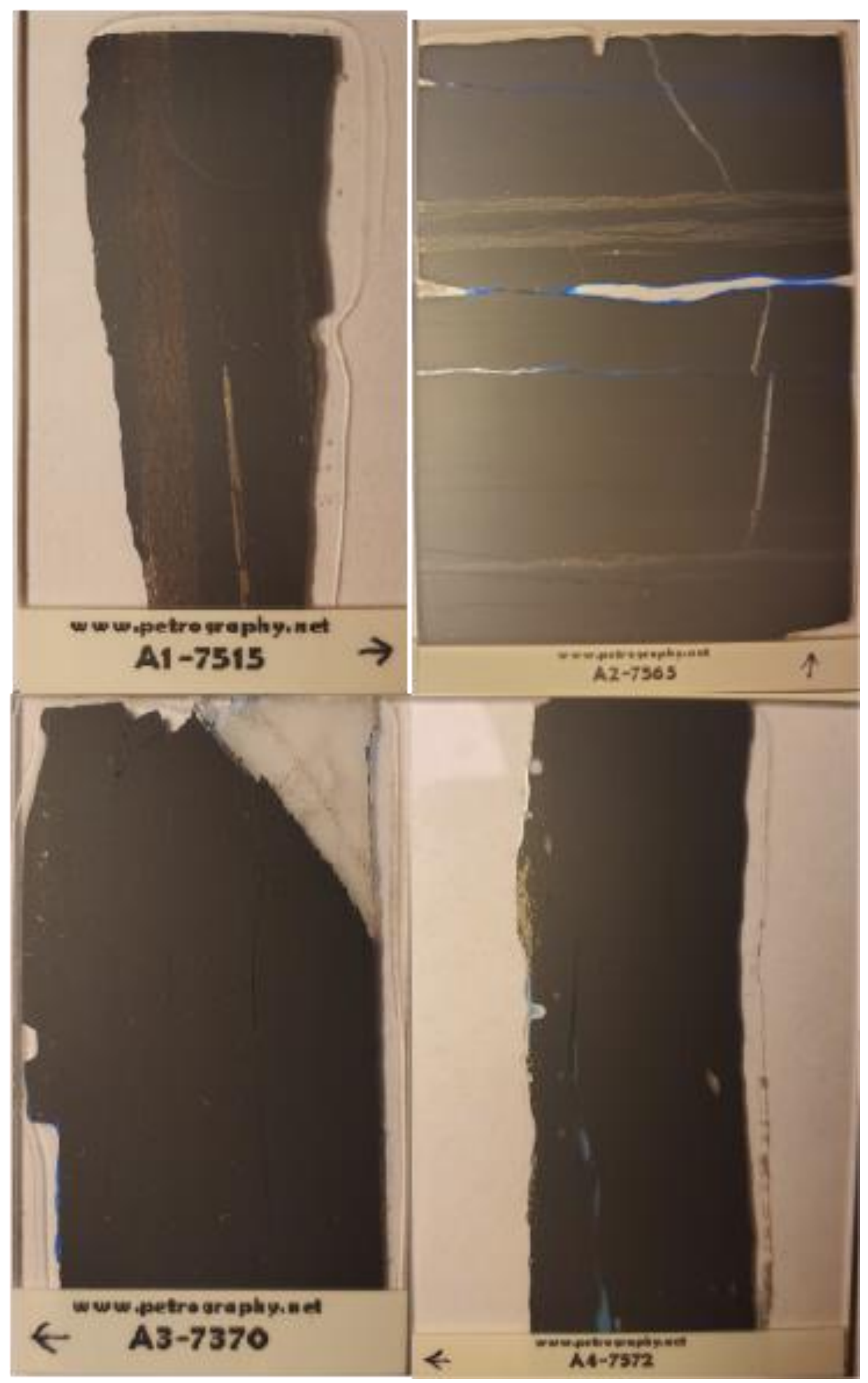

Figure 92. Coastal 1H thin sections, set A 


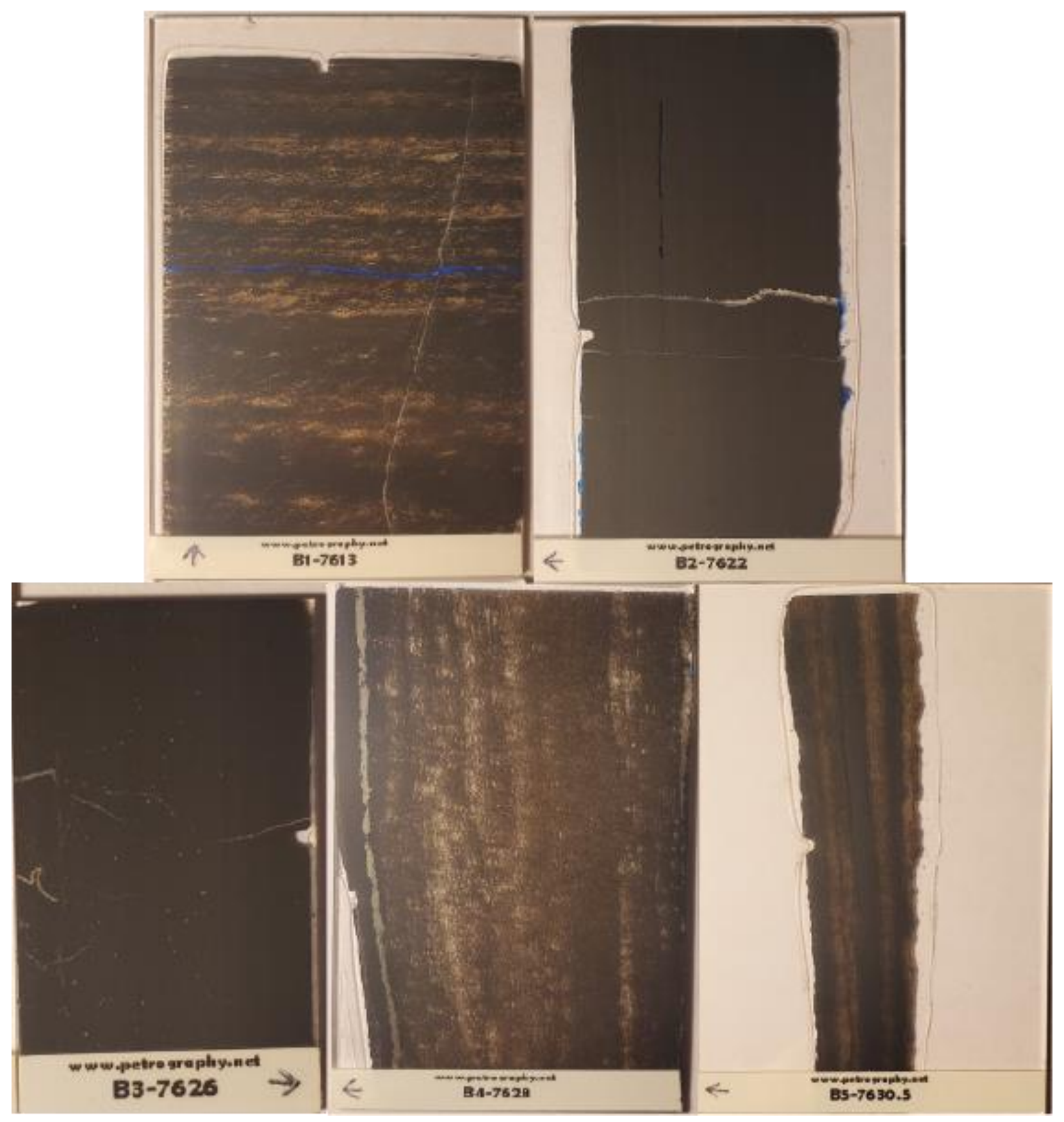

Figure 93. Coastal 1H thin sections, set B 


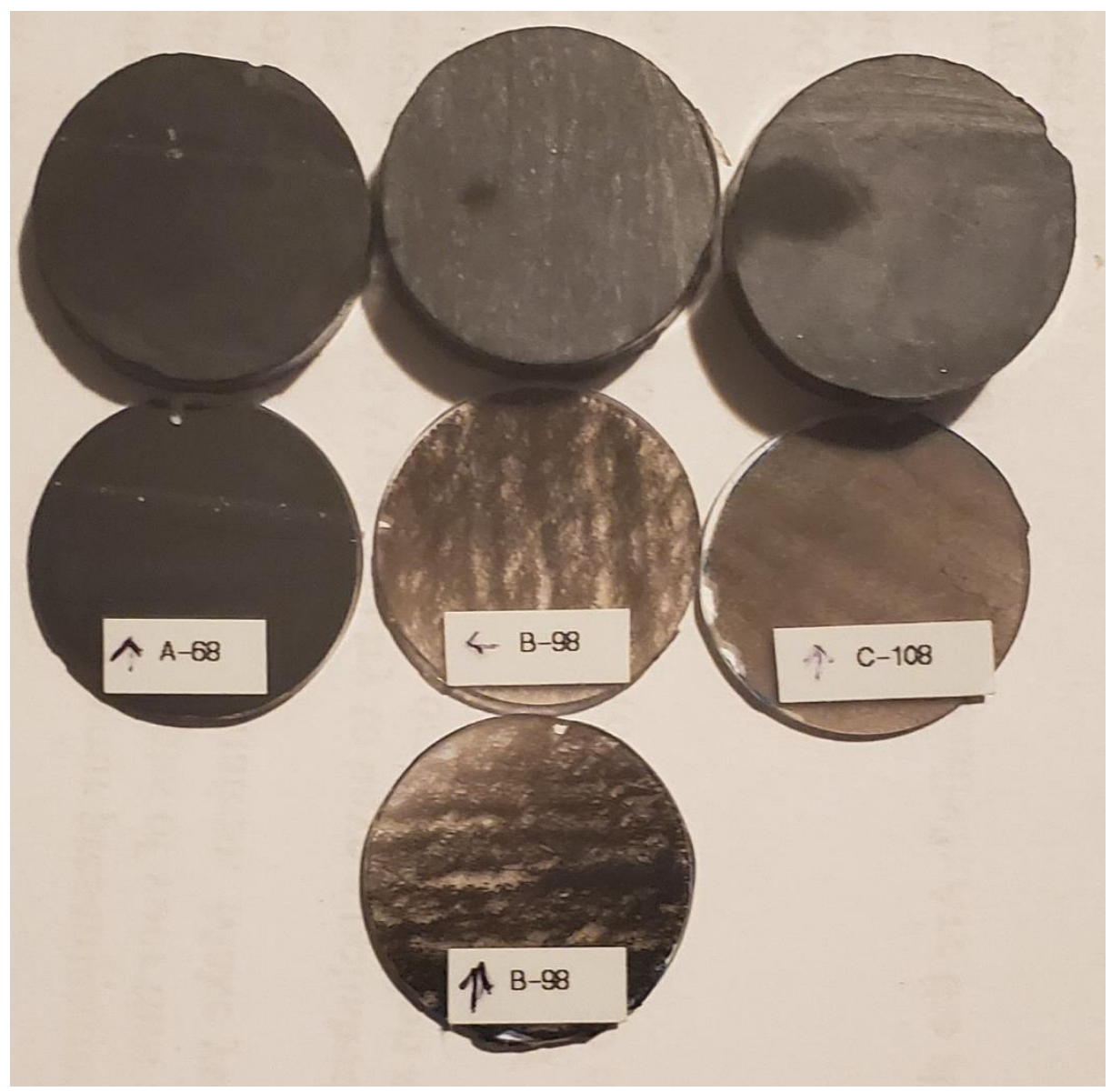

Figure 94. MIP3H core plug thin sections 